\title{
Iridium Complexes with Monodentate N-Heterocyclic Carbene Ligands
}

\author{
Gellért Sipos, ${ }^{\mathrm{a}, \mathrm{b}^{*}}$ and Reto Dorta, ${ }^{\mathrm{a}^{*}}$
}

${ }^{a}$ School of Molecular Sciences, Department of Chemistry, University of Western Australia, 35 Stirling Highway, 6009 Perth, Western Australia, Australia. Fax: (+61) 86488 7330; phone: (+61) 86488 3161; email: reto.dorta@uwa.edu.au

${ }^{b}$ Present Address: Innostudio Inc., Záhony utca 7., 1031 Budapest, Hungary. Fax:(+36) 18808 501; phone: :(+36) 18808 500; e-mail: gellert.sipos@innostudio.org 


\begin{abstract}
:
Monodentate N-hetereocyclic carbene (NHC) ligands have been an extremely successful class of ancillary ligands in transition metal chemistry over the last 3 decades. Particularly important developments during that period have seen the use of bulky, monodentate NHC ligands in late transition metal chemistry and catalysis. In this review, we have gathered results that present how these monodentate ligands have been used in iridium chemistry. A comprehensive overview on synthetic methods available to access NHC-Ir compounds, the stoichiometric activity of the resulting complexes as well as their use in catalysis and other applications is given in the following pages.
\end{abstract}

\title{
TOC graphic:
}

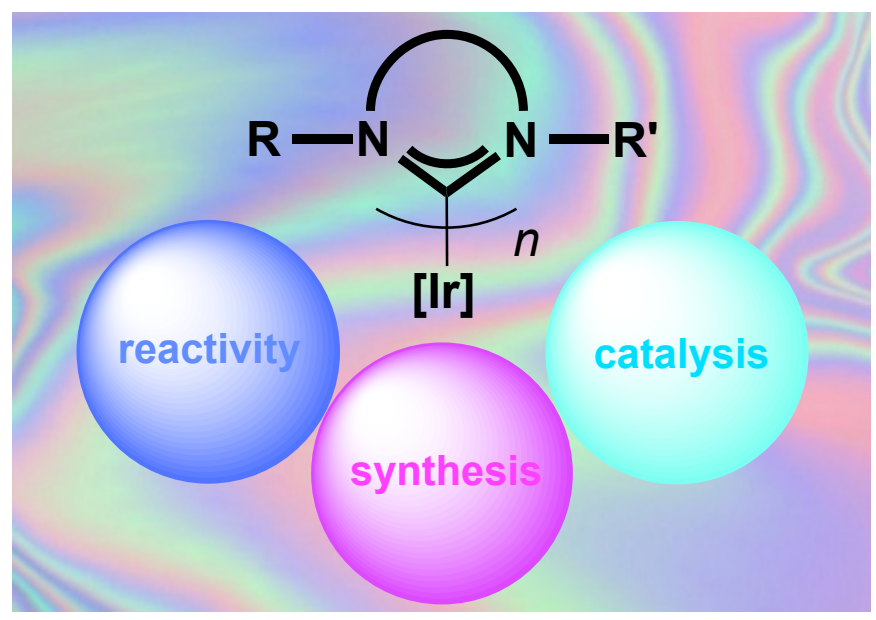




\section{Table of Contents}

Iridium Complexes with Monodentate N-Heterocyclic Carbene Ligands...................................... 1

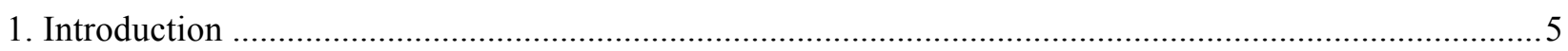

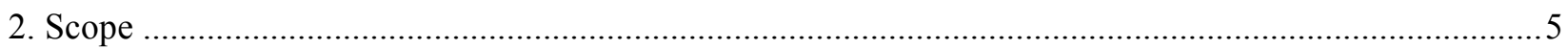

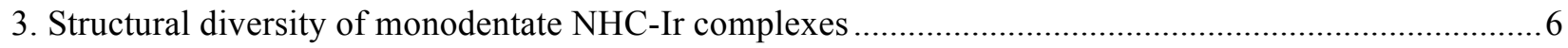

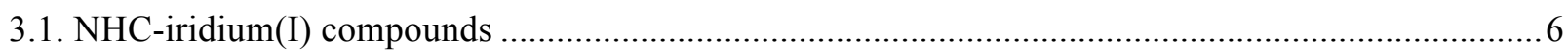

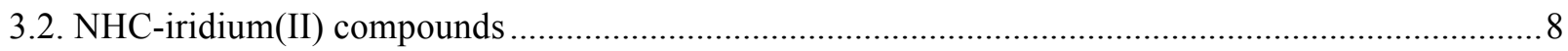

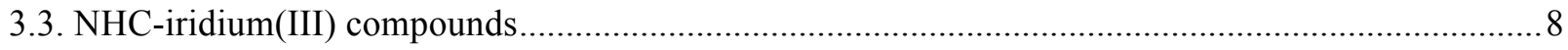

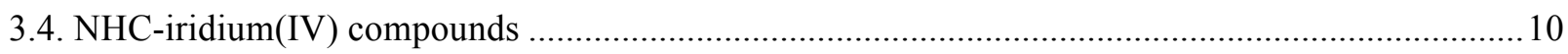

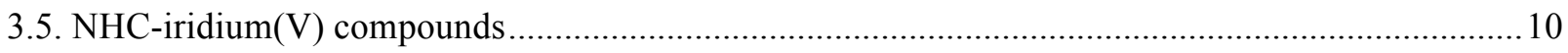

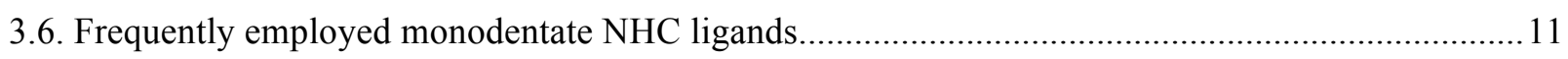

4. Synthetic methods for the preparation of monodentate NHC-Ir complexes …...................................... 11

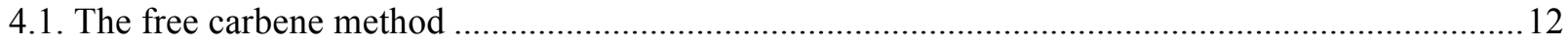

4.2. Alkoxy metal precursors and base-assisted one-pot methods ...................................................... 14

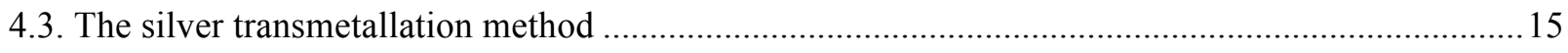

4.4. Comparison of the free carbene and the silver transmetallation method for the preparation of NHC-

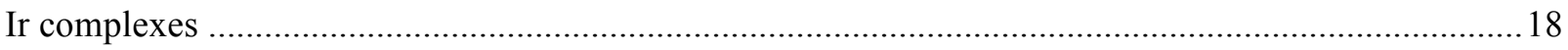

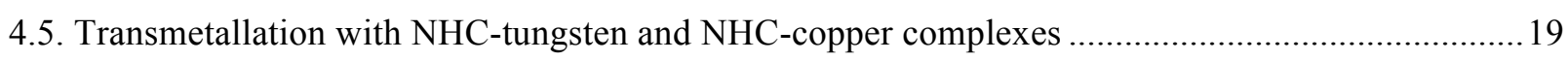

4.6. Metal-free carbene transfer agents for the synthesis of NHC-Ir complexes ..................................20

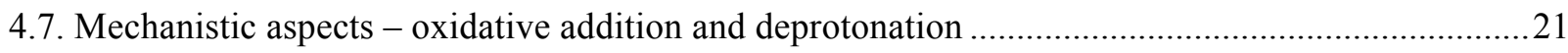

5. Stoichiometric reactivity of NHC-Ir complexes with spectator NHC ligands ......................................23

5.1. Stoichiometric reactivity of square planar NHC-Ir(I) complexes ................................................23

5.2. Stoichiometric reactivity of five- and six-coordinate NHC-Ir(III) compounds................................. 31

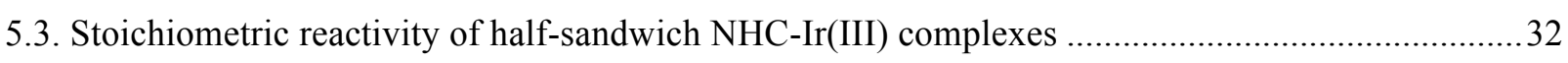

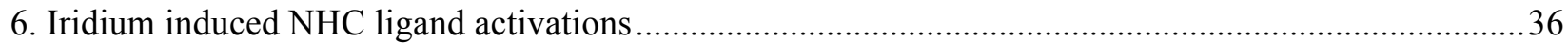

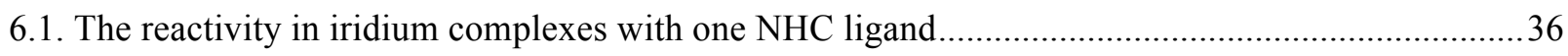

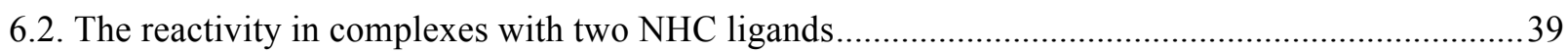

6.3. Cyclometallations of NHCs in half-sandwich NHC-Ir complexes...................................................44

7. Donor functionalized or hemilabile NHC ligands in iridium complexes ............................................48

8. Studies related to electronic, luminescent and redox properties of NHCs and their iridium complexes .55 


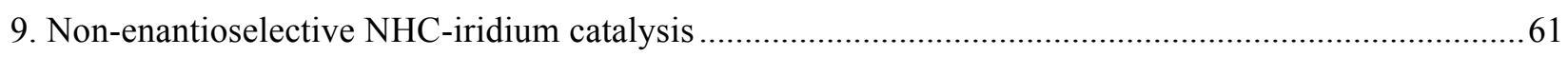

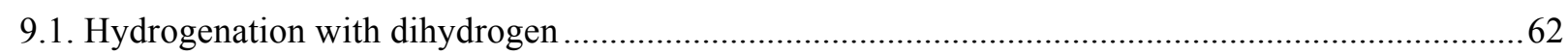

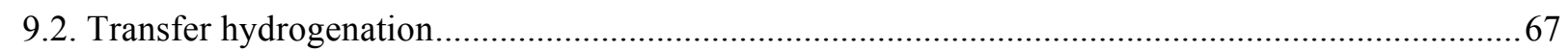

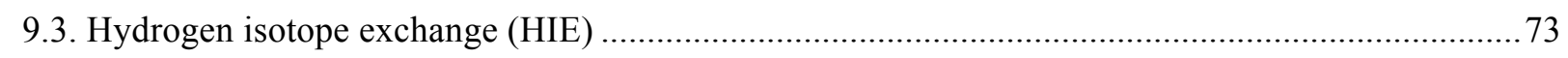

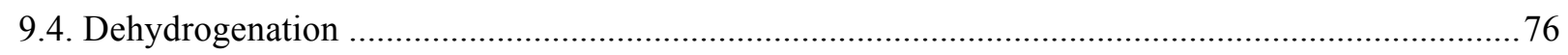

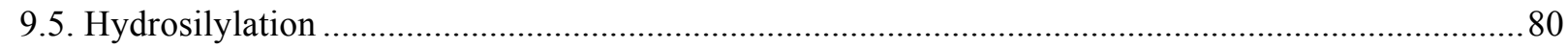

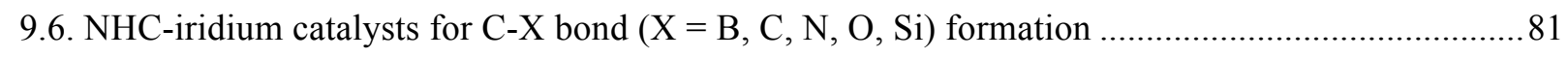

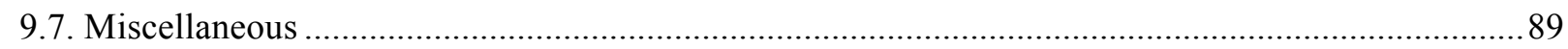

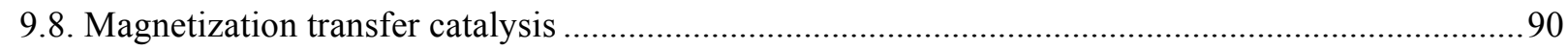

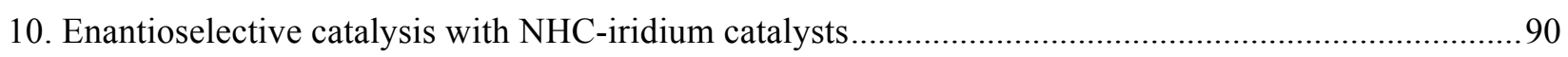

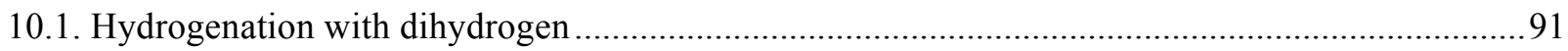

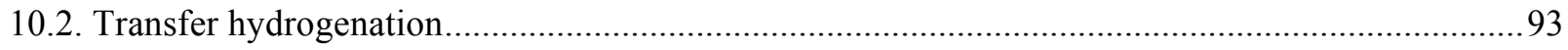

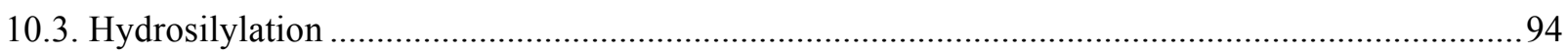

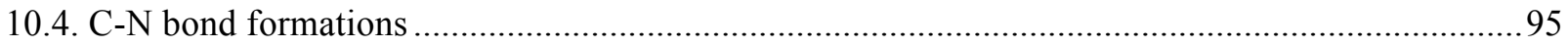

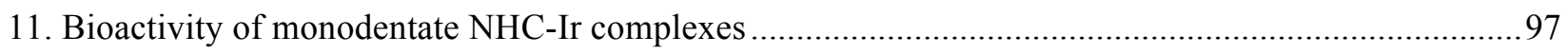

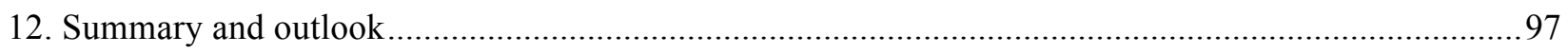

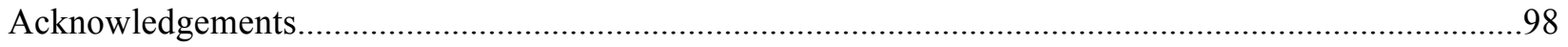

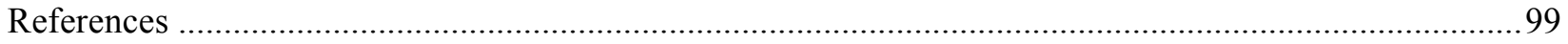




\section{Introduction}

The history of N-heterocyclic carbenes (NHCs) dates back to the pioneering work of Wanzlick and Öfele in the 1960 's. ${ }^{1}$ The synthesis and characterization of NHC-iridium compounds were also reported at a rather early stage in the 1970's and 1980's by Lappert and others. ${ }^{2,3,4}$ However, the potential of transition metalNHC chemistry was limited due to the restricted availability of suitable carbene precursors of these ligands. The real breakthrough came with the seminal discovery by Bertrand and coworkers, ${ }^{5}$ and Arduengo ${ }^{6}$ as these groups showed that such carbenes could be isolated. Especially relevant and important was the crystallographic characterization of IAd by the Arduengo group, as it paved the way to the development of NHC chemistry in the last 25 years. From this point on, it took only a couple of years until Herrmann's group showed that NHCs could be used as ancillary ligands in metal catalysis by publishing their first results on the NHC-Pd-catalyzed Heck-coupling reaction. ${ }^{7}$ During the past two decades, NHCs have seen tremendous developments and have become one of the most prominent ligand families in the fields of organometallic chemistry and catalysis.

Complexes of the platinum group elements have found important applications in homogeneous transition metal catalysis. While second row metals $\mathrm{Ru}, \mathrm{Rh}$ and $\mathrm{Pd}$ have traditionally been viewed as the most active catalyst species within the platinum group elements, iridium compounds have shown distinctive reactivity patterns in catalytic hydrogenation chemistry as highlighted by the discovery of Crabtree and coworkers who introduced what is now known as Crabtree's catalyst $\left[\operatorname{Ir}(\mathrm{COD})\left(\mathrm{PCy}_{3}\right)(\mathrm{py})\right]\left[\mathrm{BF}_{4}\right]$ in the late 1970 's. ${ }^{8}$ It is not surprising then that various hydrogenation reactions have been particularly well studied when NHC-Ir compounds became available. The application and study of NHC-Ir catalysts has expanded continuously since to include such important topical areas as activation and functionalization of inert $\mathrm{C}-\mathrm{H}$ bonds, the application of NHC-Ir compounds as magnetization transfer catalysts or as catalysts in various dehydrogenation and oxidative coupling reactions.

\section{Scope}

A truly comprehensive overview on "N-heterocyclic carbene iridium" complexes would go well beyond the scope of this review. Consequently, and given our special interest in the development of monodentate NHC ligands, we limit our survey to iridium complexes of this particular class of NHC ligands and we review the synthesis, reactivity and application of monodentate NHC-Ir complexes. Furthermore, only classical, Arduengo-type NHCs (i.e. cyclic diaminocarbenes, mostly imidazol- and imidazolin-2-ylidenes) will be discussed in detail. Triazolylidines, cyclic diamido carbenes, acyclic diamino carbenes, thiazolinylidines $\left(\mathrm{R}_{2} \mathrm{SCNR}_{2}\right)$ and related more "exotic" ligands are not the subject of this review. ${ }^{9}$ Similarly, complexes with chelating bis-carbene ligands and abnormal binding modes will only be discussed where comparison is essential.

We will first give an overview on the structural variety of NHC-Ir compounds and will then discuss the available synthesis routes towards these complexes. These sections are then followed by subchapters 
describing the stoichiometric inter- and intramolecular reactivity of such species. Electronic and luminescent properties are also briefly reviewed. For comprehensive information on electronic properties of NHCs, the reader is directed to an excellent review by Nelson and Nolan that covers the topic up to $2013,{ }^{10}$ while details on photoluminescence of NHC-Ir with data up to 2014 can be found in another review. ${ }^{11}$ Finally, and making up for a relatively important section of this review, we disclose the state-of-the-art in terms of catalytic applications employing monodentate NHC-Ir catalysts.

Two further points worth mentioning are that: 1) By and large, the synthesis of NHC-Rh and NHC-Ir complexes developed together. Herein, we do not go into details on studies with rhodium, although we note that synthetic procedures and catalytic applications are frequently interchangeable and/or complementary; 2) $(\mathrm{NHC}) \operatorname{Ir}(\mathrm{CO})_{2} \mathrm{Cl}$ complexes are frequently used as probes to measure electronic parameters of the NHC ligand under investigation. Numerous complexes have therefore been synthesized solely for this reason and will not be discussed in detail.

Finally, the reader is made aware of the fact that a number of monographs and reviews on various aspects of transition metal-NHC chemistry are available. ${ }^{12,13}$

\section{Structural diversity of monodentate NHC-Ir complexes}

\subsection{NHC-iridium(I) compounds}

Iridium(I) complexes are predominantly square planar, tetra-coordinate compounds. Figure 1 shows the typical substitution patterns existing in NHC-Ir(I) complexes. Neutral complexes with one NHC ligand (A) would feature a cis-to-NHC anionic ligand and either two two-electron donor neutral ligands or a chelating

$\eta^{4}$-bound motif such as COD (COD $=1,5$-cyclooctadiene). The cationic analogue of $\mathbf{A}$, structure $\mathbf{C}$, is typically synthesized via halide abstraction reactions in the presence of a neutral, two-electron donor ligand.

In neutral $(\mathrm{NHC})_{2} \operatorname{Ir}(\mathrm{L})(\mathrm{A})$ (B) structures the two NHCs are exclusively in the trans-configuration. In contrast, the relative orientation of the NHC ligands in cationic $\mathbf{D}$ and $\mathbf{E}$ will depend on the actual overall ligand environment. Cationic iridium(I) compounds with three NHCs (F) are also known. 
Neutral Iridium(I)<smiles>[3H][I-]([3H])([3H])N</smiles>

A

B

$\mathrm{L}=$ neutral ligand, e.g. $\mathrm{CO}, \mathrm{PR}_{3}, \mathrm{COD}$

$\mathrm{A}=$ anionic ligand, e.g. $\mathrm{Cl}$, alkyl, $\mathrm{OH}, \mathrm{OR}, \mathrm{NHR}$

$\underline{\text { Cationic Iridium(I) }}$

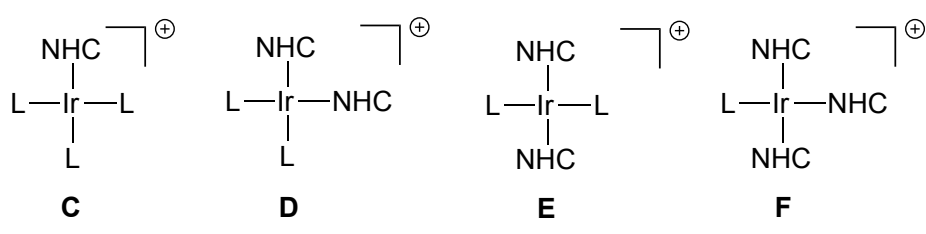

$\mathrm{L}=$ neutral ligand, e.g. $\mathrm{CO}, \mathrm{PR}_{3}$, pyridine, acetone, $\mathrm{MeCN}, \mathrm{COD}$

Figure 1. Common structural types of NHC-Ir(I) compounds.

Selected, more exotic iridium(I) examples

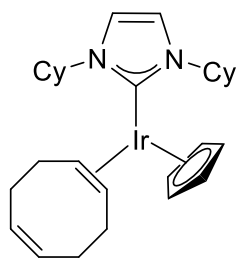

1

Herrmann, 2006

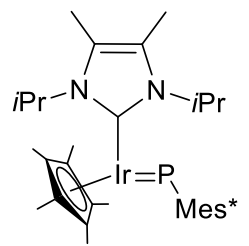

Lammertsma, 2003

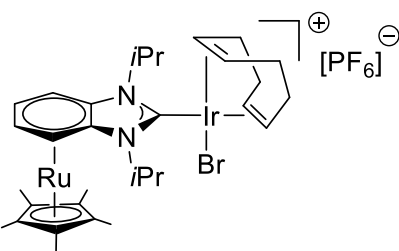

Ganter, 2012

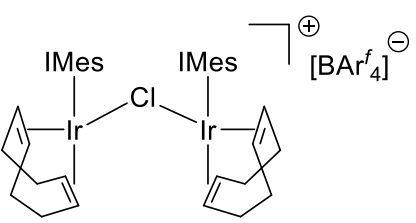

Aldridge, 2011

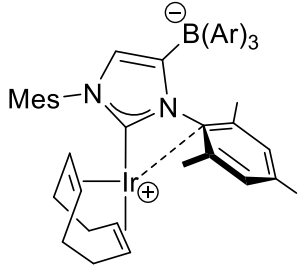

3

Tamm, 2013

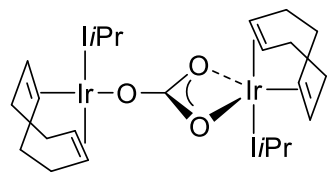

Nolan, 2014<smiles>[3H][I-](C)N</smiles>

G

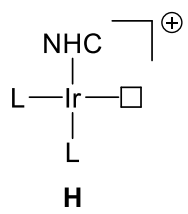

Figure 2. Uncommon structural types of NHC-Ir(I) compounds.

Most of the known NHC-Ir(I) compounds fit well into categories A-F. However, some exceptions exist and selected examples are shown in Figure 2. Herrmann synthesized compound $\mathbf{1}$ with an $\eta^{5}$-bound $\mathrm{Cp}(\mathrm{Cp}=$ cyclopentadienyl) ligand. ${ }^{14}$ In this 18 electron species, the iridium exhibits distorted trigonal planar coordination and the COD ligand is $\eta^{2}$-coordinated (also see type $\mathbf{G}$ ). A similar geometry was observed in the phosphinidene complexes (e.g. 4) described by Lammertsma and coworkers. ${ }^{15}$ Ganter et al. applied $\{\mathrm{Cp} * \mathrm{Ru}\}^{+}$fragments in combination with $(\mathrm{NHC}) \operatorname{Ir}(\mathrm{COD}) \mathrm{X}\left(\mathrm{X}=\right.$ halogen) to access, inter alia, complex $2 .{ }^{16}$ These complexes have unusual charge distribution, yet the geometry of the parent (NHC) $\operatorname{Ir}(\mathrm{COD}) \mathrm{Br}$ motif is largely unaffected. Anionic carbene ligands, developed by Tamm and coworkers, formed pseudo square planar zwitterionic iridium complexes $\mathbf{3}$ (also see the formally three-coordinate structure $\mathbf{H}$ ) ${ }^{17}$ In these, an interaction between the iridium center and the ipso-carbon of an $\mathrm{N}$-aryl ring leads to a sideways tilt of the NHC. The last two examples, $\mathbf{5}$ and $\mathbf{6}$, are $\{(\mathrm{NHC}) \operatorname{Ir}(\mathrm{COD})\}$ dimer units bridged by either a chloride or a 
carbonate motif. ${ }^{18,19}$ The carbonate bridged 6 consist of a 16- and an 18-electron $\operatorname{Ir}(\mathrm{I})$ center. While the former one is square planar, the latter adopts a pseudo trigonal bipyramidal geometry. ${ }^{19}$

\subsection{NHC-iridium(II) compounds}

NHC-Ir(II) complexes are scarce in the literature. Compounds $\mathbf{7}$ and $\mathbf{8}$ encompass $\operatorname{Ir}(\mathrm{II})$ centers and are of the general formula $\{(\mathrm{NHC}) \operatorname{Ir}(\mu-\mathrm{H})\}_{2}{ }^{2+}$ (Figure 3). ${ }^{17,20}$ Each NHC is bound to one $\operatorname{Ir}(\mathrm{II})$ center through the carbene atom and to the other $\operatorname{Ir}(\mathrm{II})$ atom by an $\eta^{6}$-arene interaction from one of the $\mathrm{N}$-aryl groups. Short Ir-Ir distances (2.65 and $2.65 \AA$ for $\mathbf{7}$ and $\mathbf{8}$, respectively) indicate the existence of an Ir-Ir single bond. It is interesting to note that a tetrahydride structure, $\left[(\operatorname{IPr})_{2} \mathrm{Ir}_{2} \mathrm{H}_{4}\right]\left[\mathrm{BAr}_{4}^{f}\right]_{2}(\mathbf{1 3})$, which is very similar to $\mathbf{8}$, has been described with an $\{\operatorname{Ir}(\mathrm{H})(\mu-\mathrm{H})\}_{2}$ core (Figure 7$) .^{18}$

The crystal structure of an $\operatorname{Ir}_{6}$ cluster with both $\operatorname{Ir}(\mathrm{II})$ and $\operatorname{Ir}(\mathrm{III})$ centers was solved. ${ }^{21}$ However, the $\operatorname{Ir}(\mathrm{II})$ atoms in this case were not bound to an NHC ligand (vide infra).
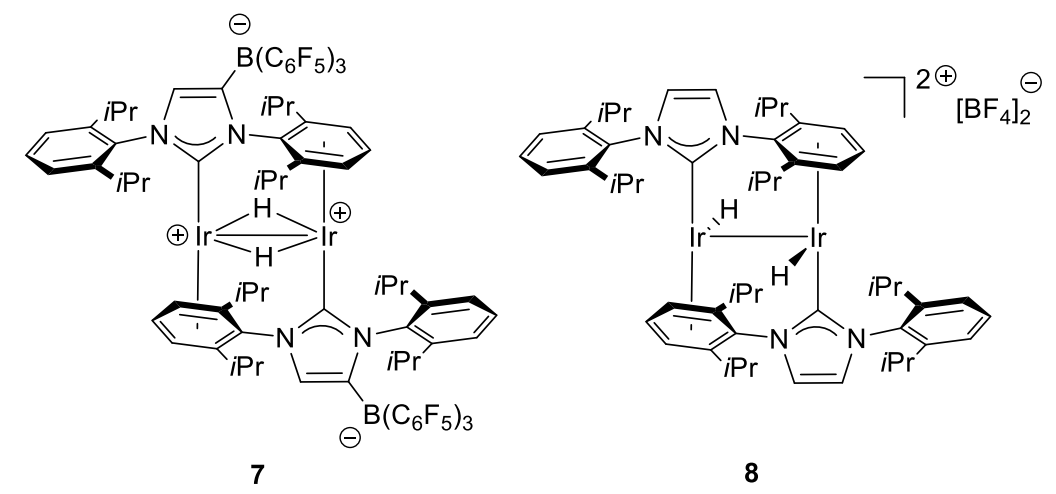

Figure 3. NHC-Ir(II) complexes 7 and 8.

\subsection{NHC-iridium(III) compounds}

NHC-iridium(III) compounds show great structural diversity due to the six accessible coordination sites. A large number of half-sandwich Ir-complexes with NHCs have been synthesized (Figure 4). These compounds (I, J, K, L) adopt a three-legged piano stool geometry. Similarly, in dimer M, the geometry around the individual iridium atoms can be described in the same way.

Somewhat surprisingly, crystal structures of octahedral complexes (type $\mathbf{N}, \mathbf{O}$ ) with only one NHC ligand are relatively uncommon (Figure 5). ${ }^{22,23,24,25}$ Furthermore, we are not aware of crystallographically characterized complexes of types $\mathbf{P}, \mathbf{Q}, \mathbf{R}$ and $\mathbf{S} .^{26,27,28}$ 


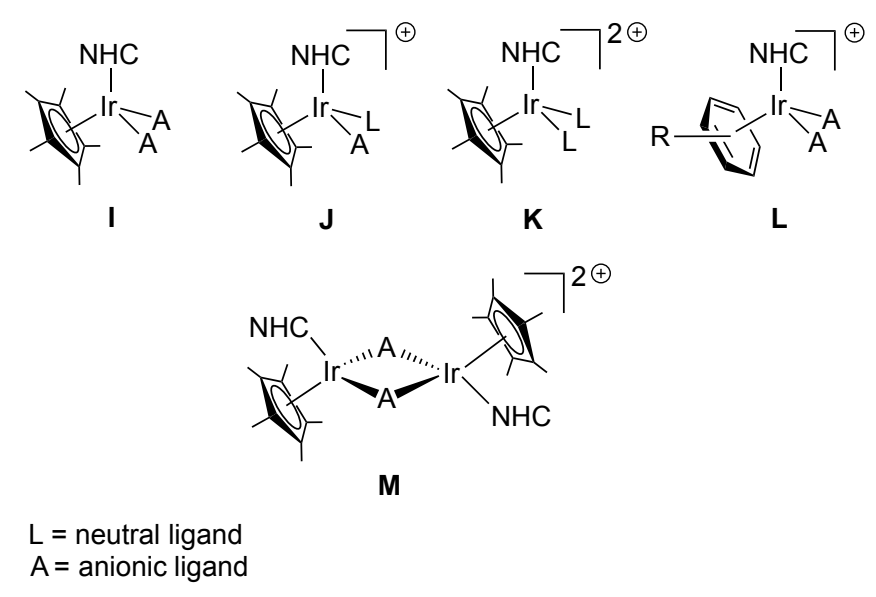

Figure 4. Half-sandwich NHC-Ir(III) complexes.
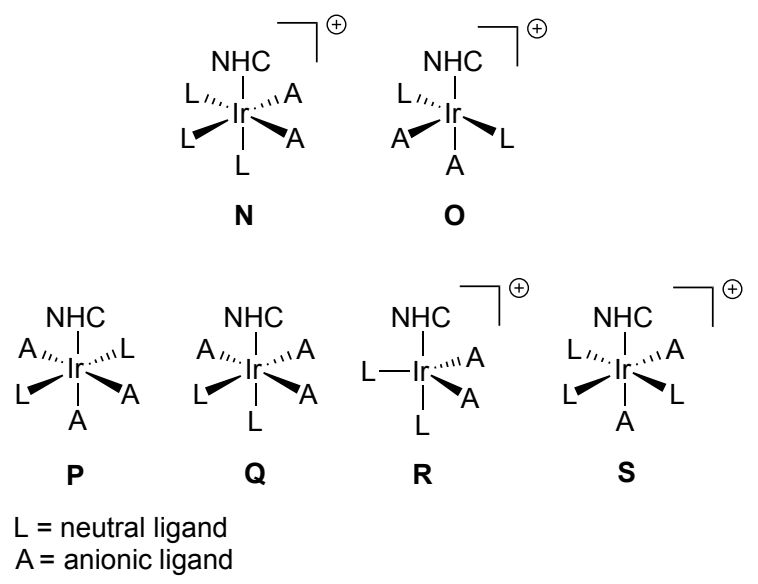

Figure 5. Octahedral NHC-Ir(III) complexes with one NHC ligand.

Ir(III)-compounds with two or more NHCs per iridium encompass octahedral and trigonal bipyramidal geometries (Figure 6). The NHC ligands, likely due to their steric bulk, are trans to each other in compounds $\mathbf{T}, \mathbf{U}$, and $\mathbf{V}$. In these structural motifs, the anionic ligands are most often hydrides. Similar structural arrangements are frequently encountered in cyclometallated NHC ligand systems. Of particular note, Nolan and coworkers described the highly unsaturated iridium(III) complex $\left[(\mathrm{I} t \mathrm{Bu})_{2} \operatorname{Ir}(\mathrm{H})_{2}\right]\left[\mathrm{PF}_{6}\right]$ (176 in Scheme 66), which we categorized as a type $\mathbf{X}$ structure. This formally four-coordinate compound shows a double agostic interaction between the metal and two hydrogens of the $t \mathrm{Bu}$ groups. These agostic interactions complete the octahedral geometry around the $\operatorname{Ir}(\mathrm{III})$ center. $^{29}$

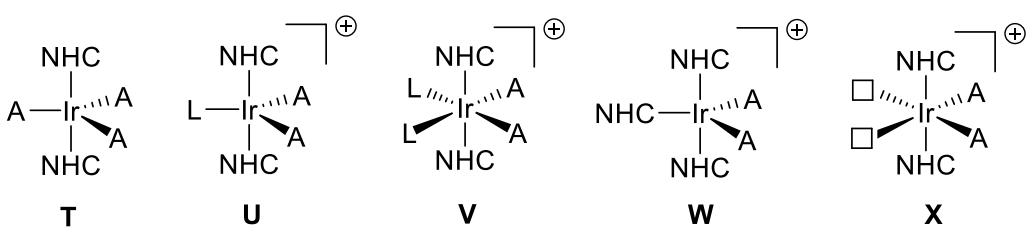

Figure 6. Ir(III) compounds with two or more NHC ligands.

Some more exotic structures of the NHC-Ir(III) type are depicted in Figure 7. Hydride complexes $\mathbf{9}$ and $\mathbf{1 0}$ are catalyst decomposition products from glycerol dehydrogenation reactions and feature three NHC ligands per iridium. ${ }^{30}$ Complex 11 is a rare example of a chloride bridged NHC-Ir(III) complex. In 11, the NHCs 
have a face-to-face alignment, the Ir-Cl-Ir bridge is almost linear $\left(171.5^{\circ}\right)$ and the $\mathrm{Ir}-\mathrm{Cl}$ bonds are disparate (2.45 and 2.49 $\AA) .{ }^{31}$ Complex 12 was isolated from a reaction between a half-sandwich complex and excess of the corresponding bisphosphine ligand $\mathrm{dmpm}(\mathrm{dmpm}=1,1-\mathrm{bis}($ dimethylphosphino $)$ methane $){ }^{32}$ Finally, complex 13 was mentioned above during the discussion on Ir(II)-dimers. ${ }^{18}$

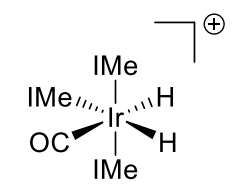

9

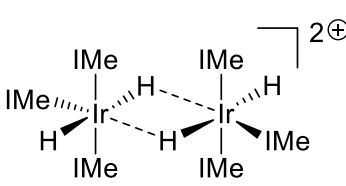

10

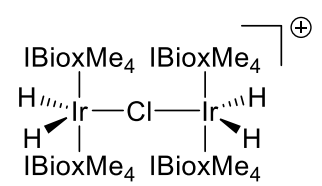

11

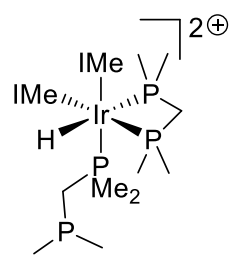

12

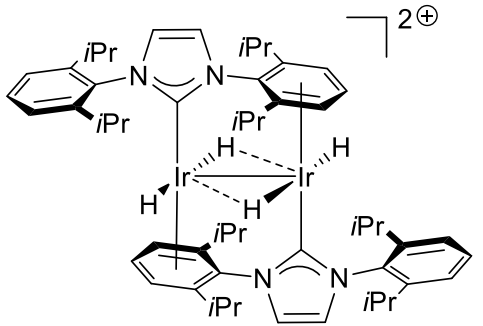

13

Figure 7. Uncommon structural types of $\mathrm{d}^{6} \operatorname{Ir}(\mathrm{III})$ complexes. Counteranions are omitted.

Iridium(III) cluster compounds with monodentate NHC ligands have also appeared in the literature during the last 5 years. For example, $\operatorname{Ir}_{3}$ units were published by Aldridge et al. ${ }^{18}$ More recently, glycerol dehydrogenation studies with $\left[(\mathrm{IMe})_{2} \operatorname{Ir}(\mathrm{COD})\right]\left[\mathrm{BF}_{4}\right]$ (vide infra, complex 358 in Figure 26) yielded compounds with $\operatorname{Ir}_{4},{ }^{33}$ and $\operatorname{Ir}_{6}$ cluster units. ${ }^{30}$

\subsection{NHC-iridium(IV) compounds}

We are only aware of a single example of an NHC-Ir(IV). Complex 14 exhibits two half-sandwich $\operatorname{Ir}(\mathrm{IV})$ centers bridged by an oxygen atom. The Ir-O distances as determined by X-ray crystallography are virtually identical $\left(1.93 \AA\right.$ ) and the Ir-O-Ir angle is $149.6^{\circ}$. The Ir- $\mathrm{C}_{\text {carbene }}$ distances are 2.06 and $2.04 \AA$.

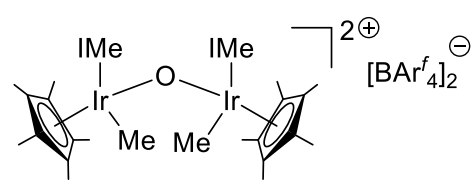

14

Figure 8. A rare $\mu$-oxo $\mathrm{d}^{5}$ iridium(IV) intermediate.

\subsection{NHC-iridium(V) compounds}

We are not aware of any isolated $\operatorname{Ir}(\mathrm{V})$ complex with a monodentate NHC. Complex 16 (not isolated) has been proposed as an intermediate in the equilibrium between $\mathbf{1 5}$ and $15,{ }^{28}$ Similarly, $\operatorname{Ir}(\mathrm{V})$ intermediates were suggested as intermediates in catalytic transfer hydrogenation reactions. ${ }^{34,35,36}$ 


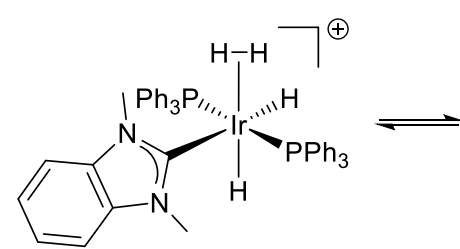

15

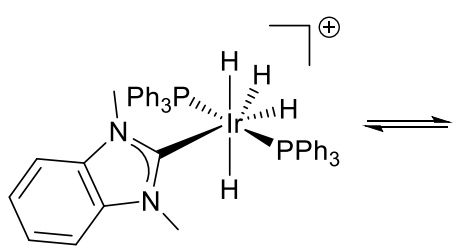

16

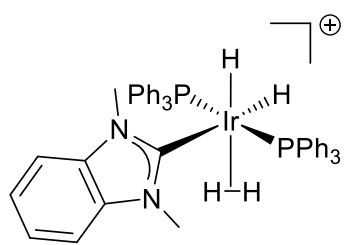

$1^{\prime}$

Scheme 1. A putative $\operatorname{Ir}(\mathrm{V})$ intermediate.

\subsection{Frequently employed monodentate NHC ligands}

Figure 9 shows the set of most commonly employed NHC ligands and the abbreviations that are normally used and employed throughout this review.<smiles></smiles>

IAd: $R=1$-adamantyl

InBu: $\mathrm{R}=n$-butyl

ItBu: $R=$ tert-butyl

ICy: $R=$ cyclohexyl

IDD: $R=$ cyclododecyl

IMe: $\mathrm{R}=\mathrm{CH}_{3}$

IMes: $\mathrm{R}=$ mesityl

IPr: $R=$ 2,6-diisopropylphenyl (DIPP)

IiPr: $\mathrm{R}=i$-propyl

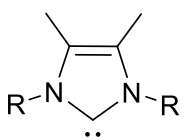

$\mathrm{IMe} \mathrm{Me}^{\mathrm{R}} \mathrm{R}=$ methyl

$\mathrm{IE} \mathrm{t}^{\mathrm{Me}}: \mathrm{R}=$ ethyl

I $\mathrm{Pr} \mathrm{Me}^{\mathrm{Me}} \mathrm{R}=$ i-propyl

$\mathrm{IPrMe}: \mathrm{R}=$ 2,6-diisopropylphenyl

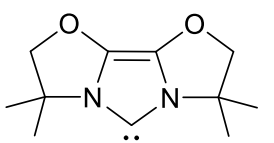

$\mathrm{IBioxMe}_{4}$<smiles>[R]N1C=CN([R])CCC1</smiles>

6iPr: $\mathrm{R}=i$-propyl

6Mes: $R=$ mesityl

6IPr: $R=$ 2,6-diisopropylphenyl
$\overbrace{}^{-N} \overbrace{}^{N-R}$

SIMe: $\mathrm{R}=\mathrm{CH}_{3}$

SIMes: $R=$ mesityl

SIPr: $R=2,6$-diisopropylphenyl (DIPP)

SIEt: $\mathrm{R}=\mathrm{CH}_{2} \mathrm{CH}_{3}$

SIBn: $\mathrm{R}=\mathrm{CH}_{2} \mathrm{Ph}(\mathrm{Bn})$

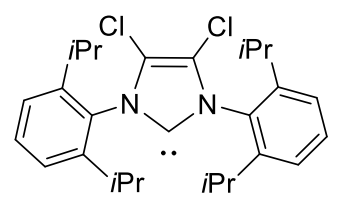

$\mathrm{IPr}^{\mathrm{Cl}}$

Figure 9. NHC ligand structures and their abbreviated names.

\section{Synthetic methods for the preparation of monodentate NHC-Ir complexes}

The first monodentate NHC-Ir(I) complex, 18, was prepared by Lappert et al., who treated Vaska's complex (17) with the dimeric $\mathrm{NHC}$ precursor (SIMe) $)_{2}$ and $\mathrm{NaBF}_{4}$ in refluxing acetone (Scheme 2). A modified procedure led to the isolation of $\left[(\mathrm{SIMe})_{3} \operatorname{Ir}(\mathrm{CO})\right]\left[\mathrm{BF}_{4}\right]$ in $77 \%$ yield through complete substitution of the phosphine ligands. ${ }^{2 a}$ In another historical example by Roper and coworkers, a rather unique approach for the construction of the NHC ligand on the metal was employed to access compound $\mathbf{2 0}$ (Scheme 3). ${ }^{3 a}$ 


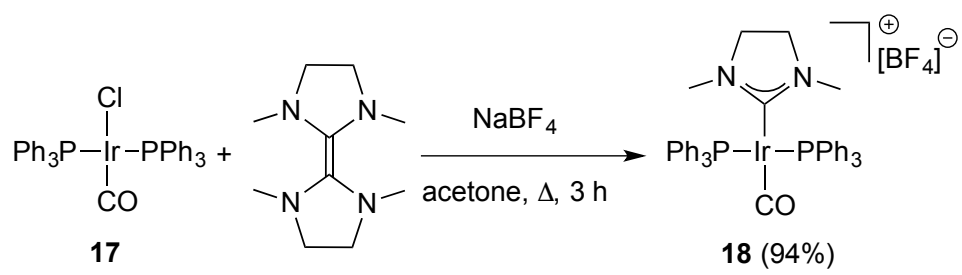

Scheme 2. Lappert's work from the 1970's.

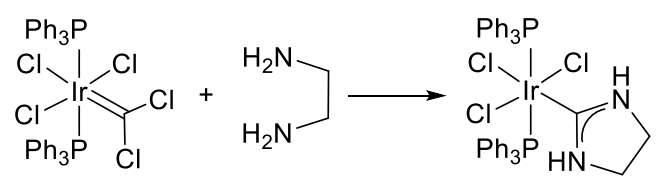

19

20

Scheme 3. Ligand synthesis on the metal.

These early examples highlight the problems that were faced before Arduengo's synthesis of stable NHCs. Modern methods for the preparation of transition metal NHC complexes employ readily available carbene precursors, which are typically derived from NHC salts. ${ }^{37}$ The most frequently applied methods (in general for TMs and in particular for iridium) are:

a) Reaction of an isolated or an in situ generated free carbene with a metal precursor \{e.g. $\left.[\operatorname{Ir}(\mathrm{COD}) \mathrm{Cl}]_{2},\left[\mathrm{Cp} * \mathrm{IrCl}_{2}\right]_{2}\right\}$.

b) In situ formation of a basic metal-alkoxide complex $\left\{\right.$ e.g. $\left.[\operatorname{Ir}(\mathrm{COD})(\mu-\mathrm{OEt})]_{2}\right\}$, followed by treatment with an NHC salt.

c) In situ formation of an often ill-defined NHC-Ag complex, followed by transmetallation to the appropriate iridium precursor.

\subsection{The free carbene method}

In 1996, the group of Herrmann used the free carbene method for the first time in the synthesis of NHC-Ir compounds. The free carbene was generated by the liquid ammonia/THF method, and was reacted with half an equivalent of $[\mathrm{Ir}(\mathrm{COD}) \mathrm{Cl}]_{2}$ to give 21 in $90 \%$ yield (Scheme 4$) .{ }^{38}$ In another early example from the same group, treatment of $[\operatorname{Ir}(\mathrm{COD}) \mathrm{Cl}]_{2}$ with free $\mathrm{I} t \mathrm{Bu}$ in THF yielded $(\mathrm{I} t \mathrm{Bu}) \operatorname{Ir}(\mathrm{COD}) \mathrm{Cl}(\mathbf{2 2 a}, 41 \%$ yield $) .{ }^{39}$

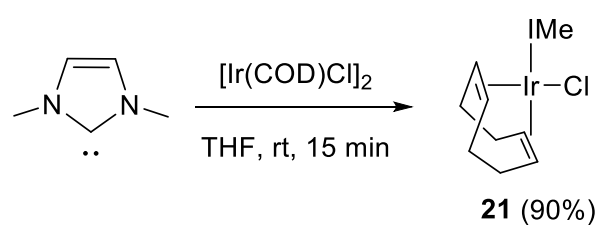

Scheme 4. The free carbene method

The free carbene methodology for the synthesis of (NHC) $\operatorname{Ir}(\mathrm{COD}) \mathrm{Cl}$ is the most straightforward and elegant method available to date. The general nature of the approach is well represented by Nolan's work on the synthesis of a large number of iridium complexes. Compounds 22 were prepared by treating $[\operatorname{Ir}(\mathrm{COD}) \mathrm{Cl}]_{2}$ 
with a slight excess of the free NHC under mild conditions (Scheme 5). In case of 22c, a substoichiometric amount of the free ICy was used in order to avoid formation of [(ICy $\left.)_{2} \operatorname{Ir}(\mathrm{COD})\right][\mathrm{Cl}] .^{40}$

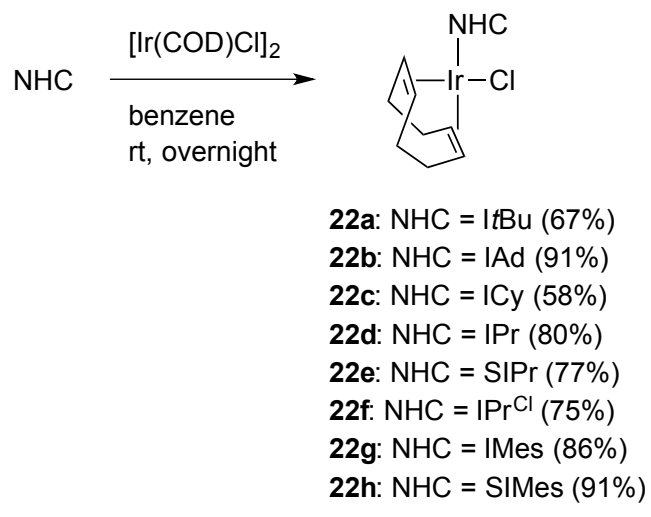

Scheme 5. A series of (NHC) $\operatorname{Ir}(\mathrm{COD}) \mathrm{Cl}$ complexes prepared by Nolan.

The first NHC analogues of Crabtree's catalyst were synthesized by Nolan and coworkers through a ligand exchange reactions between $\left[\operatorname{Ir}(\mathrm{COD})(\mathrm{py})_{2}\right]\left[\mathrm{PF}_{6}\right]\left(\mathrm{py}=\right.$ pyridine) and a free $\mathrm{NHC}$ in toluene $($ Scheme 6$){ }^{41}$ Complex 23a was isolated as a yellow-orange solid in $80 \%$ yield after 2 days of stirring at room temperature. The complex was fully characterized and tested in the catalytic hydrogenation of olefins (see below in section 9). Complex 23a displayed improved thermal stability compared to Crabtree's catalyst. ${ }^{41 a}$ This work was further extended to include the synthesis of analogous complexes featuring NHC ligands with unsaturated backbones (23b-d) ${ }^{41 \mathrm{~b}}$ At the ${ }^{1} \mathrm{H}$ NMR time scale, fluxional behavior due to the rotation around the carbene $\mathrm{N}-\mathrm{C}(\mathrm{Ar})$ bond was observed in $\mathbf{2 3 b}$ and $\mathbf{2 3} \mathbf{c}$.

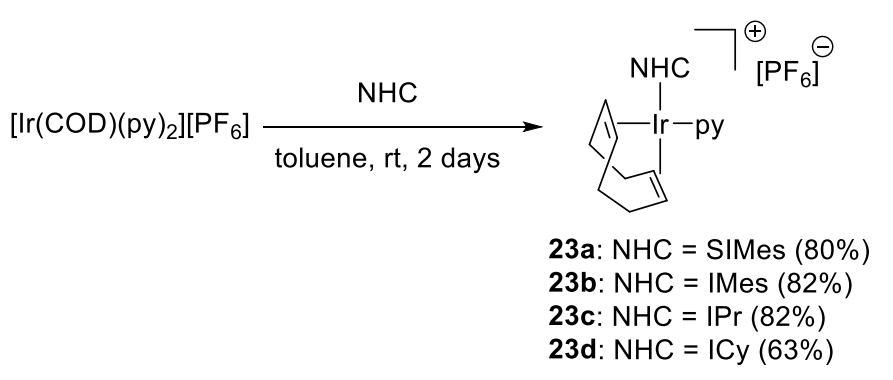

Scheme 6. The synthesis of Crabtree analogue 23a-d.

$\left[\operatorname{Ir}(\mathrm{COE})_{2} \mathrm{Cl}\right]_{2}(\mathrm{COE}=$ cyclooctene $)$ has been used as a metal precursor for the synthesis of NHC-Ir(I) complexes on several occasions. Due to the fact that COE is more labile compared to the chelating COD ligand, these reactions lack the generality seen for the COD precursor. Introduction of two NHC ligands per iridium center is generally facile, but brings about a situation where cyclometallation (vide infra) and ligand substitution are also more favored and occasionally uncontrolled. For example, the isolation of the mixed dimer $[(\mathrm{I} t \mathrm{Bu}) \mathrm{M}(\mathrm{COE}) \mathrm{Cl}]_{2}(\mathrm{M}=\mathrm{Rh})$ was possible when using a NHC:Rh ratio of 1:1, but it failed with Ir where the reaction led to cyclometallation of one of the ligands to give [(It $\mathrm{Bu})(\mathrm{I} t \mathrm{Bu}$ ') $\mathrm{IrHCl}](\mathbf{1 7 3}$ in Scheme 66) alongside unreacted starting material. ${ }^{42}$ On the other hand, when $\left[\operatorname{Ir}(\mathrm{COE})_{2} \mathrm{Cl}\right]_{2}$ was treated with 4 equivalents of IPr in cyclohexane, ( $\operatorname{IPr})_{2} \mathrm{IrH}_{2} \mathrm{Cl}$ (181 in Scheme 68) was isolated in 35\% yield. ${ }^{43}$ Furthermore, the IMes ligand shows diverse C-H activation chemistry under similar conditions. Nevertheless, by varying 
the stoichiometry, both $\left[(\mathrm{IMes}) \operatorname{Ir}(\mathrm{COE})\left(\mathrm{N}_{2}\right) \mathrm{Cl}\right]$ and $\left[(\mathrm{IMes})_{2} \operatorname{Ir}(\mathrm{COE}) \mathrm{Cl}\right]$ (198 in Scheme 75) were successfully isolated. ${ }^{44}$ Finally, as Scheme 20 in Section 4.4 shows, a series of stable $(\mathrm{NHC})_{2} \operatorname{Ir}(\mathrm{COE}) \mathrm{Cl}$ complexes were isolated either by the free carbene or the silver transmetallation method.

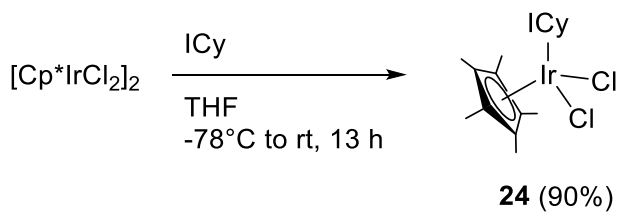

Scheme 7. The synthesis of half-sandwich NHC-Ir(III) 24.

The most commonly used precursor for the synthesis of NHC-Ir(III) complexes is $\left[\mathrm{Cp}^{*} \mathrm{IrCl}_{2}\right]_{2}$. In 2000 , Herrmann showed that treatment of $\left[\mathrm{Cp}^{*} \mathrm{IrCl}_{2}\right]_{2}$ with 1 equivalent of ICy per iridium yielded $\mathbf{2 4}$ in an excellent 90\% yield (Scheme 7). ${ }^{45}$ Termaten et al. employed the same procedure for the synthesis of $\left(\mathrm{I} i \operatorname{Pr}^{\mathrm{Me}}\right) \operatorname{Ir}\left(\mathrm{Cp}^{*}\right) \mathrm{Cl}_{2}$ (26a in Scheme 8). ${ }^{15}$

An alternative synthetic route to access free NHCs was described in 1993 by Kuhn and Kratz, who prepared free carbenes via the reduction of thiones 25 by metallic potassium in THF (Scheme 8). ${ }^{46}$ Using this method, Yamaguchi and coworkers prepared 26a-c by cannulating the solution of the in situ generated NHCs to a solution of $\left[\mathrm{Cp}^{*} \mathrm{IrCl}_{2}\right]_{2}$ in THF (Scheme 8 ). ${ }^{47}$
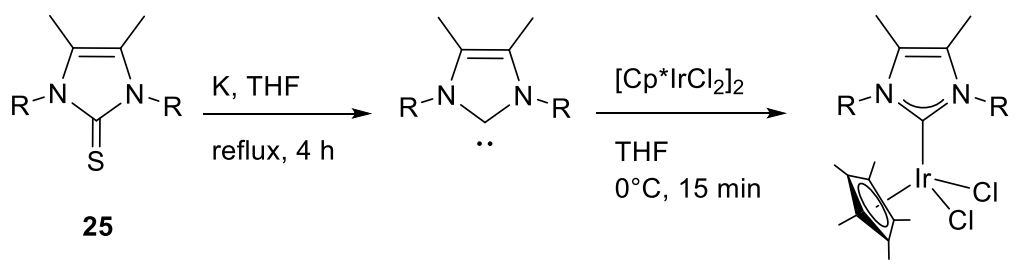

$$
\begin{aligned}
& \text { 26a: } R=\operatorname{Pr}(59 \%) \\
& \text { 26b: } R=\operatorname{Me}(84 \%) \\
& \text { 26c: } R=\operatorname{Et}(61 \%)
\end{aligned}
$$

Scheme 8. Synthesis of NHC-Ir(III) from free carbenes.

\subsection{Alkoxy metal precursors and base-assisted one-pot methods}

It was Köcher and Herrmann who first developed a one pot procedure in which $[\operatorname{Ir}(\mathrm{COD})(\mu \text {-OEt })]_{2}$ was prepared in situ by reacting $[\operatorname{Ir}(\mathrm{COD}) \mathrm{Cl}]_{2}$ with four equivalents of $\mathrm{NaOEt}$. Subsequently, four equivalents of 1,3-bis(diphenylmethyl)imidazolium bromide were added and the air and moisture stable $\mathbf{2 7}$ was isolated two days later (Scheme 9). ${ }^{48}$ Interestingly, despite the fact that a large excess of the NHC salt was employed, formation of a cationic biscarbene complex was not observed.
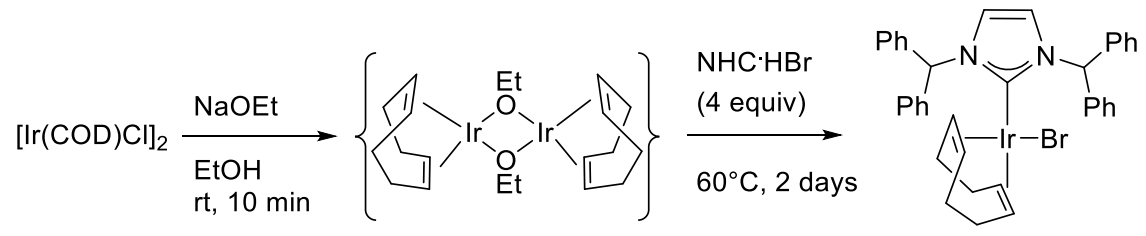

27 (95\%)

Scheme 9. NHC-Ir complex synthesis from an in situ generated metal-alkoxide. 
The procedure starting with the alkoxy metal precursor gave bis-NHC substituted complexes (28) when sterically less demanding NHC salts were applied (Scheme 10). Notably, even a 2.2:1 ratio of NHC:Ir was sufficient to isolate 28a-c in good yields (67-86\%). Iridium and rhodium bis-NHC complexes with chelating $\mathrm{N}-\mathrm{N}$ bridged NHCs were prepared in the same way. ${ }^{39}$

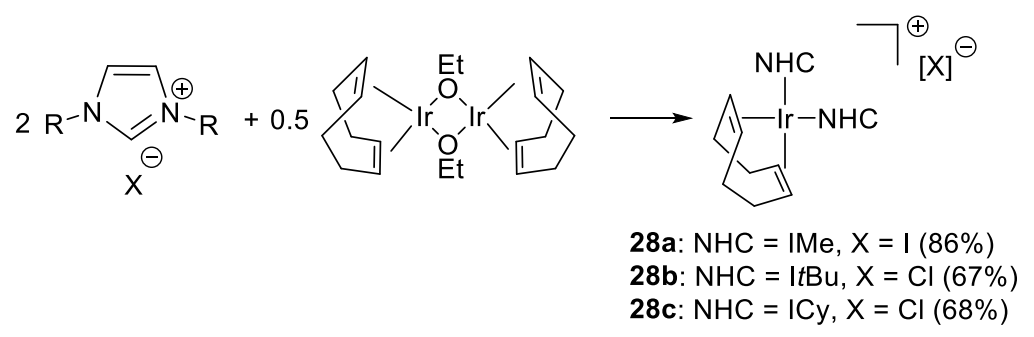

Scheme 10. Cationic biscarbene complexes.

Recently, Savka and Plenio described a one-step synthesis to access (NHC)M(COD)Cl (M = Rh, Ir) as well as $(\mathrm{NHC}) \mathrm{M}(\mathrm{CO})_{2} \mathrm{Cl}$ complexes by employing a relatively weak base $\left(\mathrm{K}_{2} \mathrm{CO}_{3}\right)$ in acetone under air (Scheme $11){ }^{49}$

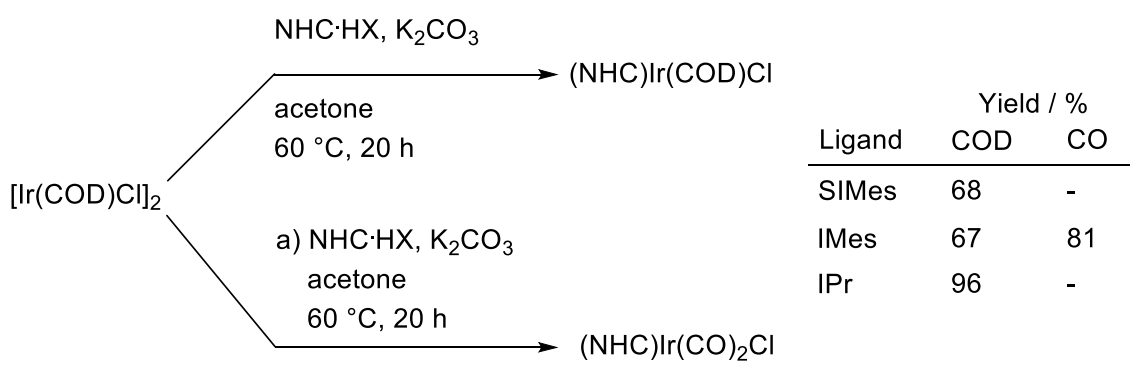

b) $\mathrm{CO}, \mathrm{rt}, 20 \mathrm{~min}$

Scheme 11. One pot synthesis of (NHC) $\operatorname{Ir}(\mathrm{COD}) \mathrm{Cl}$ and $(\mathrm{NHC}) \operatorname{Ir}(\mathrm{CO})_{2} \mathrm{Cl}$ complexes.

\subsection{The silver transmetallation method}

$$
\begin{array}{lll}
\text { 29a: } \mathrm{R}=\text { 4-tolylmethyl (95\%) } \\
\text { 29b: } \mathrm{R}=\text { n-butyl (94\%) }
\end{array}
$$

Scheme 12. The silver transmetallation method.

The silver transmetallation method for the synthesis of NHC-iridium complexes was first published by Crabtree and coworkers. ${ }^{50}$ The NHC-silver adducts (29) were generated in excellent yields by modifying the original procedure of Wang and Lin. ${ }^{51}$ Subsequent treatment of $[\operatorname{Ir}(\mathrm{COD}) \mathrm{Cl}]_{2}$ at room temperature gave 30a and 30b in 81 and 68\% yield, respectively (Scheme 12). X-ray analysis of the yellow crystals of 30a revealed square planar geometry around the iridium center. Complexes $\mathbf{3 0}$ smoothly reacted with $\mathrm{CO}$ to form bis-carbonyl compounds 31. Variable temperature ${ }^{1} \mathrm{H}$ NMR studies indicated that the rotation around the Ir- 
$\mathrm{C}_{\text {carbene }}$ bond is restricted in $\mathbf{3 0}$ between room temperature and $105^{\circ} \mathrm{C}$. In contrast, the carbonyl compounds (31) are fluxional and free rotation around the $\mathrm{Ir}-\mathrm{C}_{\text {carbene }}$ bond was indicated by coalescence of the signals at $55{ }^{\circ} \mathrm{C}$. Analogous complexes with the IiPr and ICy ligands were synthesized by Herrmann and coworkers (Scheme 13). ${ }^{39}$

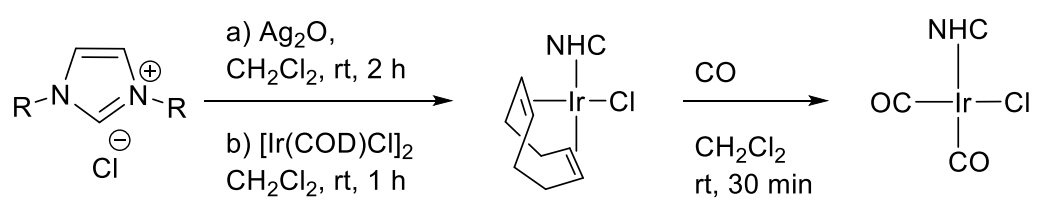

$\begin{array}{ll}\text { 22c: } \mathrm{NHC}=I \mathrm{Cy}(73 \%) & \text { 33: } \mathrm{NHC}=I \mathrm{Cy}(94 \%) \\ \text { 32: } \mathrm{NHC}=\mid \operatorname{PPr}(66 \%) & \text { 34: } \mathrm{NHC}=\mid i \operatorname{Pr}(93 \%)\end{array}$

Scheme 13. Herrmann's procedure for IiPr and (ICy)Ir(COD)Cl.

Leitner et al. demonstrated the reactivity between mono- and bis-NHC silver complexes in the transmetallation to group 9 metals. While mono-NHC silver complexes exclusively led to (NHC) $\operatorname{Ir}(\mathrm{COD}) \mathrm{Cl}$ (Scheme 12), ${ }^{50}$ the treatment of $[\operatorname{Ir}(\mathrm{COD}) \mathrm{Cl}]_{2}$ with one equivalent of $\mathbf{3 5}$ per iridium gave the bis-NHC complex 36 (Scheme 14). ${ }^{52}$ In this compound, the Ir atom exhibited the expected square planar geometry, and the $\mathrm{C}_{\text {carbene }}-\mathrm{Ir}-\mathrm{C}_{\text {carbene }}$ angle was close to $90^{\circ}$. The ethyl groups of the NHC ligands were pointing into the opposite direction.

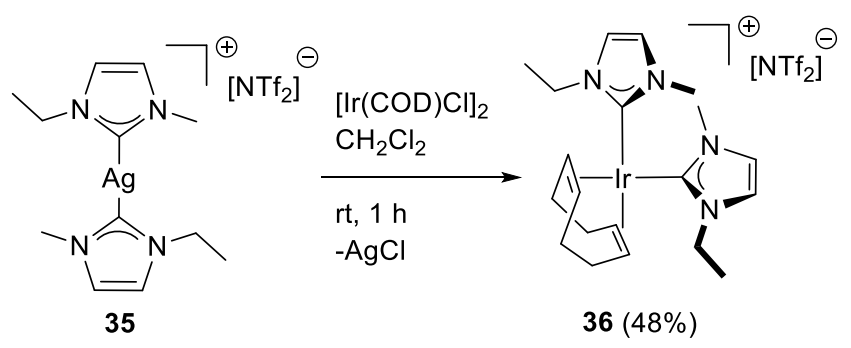

Scheme 14. Silver transmetallation with bis-NHC silver complex 35.

Very recently, Morris and coworkers synthesized a new chiral NHC ligand precursor and studied its complexation behavior using a variety of silver complexes. ${ }^{53}$ Treatment of $[\operatorname{Ir}(\mathrm{COD}) \mathrm{Cl}]_{2}$ with the silver salt 37 in refluxing THF gave a light yellow complex $\mathbf{3 8}$ which is an unusual, iodine-bridged dimer (Scheme 15).

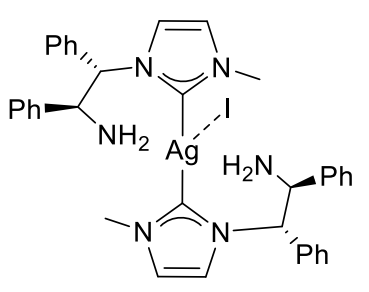

37

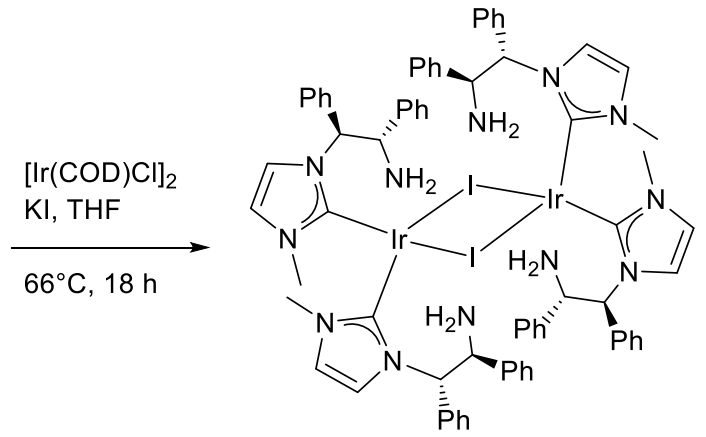

$38(80 \%)$

Scheme 15. The iodine bridged $\left[(\mathrm{NHC})_{2} \operatorname{Ir}(\mu-\mathrm{I})\right]_{2}, 38$. 
The silver transmetallation procedure is not limited to NHC-Ir(I) compounds. Yamaguchi's group employed NHC salts and $\mathrm{Ag}_{2} \mathrm{O}$ for the in situ synthesis of the NHC silver transmetallating agent, that upon treatment with $\left[\mathrm{Cp}^{*} \mathrm{IrCl}_{2}\right]_{2}$ gave NHC-Ir(III) compounds 39a-c in reasonable yields after work up (Scheme 16). ${ }^{54}$

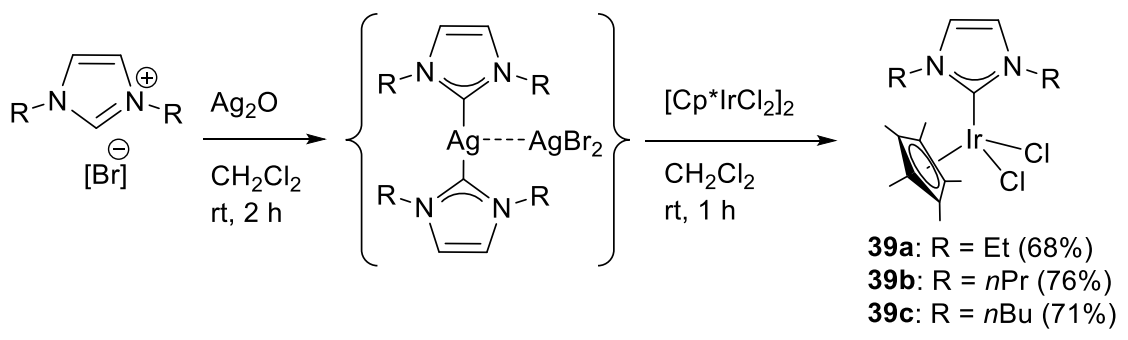

Scheme 16. The synthesis of Ir(III)-complexes 39a-c via the silver transmetallation method.

The silver transmetallation method was adapted by Thieuleux, Corriu and coworkers for the synthesis of NHC-Ir(III) complexes under heterogeneous conditions. The silicone-based nanostructured material 40, functionalized with an imidazolium salt, was prepared. Treatment of $\mathbf{4 0}$ with $\mathrm{AgOC}\left(\mathrm{CF}_{3}\right)_{3}$ led to 41, which, upon transmetallation with $\left[\mathrm{Cp}^{*} \mathrm{IrCl}_{2}\right]_{2}$, gave 42 (Scheme 17 top). A slightly modified procedure was efficient under homogeneous conditions for the synthesis of $\mathbf{4 3}$ (Scheme 17 bottom). ${ }^{55}$ This method was suitable for the synthesis of a series of transition metal-NHC complexes (Au, Ir, Pd and Ru). ${ }^{56} \mathrm{~A}$ one-pot procedure was equally efficient, and was applied in lieu of a two-step synthesis employing the isolated silver compound.
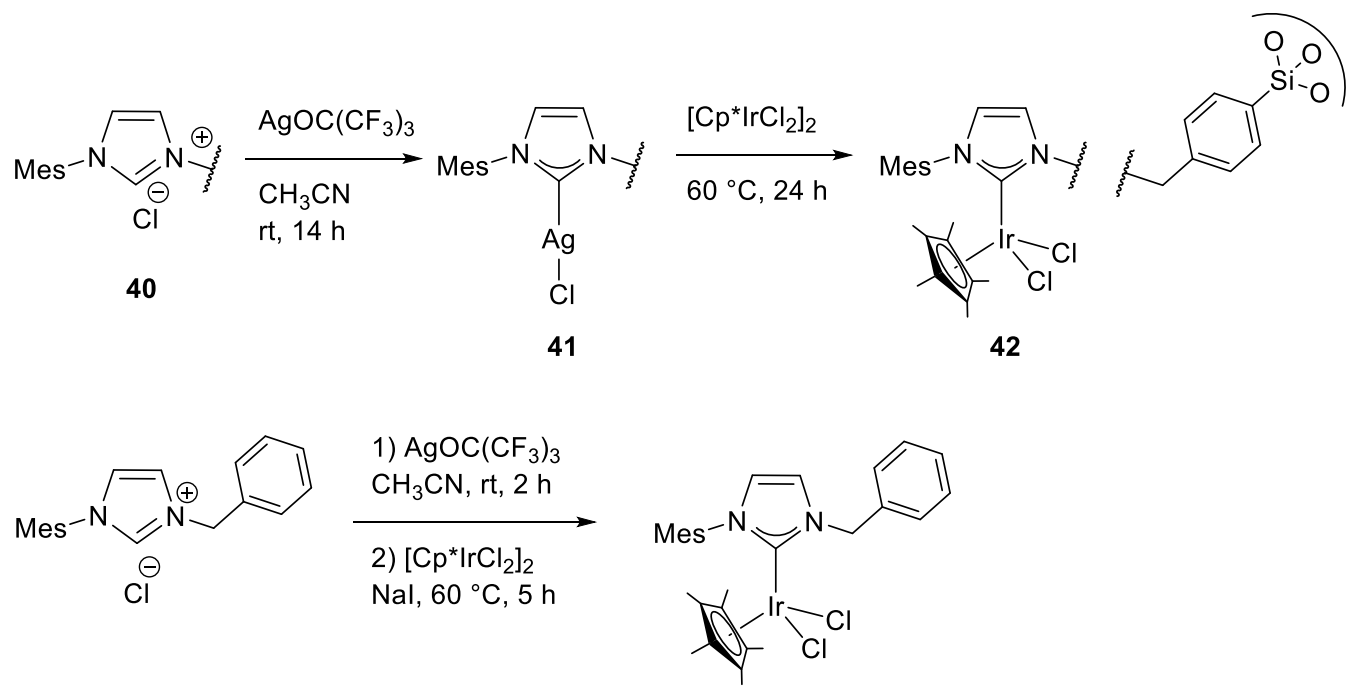

$43(87 \%)$

Scheme 17. Silver transmetallation with $\mathrm{AgOC}\left(\mathrm{CF}_{3}\right)_{3}$.

Mixed $\left(\mathrm{NHC}^{1}\right)\left(\mathrm{NHC}^{2}\right) \operatorname{Ir}(\mathrm{I})$ complexes were first prepared by Crabtree et al. ${ }^{57}$ Transmetallation of 30a with excess $\left[\left(\mathrm{NHC}^{2}\right)_{2} \mathrm{Ag}\right]\left[\mathrm{PF}_{6}\right]$ followed by anion exchange with $\mathrm{KPF}_{6}$ gave 44 and 45 (Scheme 18). Larger steric demand of the $\mathrm{NHC}^{2}$ ligand $\left(\mathrm{R}^{2}=n \mathrm{Bu}\right)$ had a detrimental effect on the yield of the reaction with heating (for $36 \mathrm{~h}$ ) and a large excess of $\left[\left(\mathrm{NHC}^{2}\right)_{2} \mathrm{Ag}\right]\left[\mathrm{PF}_{6}\right]$ (6 equivalent) was necessary to achieve appreciable yields of 44. In contrast, the synthesis of $\mathbf{4 5}$ took place smoothly at room temperature with only 2.5 equivalent of the silver salt. The same article reported mixed NHC complexes with triazole-derived and abnormal NHCs. 


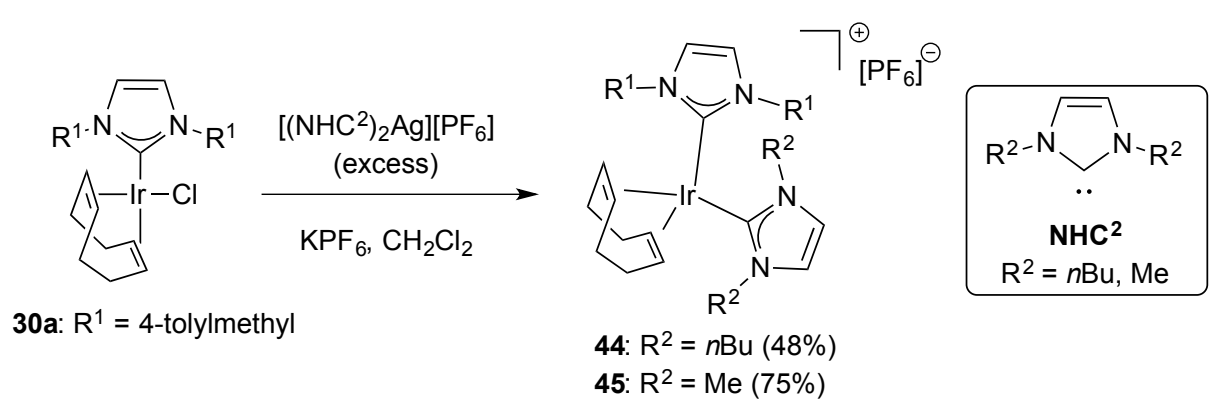

Scheme 18. Mixed $\left(\mathrm{NHC}^{1}\right)\left(\mathrm{NHC}^{2}\right) \operatorname{Ir}(\mathrm{COD}) \mathrm{Cl}, 44$ and 45.

\subsection{Comparison of the free carbene and the silver transmetallation method for the preparation of NHC-Ir complexes}

The suitability of the available methods for the synthesis of NHC-Ir compounds often depends on the ligands used. The first iridium(I) hydroxide with an NHC ligand, (IMes) $\operatorname{Ir}(\mathrm{COD})(\mathrm{OH})$ (46a), was serendipitously synthesized and was not studied in detail. ${ }^{58}$ It was not until 2013 that Nolan and coworkers carried out thorough investigations on NHC-iridium(I) hydroxides. ${ }^{59}$ It was found that complexes 46a-d are best accessed via a one-pot method employing free NHCs (Scheme 19). For the small ICy and IiPr ligands, this method gave a mixture of products. In this case, the silver transmetallation method gave 46e and $46 \mathbf{f}$ in 65 and $75 \%$ yields, respectively (Scheme 20 ).

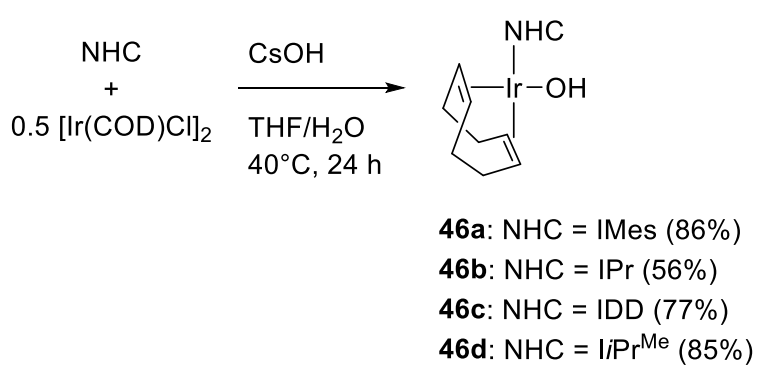

Scheme 19. NHC-iridium(I) hydroxides via the free carbene method.

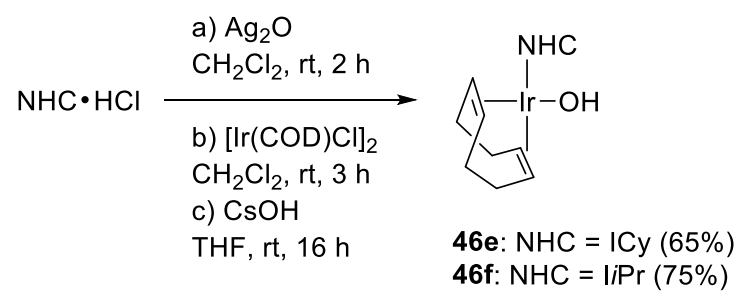

Scheme 20. NHC-iridium(I) hydroxides via silver transmetallation.

Similarly, both methods were employed for the synthesis of bis(NHC)-Ir complexes 47a-e (Scheme 21). The authors noted that the silver transmetallation was beneficial when the free carbene was an oil (IsB and IiPr) and required distillation prior to use..$^{60}$ 

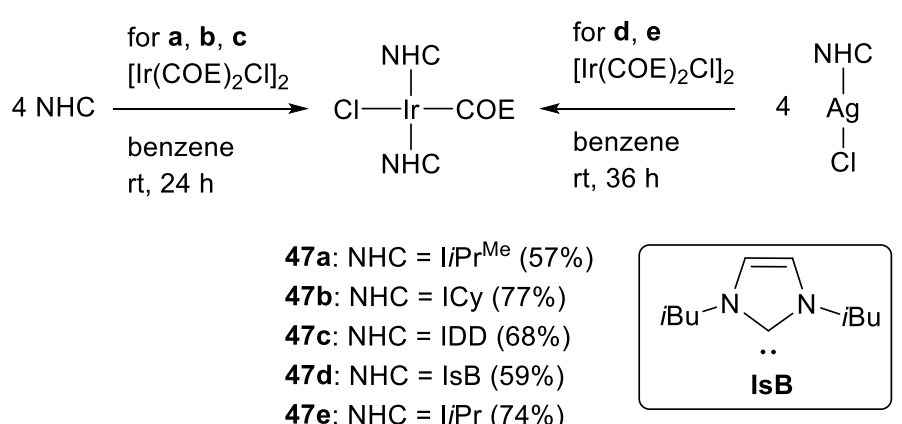

Scheme 21. The synthesis of (NHC) $)_{2}$ Ir complexes 47.

A study by the Rau group showed that complexes prepared through the silver transmetallation procedure might contain certain silver species (e.g. in form of halido argentate counterions) in the product. ${ }^{61}$ These impurities then can cause distinct reactivity differences in catalysis in comparison to 'silver-free' complexes, which were synthesized employing alkoxy metal precursors.

\subsection{Transmetallation with NHC-tungsten and NHC-copper complexes}

NHC carbene transmetallation procedures to iridium are not limited to the application of the NHC-silver method. Carbene transfer from tungsten to iridium was realized by Elsevier, Liu and coworkers. ${ }^{62}$ Interestingly, not only the NHC, but also the CO ligands were transferred from $\mathrm{W}(0)(\mathbf{4 8})$ to $\operatorname{Ir}(\mathrm{I})(\mathbf{4 9})$ (Scheme 22). The iridium complexes produced via NHC-W transmetallation were subjected to reactivity studies. Substitution of $\mathrm{CO}$ (trans to the NHC) by $\mathrm{PR}_{3}$ proceeded smoothly when the wingtips featured ethyl or benzyl substituents (50 and 51). Treatment of 49a-d with excess phosphine followed by anion exchange yielded compounds 52a-d. An analogous cationic complex featuring the chelating dppe (dppe = 1,2bis(diphenylphosphino)ethane) ligand was synthesized by the same method. ${ }^{62}$ Similar complexes with the unsaturated NHC ligands were prepared by the conventional silver transmetallation method. ${ }^{62 \mathrm{a}}$

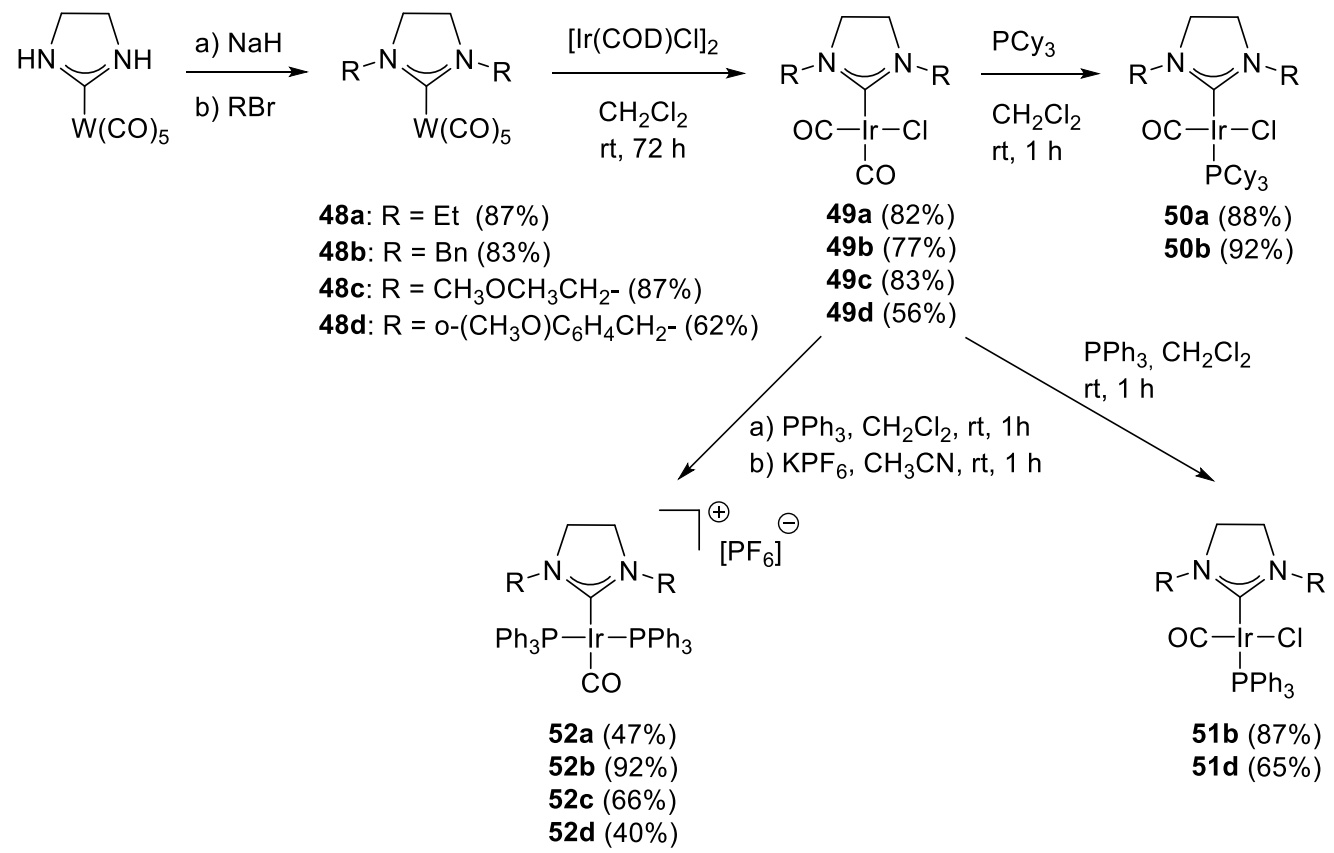


Scheme 22. Transmetallation from NHC-tungsten complexes to iridium.

Recently, the scope of NHC-copper to late transition metal transmetallation strategy has been extended to include iridium. The transfer of IMes from (IMes) $\mathrm{CuCl}$ to $[\mathrm{Ir}(\mathrm{COD}) \mathrm{Cl}]_{2}$ in $i \mathrm{PrOH}$ at $80^{\circ} \mathrm{C}$ gave the product (IMes) $\operatorname{Ir}(\mathrm{COD}) \mathrm{Cl}$ (22g) in 93\% yield after 16 hours. Other iridium complexes with a variety of non-classical NHCs were also prepared. ${ }^{63}$

\subsection{Metal-free carbene transfer agents for the synthesis of NHC-Ir complexes}

Grubbs et al. showed that alcoholate adducts of NHCs can be applied as carbene precursors at elevated temperatures, ${ }^{64}$ and this approach was adapted by Herrmann's group for the synthesis of (SIMes) $\operatorname{Ir}(\mathrm{COD}) \mathrm{Cl}$ (22h, Scheme 23). ${ }^{65}$ Iridium(III) compounds, such as (SIMe) $\operatorname{Ir}\left(\mathrm{Cp}^{*}\right) \mathrm{Cl}_{2}$ (126, vide infra in Scheme 51) can also be prepared from alcoholate adducts. ${ }^{47}$

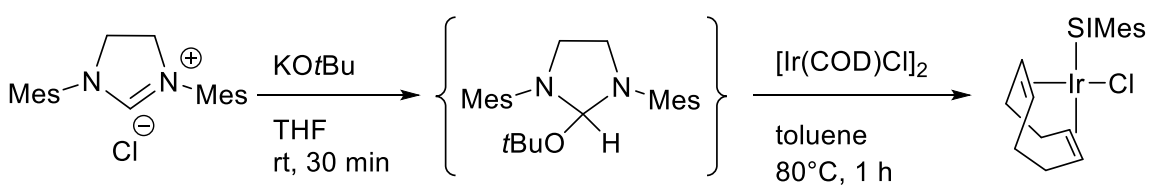

22h $(69 \%)$

Scheme 23. (NHC) $\operatorname{Ir}(\mathrm{COD}) \mathrm{Cl}$ complexes via thermolysis of an alcoholate adduct

2-Pentaflurophenyl(imidazolidines), originally reported by Waymouth, Hendrick, and coworkers, ${ }^{66}$ offer another base-free method for the synthesis of NHC-metal complexes. ${ }^{67}$ Similarly to the alcoholate adducts, thermolysis of $\mathbf{5 3}$ leads to in situ formation of SIMes (and pentafluorobenzene), ultimately giving a high yield of NHC-iridium complex $22 \mathbf{h}$ (Scheme 24). ${ }^{68}$

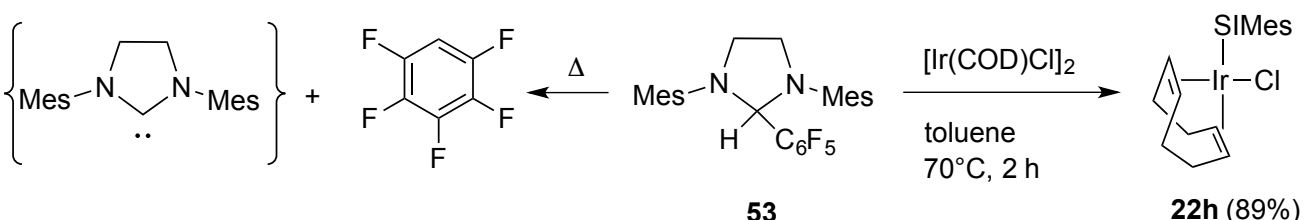

Scheme 24. Thermolysis of 2-pentaflurophenyl(imidazolidines).

At around the same time, Crabtree et al. demonstrated the usefulness of the unusual NHC transfer agent N,N'-dimethyl imidazolium-2-carboxylate (54). ${ }^{69}$ The air- and moisture-stable carboxylate cleaved the chloride bridge in $\left[\operatorname{Ir}(\mathrm{COD}) \mathrm{Cl}_{2}\right.$, and with simultaneous release of $\mathrm{CO}_{2}$, provided 21 in $82 \%$ yield (Scheme 25). When the reaction was carried out in the presence of excess $\mathrm{NaOAc}$, the final product was the cationic complex 55 incorporating two IMe ligands. The same NHC precursor species (54) was also capable of displacing one or two neutral ligands in cationic Ir(I) complexes to give 56-58 (Scheme 26). Interestingly, when Vaska's complex was employed, the reaction gave substitution of the chloride ligand to form ionic $\left[(\mathrm{IMe}) \operatorname{Ir}\left(\mathrm{PPh}_{3}\right)_{2}(\mathrm{CO})\right][\mathrm{Cl}]$, likely due to the high trans effect of the $\mathrm{CO}$ ligand. According to the authors, this results in replacement of the chloride in the coordination sphere of the metal by IMe, thus leading to a cationic iridium complex instead of the formation of a five-coordinate square pyramidal complex. Unfortunately, the experimental procedures (e.g. for 55) are rather confusing with regards to the 
stoichiometric ratios used for these reactions. ${ }^{69 b, 70}$ Mechanistic studies indicated that carboxylate $\mathbf{5 4}$ is the active transfer agent and, therefore, free NHC ligands are not involved in the transformations depicted in Schemes 25 and $26 .{ }^{69 b}$

An interesting rearrangement reaction was reported when a two-step, one-pot route was developed to access 60 (Scheme 27). ${ }^{69 \mathrm{~b}}$ The reaction proceeded through intermediate 59, which was identified by NMR spectroscopy and mass spectrometry and used dimethylcarbonate as both methylation and carboxylation agent.

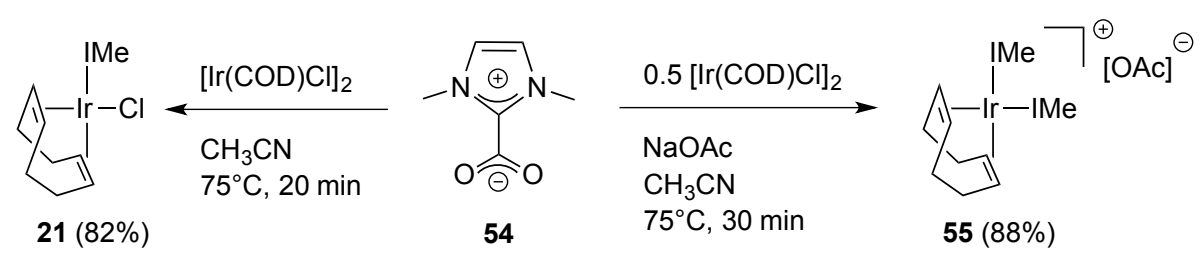

Scheme 25. Imidazolium carboxylate $\mathbf{5 4}$ as an NHC transfer agent.

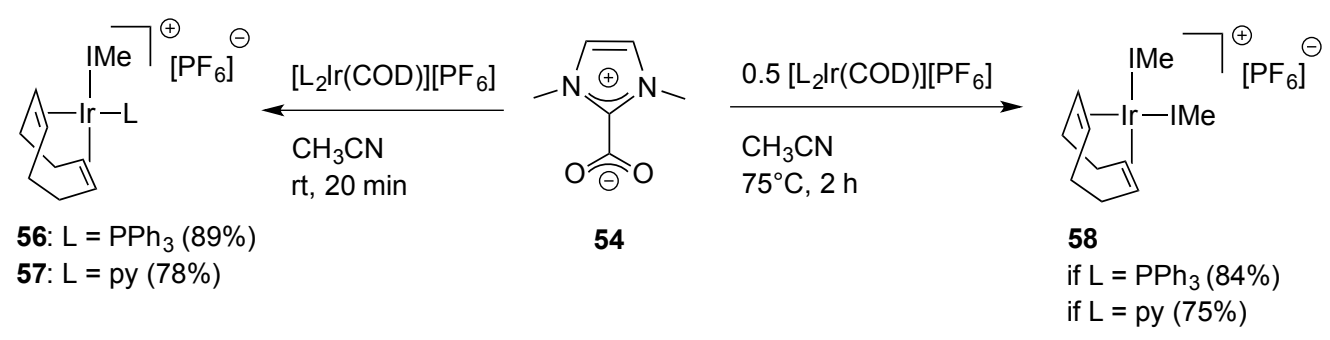

Scheme 26. Synthesis of NHC-Ir complexes via substitution of neutral ligands.

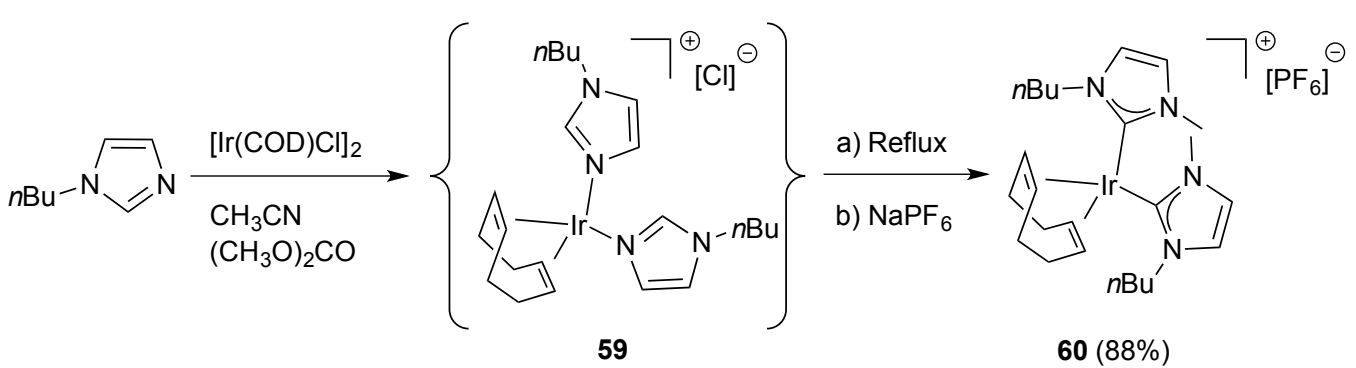

Scheme 27. An unusual intermediate 59 en route to complex $\mathbf{6 0 .}$

\subsection{Mechanistic aspects - oxidative addition and deprotonation}

Peris, Crabtree and coworkers showed that $\mathrm{C}-\mathrm{H}$ oxidative addition of an imidazolium cation onto late transition metals can play a role during NHC-M $(\mathrm{M}=\mathrm{Rh}$, Ir) complex formation. The reaction of chelating bis-NHC salt 61 with $[\mathrm{M}(\mathrm{COD}) \mathrm{Cl}]_{2}(\mathrm{M}=\mathrm{Rh}, \mathrm{Ir})$ in the presence of a weak base $\left(\right.$ e.g. $\left.\mathrm{Et}_{3} \mathrm{~N}\right)$ at first gave monometalated complexes 62a and 62b. Although the latter was not stable, it was characterized by NMR spectroscopy and X-ray crystallography. Extended reaction times with the iridium complex gave $\mathbf{6 3}$ (Scheme 28). The presence of the ferrocene motif $(\mathrm{Fc})$ on the backbone likely provides steric hindrance to protect the hydride ligand in $\mathbf{6 3}$. The authors proposed a mechanism that involved oxidative addition followed by base assisted $\mathrm{HCl}$ elimination. ${ }^{71 \mathrm{a}}$ Further extension of this work with experimental and theoretical studies showed 
that two different mechanism might be operative for the formation of complexes of type 62 and 63 : a) deprotonation of the imidazolium salt by a base; b) oxidative addition followed by deprotonation of the metal hydride. For the second metallation step (i.e. going from $\mathbf{6 2} \mathbf{b}$ to $\mathbf{6 3}$ ), oxidative addition seems to be the most feasible pathway. ${ }^{71 b}$

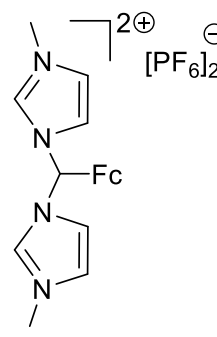

61

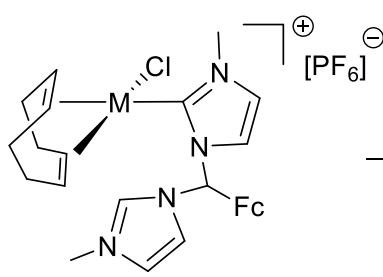

62a: $M=\operatorname{Rh}(47 \%)$

62b: $M=I r$

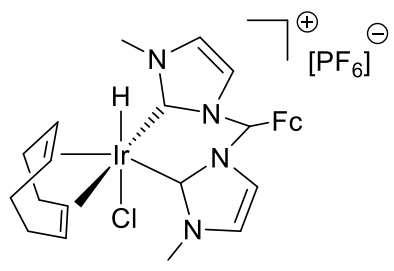

63

$(45 \%)$

Scheme 28. Formation of complexes 62 and $63(\mathrm{Fc}=$ ferrocenyl).

A remarkable base effect in the synthesis of mono- and binuclear NHC-Ir(I) complexes was discovered by Braunstein et al. The impact of different weak bases, such as $\mathrm{Cs}_{2} \mathrm{CO}_{3}$ and $\mathrm{Et}_{3} \mathrm{~N}$, for the formation of mononuclear $\operatorname{Ir}(\mathrm{I})$ complexes of bis(imidazolium) salts was compared. When approximately one equivalent of base was applied, only mono-NHC species were obtained. Interestingly, treatment with excess $\mathrm{Cs}_{2} \mathrm{CO}_{3}$ led to the chelation of the employed biscarbene ligand. ${ }^{72}$

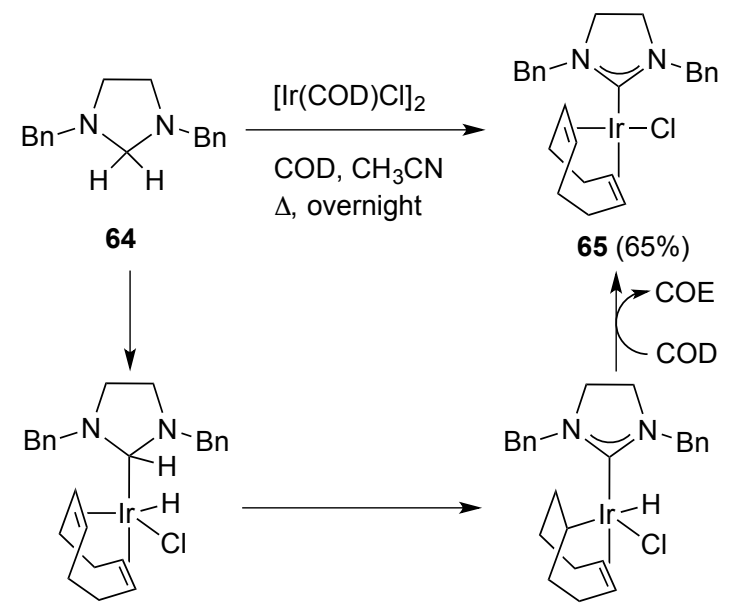

Scheme 29. Double C-H activation leading to 65.

As seen above, free NHCs are most frequently generated from their corresponding salts. As such, the results shown in Scheme 29 are surprising. Upon treatment of 64 with $[\operatorname{Ir}(\mathrm{COD}) \mathrm{Cl}]_{2}$, complex $\mathbf{6 5}$ was isolated in $45 \%$ yield, together with one equivalent of COE (partially hydrogenated COD). Adding COD to the reaction mixture led to an increased yield of $65 \%$ (Scheme 29). Other hydrogen acceptors, such as acetone, cyclohexanone, $t$-butylethene did not show any promoting effect, indicating that the chelating nature of COD is crucial during the course of the reaction. A double $\mathrm{C}-\mathrm{H}$ activation mechanism was proposed as shown on Scheme 29 (bottom). The same method was used to generate mono- and biscarbene complexes from tetraazabicyclooctane. ${ }^{73}$ 


\section{Stoichiometric reactivity of NHC-Ir complexes with spectator NHC ligands}

\subsection{Stoichiometric reactivity of square planar NHC-Ir(I) complexes}

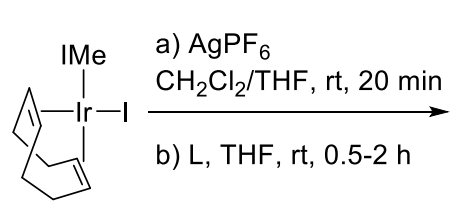

66

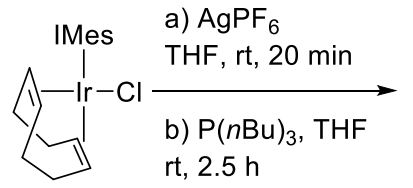

$22 \mathrm{~g}$

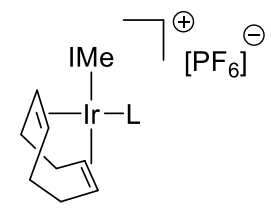

67a: $\mathrm{L}=\mathrm{PPh}_{3}(67 \%)$

67b: $L=\mathrm{PCy}_{3}(33 \%)$

67c: $\mathrm{L}=\mathrm{P}(n \mathrm{Bu})_{3}(87 \%)$

67d: $L=$ pyridine $(80 \%)$

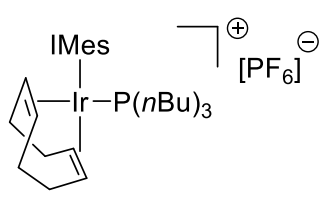

$68(87 \%)$

Scheme 30. The synthesis of cationic $[(\mathrm{NHC}) \operatorname{Ir}(\mathrm{COD}) \mathrm{L}]^{+}$complexes from neutral precursors.

Early on in 2002, Buriak and coworkers showed that straightforward halide abstraction from $\mathbf{6 6}$ or $\mathbf{2 2 g}$ in the presence of a phosphine or pyridine gave cationic complexes 67-68 (Scheme 30). ${ }^{74}$ Very recently, the exchange of the chloride in $(\mathrm{NHC}) \operatorname{Ir}(\mathrm{COD}) \mathrm{Cl}$ complexes with an azide was also demonstrated. The same study showed that biscarbonyl complexes might function as ligand-exchange triggered carbon monoxidereleasing molecules. ${ }^{75}$

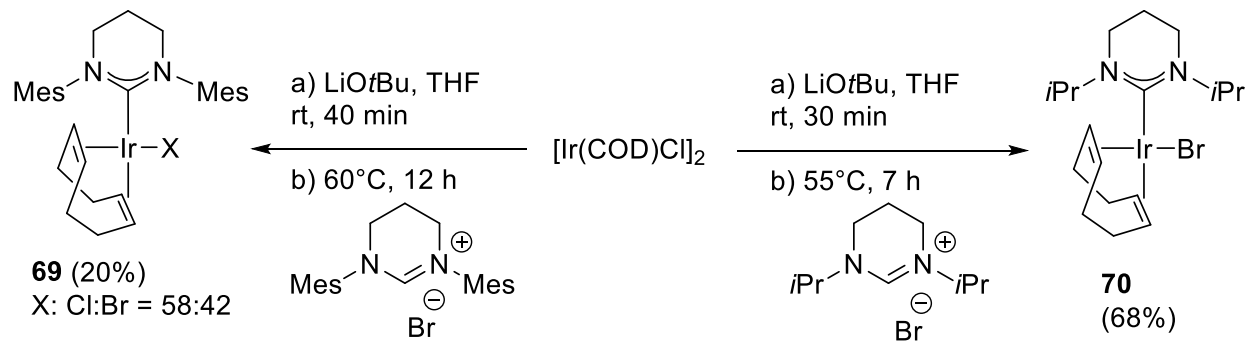

Scheme 31. Iridium complexes with 6-membered NHC ligands.

Buchmeiser and coworkers carried out basic reactivity studies with the $6 \mathrm{Mes}$ and $6 i \mathrm{Pr}$ ligands that feature a six-membered N-heterocycle. In situ formation of a metal alkoxide from the reaction of $[\operatorname{Ir}(\mathrm{COD}) \mathrm{Cl}]_{2}$ and $\mathrm{LiO} t \mathrm{Bu}$, followed by addition of $6 \mathrm{Mes} \cdot \mathrm{HBr}$ gave complex 69 in $20 \%$ yield, which was isolated as a mixture of $\mathrm{Ir}-\mathrm{Cl}$ and $\mathrm{Ir}-\mathrm{Br}$ complexes. The pure chloro-complex was prepared by using the $6 \mathrm{Mes} \cdot \mathrm{HBF}_{4}$ salt. Compound 70 featuring $i \mathrm{Pr}$ wingtips was isolated in $68 \%$ yield (Scheme 31 ). ${ }^{76}$ Anion exchange from $\mathbf{6 9 C l}$ with silver trifluoroacetate gave the neutral complex 71 in $65 \%$ yield (Scheme 32). All attempts to access a cationic NHC-Ir complex by abstraction of the chloride atom from $69 \mathrm{Cl}$ failed. ${ }^{77}$ 


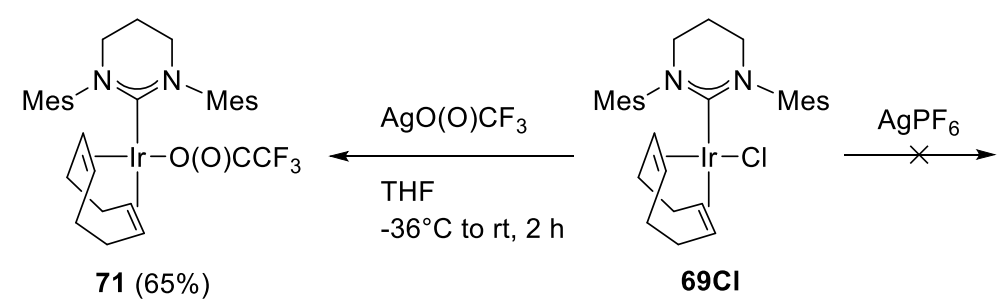

Scheme 32. Ligand exchange reaction on $69 \mathrm{Cl}$.

The structural behavior of cyclopentadienyl and indenyl ligands was investigated in their NHC-Ir(I) complexes. ${ }^{14}$ Replacement of the halide atom in (NHC) $\mathrm{Ir}(\mathrm{COD}) \mathrm{Cl}$ (28c and 66) by $\mathrm{NaCp}$ or NaInd gave compounds 72-74 (Scheme 33). Two distinct coordination modes, $\eta^{1}$-and $\eta^{5}$-Cp, were observed in complexes 72 and 73, respectively. DFT calculations indicated that formation of these was mainly governed by the steric demand of the NHC ligand employed. Furthermore, $\eta^{3}-\mathrm{Cp}$ coordination is disfavored and prevents interconversion between $\mathbf{7 2}$ and 73. In contrast, when NaInd was applied in the metathesis reaction, the 16electron square planar complex $\mathbf{7 4}$ was the only isolated species.

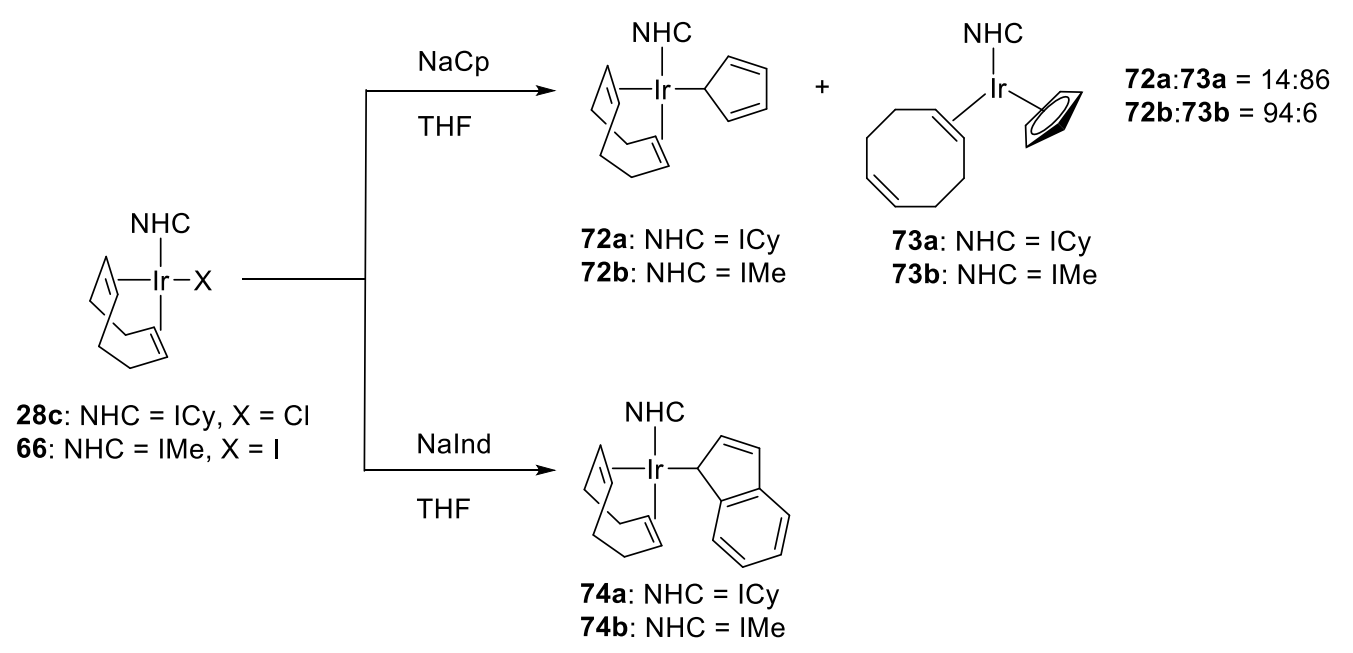

Scheme 33. Rare NHC-Ir(I) complexes with cyclopentadienyl and indenyl ligands.

Iridium(I)-hydroxides proved to be useful precursors for the synthesis of fluoride, bifluoride and trifluoromethyl complexes of $\mathrm{NHC}$-iridium(I) and -rhodium(I). Originally, experiments employed AgF for the halide metathesis on $(\mathrm{NHC}) \mathrm{M}(\mathrm{COD}) \mathrm{Cl}(\mathrm{M}=\mathrm{Rh}$, Ir). However, the method was limited to iridium (Scheme 34a). A more general approach was achieved via the reaction of $(\mathrm{NHC}) \mathrm{M}(\mathrm{COD})(\mathrm{OH})$ and $\mathrm{KHF}_{2}$ as a F-source (Scheme $34 \mathrm{~b}$ ). Furthermore, the same hydroxide precursor in combination with $\mathrm{NEt}_{3} \cdot 3 \mathrm{HF}$ was suitable for the synthesis of both fluoride (75) and bifluoride (77) complexes (Scheme 35). ${ }^{78}$

a)

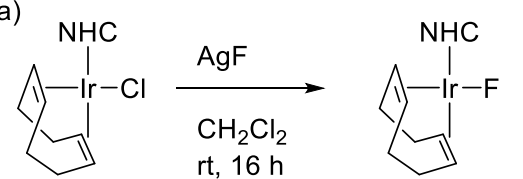

75a: $\mathrm{NHC}=\operatorname{IPr}(90 \%)$

75b: $\mathrm{NHC}=\operatorname{IDD}(98 \%)$

75c: $\mathrm{NHC}=\operatorname{liPr}(98 \%)$

75d: $\mathrm{NHC}=$ ICy $(99 \%)$ b)

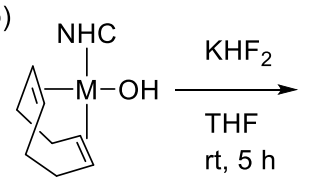

$$
\begin{aligned}
& \text { 75a: } M=\operatorname{Ir}, N H C=\operatorname{IPr}(99 \%) \\
& \text { 75c: } M=\operatorname{Ir}, \mathrm{NHC}=\operatorname{IPr}(74 \%) \\
& \text { 76a: } M=\operatorname{Rh}, \mathrm{NHC}=\operatorname{ICy}(81 \%) \\
& \text { 76b: } M=\operatorname{Rh}, \mathrm{NHC}=\operatorname{IPr}(78 \%)
\end{aligned}
$$

Scheme 34. a) [Ir]-F synthesis with AgF; b) A more general approach with $\mathrm{KHF}_{2}$. 


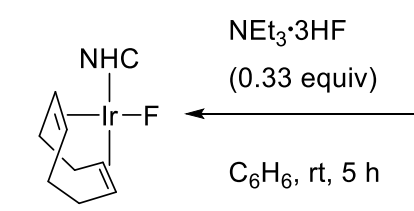

75a: $\mathrm{NHC}=\operatorname{IPr}(70 \%)$

75c: $\mathrm{NHC}=\operatorname{li} \operatorname{Pr}(97 \%)$

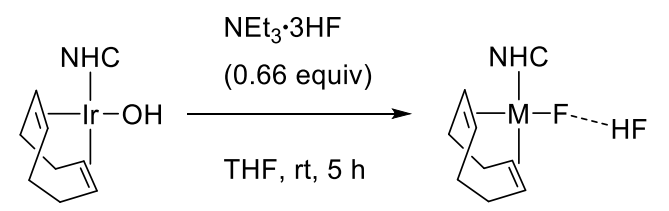

77a: $\mathrm{NHC}=\operatorname{IPr}(93 \%)$

77c: $\mathrm{NHC}=\operatorname{liPr}(82 \%)$

Scheme 35. The synthesis of fluoride and bifluoride complexes.

In the same contribution, the first $\mathrm{Ir}_{-} \mathrm{CF}_{3}$ complexes featuring $\mathrm{NHC}$ ligands (78) were synthesized using in situ prepared $\mathrm{AgCF}_{3}$ as a transfer agent (Scheme 36). The method was not general in scope of the NHC ligands that could be used. Nevertheless, two structurally interesting iridium complexes were isolated. X-ray analysis showed that $\mathrm{H}$-bonding is present between the NHC-wingtips and two of the fluorine atoms. This interaction was also present in solution as evidenced by through-space spin-spin coupling in the ${ }^{13} \mathrm{C}$ NMR spectrum.

a) $\mathrm{AgF}, \mathrm{CH}_{3} \mathrm{CN},-40^{\circ} \mathrm{C}, 15 \mathrm{~min}$

b) rt, $30 \mathrm{~min}$

c) $(\mathrm{NHC}) \mathrm{rr}(\mathrm{COD}) \mathrm{Cl}$, rt, $16 \mathrm{~h}$

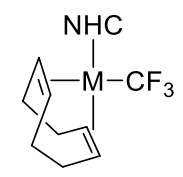

78a: $\mathrm{NHC}=\operatorname{li} \operatorname{Pr}(83 \%)$

78b: $\mathrm{NHC}=\mathrm{ICy}(70 \%)$

Scheme 36. The first Ir-CF 3 complexes.

Square planar $(\mathrm{NHC}) \operatorname{Ir}(\mathrm{COD}) \mathrm{Cl},(\mathrm{NHC}) \operatorname{Ir}(\mathrm{CO})_{2} \mathrm{Cl},[(\mathrm{NHC}) \operatorname{Ir}(\mathrm{COD}) \mathrm{L}]\left[\mathrm{BF}_{4}\right]$ and $\left[(\mathrm{NHC}) \operatorname{Ir}(\mathrm{CO})_{2} \mathrm{~L}\right]\left[\mathrm{BF}_{4}\right]$ $(\mathrm{NHC}=\mathrm{IMes}, \mathrm{IPr} ; \mathrm{L}=$ phosphine, pyridine $)$ complexes were oxidized by $\mathrm{XeF}_{2}$ to octahedral $\operatorname{Ir}(\mathrm{III})$ compounds with general formulae $(\mathrm{NHC}) \operatorname{IrClF}_{2} \mathrm{~L}_{2}$ or $\left[(\mathrm{NHC}) \mathrm{IrF}_{2} \mathrm{~L}_{2} \mathrm{~L}^{\prime}\right]\left[\mathrm{BF}_{4}\right]$. Complexes with $\mathrm{CO}$ ligands were more stable than the ones with COD, yet, all of the prepared compounds decomposed in solution within a few hours. ${ }^{26}$

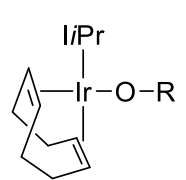

79: $\mathrm{R}=\mathrm{Si}(\mathrm{OMe})_{2} \mathrm{Ph}(99 \%)$

80: $\mathrm{R}=\mathrm{SiPh}_{3}(60 \%)$

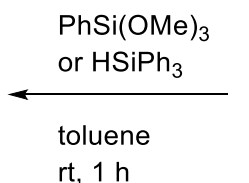

$\mathrm{rt}, 1 \mathrm{~h}$

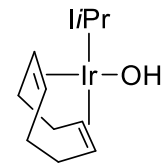

$46 f$

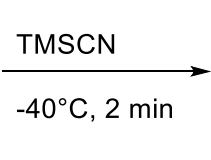

$40^{\circ} \mathrm{C}, 2 \mathrm{~min}$

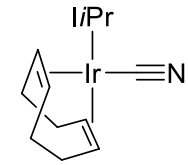

$81(90 \%)$

Scheme 37. Reactivity of (NHC)Ir-OH complexes.

The reactivity of the hydroxide complex $\mathbf{4 6} \mathbf{f}$ towards boronic acids and silicon compounds was investigated in detail by Nolan et al. ${ }^{59}$ Phenylboronic acid went through transmetallation forming $(\operatorname{Ii} \operatorname{Pr}) \operatorname{Ir}(\mathrm{COD})\left(\mathrm{C}_{6} \mathrm{H}_{5}\right)$. Reactions with silicone compounds, $\mathrm{PhSi}(\mathrm{OMe})_{3}$ and $\mathrm{HSiPh}_{3}$, gave iridium-siloxides $\mathbf{7 9}$ and $\mathbf{8 0}$ in $99 \%$ and $60 \%$ yields, respectively (Scheme 37 left). Treatment with trimethylsilylcyanide gave the (NHC) $\operatorname{Ir}(\mathrm{I})-\mathrm{CN}$ complex 81 (Scheme 37 right). Complex $46 \mathbf{f}$ was also probed in the activation of O-H (82), N-H (83) and C$\mathrm{H}$ bonds (84-86) and selected examples are shown in Scheme 38. The reactivity difference between pentafluorobenzene and 1,3,5-trifluorobenzene (the former being more acidic) indicated that $\mathbf{4 6 f}$ can activate 
$\mathrm{C}-\mathrm{H}$ bonds with a $\mathrm{pK}_{\mathrm{a}}$ close to that of $\mathrm{H}_{2} \mathrm{O}$ but not higher. It should be noted that all of these transformations are deprotonation reactions, meaning that none of them involve a change in the oxidation state of the metal.

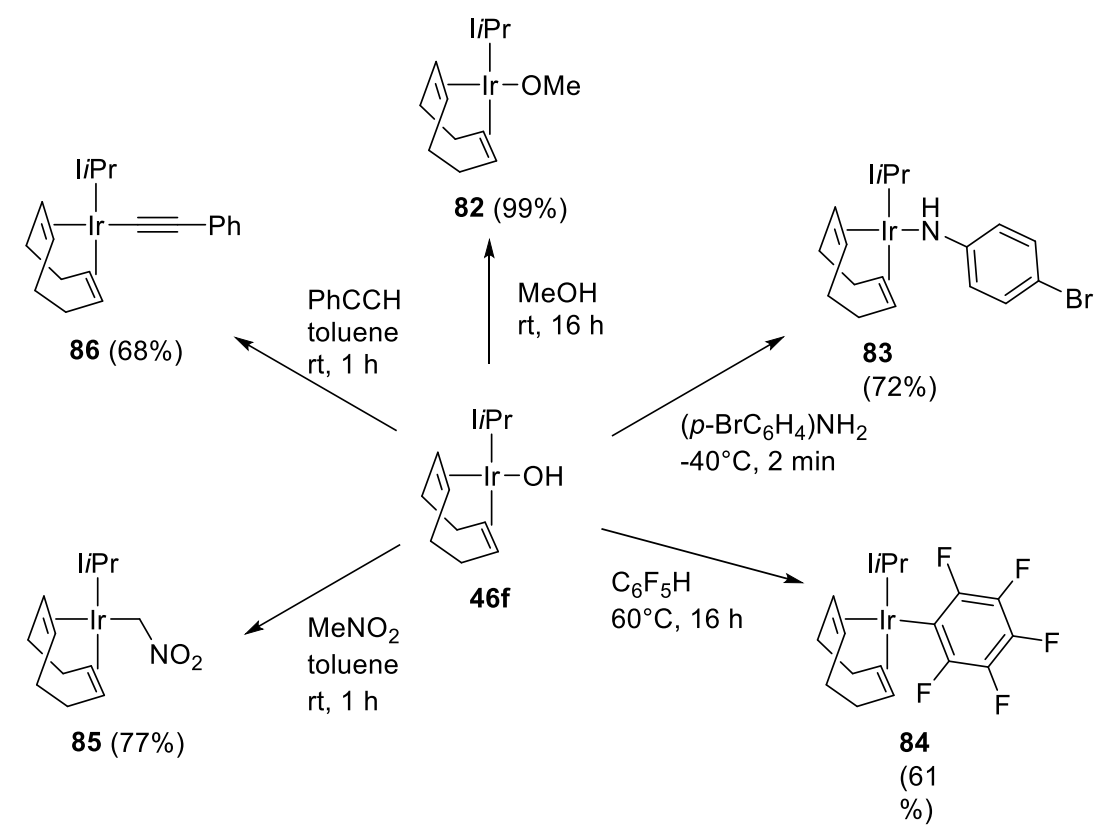

Scheme 38. Reactivity of (NHC)Ir-OH complexes; O-H, N-H and C-H bond activation.

The reactivity of Ir-hydroxide complexes towards $\mathrm{CO}_{2}$ was also examined. Complex $\mathbf{4 6 f}$ swiftly reacts with $\mathrm{CO}_{2}$ both in solution and in solid phase (Scheme 39). Product 6 consists of two $\{(\operatorname{IiPr}) \operatorname{Ir}(\mathrm{COD})\}$ motifs bridged by a carbonate moiety. In addition, the authors found that $\mathrm{CO}_{2}$ readily insert into Ir-alkoxide and amide bonds to form Ir-carbonates $(\mathbf{8 8}, \mathbf{8 9})$ and -carbamates (91 and 92, Scheme 40). In contrast, Ir-alkyl compounds proved to be unreactive towards $\mathrm{CO}_{2}{ }^{19}$ Very recently, the mechanism of $\mathrm{CO}_{2}$ fixation was investigated in detail by kinetic studies and DFT calculations. ${ }^{79}$

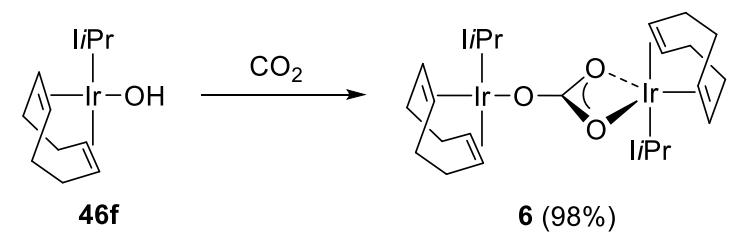

Scheme 39. The synthesis of carbonate bridged dimer 6 .
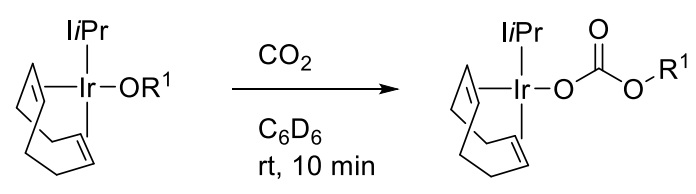

82: $R^{1}=M e$
87: $R^{1}=P h$

88: $R^{1}=\operatorname{Me}(99 \%)$

89: $\mathrm{R}^{1}=\mathrm{Ph}(99 \%)$
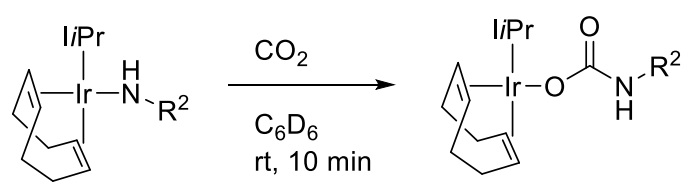

83: $\mathrm{R}^{2}=p-\mathrm{BrC}_{6} \mathrm{H}_{4}$

91: $\mathrm{R}^{2}=p-\mathrm{BrC}_{6} \mathrm{H}_{4}(92 \%)$

90: $\mathrm{R}^{2}=\mathrm{CH}_{2} \mathrm{Ph}$

92: $\mathrm{R}^{2}=\mathrm{CH}_{2} \mathrm{Ph}$ (not isolated) 
Scheme 40. $\mathrm{CO}_{2}$ insertion into Ir-O and Ir-N bonds.

The first bis(NHC) analogue of Vaska's complex was prepared by Nolan et al. by exposing $47 \mathbf{a}$ to an atmosphere of $\mathrm{CO}$ at room temperature (Scheme 41), giving compound $\mathbf{9 3}$ in good yield. Subsequent reactivity studies on complex $\mathbf{9 3}$ showed that it is not as reactive as Vaska's $\operatorname{IrCl}(\mathrm{CO})\left(\mathrm{PPh}_{3}\right)_{2}$. For example, oxidative addition of dihydrogen did not take place. Exposure of $\mathbf{9 3}$ to $\mathrm{O}_{2}$ led to slow formation of a new species, but decomposition precluded isolation and full characterization. Complex 93 was though successfully converted into the hydroxide analogue 94 which showed similar, although decreased reactivity compared to (IiPr) $\operatorname{Ir}(\mathrm{COD}) \mathrm{OH}(\mathbf{4 6 f}){ }^{60}$

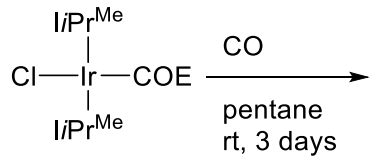

$47 a$

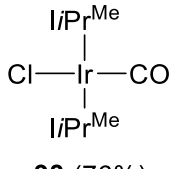

$93(76 \%)$

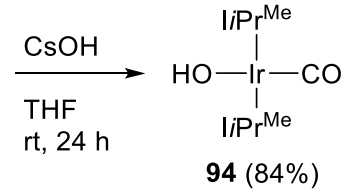

$94(84 \%)$

Scheme 41. A bis-NHC-Ir (93) and its corresponding Ir-OH (94) complex.

A strategy for the synthesis of iridium complexes featuring an NHC ligand with the parent N-H substitution was developed by Crabtree et al. The N-benzoyl substituted NHC salt 95 was reacted with $[\operatorname{Ir}(\mathrm{COD}) \mathrm{Cl}]_{2}$ in the presence of the non-nucleophilic strong base LiHMDS to give 96 (Scheme 42). N-acyl methanolysis of the corresponding cationic species 97 gave the the protic NHC-Ir(I) compound $\mathbf{9 8}$. The presence of the N-H proton was confirmed both spectroscopically and crystallographically, and a possible 1,3-shift of the N-H proton to iridium was not observed. ${ }^{80}$

The coordination chemistry of thiophene, benzothiophene and 2-methyl thiophene with NHC-Ir complexes was studied by Oro and coworkers. ${ }^{81}$ For that purpose, cationic $[(\operatorname{IPr}) \operatorname{Ir}(\mathrm{COD}) \mathrm{L}]\left[\mathrm{BF}_{4}\right](\mathrm{L}=$ acetone (99), pyridine, and $\mathrm{PMe}_{2} \mathrm{Ph}(\mathbf{1 0 1})$ ) complexes were treated with the thiophene compounds under a dihydrogen atmosphere (Scheme 43). On all occasions, highly sensitive, unstable complexes were formed which were characterized by NMR spectroscopic methods. The outcome of these reactions was crucially dependent on both ligand $\mathrm{L}$ as well as the employed thiophene compound. In general, weak donor ligands (acetone, pyridine) allowed for various coordination modes of the $\pi$-system $\left(\eta^{2}, \eta^{5}, \kappa^{1}\right.$-S) (Scheme 43a), while a clear preference for the $\kappa^{1}$-S-coordination mode was observed in the presence of a phosphine ligand (Scheme $43 \mathrm{~b}$ ). 

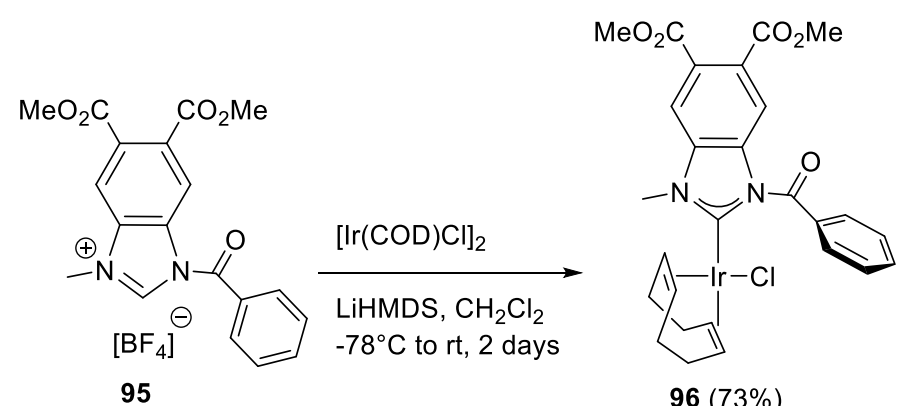

95

$96(73 \%)$

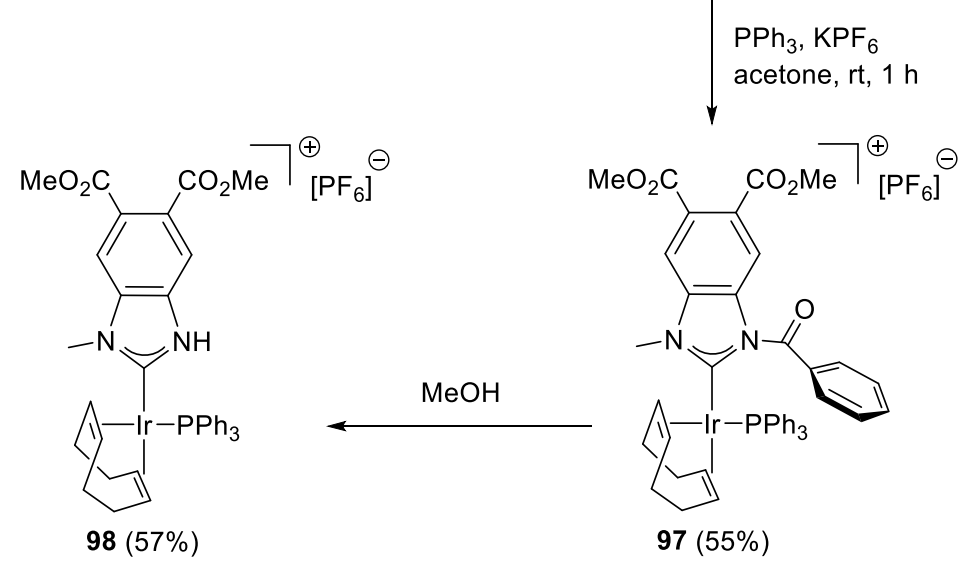

Scheme 42. The synthesis of the protic NHC-Ir complex 98.

a)

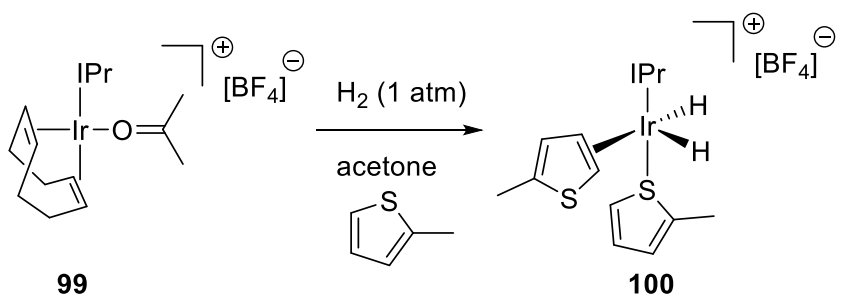

b)

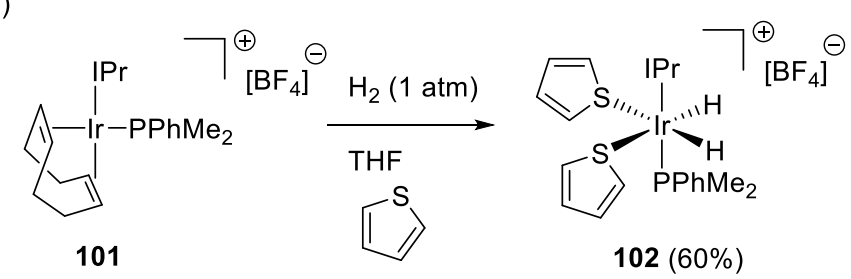

Scheme 43. a) Reaction outcome with weakly donating acetone ligand; b) Reaction outcome with a strongly donating phosphine ligand.

Structurally unusual iridium complexes were prepared by Tamm et al. when employing anionic NHC ligands (Scheme 44). ${ }^{17}$ Treatment of the lithium adduct 103 with $[\operatorname{Ir}(\mathrm{COD}) \mathrm{Cl}]_{2}$ in THF gave the zwitterionic complexes 104 in moderate to good yields (50-74\%). All of these complexes are stabilized by an intramolecular arene-metal interaction, which involves the ipso carbon of the arene ring next to the borate moiety. The interaction results in disparate Ir-C-N angles. Complex 104b was hydrogenated in benzene to give 105. In contrast, hydrogenation in cyclohexane resulted in dimerization leading to 7 (structure shown in Figure 3), where one arene wingtip of each NHC participated in $\eta^{6}$-coordination to Ir. These arene-stabilized 
$\operatorname{Ir}(\mathrm{III})$ complexes were not active in catalysis (complexes 104 were highly competent in the hydrogenation of alkenes, vide infra in Section 9.1).

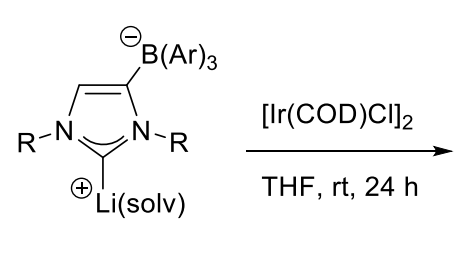

103a-d

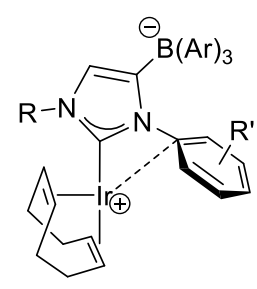

104a: $R=$ Mes, $A r=C_{6} F_{5}(72 \%)$

104b: $R=$ Dipp, $A r=C_{6} F_{5}(74 \%)$

104c: $\mathrm{R}=\mathrm{Dipp}, \mathrm{Ar}=m-\mathrm{XyF} 6(70 \%)$

104d: $R=$ Dipp, $A r=p$-tol $(50 \%)$ for 104b: $\mathrm{H}_{2}$

$\mathrm{C}_{6} \mathrm{D}_{6}, \mathrm{rt}, 2 \mathrm{~h}$

$05(99 \%)$

Scheme 44. Zwitterionic (NHC)Ir-complexes reported by Tamm and coworkers.

Very recently, a series of neutral and cationic NHC-Ir(I) complexes were synthesized by Dorta et al. who studied the reactivity of (2,7-SICyNap) $\operatorname{Ir}(\mathrm{COD}) \mathrm{Cl}(\mathbf{1 0 6})$ in the silver salt metathesis reaction (Scheme 45). ${ }^{82}$ In these studies, the authors showed how the nucleophilicity of the WCA (weakly coordinating anion) and the solvent used can influence the reaction outcome. Chloride abstraction with $\mathrm{AgPF}_{6}$ in $\mathrm{CH}_{2} \mathrm{Cl}_{2}$ afforded the deep red complex $107\left[\mathrm{PF}_{6}\right]$, in which one of the aromatic wingtips approaches the metal center and displays an arene-metal interaction that involves the $\mathrm{C} 8$ and $\mathrm{C} 8 \mathrm{a}$ carbon atoms of the naphthyl unit. The interaction stabilizes the otherwise very reactive 14-electron $\operatorname{Ir}(\mathrm{I})$ species and also leads to a sideways tilt of the NHC-M bond. Experimental and computational studies showed that the tilting causes a large upfield shift of the carbene carbon ${ }^{13} \mathrm{C}$ NMR signal.

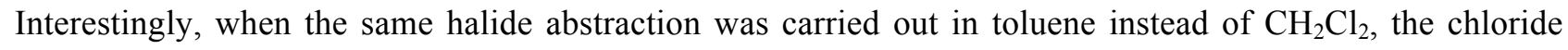
bridged $\mathrm{Ir}-\mathrm{Ag}$ adduct $\left[\{(2,7-\mathrm{SICyNap}) \operatorname{Ir}(\mathrm{COD})(\mu-\mathrm{Cl})\} \cdot\left\{\mathrm{Ag}\left(\eta^{2}-\mathrm{tol}\right)\right\}\right]\left[\mathrm{PF}_{6}\right]\left(\mathbf{1 0 9}\left[\mathrm{PF}_{6}\right]\right)$ was isolated. When a switch was made to the more nucleophilic OTf anion, independent of the reaction medium used (DCM, toluene), a bimetallic Ir-Ag complex 110 was isolated. Only a further increase in nucleophilicity of the anion (TFA) brought about a situation favorable enough to drive the reaction to completion with covalent bonding of the TFA moiety to iridium in the neutral complex 111. Treatment of $107\left[\mathrm{PF}_{6}\right]$ and $109\left[\mathrm{PF}_{6}\right]$ with the coordinating solvent acetonitrile afforded $\mathbf{1 0 8}\left[\mathrm{PF}_{6}\right]$. 


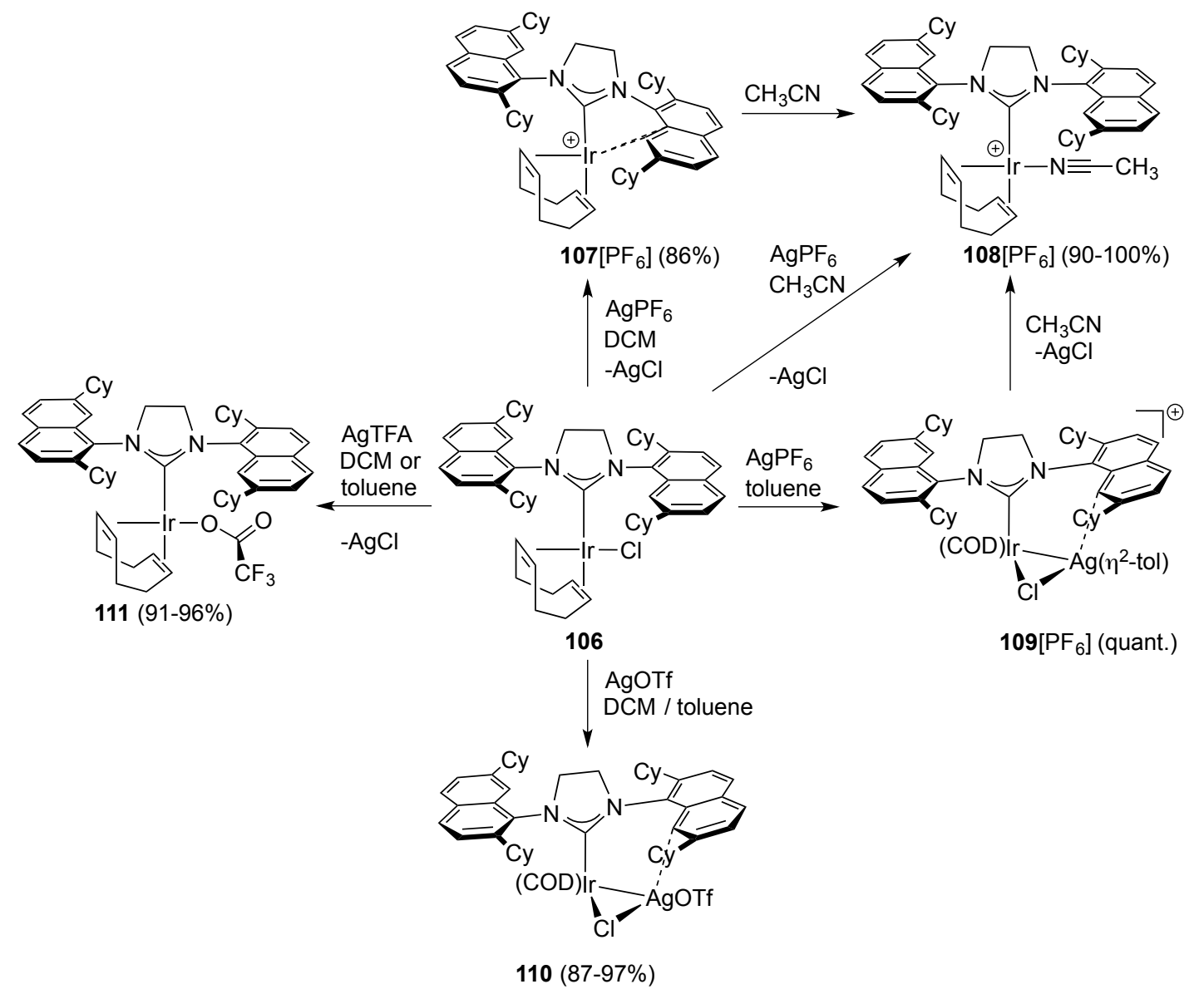

Scheme 45. Silver salt metathesis on (2,7-SICyNap) $\operatorname{Ir}(\mathrm{COD}) \mathrm{Cl}$ (106).

An intriguing $\operatorname{Ir}_{6}$ cluster featuring NHC ligands was originally isolated as a deactivation product during catalytic glycerol dehydrogenation (vide infra in Section 9.4), and then was independently synthesized and characterized. ${ }^{30}$ The cluster, which has the formula of $\left[(\mathrm{IMe})_{8} \operatorname{Ir}_{6}(\mathrm{CO})_{2} \mathrm{H}_{14}\right]\left[\mathrm{BAr}_{4}^{f}\right]_{2}$ (113), can be best described with a "bow-tie" geometry (Scheme 46). The four peripheral Ir(III) units have terminal $\kappa^{1}-\mathrm{H}$ and $\mu^{2}$-H ligands, two IMe ligands and are also bound to three other Ir atoms. The Ir(II) units in the center of the molecule are $\sigma$-bonded to each other ( $\operatorname{Ir}-\operatorname{Ir}=2.691 \AA$ ). Overall, cluster 113 is unique in many aspects; i) It is the first metal cluster with more than two carbene ligands and, at the same time, it is poor in carbonyl ligands; ii) The source of hydride ligands is glycerol, not $\mathrm{H}_{2}$; iii) It is the first "bow-tie" all-Ir structure. ${ }^{21}$ More recently, two carbene-rich $\mathrm{Ir}_{4}$ clusters have been synthesized from the glycerol dehydrogenation reaction. ${ }^{33}$

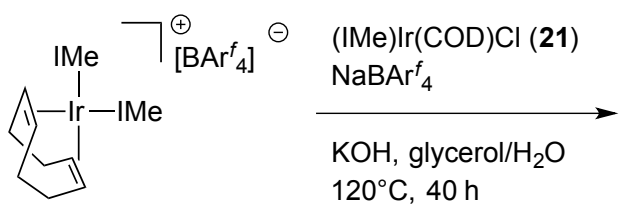

112

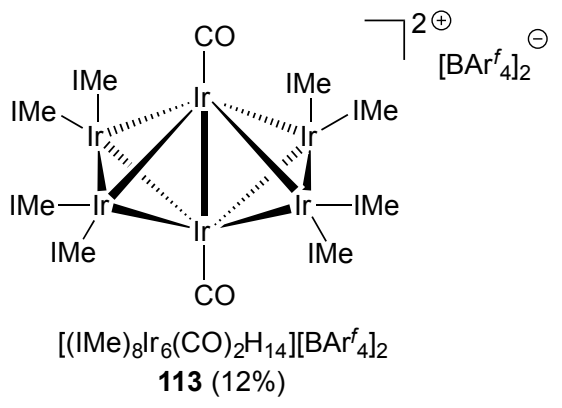

$113(12 \%)$

Scheme 46. The synthesis of $\operatorname{Ir}_{6}$ cluster 113. Metal hydrides are omitted for clarity. 


\subsection{Stoichiometric reactivity of five- and six-coordinate NHC-Ir(III) compounds}

Transition metal complexes with a low coordination number have a distinctive and crucial role in catalysis. ${ }^{83}$ Chaplin and coworkers successfully isolated the 14-electron complex [(IBioxMe $\left.)_{3} \mathrm{Rh}\right]\left[\mathrm{BAr}_{4}^{f}\right]{ }^{84}{ }^{8 n}$ contrast, attempts towards the synthesis of $\left[\left(\mathrm{IBioxMe}_{4}\right)_{3} \operatorname{Ir}\right]\left[\mathrm{BAr}_{4}^{f}\right]$ failed, and instead gave the oxidative addition product $\mathbf{1 1 4}$ as a mixture of rotamers in $76 \%$ yield. Stepwise synthesis revealed the intermediacy of $\mathbf{1 1 5}$, which was converted to the unstable species 116 upon halide abstraction in 1,2- $\mathrm{C}_{6} \mathrm{H}_{4} \mathrm{~F}_{2}$. The 14-electron fragment $\left\{\left(\mathrm{IBioxMe}_{4}\right)_{3} \mathrm{Ir}\right\}^{+}$was trapped when a coordinating solvent was used, giving complex 117 (Scheme 47). The oxidative addition of the $\mathrm{C}-\mathrm{H}$ bond of the aromatic molecule/solvent is reversible, as evidenced by arene exchange reactions with $\mathrm{C}_{6} \mathrm{H}_{5} \mathrm{~F}$ and $1,3,5-\mathrm{C}_{6} \mathrm{H}_{3} \mathrm{~F}_{3}$ (Scheme 48$) .{ }^{85}$

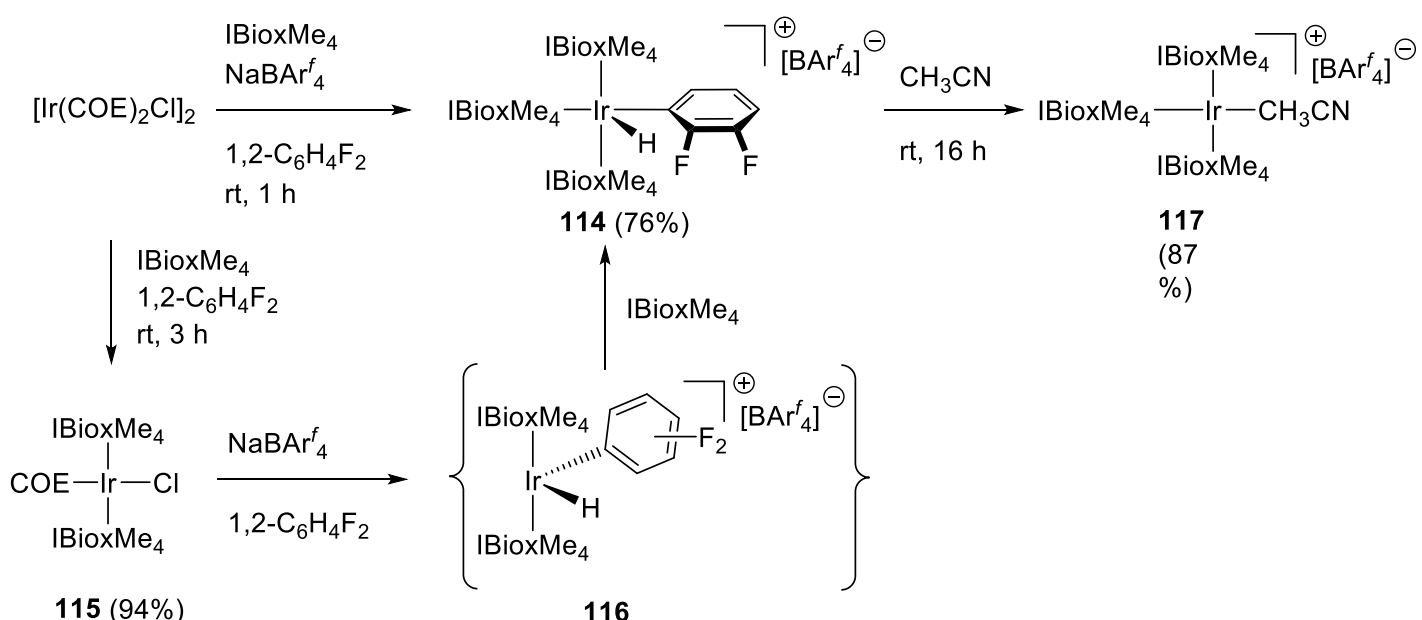

Scheme 47. Attempts for the synthesis of low-coordinate (NHC)-Ir complexes.

Another 14-electron fragment, $\left\{(\operatorname{IBioxMe})_{2} \operatorname{Ir}(\mathrm{H})_{2}\right\}^{+}$, was accessed by exposing 115 to simultaneous hydrogenation and halide abstraction conditions. ${ }^{31}$ During these studies, $\left[\left\{(\operatorname{IBioxMe})_{2} \operatorname{Ir}(\mathrm{H})_{2}\right\}(\mu-\mathrm{Cl})\right](\mathbf{1 1})$ was identified as an isolable intermediate (Scheme 49). In situ generated $\mathbf{1 1}$ was then transformed into $\mathbf{1 2 0}$ and $\mathbf{1 2 1}$ (Scheme 50). A mixture of $\mathbf{1 1 5}$ and $\mathrm{NaBAr}_{4}^{f}$ smoothly reacted with ethylene to give complex 114, in which differently orientated ethylene ligands were observed. Similarly, treatment with excess COE led to 115. This interesting example of transfer dehydrogenation proceeded quantitatively and generated two equivalents of cyclooctane (hydrogen acceptor).

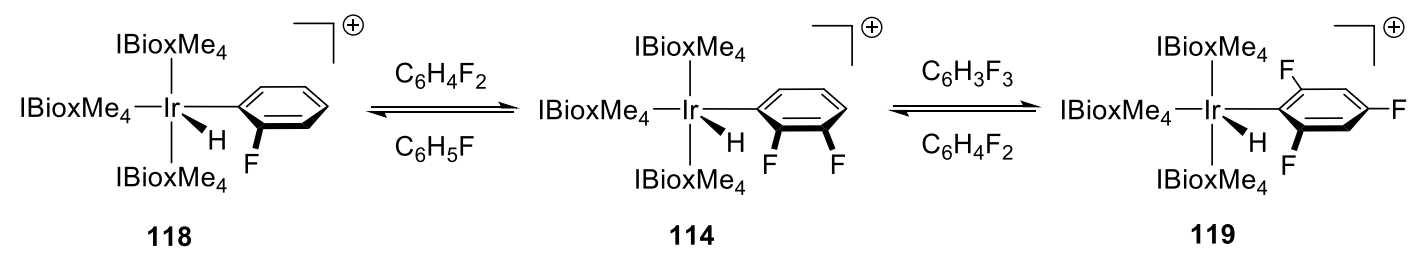

Scheme 48. Reversible C-H activation in 114. The $\mathrm{BAr}_{4}^{f}$ anion is omitted.

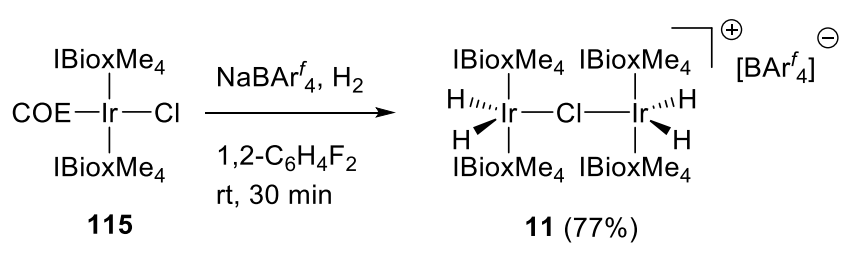


Scheme 49. The synthesis of chloride bridged dimer 11.

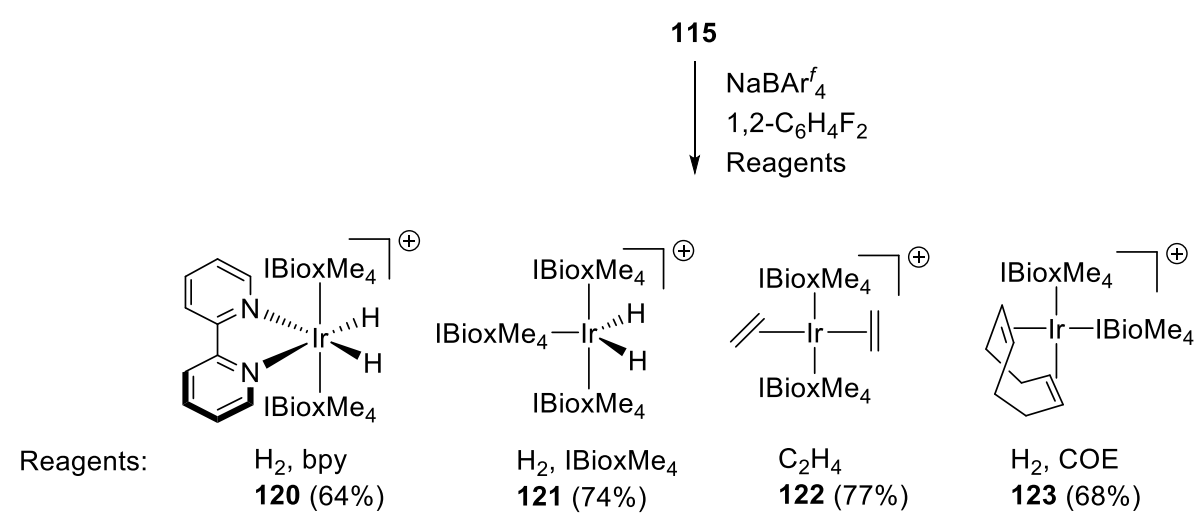

Scheme 50. Synthesis of complexes 120-123. The $\mathrm{BAr}_{4}^{f}$ anion is omitted.

Metalloporhyrin diaminocarbenes of rhodium and iridium were comparatively studied. ${ }^{86}$ Axial ligand disorder in the open chain diaminocarbene complexes prohibited direct solid-state comparison, but the NHC analogues were accessible (Figure 10).

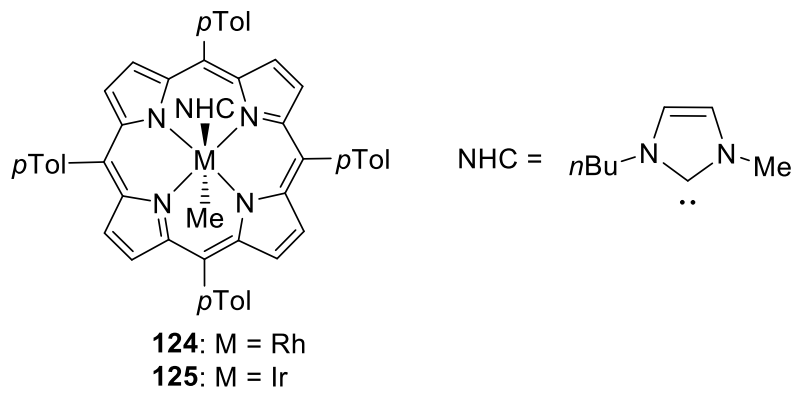

Figure 10. (Tetra-p-tolylporphyrinato)rhodium and -iridium NHC complexes.

\subsection{Stoichiometric reactivity of half-sandwich NHC-Ir(III) complexes}

The Yamaguchi group studied ligand substitution reactions of $(\mathrm{NHC}) \operatorname{Ir}\left(\mathrm{Cp}^{*}\right) \mathrm{Cl}_{2}$ complexes in detail. ${ }^{47}$ Dicationic Ir(III) complexes 127-128 were synthesized via the silver salt metathesis route (Scheme 51). Treatment of 26b with $\mathrm{NaBH}_{4}$ in $i \mathrm{PrOH}$ gave the dihydride $\left(\mathrm{IMe}^{\mathrm{Me}}\right) \operatorname{Ir}(\mathrm{Cp} *)(\mathrm{H})_{2}$ (129). The bistriflate complex $\left(\mathrm{IMe}^{\mathrm{Me}}\right) \operatorname{Ir}\left(\mathrm{Cp}^{*}\right)(\mathrm{OTf})_{2}(\mathbf{1 3 0})$ was prepared in quantitative yield by halide abstraction on 26b using AgOTf in $\mathrm{CH}_{2} \mathrm{Cl}_{2}$ (Scheme 52). The crystal structures of $\mathbf{1 2 7} \mathbf{a}$ and $\mathbf{1 2 8}$ revealed that the geometry around the iridium(III) center shows the expected three-legged piano stool in both complexes with typical Ir-C(NHC) bond distances (e.g. Ir-C = 2.055(8) $\AA$ for 127a).

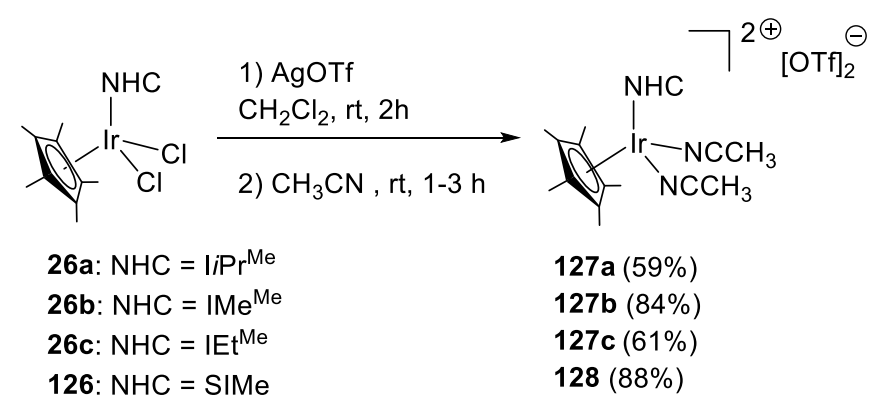


Scheme 51. Silver salt metathesis with (NHC) $\operatorname{Ir}\left(\mathrm{Cp}^{*}\right) \mathrm{Cl}_{2}$.

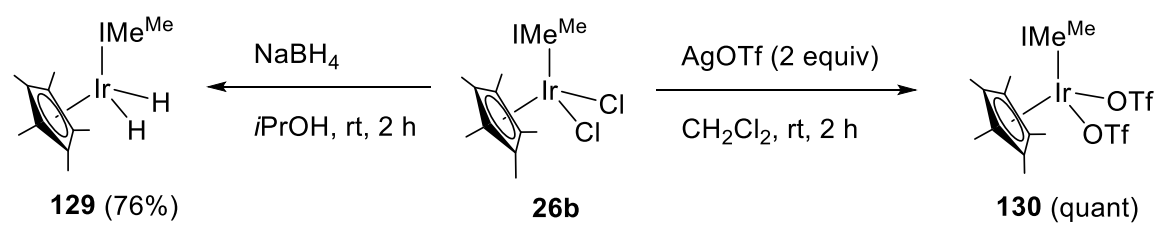

Scheme 52. Ligand exchange reactions on 26b.

An interesting binuclear iridium complex 131 was isolated in good yield from the reaction between $\mathbf{1 2 7} \mathbf{b}$ and 129 (Scheme 53). The hydride ligands were assigned in the ${ }^{1} \mathrm{H}$ NMR spectrum as a singlet at $-17.50 \mathrm{ppm}$. In the solid state, the short Ir-Ir distance $(2.71 \AA)$ indicated double-bond character.

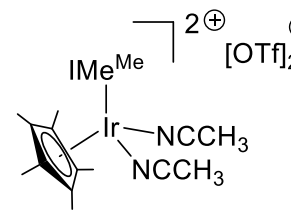

$127 b$

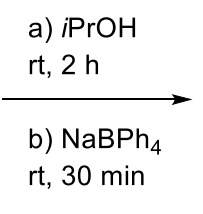

129

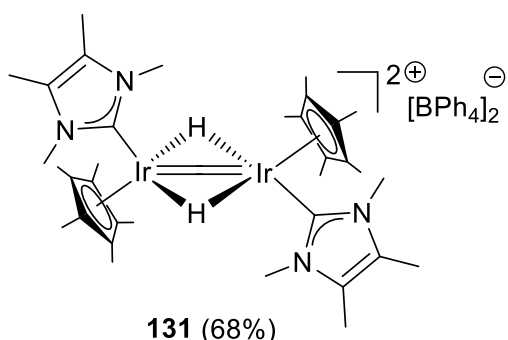

$131(68 \%)$

Scheme 53. Binuclear Ir-complex 131.

The reactivity scope of (NHC) $\operatorname{Ir}\left(\mathrm{Cp}^{*}\right)$ complexes was further extended through a study on ligand exchange reactions under wet conditions (Figure 11). Complexes 132-135 are structurally very similar to the parent 26b (Scheme 8). However, adduct formation through equilibrium processes can occur in this case (135 vs 135-aqua). Furthermore, partial halide abstraction when using only 1 equiv of AgOTf gave a mixture of 136dim and 136-mon which are in equilibrium with each other (Scheme 54). In poorly coordinating solvents (e.g. $\mathrm{CF}_{3} \mathrm{COOD}, \mathrm{CD}_{2} \mathrm{Cl}_{2}$ ), the equilibrium was pushed towards dimer formation. On the other hand, full conversion to 136-mon occurred in coordinating solvents $\left(\mathrm{CD}_{3} \mathrm{CN}\right.$, pyridine- $\left.d_{5}\right) .{ }^{87}$ Some of these $(\mathrm{NHC}) \operatorname{Ir}\left(\mathrm{Cp}^{*}\right)$ complexes were probed as catalysts in $\mathrm{H} / \mathrm{D}$ exchange reactions (vide infra in Section 9.3). ${ }^{87,88}$
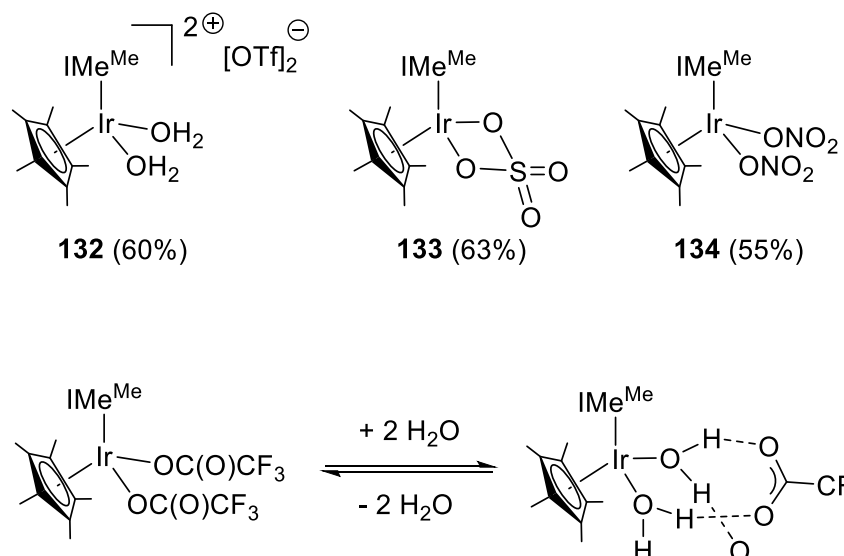

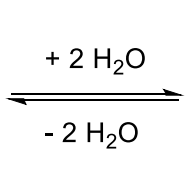

$135(38 \%)$

$134(55 \%)$

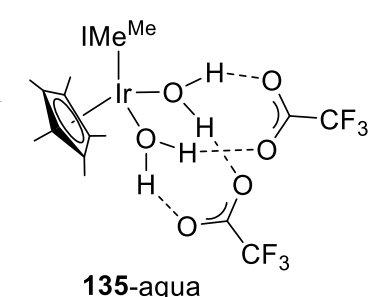

Figure 11. Half-sandwich complexes 132-135. 


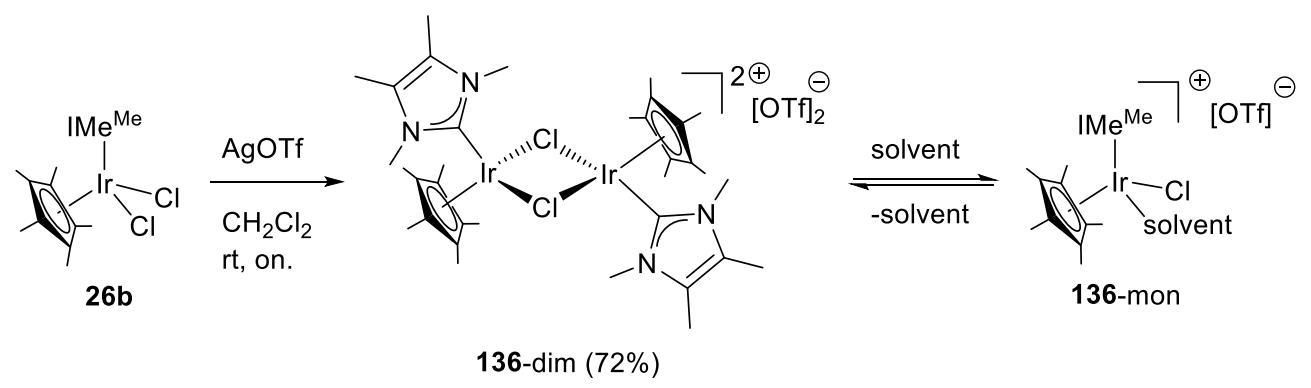

Scheme 54. Partial halide abstraction from $26 \mathbf{b}$.

An interesting oxyfunctionalization to produce methanol via Ir-methyl bond cleavage was described by the Ison group. ${ }^{89}$ Treatment of half-sandwich NHC-Ir(III) complexes 138 with dioxygen in water gave rise to methanol formation (Scheme 55). Isotope labeling studies showed that the source of oxygen in the methanol product was $\mathrm{O}_{2}$ and the methyl group directly came from the Ir-Me unit. Under the original conditions, identification of the iridium compound formed was not possible. However, a modified system led to slower reaction rates and allowed for the identification of $\mathbf{1 3 9}$ (Scheme 56).

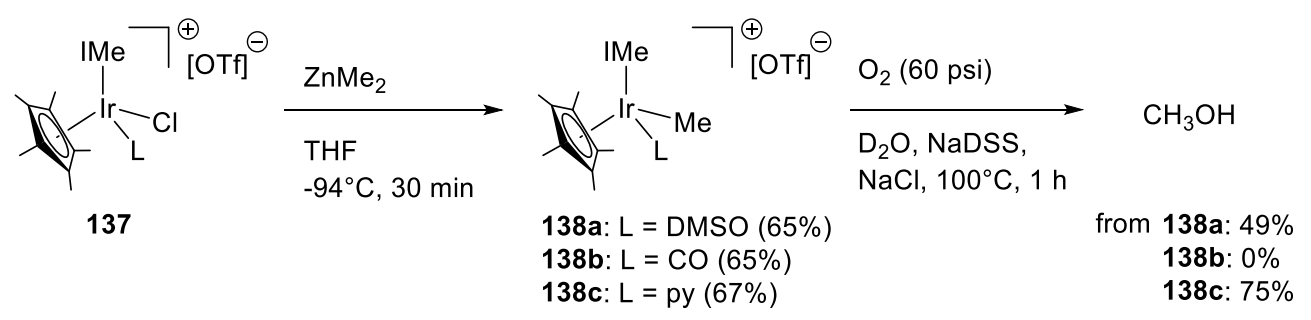

Scheme 55. Methanol production via oxyfunctionalization.

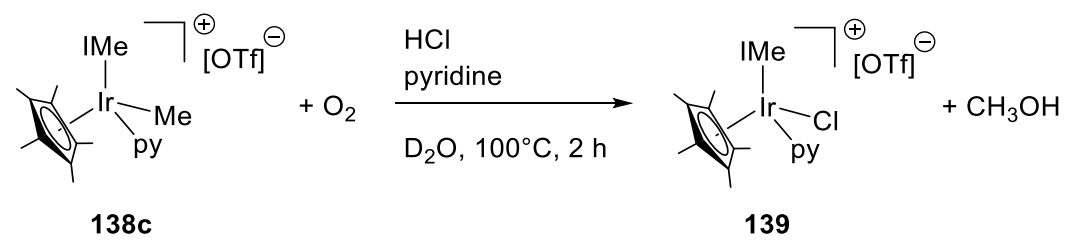

Scheme 56. Formation of the iridium complex 139 during oxyfunctionalization.

Mechanistic studies indicated that the rate determining step is the dissociation of pyridine from $\mathbf{1 3 8 c}$ to form the 16-electron fragment $\left\{(\mathrm{IMe}) \operatorname{Ir}\left(\mathrm{Cp}^{*}\right)(\mathrm{Me})\right\}^{+}$. Therefore, the authors hypothesized that mild reaction conditions for methanol production are realized via facile generation of $141 .^{90}$ When 141 was exposed to air, a blue crystalline product (142) was isolated (Scheme 57). This compound is a rare example of an $\operatorname{Ir}(\mathrm{IV})$ bimetallic complex. Complex 142 is best described as two half sandwich $\mathrm{d}^{5} \operatorname{Ir}(\mathrm{IV})$ centers that are bridged by an oxygen atom. Upon addition of an external proton source (ethanol), $\mathbf{1 4 2}$ indeed gives rise to quantitative formation of methanol.

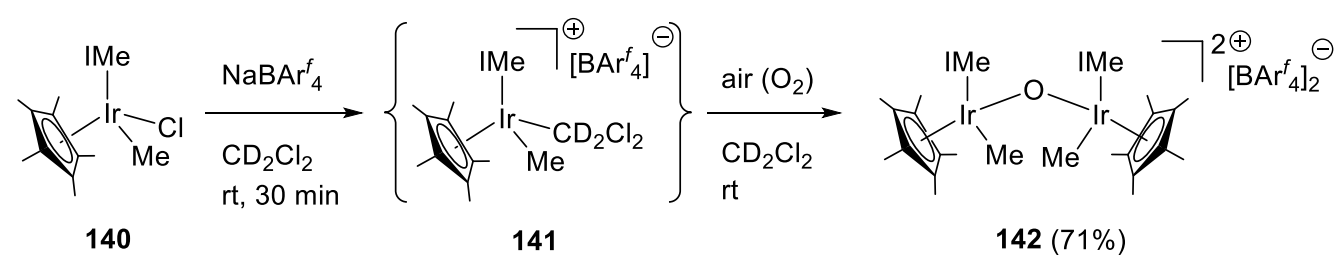


Scheme 57. A rare Ir(IV) complex, 142.

In other studies involving such half-sandwich iridium complexes, Li and coworkers observed C-bound to Nbound tautomerization of an NHC (Scheme 58, 146 to 147). ${ }^{91}$ Exposure of 144 to $\mathrm{KPF}_{6}$ under mild conditions resulted in nucleophilic addition of the $\mathrm{NH}$ bond across the $\mathrm{CN}$ triple bond of acetonitrile to give 146 in $86 \%$ yield. Heating a solution of 146 in $\mathrm{CDCl}_{3}$ gave 147, which was also prepared from 145 under halide abstraction conditions (Scheme 58). More recently, Cross and coworkers reported an interesting NHC ligand system where the synthesis of either N-ylide or NHC-Ir complexes of the half-sandwich type was observed depending on the reaction conditions used (Scheme 59). ${ }^{92}$

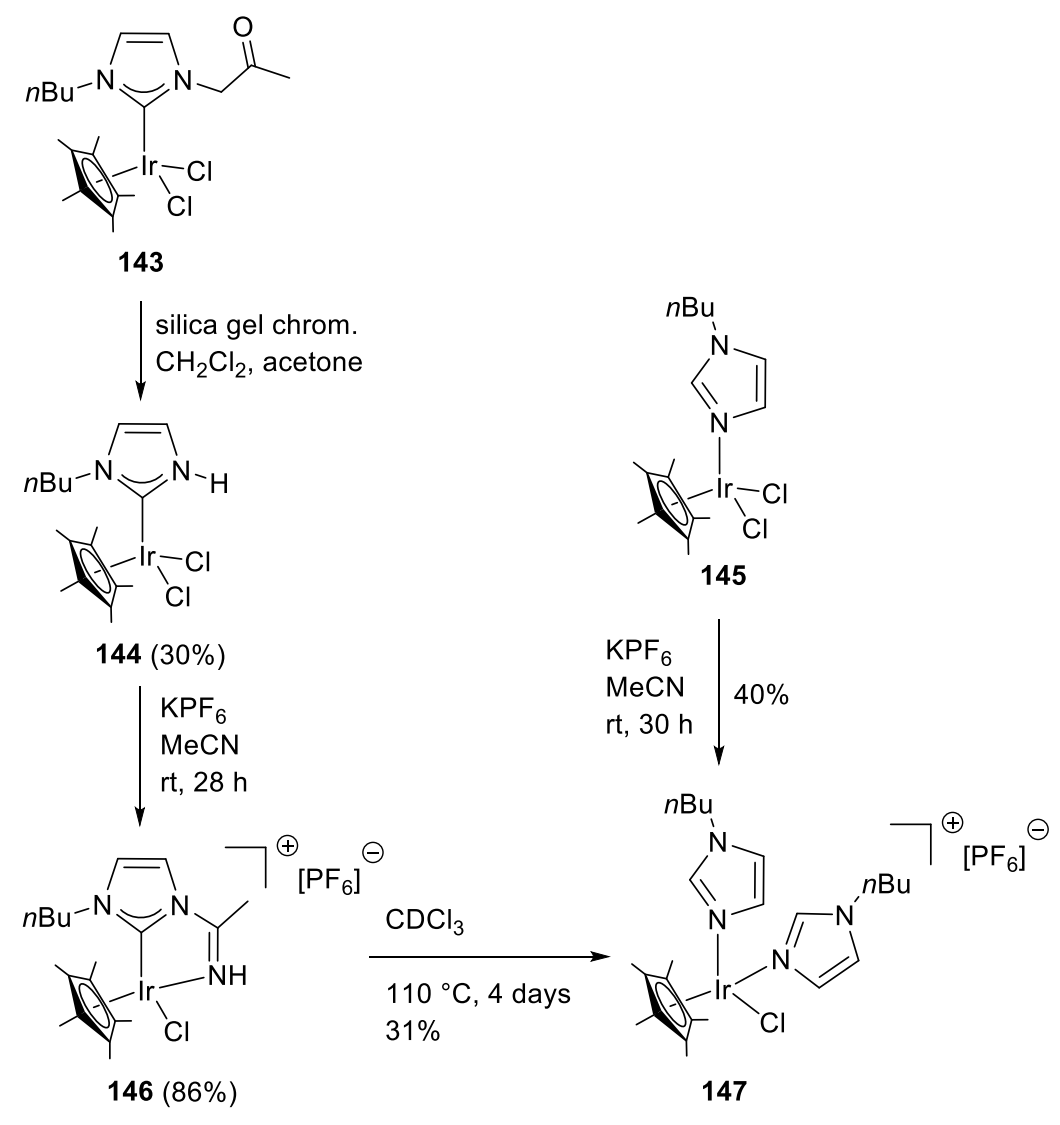

Scheme 58. C-bound to N-bound tautomerization of NHC-Ir 146.

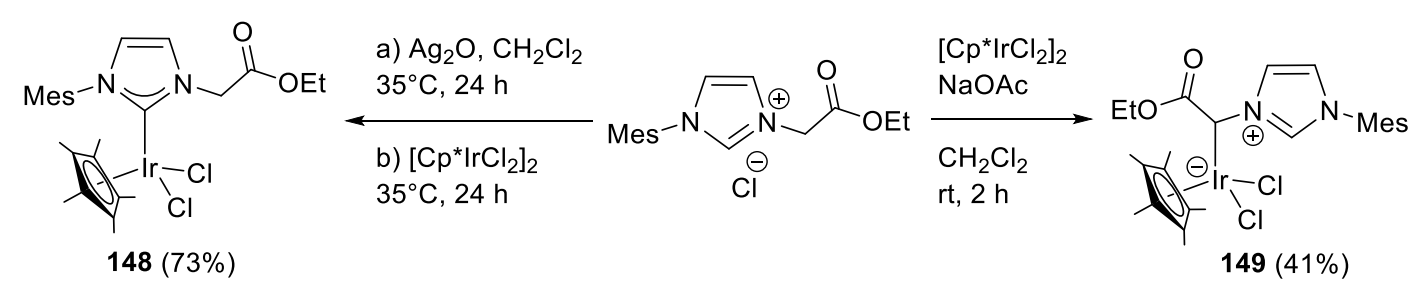

Scheme 59. Regioselectivity dependence of N-ylide or NHC complex formation.

Early on in 2003, the NHC functionalized iridium(I) phosphinidene complex $\mathbf{1 5 2}$ was isolated in $78 \%$ yield from a metathesis reaction between $\mathbf{1 5 0}$ and the lithiumphosphide $\mathbf{1 5 1}$ (Scheme 60 left). ${ }^{15}$ Further development revealed that the use of lithium reagents may be avoided through a double dehydrogenationligation sequence employing $\mathbf{1 5 3}$ as a precursor (Scheme 60 right). ${ }^{93}$ DFT calculations on analogous 
complexes $[\mathrm{Cp}(\mathrm{NHC}) \mathrm{Ir}=\mathrm{E}]\left(\mathrm{E}=\mathrm{PH}, \mathrm{NH}, \mathrm{CH}_{2} ; \mathrm{NHC}=\right.$ imidazol-2-ylidine $)$ showed that the $\mathrm{NHC}$ ligand acts as a strong $\sigma$-donor/weak $\pi$-acceptor ligand. ${ }^{15}$

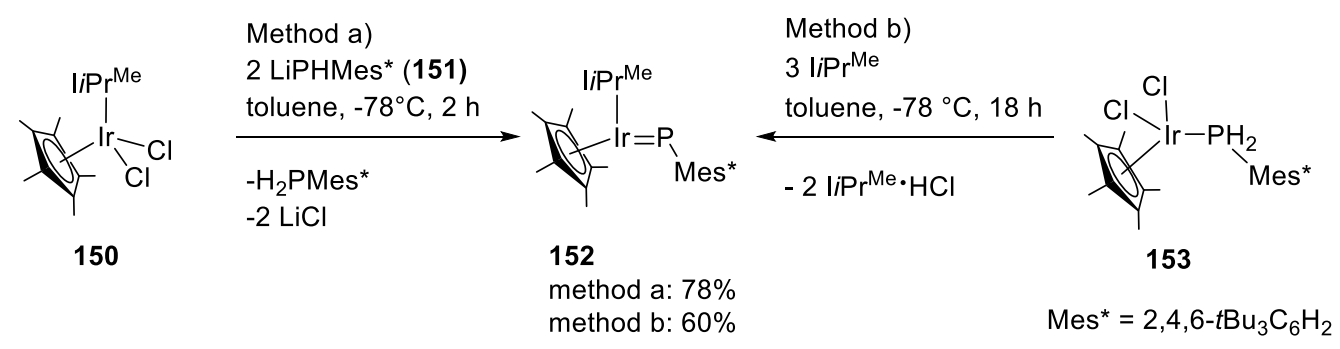

Scheme 60. NHC-Ir phosphinidene complex 152.

\section{Iridium induced NHC ligand activations}

\subsection{The reactivity in iridium complexes with one NHC ligand}

In 2011, Aldridge and coworkers carried out investigations on ( $\mathrm{NHC}) \operatorname{Ir}(\mathrm{COD}) \mathrm{Cl}$ complexes $(\mathrm{NHC}=\mathrm{IPr}$, IMes, complexes 22d and 22g, respectively). ${ }^{18}$ Halide abstraction with $\mathrm{NaBAr}_{4}$ on (IMes) $\operatorname{Ir}(\mathrm{COD}) \mathrm{Cl}(\mathbf{2 2 g})$ generated the $\mu-\mathrm{Cl}$ bridged species $\left[\{(\mathrm{IMes}) \operatorname{Ir}(\mathrm{COD})\}_{2}(\mu-\mathrm{Cl})\right]$. Rather unexpected results were obtained when the same procedure was attempted with (IPr) $\operatorname{Ir}(\mathrm{COD}) \mathrm{Cl}(\mathbf{2 2 d})$. In this case, one of the $i \mathrm{Pr}$ groups of the NHC wingtip went through a cyclometallation / dehydrogenation process to give complex 154 in high isolated yield (Scheme 61). Subsequent hydrogenation of the coordinated alkene was facile in fluorobenzene and gave the arene-coordinated NHC-Ir(III) compound 155. Thermolysis of $\mathbf{1 5 5}$ led to the formation of the unusual dimer 13.

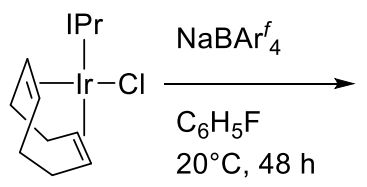

22d

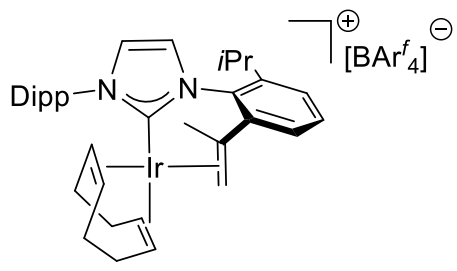

$154(73 \%)$

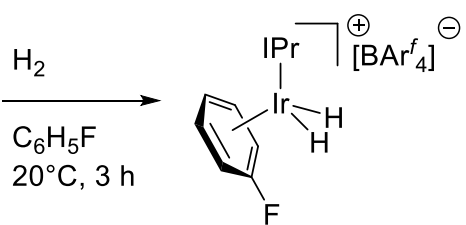

$155(82 \%)$

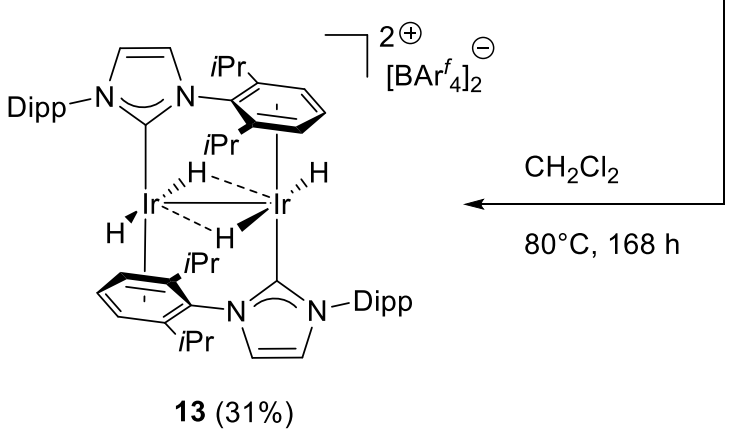

Scheme 61. Reversible NHC ligand activation in (IPr) $\operatorname{Ir}(\mathrm{COD}) \mathrm{Cl}$ (22d). 


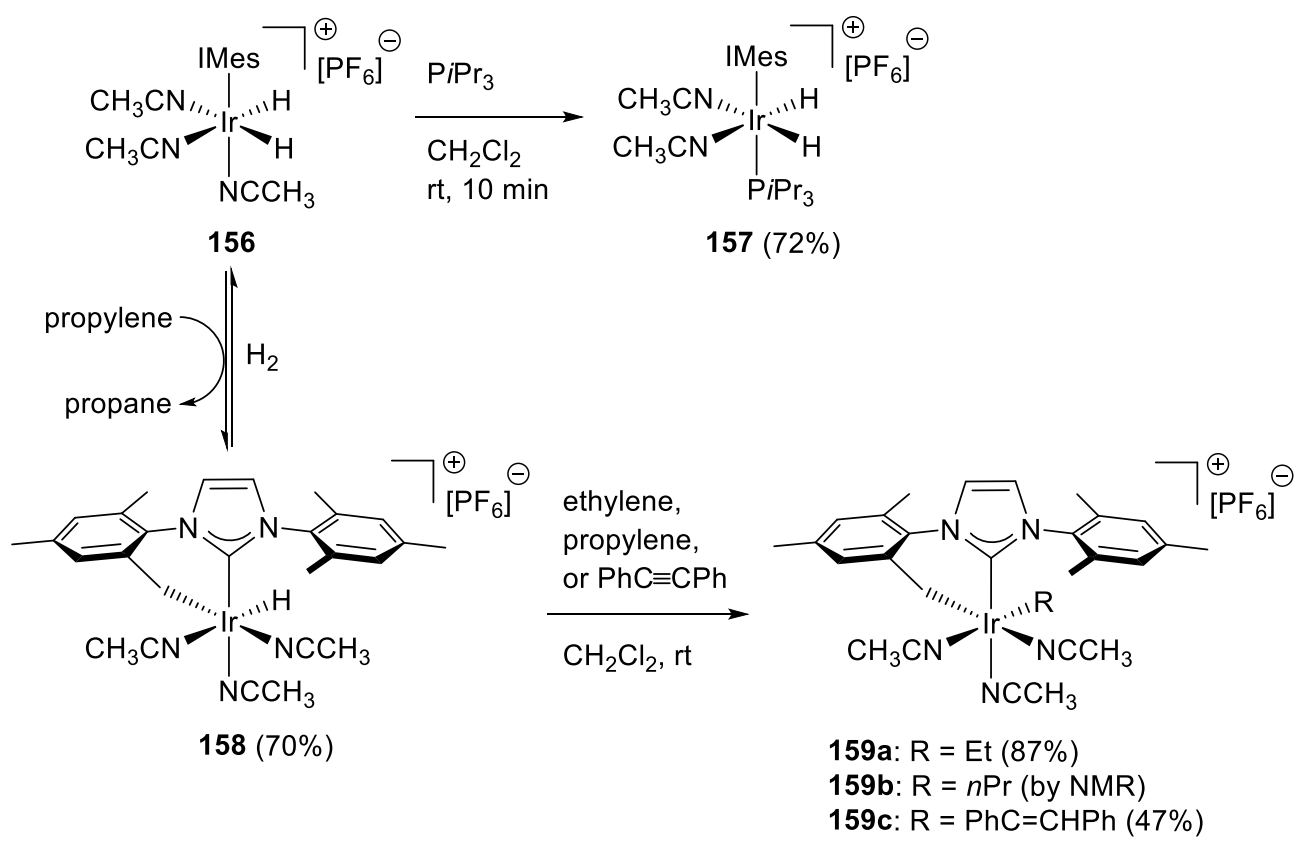

Scheme 62. IMes-Ir complexes with labile ligands.

The cationic $\left[(\mathrm{IMes}) \operatorname{Ir}(\mathrm{COD})\left\{\left(\mathrm{CH}_{3}\right)_{2} \mathrm{CO}\right\}\right]\left[\mathrm{PF}_{6}\right]$ was synthesized by salt metathesis between (IMes) $\operatorname{Ir}(\mathrm{COD}) \mathrm{Cl}(\mathbf{2 2 g})$ and $\mathrm{AgPF}_{6}$ in acetone. ${ }^{22}$ Treatment of this NHC-Ir(I) complex with dihydrogen in presence of benzene gave [(IMes) $\left.\operatorname{Ir}\left(\eta^{6}-\mathrm{C}_{6} \mathrm{H}_{6}\right)(\mathrm{H})_{2}\right]\left[\mathrm{PF}_{6}\right]$, in which the benzene ligand can be easily replaced by acetonitrile to form $\left[(\mathrm{IMes}) \operatorname{Ir}\left(\mathrm{CH}_{3} \mathrm{CN}\right)_{3}(\mathrm{H})_{2}\right]\left[\mathrm{PF}_{6}\right](\mathbf{1 5 6})$. Complex 156 was subsequently used for ligand activation studies. Replacement of the acetonitrile ligand trans to IMes by $\mathrm{P} \mathrm{Pr}_{3}$ was facile (Scheme 62). The IMes ligand, in both 156 and 157, went through cyclometallation of the NHC side chain when the iridium complex was treated with stoichiometric amounts of a hydrogen acceptor (ethylene, propylene, or diphenylacetylene) (for example see compound 158). Alkyl or alkenyl complexes (159) were isolated upon treatment of 156 with large excess of hydrogen acceptors (Scheme 62).

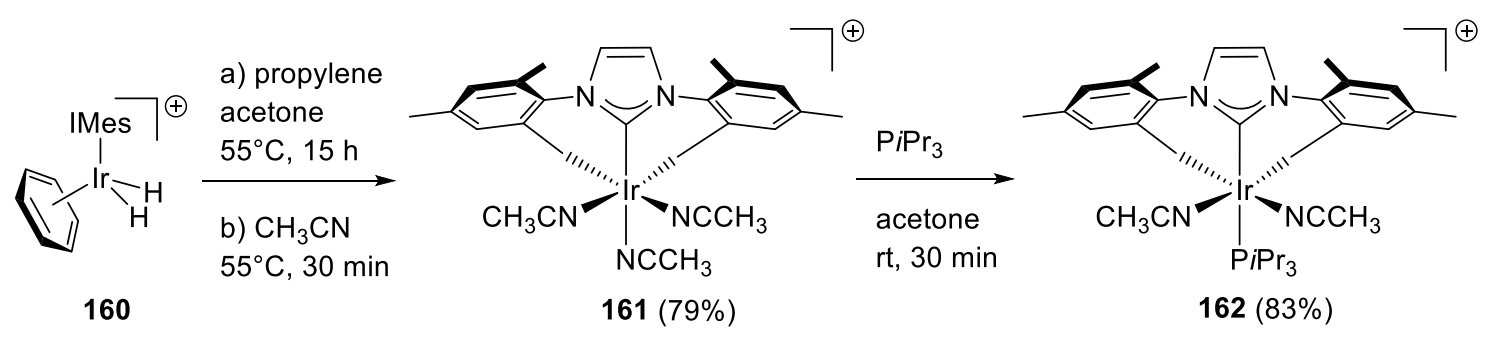

Scheme 63. Synthetic route to (IMes")Ir-compounds. The $\mathrm{PF}_{6}$ anion is omitted for clarity.

Following their earlier work, ${ }^{22}$ Sola and coworkers found that double cyclometallation can be promoted in $\left[(\mathrm{IMes}) \operatorname{Ir}\left(\eta^{6}-\mathrm{C}_{6} \mathrm{H}_{6}\right)(\mathrm{H})_{2}\right]\left[\mathrm{PF}_{6}\right]$ (160) to form complexes with $\kappa^{3}-\mathrm{C}$ fac-coordinated ligand IMes" (Scheme 63). ${ }^{94}$ On the one hand, complexes 163-165 with three-legged piano stool geometry depicted in Figure 12 proved to be surprisingly stable towards conventional hydrogen sources $\left(\mathrm{H}_{2}\right.$ at 60 bar, $\mathrm{Et}_{3} \mathrm{SiH}, \mathrm{HBpin}$, $\mathrm{HCCPh}$ ). On the other hand, complex 162 featuring a phosphine ligand trans to the IMes" ligand readily went through demetallation by $\mathrm{H}_{2}$ to give $\mathbf{1 6 6}$. The reaction of $\mathbf{1 6 2}$ with pinacol borane led to boron incorporation into the NHC ligand of $\mathbf{1 6 7}$ and C-C functionalization occurred upon treatment with 
phenylacetylene to give 168 (Scheme 64). Protonation experiments on 164 provided alternative access to half-sandwich complexes (IMes) $\operatorname{Ir}(\mathrm{Cp})(\mathrm{OTf})_{2}$, [(IMes) $\left.\operatorname{Ir}(\mathrm{Cp})\left(\mathrm{CH}_{3} \mathrm{CN}\right)_{2}\right][\mathrm{OTf}]_{2}$, and to mono-cyclometallated $\left.\left[(\mathrm{IMes})^{\prime}\right) \operatorname{Ir}(\mathrm{Cp})\left(\mathrm{CH}_{3} \mathrm{CN}\right)\right][\mathrm{OTf}]$ and $\left.\left[(\mathrm{IMes})^{\prime}\right) \operatorname{Ir}(\mathrm{Cp})\left(\mathrm{C}_{2} \mathrm{H}_{4}\right)\right][\mathrm{OTf}]$.

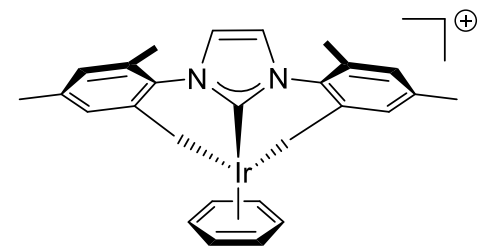

163

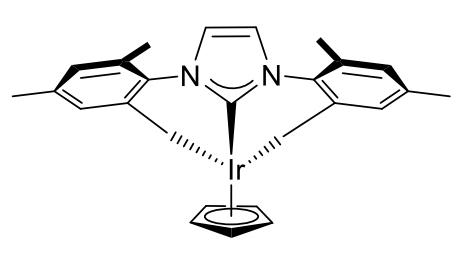

164

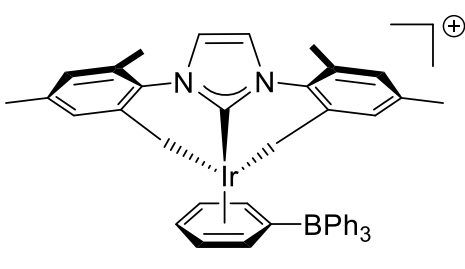

165

Figure 12. Arene complexes with doubly cyclometallated IMes". The $\mathrm{PF}_{6}$ anion is omitted for clarity.

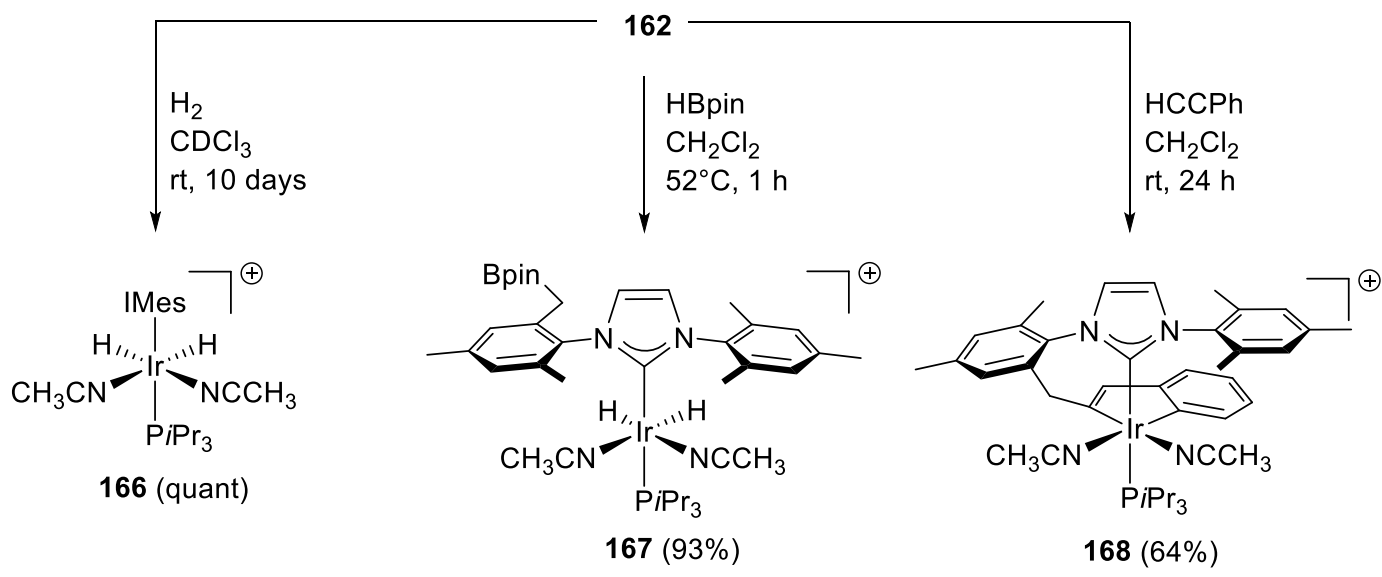

Scheme 64. Reactivity studies with 162.

In an excellent recent contribution, Mashima et al. showed that the reaction of 169 with 2-phenylpyridine at reflux in toluene affords the bis-cyclometallated complex $\mathbf{1 7 0}$ (Scheme 65). ${ }^{95}$ Complex 171 was subsequently generated in situ via demetallation of the N-3,5-xylyl ring of the carbene ligand. Subsequent treatment of the $\mathrm{Ir}-\mathrm{H}$ species yielded the isolable $\mathrm{Ir}-\mathrm{Cl}$ complex 172, which was characterized by X-ray crystallography. The hemilabile nature of the NHC ligand was utilized in the dehydrogenative silylation of arenes (vide infra in Section 9.6.5).

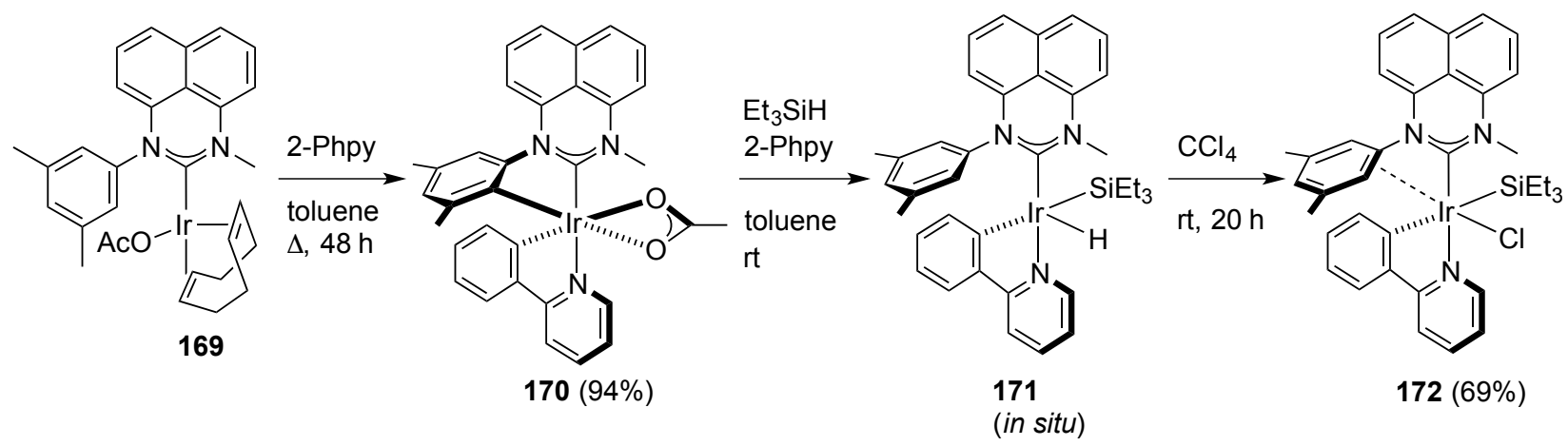

Scheme 65. Hemilability of an NHC via metallation/demetallation. 


\subsection{The reactivity in complexes with two NHC ligands}

Nolan's group was amongst the first who carried out thorough reactivity studies on NHC-rhodium and NHCiridium complexes, in particular on compounds featuring the $\mathrm{I} t \mathrm{Bu}$ ligand. ${ }^{96,42}$ Most frequently, $[\mathrm{Ir}(\mathrm{COD}) \mathrm{Cl}]_{2}$ is the precursor to access easily available (NHC) $\operatorname{Ir}(\mathrm{COD}) \mathrm{X}$ complexes. However, more versatile reactivity is offered through the use of the labile cyclooctene precursor $\left[\operatorname{Ir}(\mathrm{COE})_{2} \mathrm{Cl}\right]_{2}$. The interaction of 4 equivalents of $\mathrm{I} t \mathrm{Bu}$ and $\left[\mathrm{Ir}(\mathrm{COE})_{2} \mathrm{Cl}\right]_{2}$ in benzene led to the formation of $\mathbf{1 7 3}$ in $91 \%$ yield. Prolonged reaction times resulted in double C-H activation (174, Scheme 66). X-ray crystal analysis showed that an agostic interaction between a hydrogen atom of a non-cyclometallated $t \mathrm{Bu}$ group and the metal center completes the octahedral coordination geometry in $\mathbf{1 7 3}$ and $\mathbf{1 7 4}$. Formation of $\mathbf{1 7 4}$ paved the way to the synthesis of the unique 14electron NHC-Ir(III) complex 175, where stabilizing agostic interactions are not observed. ${ }^{42}$ Exposure of $\mathbf{1 7 5}$ to dihydrogen afforded $\mathbf{1 7 6}$ in excellent yield (Scheme 66 bottom). ${ }^{29} \mathbf{1 7 6}$ is stabilized by a double agostic interaction between the hydrogens of the $t \mathrm{Bu}$ group and the $\operatorname{Ir}(\mathrm{III})$ center. Interestingly, when $\mathrm{D}_{2}$ was applied, complete deuteration of the hydride ligands and the $t \mathrm{Bu}$ groups occurred.

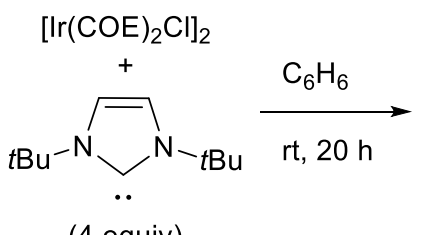

(4 equiv)

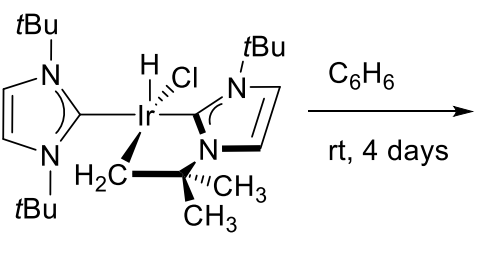

$173(91 \%)$

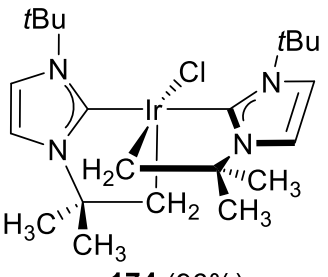

$174(96 \%)$

$\mathrm{AgPF}_{6}$ $\mathrm{CH}_{2} \mathrm{Cl}_{2}$ rt, 40 min

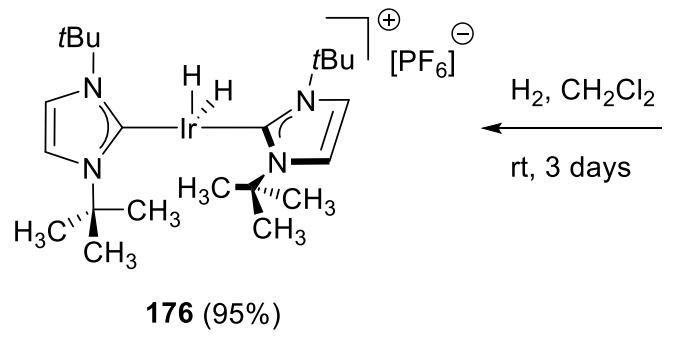

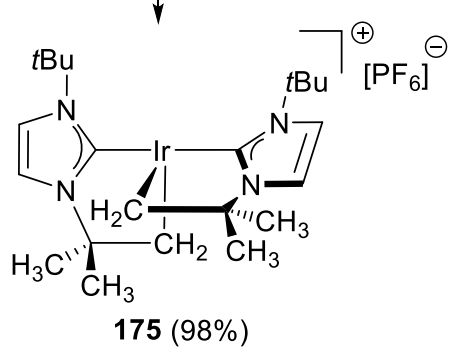

Scheme 66. Cyclometallation reactions of $\mathrm{I} t \mathrm{Bu}$ in its $\mathrm{Ir}(\mathrm{III})$ complexes.

Cylcometallated complexes 174 and $\mathbf{1 7 5}$ are competent catalysts in ammonia-borane solvolysis (vide infra in section 9.4). Stoichiometric studies with 175 and ammonia-borane gave a mixture of 176 and 177 (Scheme 67), both of which are catalytically active. A reversible equilibrium between 176 and $\mathbf{1 7 7}$ was identified. ${ }^{97}$

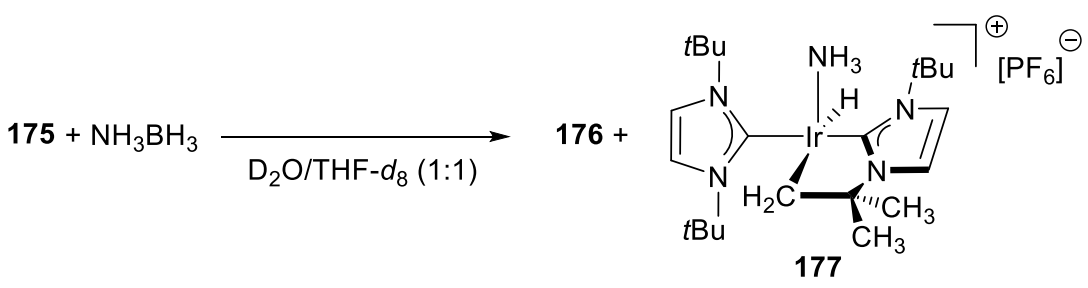

Scheme 67. Stoichiometric reactivity of $\mathbf{1 7 5}$ with ammonia-borane. 
In 2009, Aldridge and coworkers started to explore the chemistry of bis(NHC)-Ir complexes in E-H $(\mathrm{E}=\mathrm{B}$, $\mathrm{C}, \mathrm{N})$ bond activation. ${ }^{98}$ Reaction of excess IPr ligand with $\left[\operatorname{Ir}(\mathrm{COE})_{2} \mathrm{Cl}\right]_{2}$ in THF gave (IPr)(IPr') $\operatorname{IrCl}(\mathbf{1 7 8})$ as a main product in $40 \%$ yield, together with small amounts of complex 179 with an abnormally bound NHC ligand. Sequential hydrogenation of $\mathbf{1 7 8}$ ultimately gave $\mathbf{1 8 1}$ (Scheme 68), a complex previously described by the group of Sames. ${ }^{43}$ The NHC ligands are trans to each other in these complexes, and the alkene ligand (in $\mathbf{1 7 8}$ and 180) is coordinating in a classical $\eta^{2}$-fashion. Upon exposure to dioxygen, $\mathbf{1 8 1}$ was converted into the $\operatorname{Ir}(\mathrm{III})$ peroxide complex 182. This transformation proved to be reversible, treatment of $\mathbf{1 8 2}$ with various hydrogen sources led to recovery of $\mathbf{1 8 1}$ (Scheme 69). ${ }^{98}$

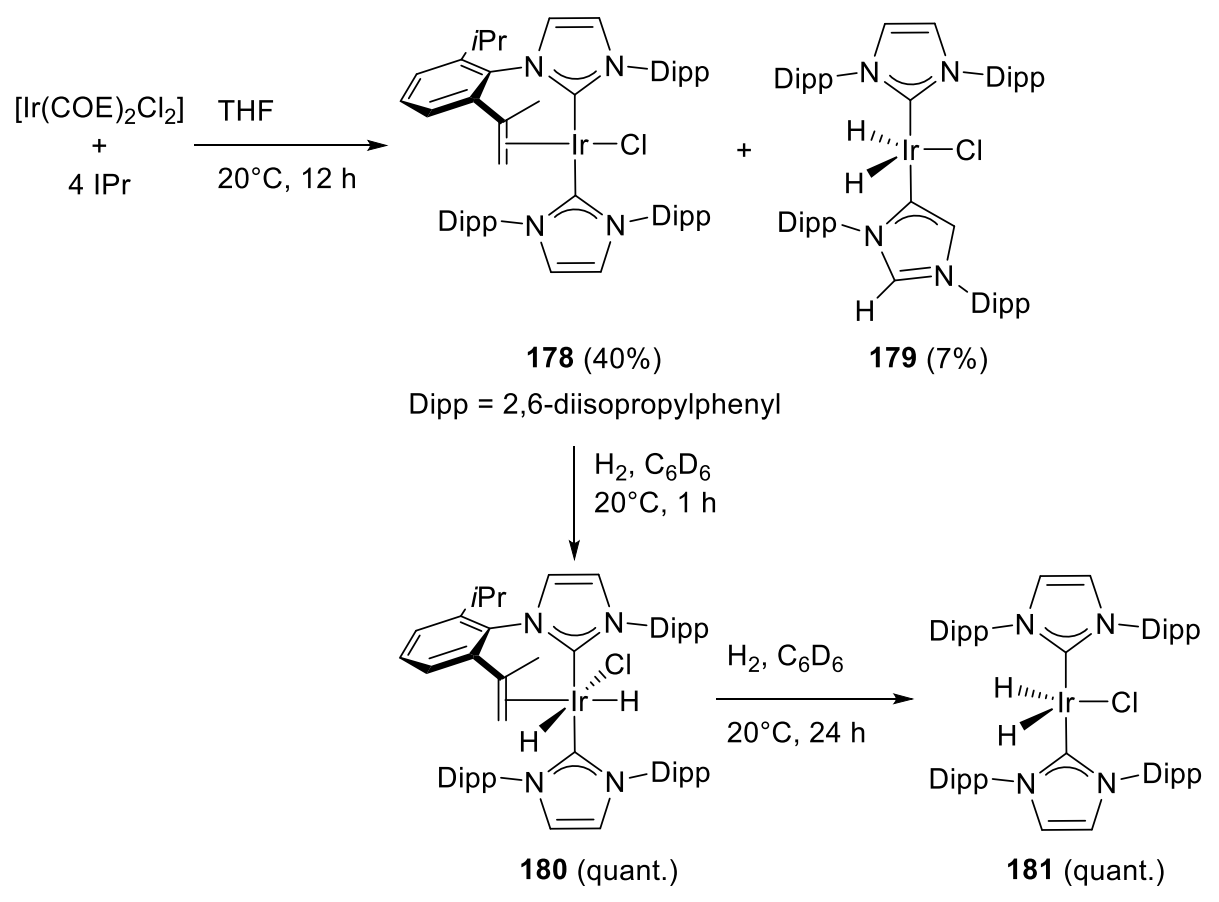

Scheme 68. Reactivity studies on (NHC) $)_{2}$ Ir-complexes.

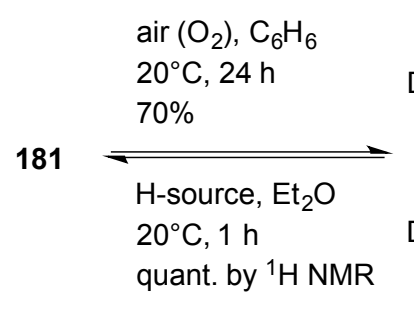

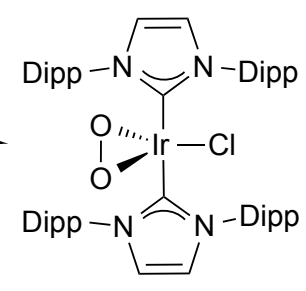

182
H-source: $\mathrm{H}_{3} \mathrm{~N} \cdot \mathrm{BH}_{3}, \mathrm{MeH}_{2} \mathrm{~N} \cdot \mathrm{BH}_{3}$, $\mathrm{Me}_{2} \mathrm{HN} \cdot \mathrm{BH}_{3}, \mathrm{P}_{2} \mathrm{HN} \cdot \mathrm{BH}_{3}, \mathrm{LiBH}_{4}$, or $\mathrm{H}_{2}$

Scheme 69. A reversible oxygenation / hydrogenation reaction.

Halide abstraction from $\mathbf{1 7 8}$ with $\mathrm{NaBAr}_{4}^{f}$ gave $\mathbf{1 8 3}$ through cyclometallation of a methyl group (Scheme 70 top). ${ }^{98}$ Similarly, the chloride atom in $\mathbf{1 8 1}$ was susceptible to halide abstraction, ${ }^{99}$ and led to generation of 184, where the formally 14-electron $\operatorname{Ir}(\mathrm{III})$-species is stabilized by a double agostic interaction, while prolonged reaction times resulted in dehydrogenation of one of the $i \operatorname{Pr}$ substituents (Scheme 70 bottom).

Attempted salt metathesis on (IMes) $)_{2} \mathrm{Ir}(\mathrm{H})_{2} \mathrm{Cl}(\mathbf{1 8 6})$ produced the surprising complex 187 in good yield. In the cationic component of $\mathbf{1 8 7}$, the chloride ligand remained intact and a sodium cation was intercalated between two aryl rings of the NHC ligands (Scheme 71, top). This interesting halide abstraction intermediate 
was a highly reactive source of the targeted $\left\{(\mathrm{IMes})_{2} \mathrm{Ir}(\mathrm{H})_{2}\right\}^{+}$fragment, and complexes with both dinitrogen or THF ligands were isolated (188 and $\mathbf{1 8 9}$, respectively) ${ }^{99,100}$ In contrast, a simple change in solvent, from fluorobenzene to THF, gave rise to a double C-H activation / cyclometallation pathway of one of the NHC ligands (190 in Scheme 71 bottom). ${ }^{101}$
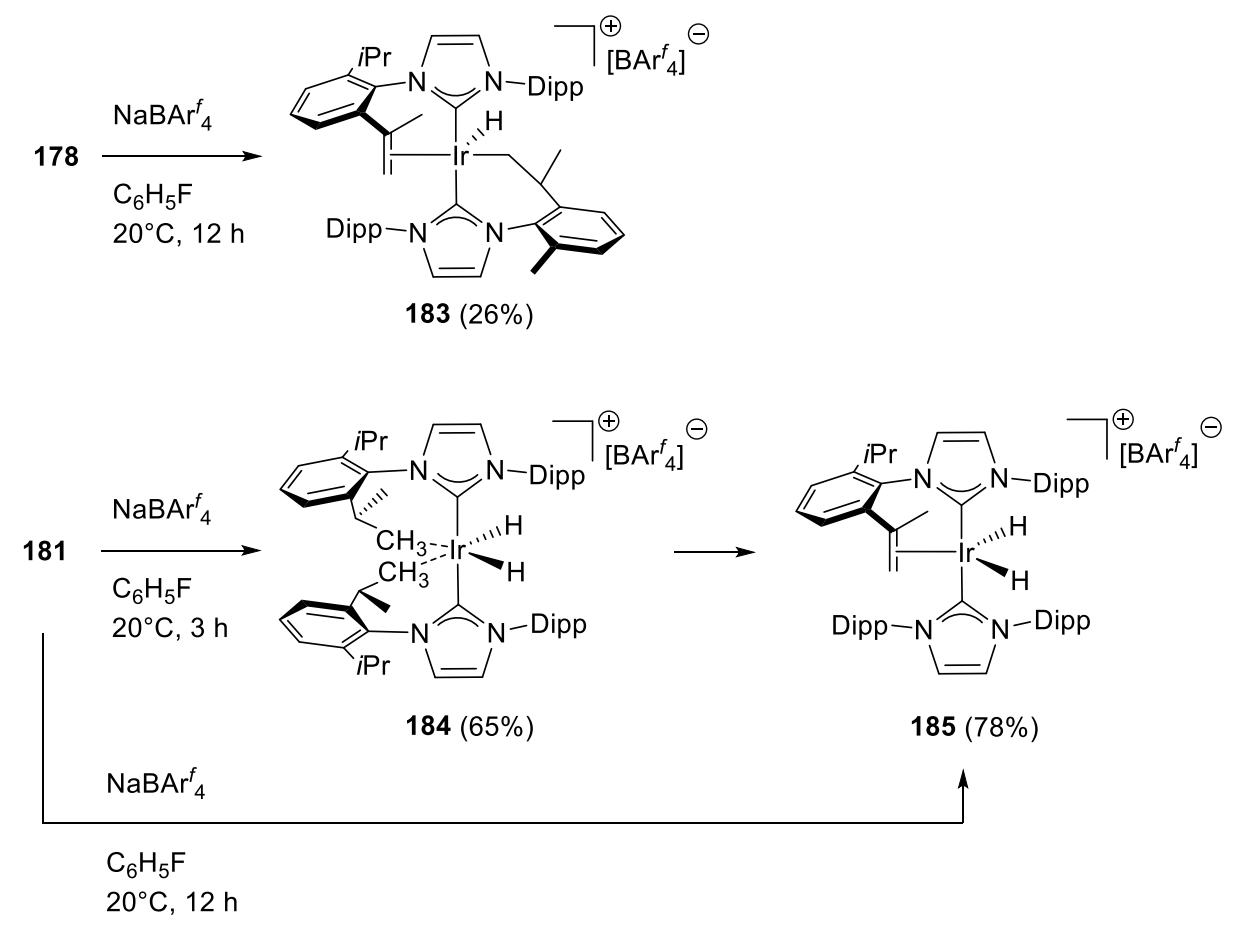

Scheme 70. Halide abstraction on bis-NHC iridium compounds.

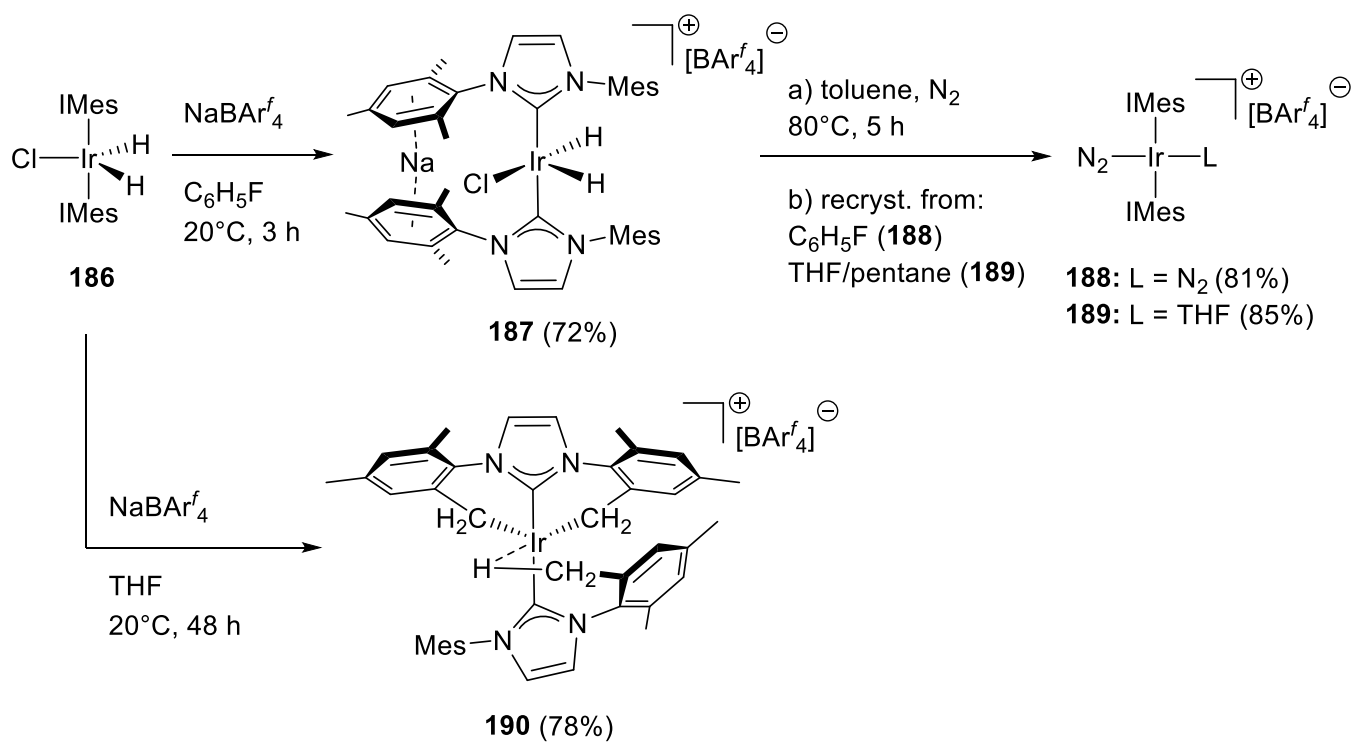

Scheme 71. Halide abstraction attempts on $(\mathrm{IMes})_{2} \operatorname{Ir}(\mathrm{H})_{2} \mathrm{Cl}(\mathbf{1 8 6})$.

Rhodium- and iridium-catalyzed dehydrogenation of saturated B-N bonds were investigated in detail by the Aldridge group. ${ }^{44,99,100,101,102,103 \mathrm{c}}$ Complex $\mathbf{1 8 7}$ readily formed an adduct with $\mathrm{Me}_{3} \mathrm{~N} \cdot \mathrm{BH}_{3}$ (Scheme 72, left). No direct contact between boron and iridium was observed in 191. Treatment of 187 with N-H bond containing aminoboranes resulted in dehydrogenations and gave complexes with unsaturated aminoborane ligands (Scheme 72, right). The unusual bis( $\sigma$-borane) coordination mode of the aminoboranes in 192 is in 
contrast with the conventional side-on binding of alkenes. It is likely that the hydridic nature of the B-H bond (vs $\mathrm{C}-\mathrm{H}$ ) and the significantly lower energy of the $\mathrm{B}=\mathrm{N} \pi$-system $(v s \mathrm{C}=\mathrm{C}$ ) brings about different electronic properties, which are reflected in the bonding situation seen in $192 .{ }^{99}$ Catalytic aspects of these systems are discussed in section 9.4 .

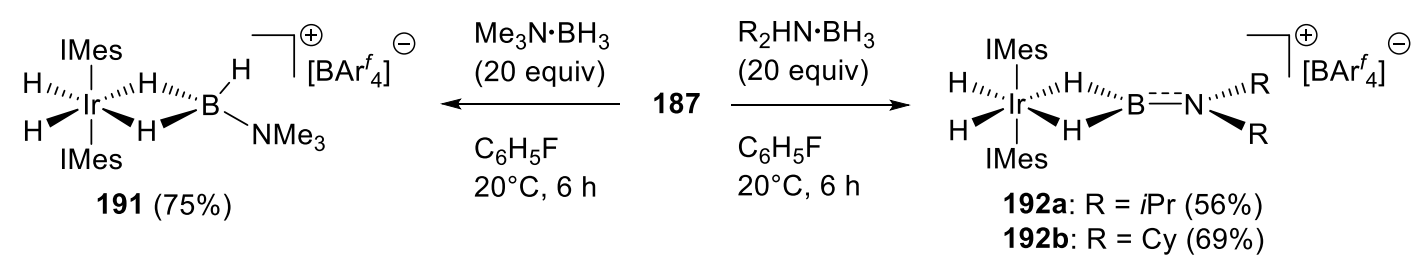

Scheme 72. Reactivity of $\mathbf{1 8 7}$ with aminoboranes.

Loss of $\mathrm{H}_{2}$ from 192b can be initiated by the addition of tert-butylethylene as a sacrificial hydrogen acceptor (Scheme 73). Heating 193 in toluene resulted in elimination of one mole of $\mathrm{H}_{2}$ and in the formation of 194, which features direct Ir-B bonding with a bridging hydride ligand. ${ }^{99}$ In situ prepared or isolated 190 shows similar reactivity towards $\mathrm{H}_{3} \mathrm{~B} \cdot \mathrm{NMe}_{3}$ and $i \mathrm{Pr}_{2} \mathrm{NH} \cdot \mathrm{BH}_{3}$ as observed for $187{ }^{101}$ When $\mathbf{1 8 6} / \mathrm{NaBAr}_{4}^{f}$ was exposed to dimethyl aminoborane in a catalytic run, the iridium containing product, 195 was isolated in $76 \%$ yield, and neutron diffraction studies allowed location of the hydrogen atoms in 195 (Scheme 74, left). ${ }^{102} \mathrm{On}$ the other hand, similar treatment of (IMes) $)_{2} \mathrm{Rh}(\mathrm{H})_{2} \mathrm{Cl}(\mathbf{1 9 6}) / \mathrm{NaBAr}_{4}^{f}$ led to a different outcome (Scheme 74, right).

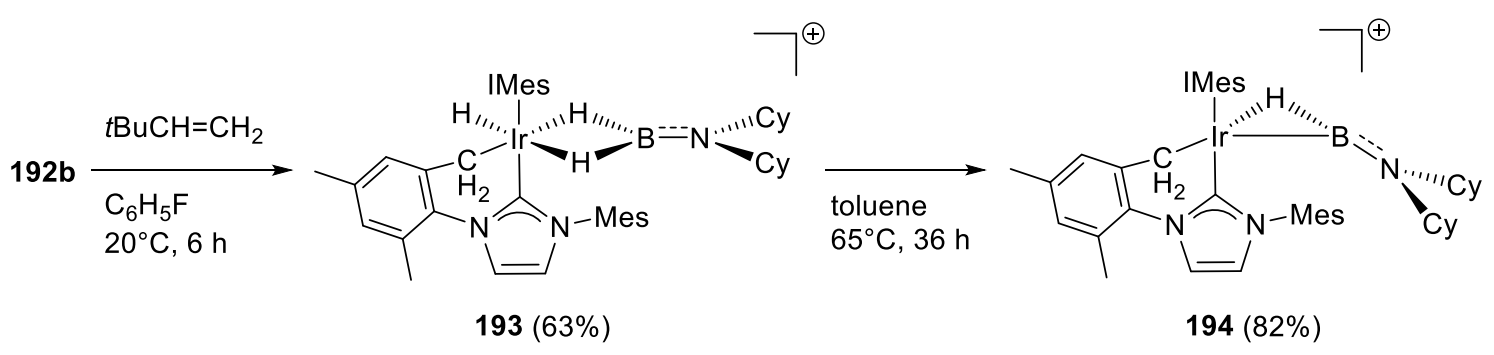

Scheme 73. Dehydrogenations from 192b. The BAr ${ }_{4}^{f}$ anion is omitted.

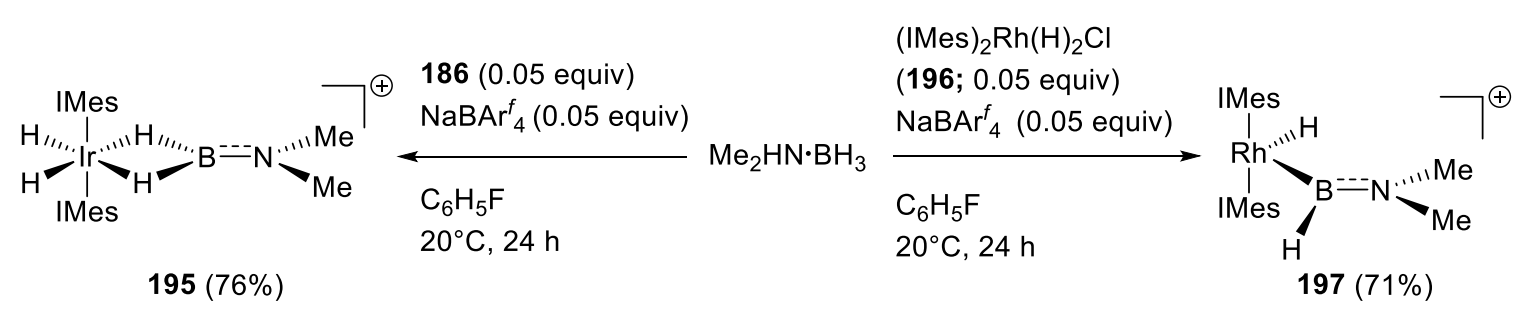

Scheme 74. Reactivity difference between rhodium and iridium. The $\mathrm{BAr}_{4}^{f}$ anion is omitted.

The same authors also discovered an unusual intramolecular $\mathrm{C}-\mathrm{H}$ borylation process mediated by $\left[\operatorname{Ir}(\mathrm{COE})_{2} \mathrm{Cl}\right]_{2} .{ }^{44}$ Treatment of IMes with $\left[\operatorname{Ir}(\mathrm{COE})_{2} \mathrm{Cl}\right]_{2}$ and excess $\mathrm{LiBH}_{4}$ ultimately gave dimer $\mathbf{2 0 2}$ in $42 \%$ yield (Scheme 75). Stepwise reactions were carried out in order to uncover the mechanism behind this transformation. Scheme 75 shows how the cyclometallated complex 199 can go through salt metathesis followed by an intramolecular Ir-to-B benzyl migration step to yield 201, which can subsequently be converted to 202 by treatment with a large excess of $\mathrm{LiBH}_{4}$. 


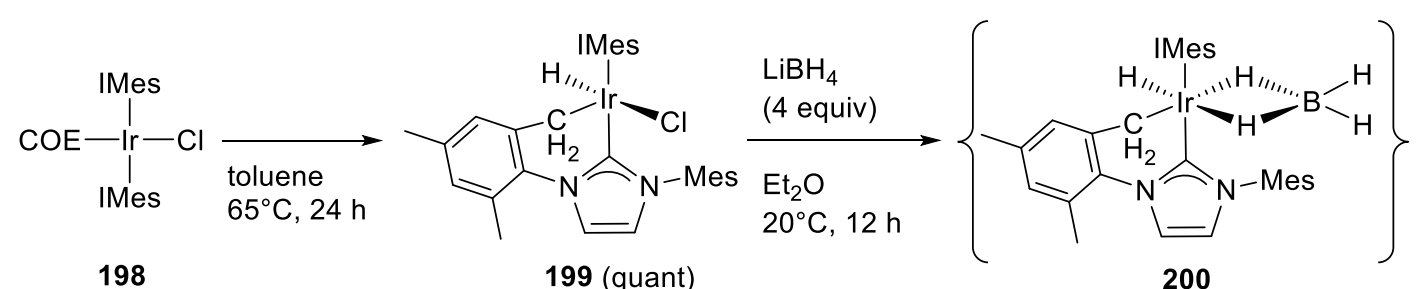

198

199 (quant)

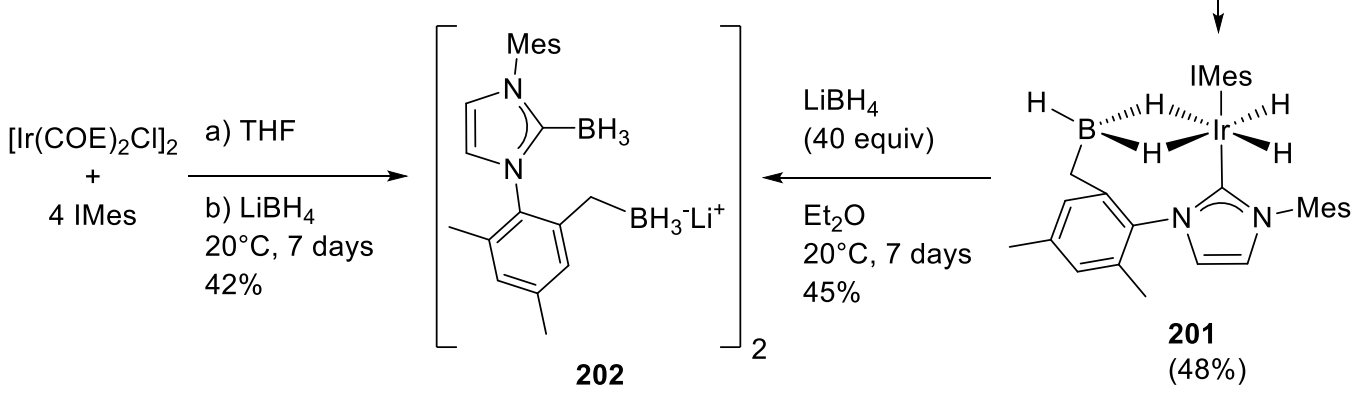

Scheme 75. Intramolecular C-H borylation mediated by $\left[\operatorname{Ir}(\mathrm{COE})_{2} \mathrm{Cl}\right]_{2}$.

Aldridge's group investigated NHC ring size and saturation effects on the C-H activation chemistry of NHCs in their iridium complexes. ${ }^{103,36}$ SIMes showed similar reactivity compared to IMes, and both (SIMes) $)_{2} \operatorname{Ir}(\mathrm{COE}) \mathrm{Cl}$ and [(SIMes)(SIMes') $\left.\operatorname{Ir}(\mathrm{H}) \mathrm{Cl}\right]$ (203) were isolated in good yields $(82 \%$ and $79 \%$, respectively). ${ }^{103 \mathrm{c}}$ Analogous complexes where the NHC ligands feature 6-membered N-heterocycles went through double $\mathrm{C}-\mathrm{H}$ activation accompanied by $\mathrm{HCl}$ elimination (complexes 204-206, Scheme 76). ${ }^{103 a, c}$ Such reactivity can be rationalized given that these NHCs are known to be more basic and stronger $\sigma$-donors than their 5-membered counterparts. Moreover, their large N-C-N angle brings the NHC wingtips closer to the metal center.
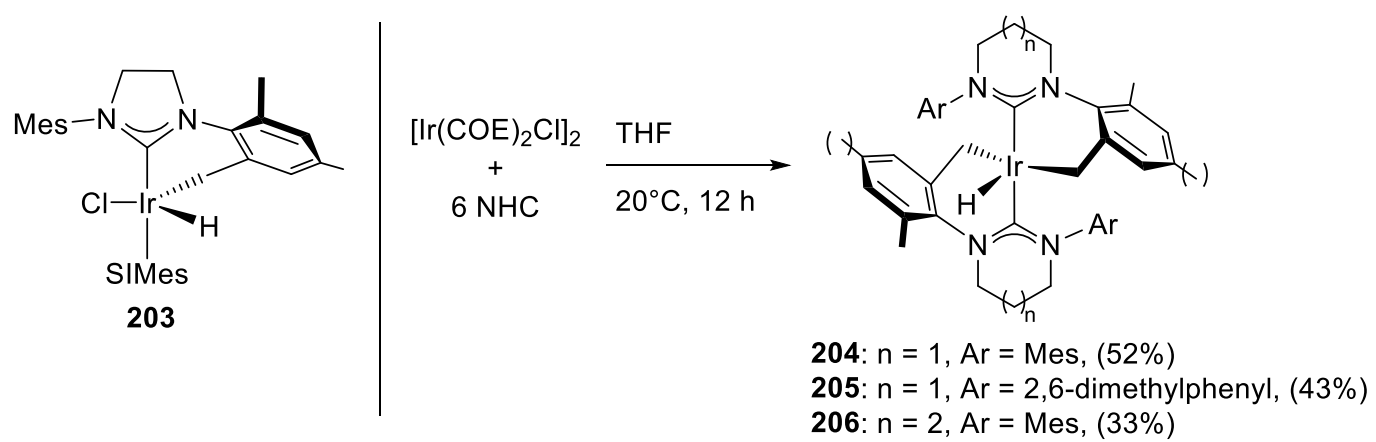

Scheme 76. NHC ring size dependent reactivity difference.

The C-H activation chemistry in these complexes is reversible via reactions with Brookhart's acid or HX (X $=\mathrm{H}, \mathrm{Cl})$. Employing such reagents, a series of hydrido (207-209) or mixed hydrido/chloride (210-212) complexes were prepared (Scheme 77). These complexes offer convenient routes to putative 14-electron $\left\{(\mathrm{NHC})_{2} \operatorname{Ir}(\mathrm{H})_{2}\right\}^{+}$fragment (see 207 and 208) via hydride or halide abstraction reactions. It is interesting to note how these highly unsaturated complexes are stabilized either by agostic $\mathrm{C}-\mathrm{H}$ bonds (207) or by arenemetal interactions involving the $C_{\text {ipso }}$ atom of the mesityl group (208). Complex 208 was bench stable and proved to be unreactive towards aminoboranes. In contrast, the more labile $\left\{(\mathrm{SIMes})_{2} \operatorname{Ir}(\mathrm{H})_{2}\right\}^{+}$could not be isolated. However, when generated in situ it was able to catalyze the dehydrogenation of $\mathrm{Me}_{2} \mathrm{HN} \cdot \mathrm{BH}_{3}$ to 
dimethyl aminoborane (see also section 9.4.). The iridium containing product, $\left[(\mathrm{SIMes})_{2} \operatorname{Ir}(\mathrm{H})_{2}\left(\kappa^{2}-\right.\right.$ $\left.\left.\mathrm{H}_{2} \mathrm{~B} \cdot \mathrm{NMe}_{2}\right)\right]\left[\mathrm{BAr}_{4}^{f}\right]$, showed similar characteristics to $195{ }^{103 a, \mathrm{c}}$

Variable-temperature NMR studies on $\mathbf{2 0 7}$ showed that this complex undergoes degenerate fluxional exchange between the agostic $\mathrm{C}-\mathrm{H}$ bond and the alkyl/hydride ligands. DFT calculations together with experimental evidence indicated that an associative oxidative pathway, involving an $\operatorname{Ir}(\mathrm{V})$ species, is likely operative. ${ }^{36}$ Finally, a previously unprecedented backbone $\mathrm{C}-\mathrm{H}$ and $\mathrm{C}-\mathrm{N}$ activation during the reaction between $\left[\operatorname{Ir}(\mathrm{COE})_{2} \mathrm{Cl}\right]_{2}$ and $6 \operatorname{IPr}$ precluded the synthesis of $(6 \mathrm{IPr})_{2} \mathrm{Ir}$-type complexes. ${ }^{103 \mathrm{~b}}$

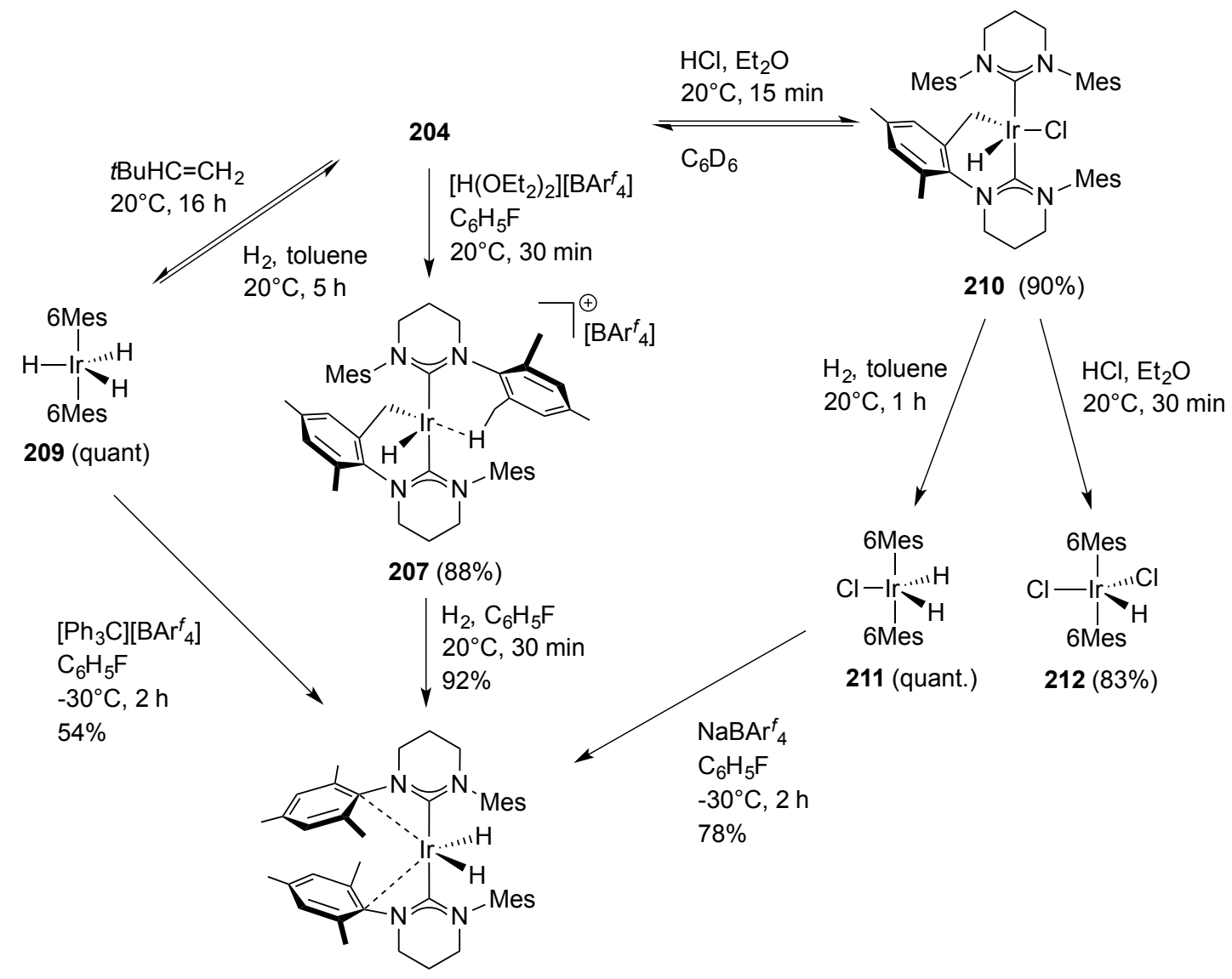

208

Scheme 77. The reactivity of (6Mes) $)_{2}$ Ir-complexes.

\subsection{Cyclometallations of NHCs in half-sandwich NHC-Ir complexes}

Early on in 2000, Prinz et al. explored the reactivity of $\mathbf{2 4} .^{45}$ Ligand exchange with $\mathrm{CH}_{3} \mathrm{MgCl}$ smoothly gave the bisalkylated complex 213. Subsequent treatment with trifluoromethanesulfonic acid led to the unsymmetrically substituted 214 (Scheme 78). Mechanistically speaking, initial release of one equivalent of methane gas would lead to the formation of $\left[(\mathrm{ICy}) \operatorname{Ir}\left(\mathrm{Cp}^{*}\right)\left(\mathrm{CH}_{3}\right)\right][\mathrm{OTf}]$. Next, one of the cyclohexyl substituents would undergo C-H activation / cyclometallation and elimination of a second equivalent of methane would take place. Finally, $\beta$-hydride elimination would afford complex 214. 
<smiles></smiles>

24

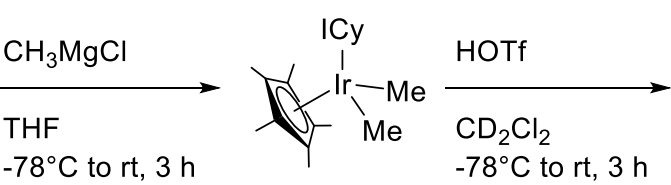

$213(77 \%)$

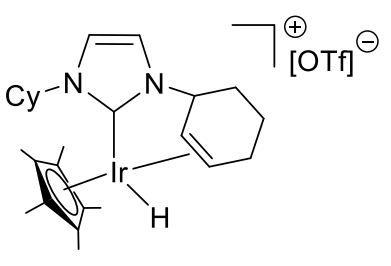

$214(71 \%)$

Scheme 78. Intramolecular dehydrogenation of ICy.

Peris and coworkers employed the silver transmetallation procedure to access NHC complex 216, which was unstable and readily underwent $\mathrm{C}-\mathrm{H}$ activation to give the orthometallated product 217 a (Scheme 79). When 217 was refluxed in $\mathrm{CD}_{3} \mathrm{OD}$, quantitative deuteration of the ortho-position of the phenyl group occurred (218). The catalytic application of 217 in H/D exchange reactions will be discussed in section $9.3 .{ }^{35}$ Related to the studies with complex 216, Marr, Saunders and coworkers showed that silver particles can mediate cyclometallation of perfluorinated aryl groups via C-F bond fission. ${ }^{104}$

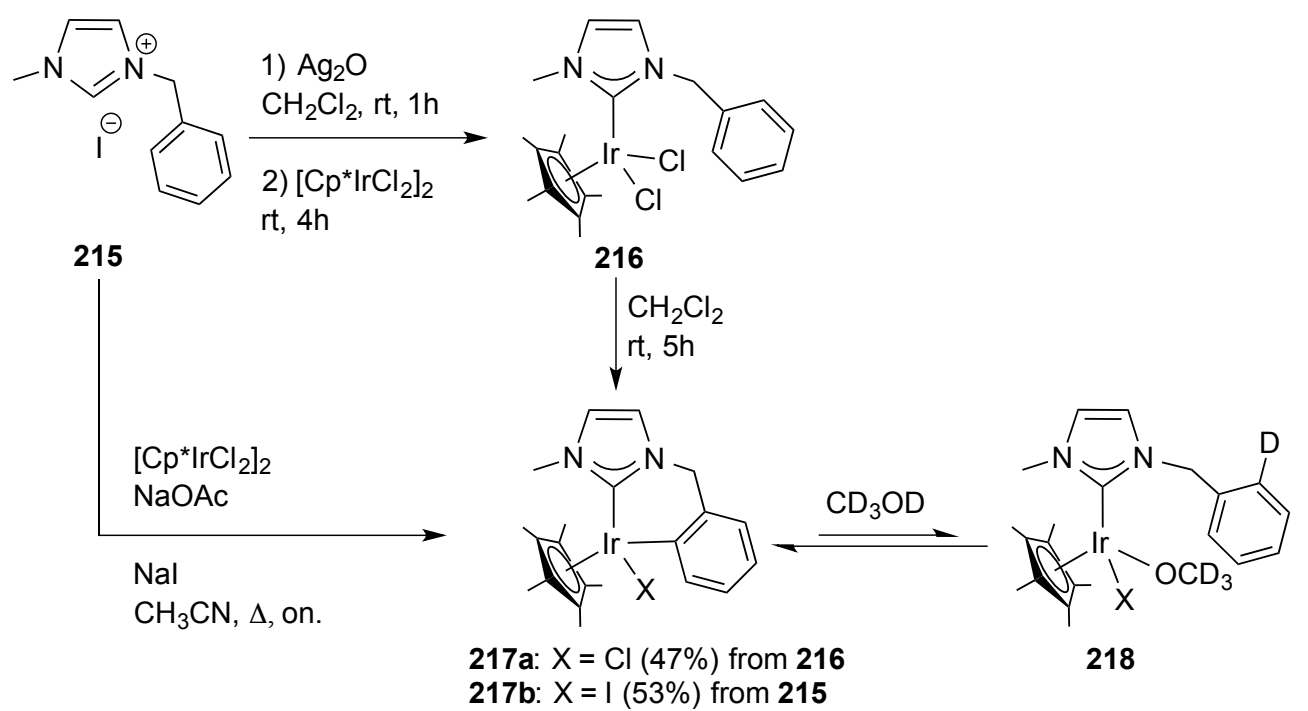

Scheme 79. Reversible C-H activation of N-benzyl substituted NHC, 215.

Peris and coworkers also showed that a variety of non-symmetrically substituted NHC ligands with aliphatic and aromatic wingtips produced the aforementioned iridacycles. ${ }^{105} \mathrm{~A}$ clear preference for $\mathrm{C}-\mathrm{H}$ bond activation in 219-222 was not observed (Figure 13). In case of 222, the presence of a strong base was required to promote cyclization (Scheme 80).

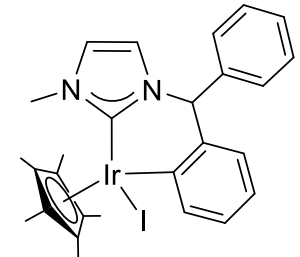

219

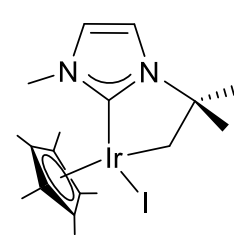

220

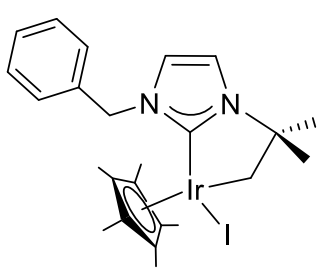

221

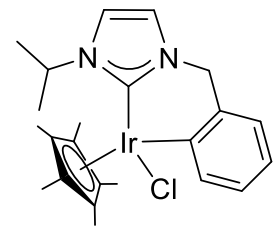

222

Figure 13. Cyclometallated NHC-Ir(III) complexes 219-222. 


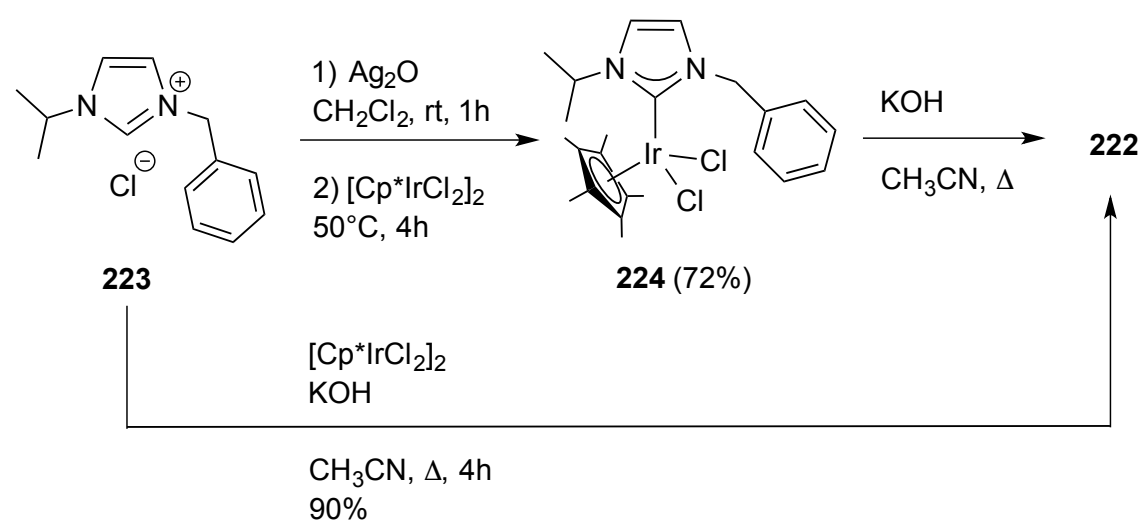

Scheme 80. Base-assisted cyclometallation of NHC salt 223.

Independently from Peris, Yamaguchi and coworkers carried out reactivity studies with symmetrically substituted ligands such as $\mathrm{I}_{\mathrm{Pr}}{ }^{\mathrm{Me}} \cdot{ }^{106}$ A five-membered iridacycle 225 was formed by reacting $\mathbf{2 6 a}$ with $\mathrm{NaOMe}$ in $i \mathrm{PrOH}$ (Scheme 81). Mechanistic insight was gained by low temperature NMR analysis. A single dechlorination in an acid-base reaction followed by ligand exchange of the second $\mathrm{Cl}$ with $\mathrm{OMe}$ would give $\left[\left(\mathrm{IiPr}^{\mathrm{Me}}\right) \operatorname{Ir}\left(\mathrm{Cp}^{*}\right)(\mathrm{OMe})\right]^{+}$. Subsequently, this intermediate would undergo $\mathrm{C}-\mathrm{H}$ activation followed by elimination of $\mathrm{MeOH}$ to produce $\mathbf{2 2 5}$ in quantitative yield.

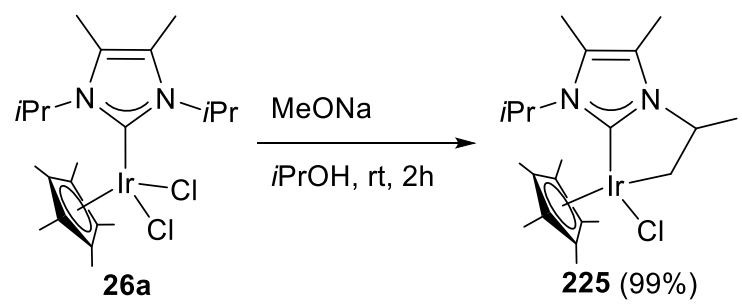

Scheme 81. The synthesis of 225.

To demonstrate the importance of the base in the transmetallation step, halide abstraction from complexes 226 and 228 was compared. While the metathesis reaction with 226 gave the cyclometallated product 227, such reactivity with $\mathbf{2 2 8}$ was not observed (Scheme 82). Furthermore, deprotonation of the ammonium salt in complex 227 resulted in an $\eta^{5}: \eta^{1}$-coordination of the $\mathrm{Cp}^{\mathrm{N}}$ ligand. ${ }^{106}$ While not related to the cyclometallation reaction, we would like to note that the synthesis of complexes $\mathbf{2 2 6}$ and $\mathbf{2 2 8}$ was accomplished in a rather unusual way. First, $\left(\mathrm{I} i \mathrm{Pr}^{\mathrm{Me}}\right) \operatorname{Ir}\left(\eta^{4}-\mathrm{COD}\right) \mathrm{Cl}$ was formed using the free carbene method. Subsequent reaction with $\mathrm{NaCp}$ (or $\mathrm{NaCp}^{\mathrm{N}}$ for 226) afforded $\left(\mathrm{I} \mathrm{Pr}^{\mathrm{Me}}\right) \operatorname{IrCp}\left(\eta^{2}-\mathrm{COD}\right.$ ), which was oxidized to 226/228 with $\mathrm{I}_{2}{ }^{106}$

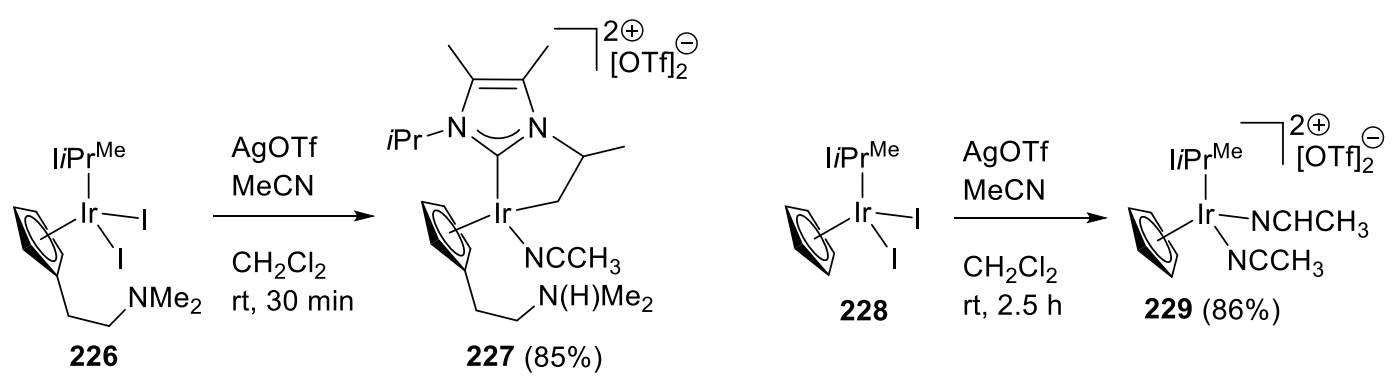

Scheme 82. Impact of an internal base on intramolecular C-H bond activation. 
In a more recent contribution, the Yamaguchi group employed NHC ligands with normal alkyl side chains for the synthesis of $\mathrm{Ir}(\mathrm{III})$ half-sandwich complexes and studied their behavior in $\mathrm{C}-\mathrm{H}$ bond activation. ${ }^{54}$ Reaction of $\mathbf{3 9}$ with one equivalent of $\mathrm{NaO} i \operatorname{Pr}$ gave hydrido complexes (230, Scheme 83). When a further equivalent of base was added to 230a, cyclometallated 231 a was isolated from the reaction. This compound went through various transformations to afford complexes 232a and 233a. Compound 232a was also prepared directly from 39a with $\mathrm{NaBH}_{4}$ in $i \mathrm{PrOH}$. Cationic complexes 234a and 235a were accessed via standard silver salt metathesis procedures from 233a. In contrast to results achieved with 39a and derivatives, treatment of $\mathbf{3 9 b}$ and $39 \mathbf{c}$ with excess base gave a mixture of products. The diverse reactivity pattern observed with different NHC ligands suggests that C-H bond activation / cyclometallation in such NHC-Ir(III) complexes are largely governed by subtle steric and electronic differences in the ligand architecture.

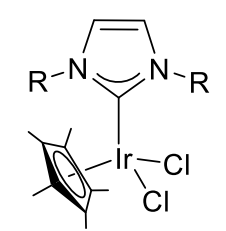

39a: $R=E t$ 39b: $\mathrm{R}=n \mathrm{Pr}$ 39c: $\mathrm{R}=n \mathrm{Bu}$
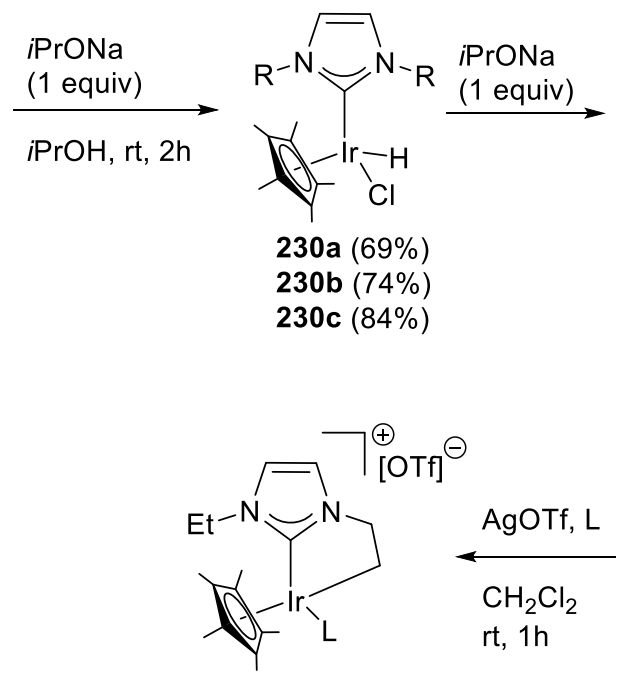

234a: $\mathrm{L}=\mathrm{CH}_{3} \mathrm{CN}(88 \%)$

235a: $L=$ pyridine $(86 \%)$

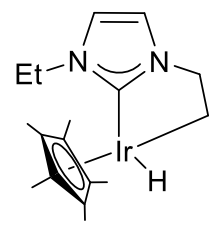

231a $(90 \%)$

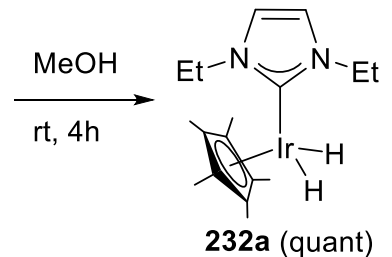

$\mathrm{CHCl}_{3}$ $\mathrm{rt}, 30 \mathrm{~min}$

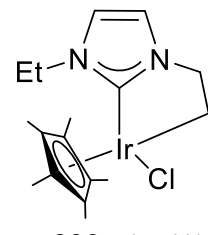

233a $(86 \%)$

Scheme 83. Reactivity of half-sandwich (NHC)Ir-complexes.

Willans et al. developed NHC ligands with pendant carborane groups. ${ }^{107}$ The corresponding iridium complexes showed a high tendency to give C- and B-cyclometallated $\mathbf{2 3 7}$ and $\mathbf{2 3 8}$ respectively, as a mixture of products (Scheme 84). However, clean C- or B-cyclometallated complexes can be accessed via different synthetic strategies (for example via a lithiation pathway or using C-Me protected carborane group).

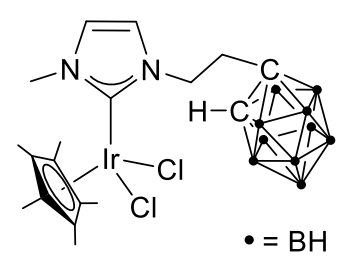

234

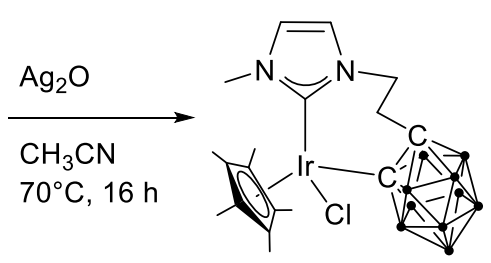

237

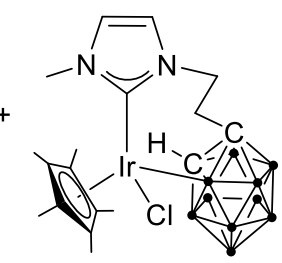

238

Scheme 84. Potentially chelating NHC-carboranes.

As with the other authors mentioned above, Heinekey and coworkers evaluated $\mathrm{C}-\mathrm{H}$ bond activations in NHC-Ir(III) complexes, ${ }^{108,109}$ by taking inspiration from Bergman's seminal contributions to this field of 
study. ${ }^{110}$ To prevent unwanted cyclometallation events, small NHCs were chosen. One of the methyl groups in complex 239 was susceptible to abstraction by $\mathrm{B}\left(\mathrm{C}_{6} \mathrm{~F}_{5}\right)_{3}$ to give $\mathbf{2 4 0}$ in quantitative yield according to ${ }^{1} \mathrm{H}$ NMR spectroscopy (Scheme 85). When $\mathbf{2 4 0}$ was treated with a large excess of benzene or fluorobenzene, slow $\mathrm{C}-\mathrm{H}$ bond activation rates were measured. Even slower rates were observed in reactions with alkanes, where full conversion of the starting material was not achieved without concurrent decomposition. ${ }^{108}$ More

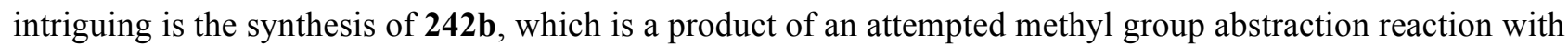
$\left[\mathrm{CPh}_{3}\right]\left[\mathrm{B}\left(\mathrm{C}_{6} \mathrm{~F}_{5}\right)_{4}\right]$. This resulted in conversion of the $\eta^{5}-\mathrm{Cp}^{*}$ ligand to an $\eta^{6}$-coordinated tetramethylfulvene

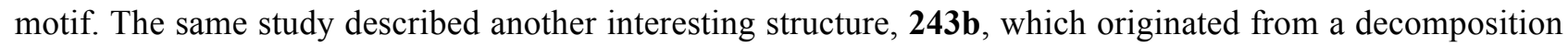
reaction of $\mathbf{2 4 1 b}$. This dimer incorporates a $\mu-\eta^{3}, \eta^{3}-\mathrm{C}_{6} \mathrm{H}_{6}{ }^{2-}$ anion in the chair conformation. ${ }^{109}$

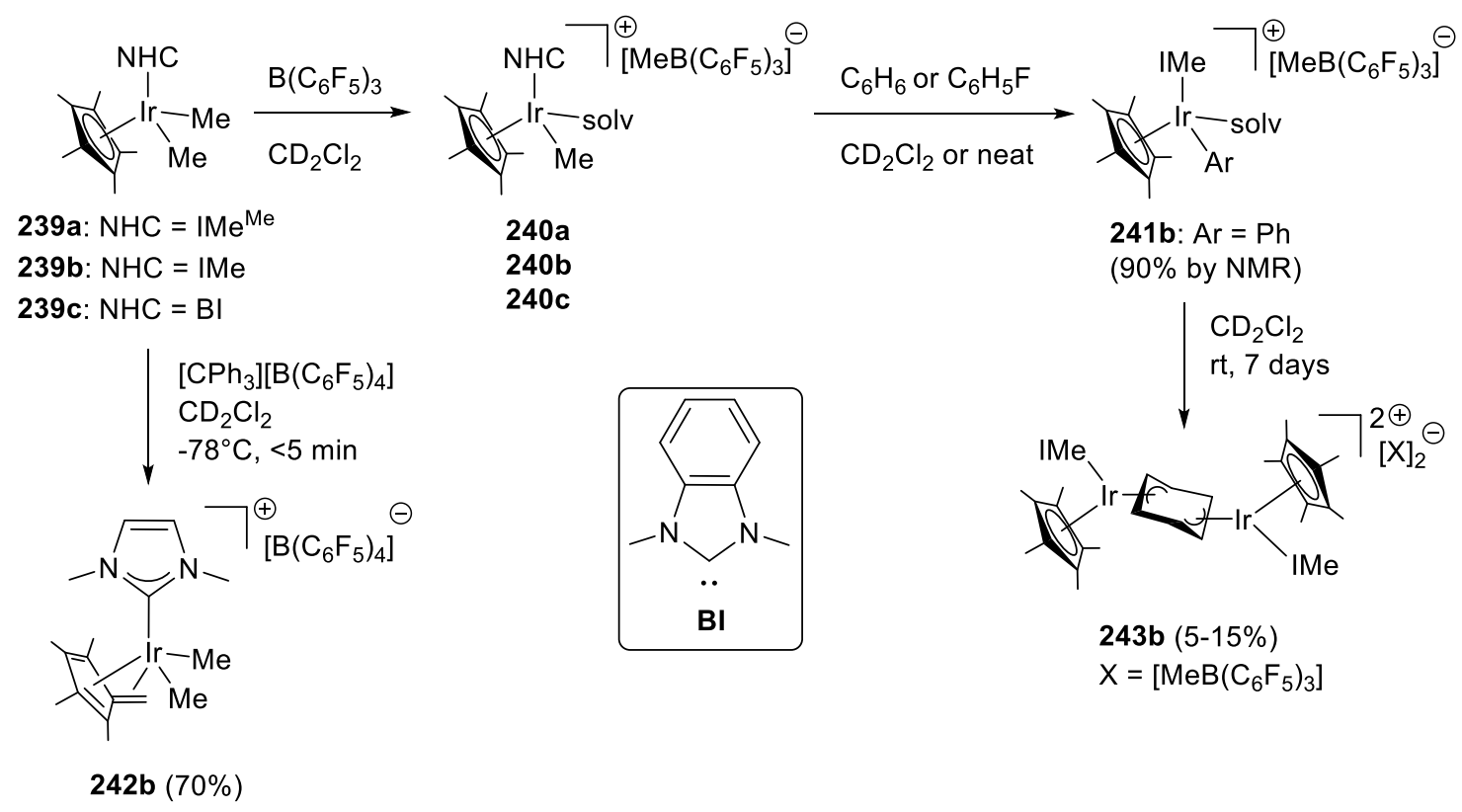

Scheme 85. Unusual complexes $242 b$ and $243 b$.

\section{Donor functionalized or hemilabile NHC ligands in iridium complexes}

Hemilabile ligands in general offer the potential to access catalysts that combine the increased catalytic activity associated with monodentate ligands with catalyst stability that frequently originates from the use of chelating ligand classes. As a consequence, there are numerous examples in the literature where NHCs with potential donor functionality have been synthesized and applied to the synthesis of Ir-complexes.
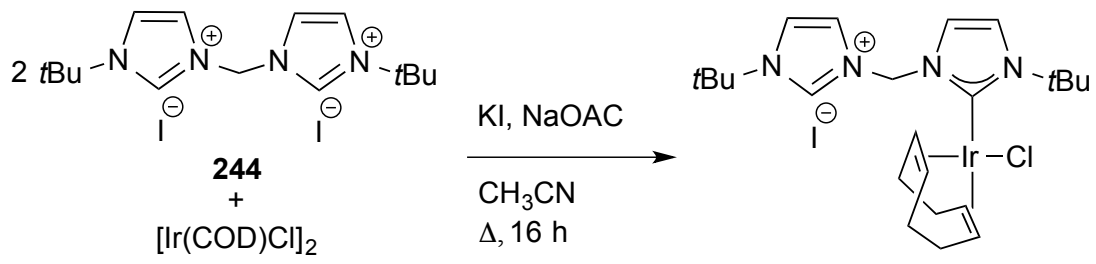

$245(38 \%)$

Scheme 86. Non-chelating bis-NHC 244. 
Bridged bis-NHC ligands readily form classical chelates in their metal complexes. An interesting exception is $\mathrm{NHC}$ salt 244, where even the addition of an appropriate base $\left(\mathrm{K}_{2} \mathrm{CO}_{3}, \mathrm{NaOAc}, \mathrm{KO} t \mathrm{Bu}\right)$ was not sufficient to promote deprotonation of both NHC salts and hence chelation (Scheme 86). ${ }^{111}$

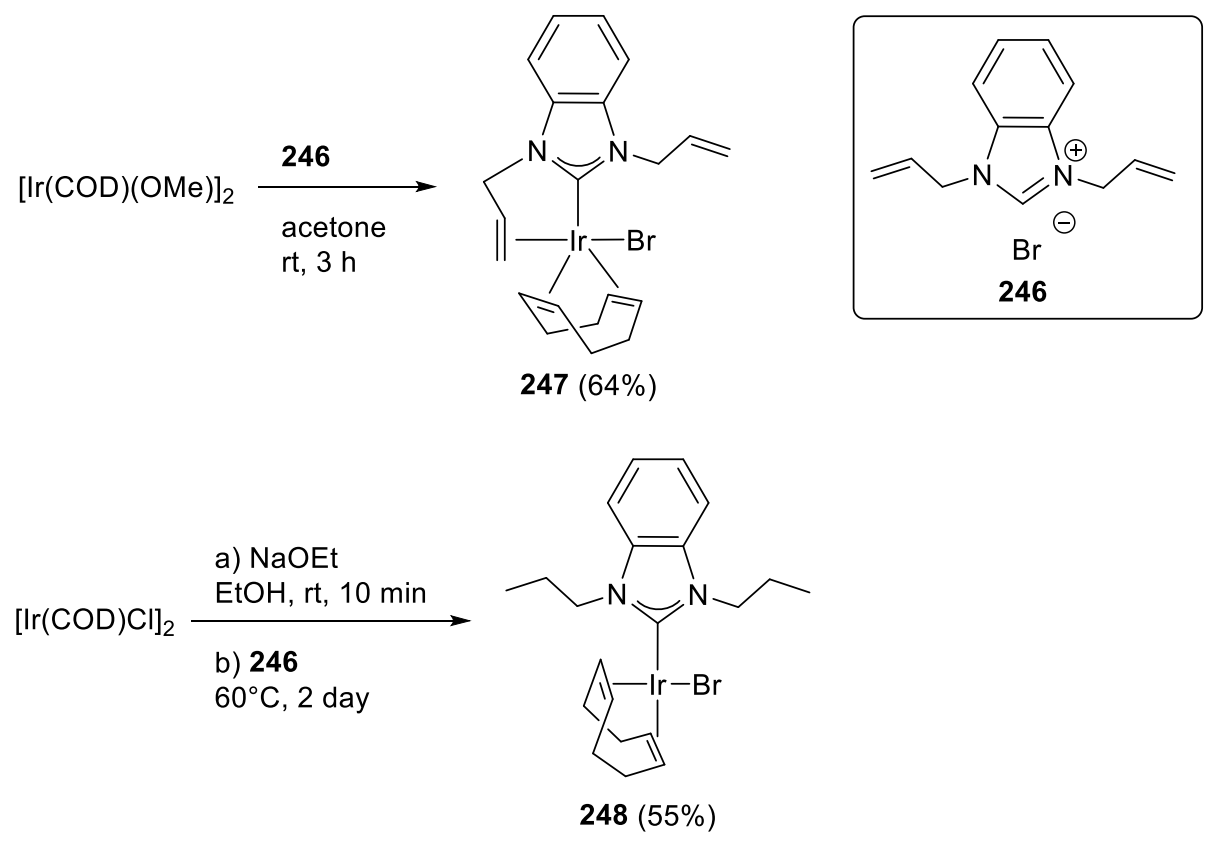

Scheme 87. The reactivity of allyl substituted NHC 246 with $\operatorname{Ir}(\mathrm{I})$ precursors.

Going to more classical hemilabile systems that normally incorporate a second, labile attachment point; Scheme 87 shows the synthesis of $\mathbf{2 4 7}$ which was achieved by taking the potential pincer-type ligand precursor salt 246 and the $[\operatorname{Ir}(\mathrm{COD})(\mu-\mathrm{OMe})]_{2}$ precursor. ${ }^{112 \mathrm{a}}$ In contrast, treatment of the in situ prepared $[\operatorname{Ir}(\mathrm{COD})(\mu-\mathrm{OEt})]_{2}$ with $\mathbf{2 4 6}$ gave the saturated complex 248 (Scheme 87 bottom). The analogous complexes 249 and 251 were similarly prepared from $\mathrm{N}$-allyl substituted imidazolium bromides (Scheme 88 and Figure 14, respectively). When 249 was treated with $\mathrm{AgBF}_{4}$, only partial halide abstraction occurred and the bromobridged 250 formed (Scheme 88). Silver salt metathesis on $\mathbf{2 4 7}$ and $\mathbf{2 5 1}$ gave pincer complexes, where both olefin moieties of the allyl units were bound to the metal center. ${ }^{112 \mathrm{~b}}$

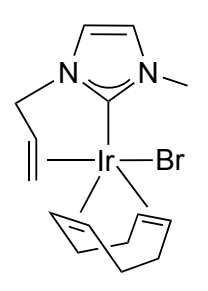

249

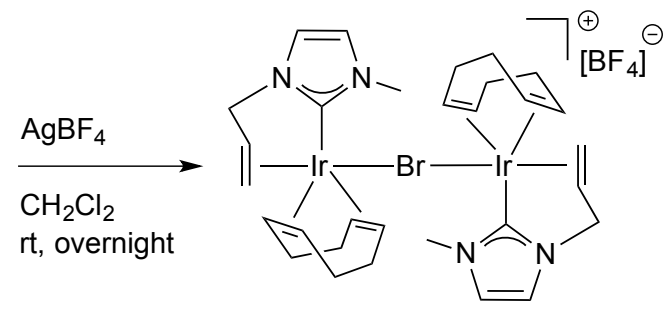

$250(93 \%)$

Scheme 88. The synthesis of dimer 234.

Peris and Mata extended the investigations on alkenyl-functionalized NHC-Ir complexes. Modifications on the backbone did not affect overall coordination abilities of these ligands (complexes 252-254), however the introduction of a pentenyl side chain gave a monodentate NHC species 255 (Figure 15). ${ }^{113}$ Analogous NHCIr(III) compounds were also obtained (256, 257), and compounds 257 were employed in transfer 
hydrogenation reactions (vide infra in Section 9.2). It was suggested that the catalytic activity might originate from the irreversible cleavage of the Ir-alkene bond. However, attempts to isolate intermediates that would support this hypothesis failed. ${ }^{114}$

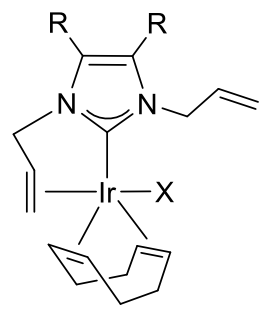

251: $\mathrm{R}=\mathrm{H}, \mathrm{X}=\mathrm{Br}$

252: $\mathrm{R}=\mathrm{H}, \mathrm{X}=\mathrm{Cl}$

253: $\mathrm{R}=\mathrm{Cl}, \mathrm{X}=\mathrm{Cl}$

254: $\mathrm{R}=\mathrm{CH}_{3}, \mathrm{X}=\mathrm{Cl}$

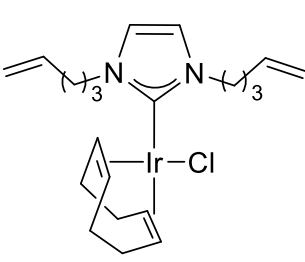

255

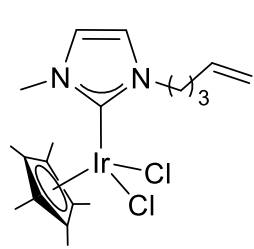

256

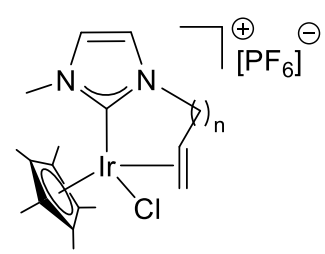

257a: $\mathrm{n}=1$

257b: $n=2$

Figure 14. NHC-Ir complexes with alkenyl functionality.

Contrasting results were obtained with rhodium and iridium when complexation of S-functionalized NHC precursor salt 258 was investigated (Scheme 89). The reaction with iridium gave bis-carbene complex 259 in low yield (21\%). On the other hand, $\kappa^{2}-\mathrm{C}, \mathrm{S}$ coordination of the ligand to rhodium was observed in $\mathbf{2 6 0}$. ${ }^{115 a}$

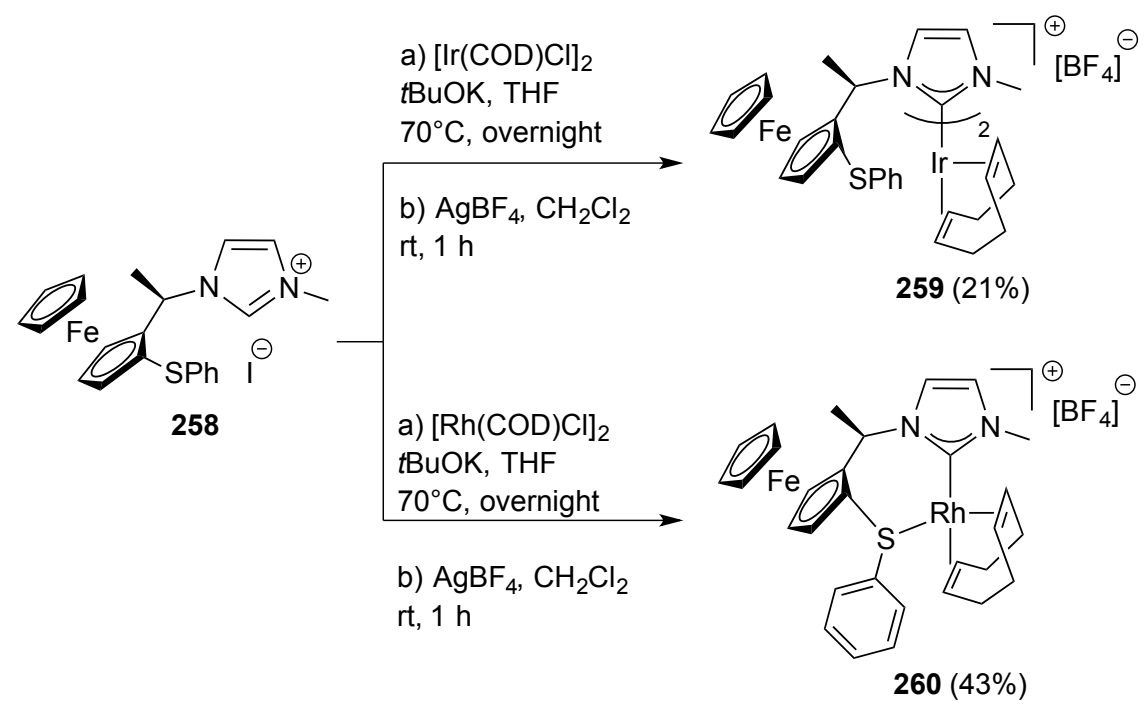

Scheme 89. Complexation with S-functionalized 258.

(NHC) $\operatorname{Ir}\left(\mathrm{Cp}^{*}\right)$ complexes have found catalytic applications in various oxidative transformations of alcohol substrates. Mas-Marzá, Peris, and coworkers surmised that a study of NHC ligands with pendant alcohol functionality in $\mathrm{Cp} * \operatorname{Ir}(\mathrm{III})$ complexes might improve our understanding of oxidative reaction pathways governing such processes. ${ }^{116}$ Therefore, iridium complexes with ligand salts $\mathbf{2 6 1}$ were accessed using a range of reaction conditions (Scheme 90). During these transformations, the hydroxyl group either remained intact (262a and 262d), or intramolecular oxidation resulted in the generation of carbonyl (263) and ester (264 and 265) functionalities. In some cases, these transformations were accompanied by cyclometallation events (in 263 and 265). Compound 265 has two stereogenic centers (at iridium and at the metalated carbon atom) and it formed as a 3:2 mixture of diastereomers. 
$\left[\mathrm{Cp}^{*} \mathrm{IrCl}_{2}\right]_{2}, \mathrm{KI}, \mathrm{Cs}_{2} \mathrm{CO}_{3}$

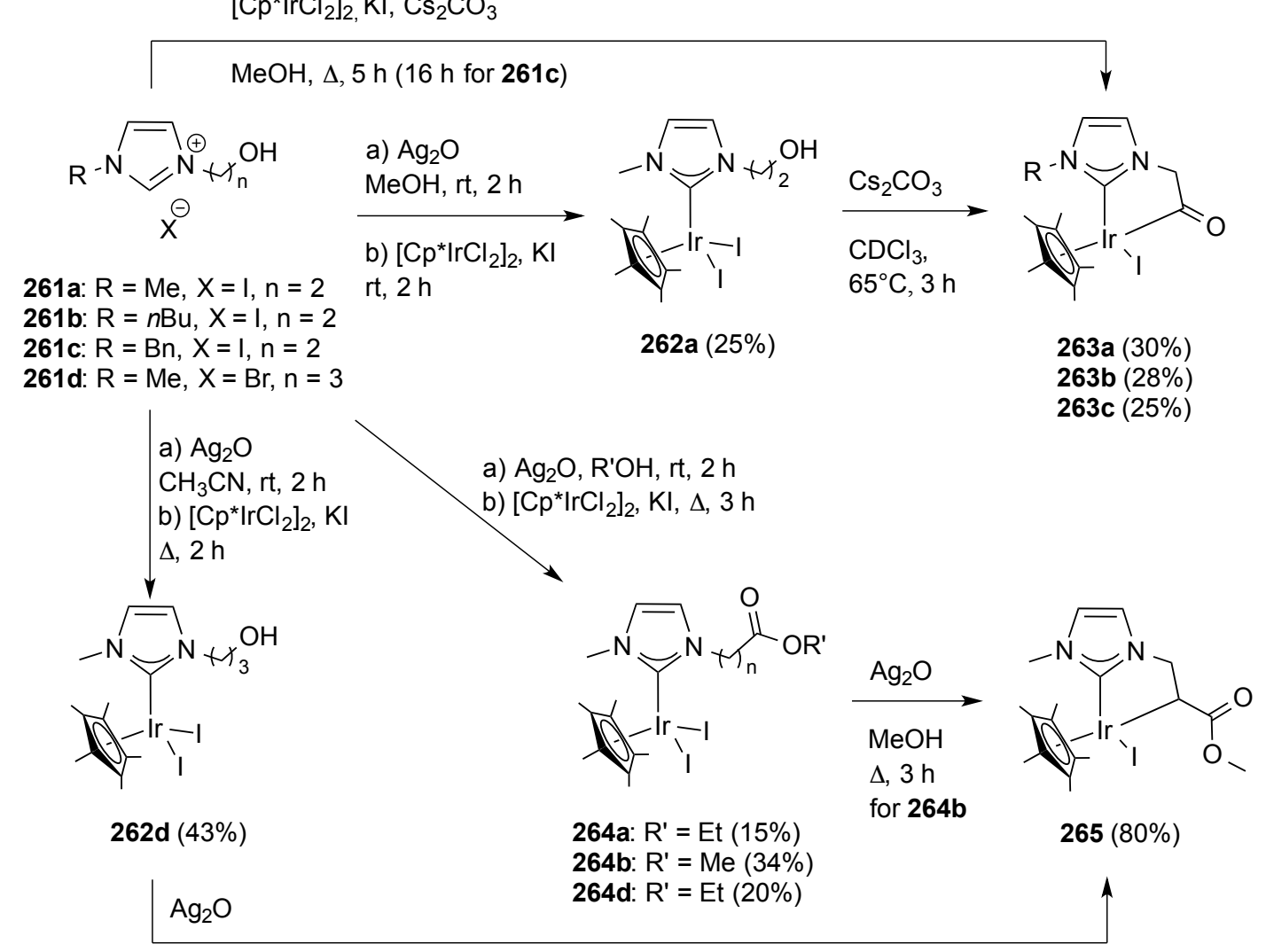

$\mathrm{MeOH}, \Delta, 3 \mathrm{~h}$

Scheme 90. Intramolecular oxidation of N-hydroxyalkyl NHCs.

Bartoszewicz et al. reported the synthesis of Cp*Ir(III) complexes having hydroxy-, ether- and alkoxidefunctionalized NHC ligands. Coordination of the oxygen-containing group in $(\mathrm{NHC}) \operatorname{Ir}\left(\mathrm{Cp}^{*}\right) \mathrm{Cl}_{2}$ compounds (266 and 267) did not occur. On the other hand, halide abstraction from the iridium center or deprotonation of the pendant hydroxyl group resulted in oxygen to metal ligation in complexes 268-270 (Scheme 91). ${ }^{117 a}$

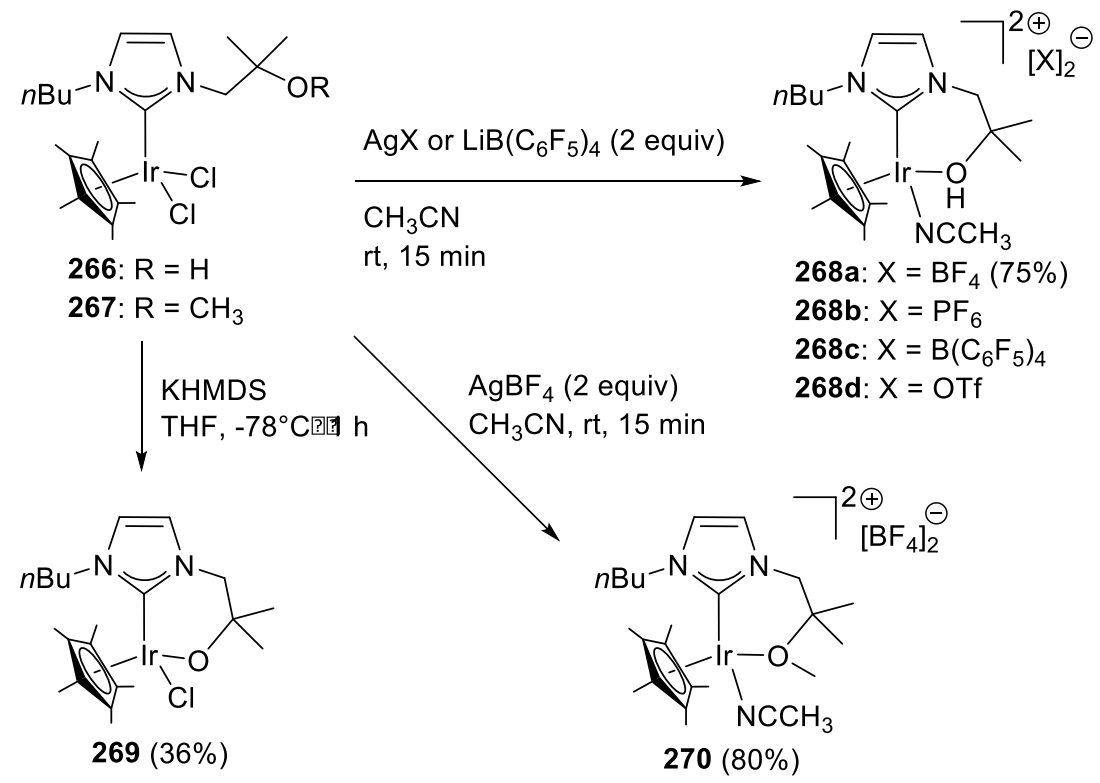

Scheme 91. Iridium(III) complexes having O-functionalized NHC ligands. 
Iridium(I)/(III) complexes of hemilabile quinoline-tethered NHC ligands showed both monodentate or chelating coordination modes. ${ }^{118}$ Neutral complexes of $\operatorname{Ir}(\mathrm{I})$ displayed monodentate ligation, whereas chelation occurred upon salt metathesis (Scheme 92). On the other hand, transmetallation of the corresponding NHC-silver complex with $\left[\mathrm{Cp}^{*} \mathrm{IrCl}_{2}\right]_{2}$ gave an equilibrium mixture of neutral 273 and ionic 274 (Scheme 93). Exposure of this mixture to $\mathrm{KPF}_{6}$ exclusively yielded $\left[(\mathrm{NHC} \wedge \mathrm{N}) \operatorname{Ir}\left(\mathrm{Cp}^{*}\right) \mathrm{Cl}\right] \mathrm{PF}_{6}(\mathbf{2 7 5})$. Compounds with similar coordination behavior as seen in $\mathbf{2 7 1}$ and $\mathbf{2 7 2}$ were described with pendant tertiary amine, pyridine or quinoline motifs. ${ }^{23,119,120,121,122}$

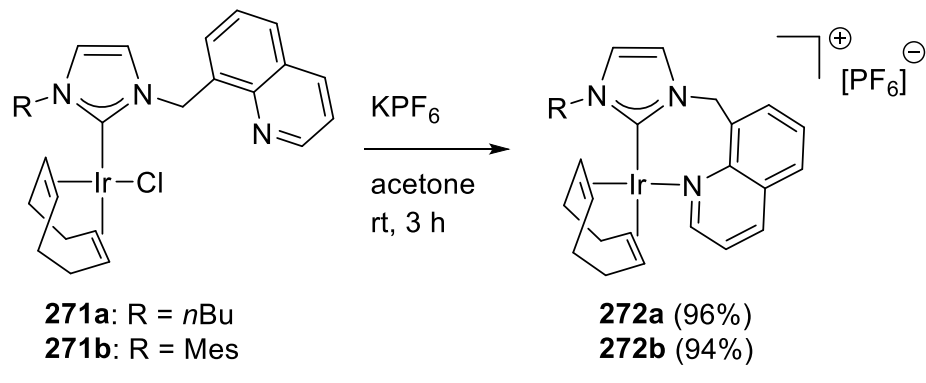

Scheme 92. Cyclooctadiene-Ir complexes with quinoline-tethered NHCs.
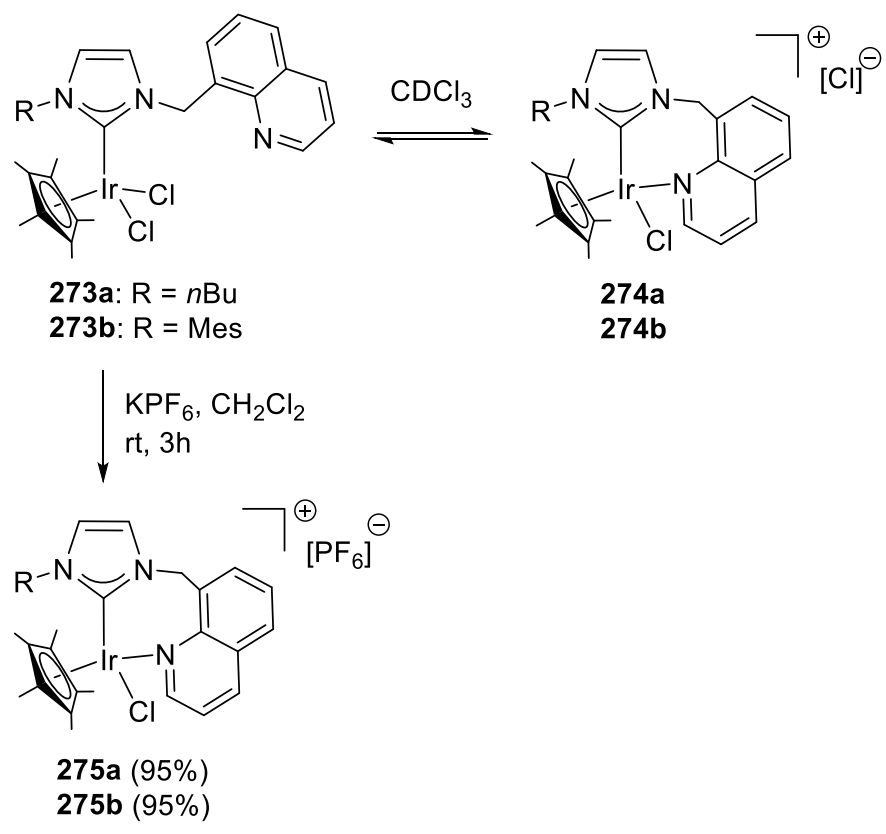

Scheme 93. Cp*Ir complexes with quinoline-tethered NHCs.

Related N-donor-functionalized hemilabile NHC ligands with pyridine wingtips were studied in their $\operatorname{Ir}(\mathrm{I})$ complexes. ${ }^{123}$ The syntheses of complexes $277 \mathbf{a}$ and $\mathbf{2 7 7} \mathbf{b}$ were achieved from $[\operatorname{Ir}(\mathrm{COD})(\mathrm{acac})]$ (acac $=$ acetylacetonate) and the corresponding imidazolium salts (Scheme 94). Low solubility in chlorinated solvent, along with decomposition in DMSO- $d_{6}$, precluded the exact determination of the coordination geometry in $\mathbf{2 7 7} \mathbf{a}-\mathbf{b}$. In contrast, single crystals of $\mathbf{2 7 7} \mathbf{c}-\mathbf{d}$ were obtained, and a single batch of $\mathbf{2 7 7} \mathbf{c}$ gave yellow and red crystals with $\kappa^{1}-\mathrm{C}$ and $\kappa^{2}-\mathrm{C}, \mathrm{N}$ coordination modes, respectively. Variable temperature NMR spectroscopy, together with DFT calculations indicated that a fast equilibrium between the $\kappa^{1}$-C- and the $\kappa^{2}$ $\mathrm{C}, \mathrm{N}$-species is present in solution (Scheme 95). Furthermore, complex 277d showed unexpected reactivity towards phosphines. As shown in Scheme 96 (left), the Ir-N coordination mode remained intact and 
substitution of the anion took place. Similarly, reaction with CO did not give the expected biscarbonyl complex, instead a rare monocarbonyl compound 279 was isolated.
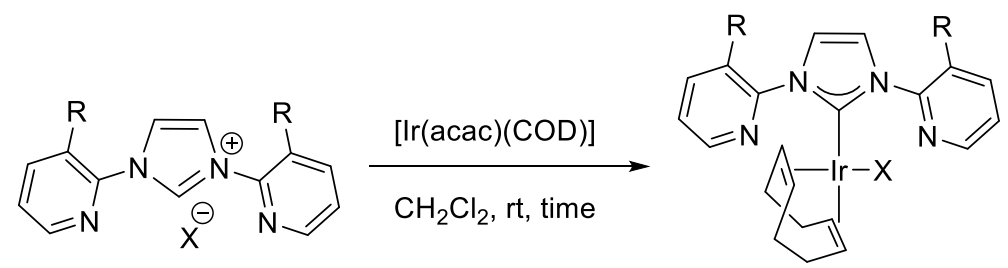

276a: $\mathrm{R}=\mathrm{H}, \mathrm{X}=\mathrm{Cl}$

276b: $R=H, X=B r$

277a: $40 \min (80 \%)$

276c: $\mathrm{R}=\mathrm{CH}_{3}, \mathrm{X}=\mathrm{Cl}$

277b: 2 h $(83 \%)$

277c: 1 h $(70 \%)$

276d: $\mathrm{R}=\mathrm{CH}_{3}, \mathrm{X}=\mathrm{Br}$

Scheme 94. The synthesis of complexes 277.

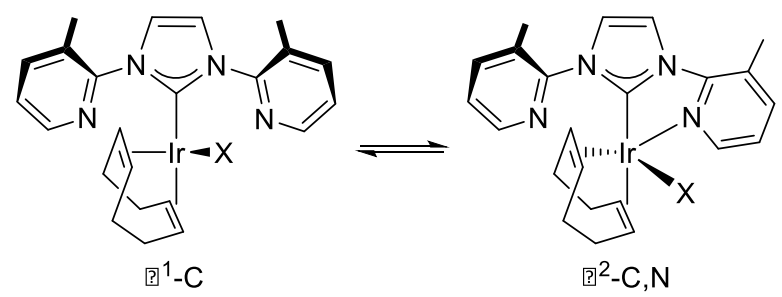

Scheme 95. Equilibrium between $\kappa^{1}$-C- and the $\kappa^{2}$-C,N-coordination modes.

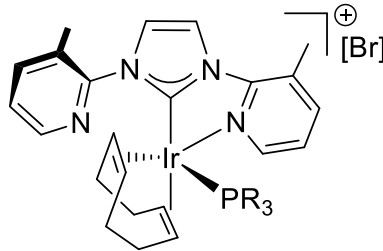

278a: $R=M e, 30 \min$ $(75 \%)$

278b: $\mathrm{R}=\mathrm{Ph}, 5 \mathrm{~min}$ $(95 \%)$

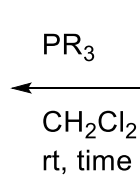

t, time

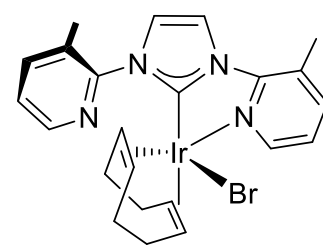

277d
$\mathrm{CO}$

$\mathrm{CH}_{2} \mathrm{Cl}_{2}$

rt, 5 min<smiles></smiles>

279 (quant)

Scheme 96. Unique reactivity of NHC-Ir complex 277d.

Grotjahn and coworkers demonstrated that steric tuning of N-base bearing NHC ligands might lead to a significant change in the stability of the Ir-N interaction. ${ }^{124}$ For example, the pyrimidine ring is tightly bound in NHC-Ir(III) complex 280a. Nonetheless, introduction of a bulky substituent next to the pyrimidine nitrogen lowered the activation energy of the pyrimidyl ring flip in $\mathbf{2 8 0 b}-\mathbf{d}$ and $\mathbf{2 8 1}$ (Figure 15). ${ }^{124,125}$ Furthermore, crystallization attempts from a solution of 280d gave the chloride-bridged dimer [ $\left(\kappa^{1}-\mathrm{C}-\right.$ $\left.\mathrm{NHC}) \operatorname{Ir}\left(\mathrm{Cp}^{*}\right) \mathrm{Cl}\right]_{2}\left[\mathrm{PF}_{6}\right]_{2}$, indicating the presence of a rather weak Ir-N interaction. ${ }^{124 b}$ Likewise, addition of benzylamine to complex 280c or $\mathbf{2 8 1}$ generated adducts $\mathbf{2 8 2}$ and 283, respectively (Scheme 97). Low temperature ${ }^{1} \mathrm{H}^{-15} \mathrm{~N}$ gHMBC NMR provided strong evidence for hydrogen-bonding in these compounds. The importance of such hemilable interactions was apparent and was highlighted in catalytic hydroamination/cyclization reactions (vide infra). ${ }^{124}$ Reaction between the N-donor functionalized dication $\mathbf{2 8 4}$ and $[\operatorname{Ir}(\mathrm{COD})(\mu-\mathrm{OMe})]_{2}$ gave intermediate $\mathbf{2 8 5}$, which was deprotonated to give $\mathbf{2 8 6}$ in good yields (Scheme 98). ${ }^{126,23}$ 


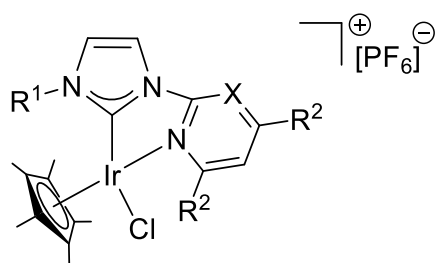

280a: $\mathrm{R}^{1}=n \mathrm{Bu}, \mathrm{R}^{2}=\mathrm{H}, \mathrm{X}=\mathrm{N}$

280b: $R^{1}=\mathrm{CH}_{3}, \mathrm{R}^{2}=\mathrm{Ph}, \mathrm{X}=\mathrm{N}$

280c: $\mathrm{R}^{1}=\mathrm{CH}_{3}, \mathrm{R}^{2}=t \mathrm{Bu}, \mathrm{X}=\mathrm{N}$

280d: $R^{1}=\mathrm{CH}_{3}, \mathrm{R}^{2}=t \mathrm{Bu}, \mathrm{X}=\mathrm{CH}$

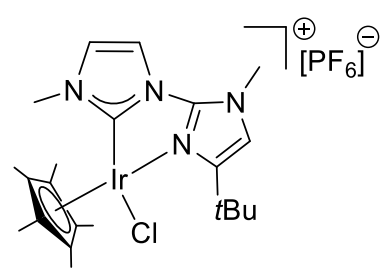

281

Figure 15. NHC-Ir complexes with pendant N-bases.

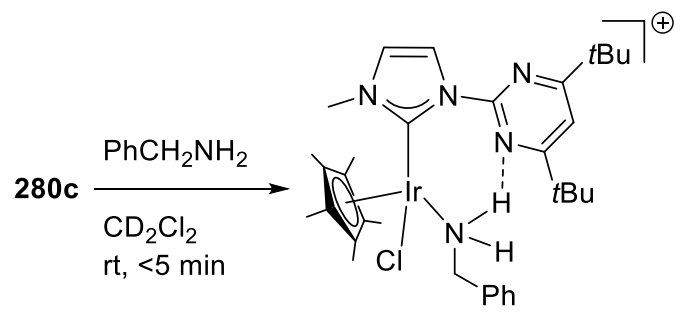

282

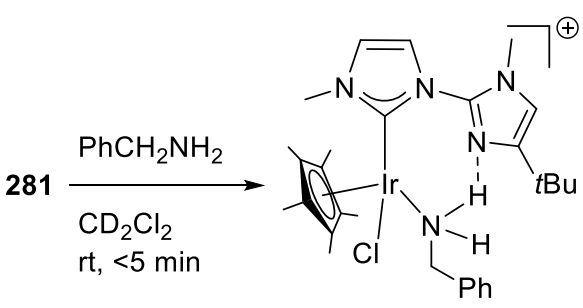

283

Scheme 97. Adduct formation with benzylamine. The $\mathrm{PF}_{6}$ anion is omitted for clarity.

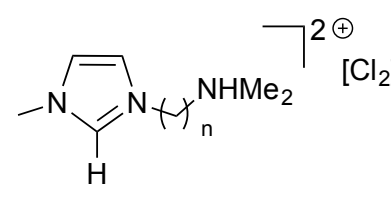

284a: $n=2$

284b: $n=3$<smiles></smiles>

285a (not isolated) 285b (not isolated)

$\mathrm{NaH}, \mathrm{H}_{2} \mathrm{O}$ rt, $10 \mathrm{~min}$

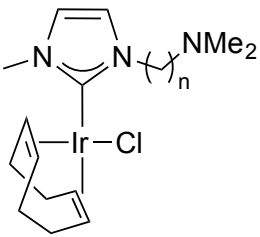

$286 a(69 \%)$

286b $(72 \%)$

Scheme 98. Synthesis of $\mathbf{2 8 6}$ through the unusual intermediate $\mathbf{2 8 5}$.

Related NHCs with pendant aniline functionality were investigated by de Bruin, Elsevier and coworkers. ${ }^{127}$ An Ir(III)-compound with a chelated $\kappa^{2}-C, N-\left(\mathrm{C}^{\mathrm{NHC}}-\mathrm{NH}_{2}\right)$ moiety was formed through the silver transmetallation procedure. In contrast, reaction with an $\operatorname{Ir}(\mathrm{I})$ precursor led to a monodentate coordination mode of the $\mathrm{C}_{\mathrm{NHC}}-\mathrm{NH}_{2}$ ligand in complex 287 (Scheme 99). ${ }^{128} \mathrm{X}$-ray crystal structure analysis revealed the expected square planar geometry around iridium and the presence of an intramolecular hydrogen bond $\left(\mathrm{H}^{\cdots} \mathrm{Cl}\right.$ 2.57(3) $\AA$ ), while in the ${ }^{1} \mathrm{H}$ HMR spectrum, the $\mathrm{NH}_{2}$ signal was not visibly split. Ligand chelation was achieved via deprotonation of the $\mathrm{NH}_{2}$ group. 


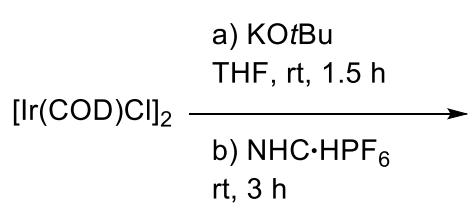

rt, $3 \mathrm{~h}$

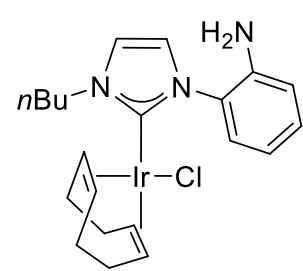

$287(53 \%)$

Scheme 99. Monodentate coordination in the presence of a pendant $\mathrm{NH}_{2}$-functionality.

\section{Studies related to electronic, luminescent and redox properties of NHCs and their iridium complexes}

Bonding properties of NHC-metal complexes have faced extensive experimental and theoretical scrutiny, and numerous accounts are therefore available on the topic. ${ }^{10,13,129,130}$ Here, we will focus on a select few examples where TEP values $($ TEP $=$ Tolman Electronic Parameter $){ }^{131}$ were determined using $(\mathrm{NHC}) \operatorname{Ir}(\mathrm{CO})_{2} \mathrm{Cl}$ compounds that are of general interest with regards to electronic properties of NHCs, ${ }^{10,11}$ before covering some interesting Ir systems with luminescent properties.

Originally, the TEP was developed to compare electron donation properties of tertiary phosphine ligands in $\left(\mathrm{PR}_{3}\right) \mathrm{Ni}(\mathrm{CO})_{3}$ type complexes. A first systematic study on corresponding $(\mathrm{NHC}) \mathrm{Ni}(\mathrm{CO})_{3}(\mathrm{NHC}=\mathrm{IMes}$, SIMes, IPr, SIPr, ICy) complexes has appeared more than a decade ago. ${ }^{132}$ The use of nickel complexes however is not straightforward because of $a$ ) the very high toxicity of the $\mathrm{Ni}(\mathrm{CO})_{4}$ precursor and because $b$ ) the reaction of $\mathrm{Ni}(\mathrm{CO})_{4}$ with bulky NHCs (IAd, $\left.\mathrm{I} t \mathrm{Bu}\right)$ can yield $(\mathrm{NHC}) \mathrm{Ni}(\mathrm{CO})_{2}$ instead of $(\mathrm{NHC}) \mathrm{Ni}(\mathrm{CO})_{3}$ compounds, precluding characterization through the TEP. Crabtree et al. found that $(\mathrm{L}) \operatorname{Ir}(\mathrm{CO})_{2} \mathrm{Cl}$ systems can be linked to $(\mathrm{L}) \mathrm{Ni}(\mathrm{CO})_{3}$ by linear regression analysis, and the equation was later fine-tuned by Nolan and coworkers (Equation 1). ${ }^{40,50}$

$$
\mathrm{TEP}=0.847 v_{\mathrm{CO}}^{\text {average }}+336 \mathrm{~cm}^{-1}(\mathrm{Eq} \mathrm{1})
$$

In 2008, Plenio and coworkers carried out a thorough study on tuning the electronic properties of NHC ligands. ${ }^{133}$ A range of IMes and SIMes analogues were prepared and 28 NHC-Ir(I) complexes of those were reported. The TEP values were determined from IR spectroscopic analysis of $(\mathrm{NHC}) \operatorname{Ir}(\mathrm{CO})_{2} \mathrm{Cl}$ complexes. The electrochemistry of $(\mathrm{NHC}) \operatorname{Ir}(\mathrm{CO})_{2} \mathrm{Cl}$ was irreversible, likely due to dissociation of the $\mathrm{CO}$ ligand after oxidation of the iridium(I) center. On the other hand, (NHC) $\operatorname{Ir}(\mathrm{COD}) \mathrm{Cl}$ complexes showed reversible electrochemistry and the redox potentials were correlated with the electron-donating nature of the ligands. This analysis showed that saturated NHCs when compared to unsaturated ones are somewhat better electron donors. NHC ligand 288 (Figure 16), having strongly electron-withdrawing groups, showed virtually the same electronic characteristics as $\mathrm{PCy}_{3}$. Due to its higher precision, cyclic voltammetry was judged as a superior method to IR spectroscopy. 


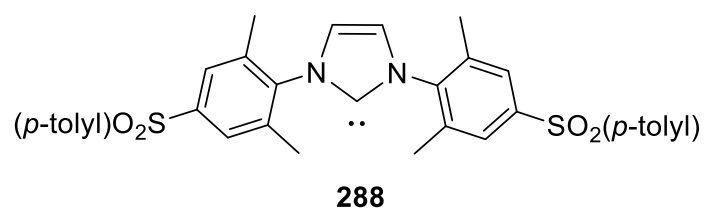

Figure 16. An example of an 'electron-poor' NHC, 288.

Recently, Togni and coworkers synthesized N-trifluoromethyl benzimidazolium salts. ${ }^{134}$ As expected, the TEP values determined from $(\mathrm{NHC}) \operatorname{Ir}(\mathrm{CO})_{2} \mathrm{Cl}$ compounds indicated decreased $\sigma$-donation. The increase in $\pi$ acceptor properties was confirmed by ${ }^{77} \mathrm{Se}$ NMR measurement of their corresponding NHC-Se compounds and also by the redox potentials of the (NHC) $\mathrm{Rh}(\mathrm{COD}) \mathrm{Cl}$ species. The effect of methoxy functionalization on the aromatic wingtip parts of NHCs was assessed in detail by Nelson, Nolan et al. ${ }^{135}$ Donor abilities of some other, recently synthesized NHCs were probed through IR spectroscopic or electrochemical methods. ${ }^{136,137,138,139}$

Tonner, Chaplin and coworkers carried out computational analysis on NHC-metal complexes with distorted geometries. ${ }^{140}$ In particular, the authors looked at in-plane (yawing) and out-of-plane (pitching) movement of the NHC ligand (Figure 17). Computed restricted potential energy surfaces on the ( $\left.\mathrm{IBioxMe}_{4}\right) \mathrm{M}(\mathrm{CO})_{2} \mathrm{Cl}(\mathrm{M}$ $=\mathrm{Ir}, \mathrm{Rh})$ model complexes showed that the yawing movement comes with significantly higher energy penalty due to Pauli repulsion (i.e. sterics) and to decreased M-to-NHC $\pi$ back donation. However, yawing also offers additional stabilization due to closer proximity of the methyl substituents to the metal (e.g. weak agostic interaction) and ancillary ligands.
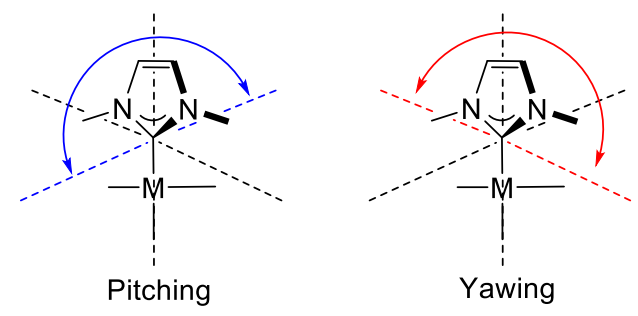

Figure 17. Yawing and pitching.

The Bielawski group carried out extensive research on NHCs with flanking redox active moieties. In 2009, a series of ferrocenyl or quinone functionalized NHCs were electronically investigated in their iridium complexes. Spectroelectrochemistry showed that reduction or oxidation of these groups lead to a change in donicity of the NHC ligand. ${ }^{141}$ In the same vein, a redox-switchable Ru-based olefin metathesis catalyst with a ferrocene-containing NHC was synthesized, and key electrochemical and spectroscopic properties of the ligand were studied through its iridium complexes. ${ }^{142}$ More recently, Poyatos, Peris and coworkers studied the redox-switching abilities of a ferrocenyl-imidazolylidene ligand. ${ }^{143}$

The study of ferrocene-functionalized NHCs was further extended to the synthesis of cationic iridium complexes with anionic iridium counterions (Scheme 100). ${ }^{144}$ The synthesis of 290 was carried out with an in situ prepared free carbene starting from NHC salt 289. Anion metathesis using $\left[\mathrm{N}(n \mathrm{Bu})_{4}\right]^{+}\left[\operatorname{Ir}(\mathrm{COD}) \mathrm{Cl}_{2}\right]^{-}$gave 291 in an excellent $91 \%$ yield. Further treatment with CO gave ligand substitution both in the cationic and 
anionic component. Spectroelectrochemical analysis showed that the number of redox active Fc-NHC units did not influence the oxidation properties of these compounds, since simultaneous oxidation on both Fe units took place.

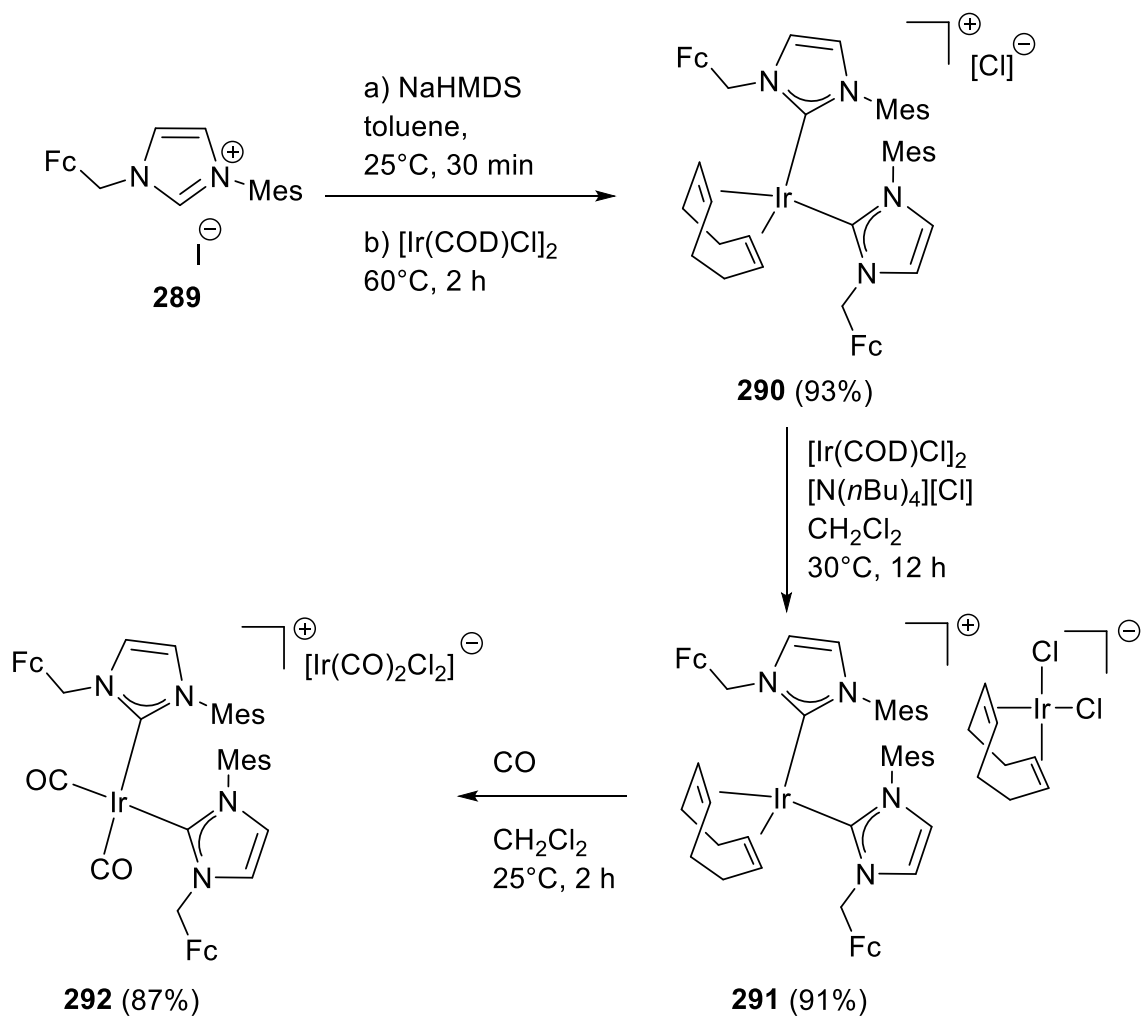

Scheme 100. Redox-active cationic iridium complexes with anionic iridium counterions $(\mathrm{Fc}=$ ferrocenyl $)$.

Modulation of the electron donation of NHC ligands is also possible by introducing charge effects. Heterobimetallic Ir/Ru complexes featuring an $\eta^{6}$-coordinated $\{\mathrm{Cp} * \mathrm{Ru}\}^{+}$fragment were synthesized by Ganter, ${ }^{16,145}$ and by Valdés et al. ${ }^{146}$ Not surprisingly, the cationic fragment renders the ligand less electron donating in comparison with its neutral counterpart (Scheme 101, bottom). ${ }^{16}$

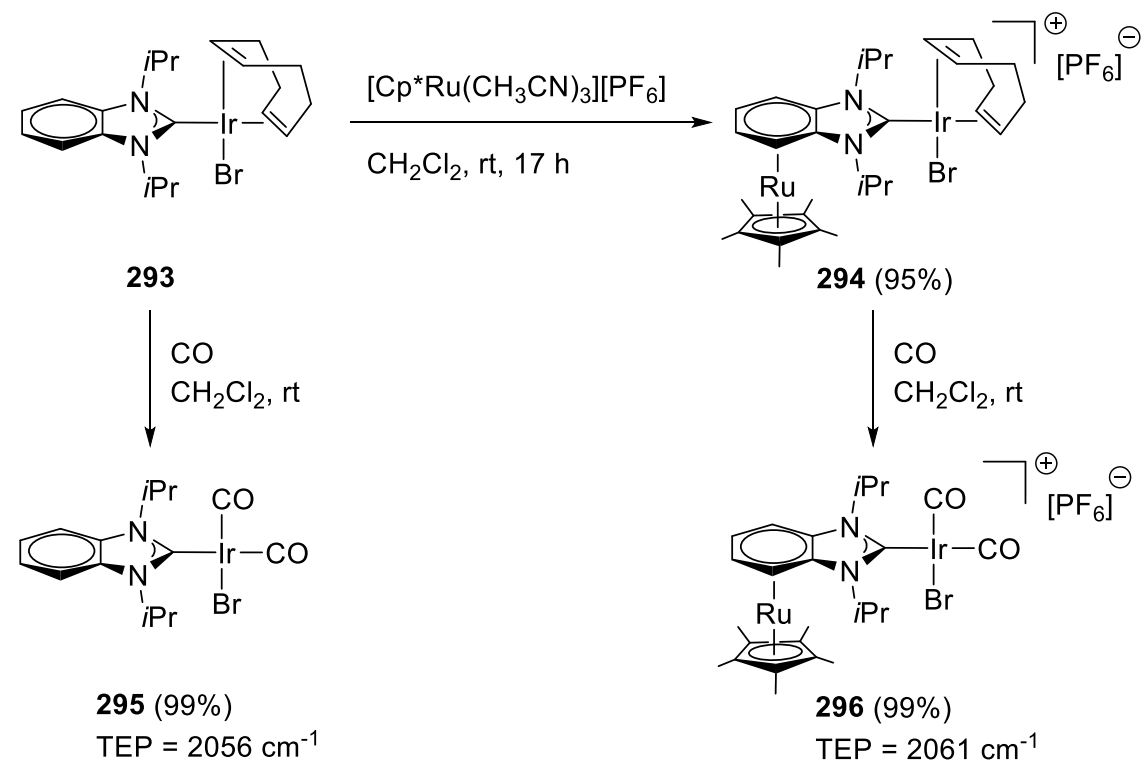

Scheme 101. Post-modification of the donicity in 293. 
A similar approach was taken when electron-poor NHCs with increased $\pi$-acceptor properties were synthesized by Buhl and Ganter. ${ }^{147}$ The combination of mesomeric and charge effects arising from an incorporated pyridinium fragment resulted in a $12 \mathrm{~cm}^{-1}$ shift in the TEP value going from 297 to 298 (Figure $18)$.

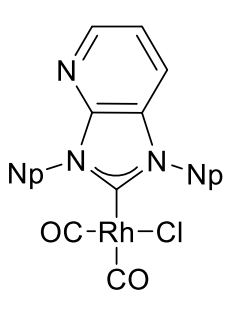

297

TEP $=2055 \mathrm{~cm}^{-1}$

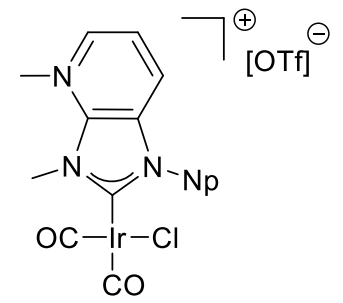

298

TEP $=2067 \mathrm{~cm}^{-1}$

Figure 18. Mesomeric and charge effect in 298.

NHC-iridium carbonyls were recently used to probe post-modification of the electronic properties in NHC ligands via $\pi$-stacking of aromatic molecules to NHCs that contain extended aromatic backbones (Figure 19). ${ }^{148}$ IR spectroscopic measurements, supported by ${ }^{1} \mathrm{H}$ NMR studies, showed that addition of pyrene to a solution of (299) $\operatorname{Ir}(\mathrm{CO})_{2} \mathrm{Cl}$ in $\mathrm{CH}_{2} \mathrm{Cl}_{2}$ resulted in decreased average $\mathrm{CO}$ stretching frequencies (i.e. increased donicity). In contrast, addition of perfluorobenzene showed an opposite trend (i.e. increased average CO stretching frequencies).

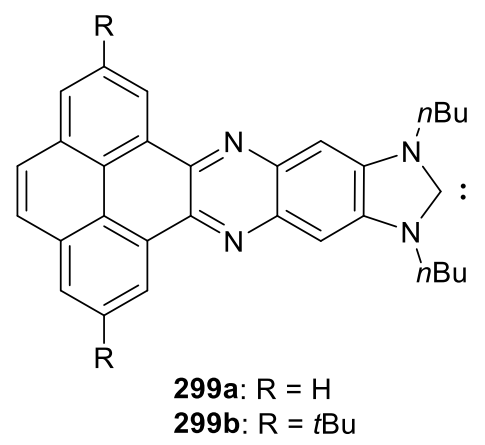

Figure 19. The structure of NHC 299.

A phenanthrene-fused imidazolium salt, $\mathbf{3 0 0} \cdot \mathbf{H B F}{ }_{4}$ was prepared in order to study the annulation effect on $\sigma$ donor/ $\pi$-acceptor and photophysical properties of the derived carbene species (Figure 20). ${ }^{149}$ The fluorescence emission spectra of $\mathbf{3 0 0} \cdot \mathbf{H B F}_{\mathbf{4}},(\mathbf{3 0 0}) \mathrm{Rh}(\mathrm{COD}) \mathrm{Cl},(\mathbf{3 0 0}) \operatorname{Ir}(\mathrm{COD}) \mathrm{Cl}$ and phenanthrene was compared. With excitation at $256 \mathrm{~nm}$, the strongest emission spectra belonged to $\mathbf{3 0 0} \cdot \mathbf{H B F}_{4}$, while emission intensities for the Rh- and Ir-compounds were significantly lower than that of phenanthrene. More detailed investigations were carried out with $(\mathbf{3 0 1}) \operatorname{Ir}(\mathrm{COD}) \mathrm{Cl}$ and $(\mathbf{3 0 2}) \operatorname{Ir}(\mathrm{COD}) \mathrm{Cl}$, the focus being on the electronic communication in the latter one. ${ }^{150}$ Similar to (300) $\operatorname{Ir}(\mathrm{COD}) \mathrm{Cl}$, neither compound exhibited measurable phosphorescence. However, phosphorescence emission was detected when the same ligands were incorporated in $\left\{\operatorname{Ir}(\mathrm{ppy})_{2}\right\}$ systems, indicating that the NHC fragment does not influence luminescent properties in these complexes. Another example by Tapu et al. incorporated a fused dibenzo[a,c]phenazine into the backbone of NHC $\mathbf{3 0 3}$ (Figure 20). ${ }^{151}$ The electron-releasing capacity of $\mathbf{3 0 3}$ was examined through 
TEP value determination and cyclic voltametry, and overall it was found to be attenuated relative to the nonannulated ligand. Furthermore, $(\mathbf{3 0 3}) \operatorname{Ir}(\mathrm{COD}) \mathrm{Cl}$ exhibited reduced fluorescence compared to $\mathbf{3 0 3} \cdot \mathbf{H B F}_{\mathbf{4}}$. This is similar to the fluorescent quenching observed for $(\mathbf{3 0 0}) \operatorname{Ir}(\mathrm{COD}) \mathrm{Cl},{ }^{149}$ and for $(\mathbf{3 0 1}) \operatorname{Ir}(\mathrm{COD}) \mathrm{Cl}$ and (302) $\operatorname{Ir}(\mathrm{COD}) \mathrm{Cl}^{150}$ On all occasion, it was reasoned that the quenching might originate from the heavy atom effect.<smiles>CCCCN1CN(CCCC)c2c1c1ccccc1c1ccccc21</smiles>

300<smiles>CN1CN(c2ccccc2)c2ccccc21</smiles>

301<smiles>CN1CN(c2ccccc2)c2cc3c(cc21)N(C)CN3c1ccccc1</smiles>

302<smiles>CCCCN1CN(CCCC)c2cc3nc4c5ccccc5c5ccccc5c4nc3cc21</smiles>

303

Figure 20. NHC-ligands for luminescent investigations.

More recently, Ibánez, Poyatos and Peris synthesized a new $D_{3 \mathrm{~h}}$-symmetric hexaazatriphenylene-tris-Nheterocyclic carbene ligand precursor salt 304 (Scheme 102) analogous to 303. ${ }^{152}$ After deprotonation, each carbene unit was able to take up an $\{\operatorname{Ir}(\mathrm{COD}) \mathrm{Cl}\}$ motif to afford 305. Analysis of the corresponding hexacarbonylated complex (not shown) indicated reduced electron-donating character in comparison to related NHC-Ir complexes.

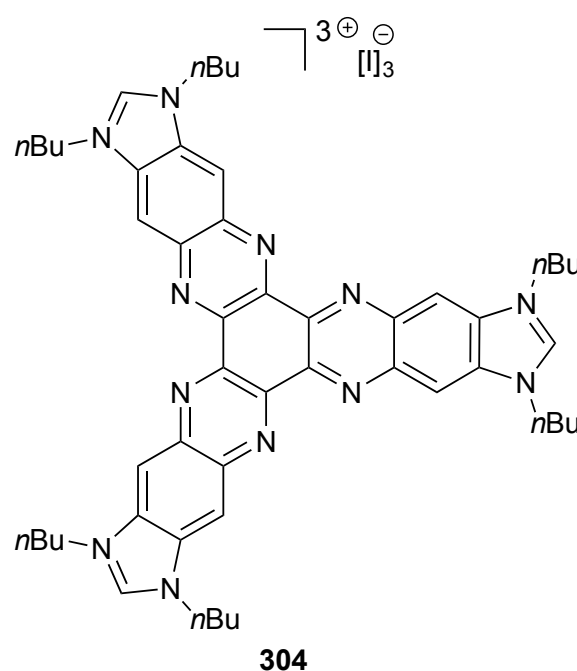

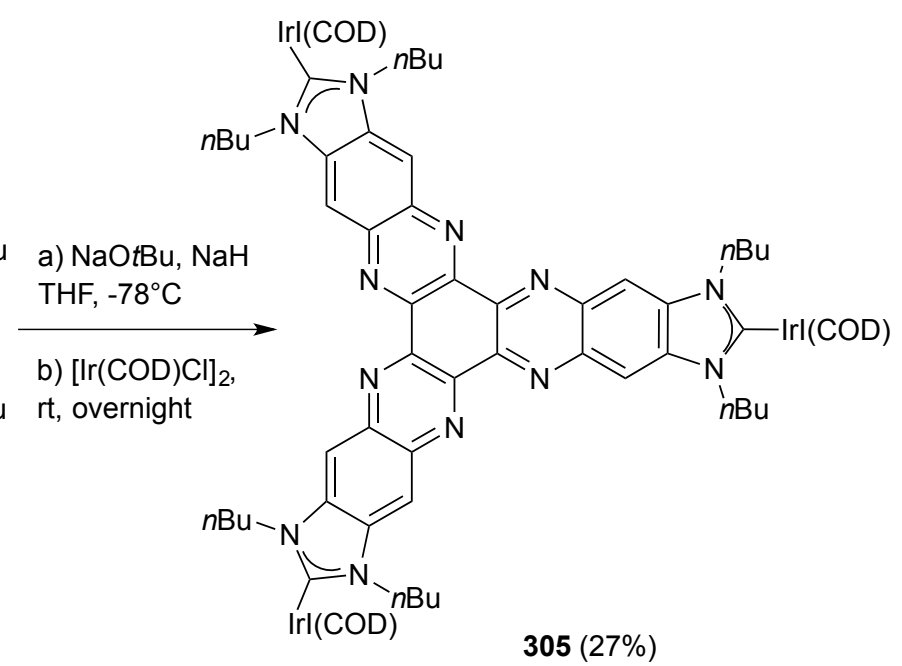

Scheme 102. Iridium complex 305, with a $\mathrm{D}_{3 \mathrm{~h}}$-symmetric carbene ligand.

A new NHC ligand family with flanking bithiophene moieties on the backbone was also prepared (Scheme 103). ${ }^{153}$ NHC-Ir monomer 306 was synthesized by the silver transmetallation method in an excellent $95 \%$ yield and was further converted to carbonyl derivate 307. Next, $\mathbf{3 0 8}$ and $\mathbf{3 0 9}$ were obtained as thin films by electropolymerization of their thiophene backbones. Electrochromic properties of these complexes were dependent on the incorporated metallic moiety. ${ }^{153 \mathrm{~b}}$ 

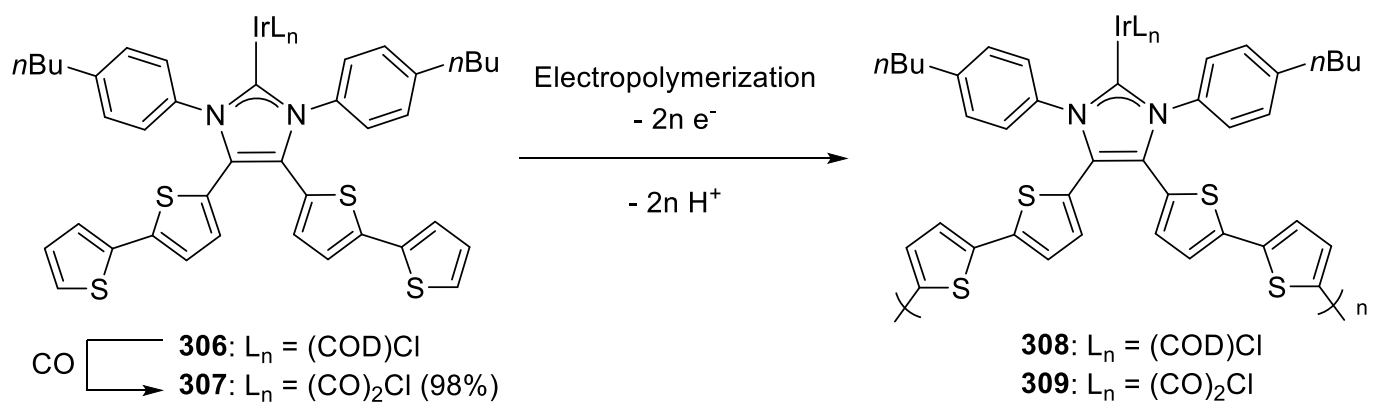

Scheme 103. Electropolymerization of $\mathbf{3 0 6}$ and $\mathbf{3 0 7}$.

An interesting approach towards modulating catalytic activity and selectivity was published by the Bielawski group. ${ }^{154} \mathrm{~N}$-heterocyclic carbene ligands with an incorporated photochromic diarylethene moiety went through reversible photocyclization upon irradiaton (Scheme 104). The higher average CO stretching frequencies in 311 (by $7 \mathrm{~cm}^{-1}$ compared to 310) indicated significant decrease in electron donation towards the metal. Applicability of such a photoswitchable catalyst was demonstrated in the NHC organocatalyzed transesterification and transamidation reactions. ${ }^{155}$
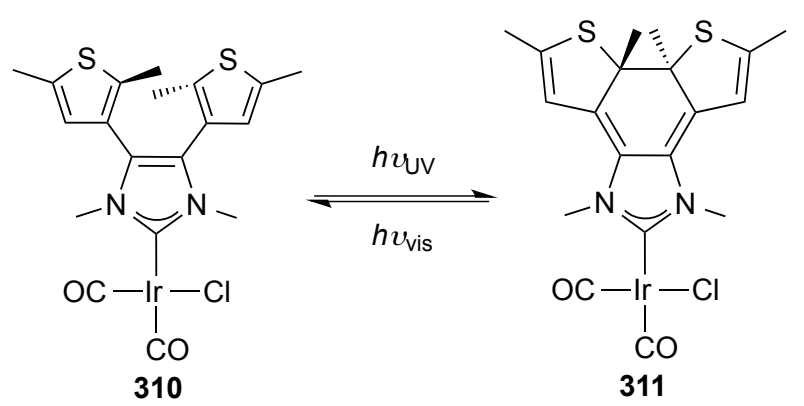

Scheme 104. Light induced backbone cyclization.

The BODIPY-tagged NHC salt $\mathbf{3 1 2} \cdot \mathbf{H I}$ was applied for the synthesis of carbon monoxide chemodosimeters by Kos and Plenio. ${ }^{156}$ Complexes $(\mathbf{3 1 2}) \mathrm{M}(\mathrm{COD}) \mathrm{X}(\mathrm{M}=\mathrm{Rh}$, Ir; $\mathrm{X}=\mathrm{Cl}$, I) featured strongly quenched fluorescent properties. In contrast, reaction with $\mathrm{CO}$ immediately led to the formation of highly fluorescent (312) $\mathrm{M}(\mathrm{CO})_{2} \mathrm{X}$, where the fluorescence quantum yields were approximately the same for the iodo and chloro complexes. In particular, (312) $\operatorname{Ir}(\mathrm{COD}) \mathrm{Cl}$ showed immediate response to the presence of substoichiometric amounts of $\mathrm{CO}$, demonstrating the potential applicability of these complexes as fluorescent probes for $\mathrm{CO}$ detection. Furthermore, exposure of $(\mathbf{3 1 2}) \operatorname{Ir}(\mathrm{COD}) \mathrm{Cl}$ to atmospheric air containing small amounts of $\mathrm{CO}$ led to the same response, however with significantly lower reaction rates. The authors reasoned that fluorescent quenching in (312) $\mathrm{M}(\mathrm{COD}) \mathrm{X}$ complexes likely originates from a change in electron density at the metal and not from heavy-atom effects.

More recently, the scope of bodipy-tagged NHC-Ir complexes for CO detection was extended with further examples. ${ }^{157}$ In these (NHC) $\operatorname{Ir}(\mathrm{COD}) \mathrm{X}$ complexes the $\mathrm{X}=\mathrm{Cl}$ ligand was replaced by electron-rich thiolate $\mathrm{RC}_{6} \mathrm{H}_{4} \mathrm{~S}$. A fluorescence gain (defined as a ratio of fluorescence intensities of the complexes) was observed upon conversion of $(\mathrm{NHC}) \operatorname{Ir}(\mathrm{COD}) \mathrm{X}$ to $(\mathrm{NHC}) \operatorname{Ir}(\mathrm{CO})_{2} \mathrm{X}$. While this gain was equal to 5 for $\mathrm{X}=\mathrm{Cl}$, an excellent gain of 26 for $\mathrm{X}=p-\mathrm{NO}_{2} \mathrm{C}_{6} \mathrm{H}_{4} \mathrm{~S}$ was measured. 
NHC ligand 313 was incorporated into Crabtree-type hydrogenation catalysts $[(313) \operatorname{Ir}(\mathrm{COD})(\mathrm{py})][\mathrm{X}](\mathrm{X}=$ OTf, $\left.\mathrm{BAr}_{4}^{f}\right) .{ }^{158}$ Similar to their previous study, these NHC-Ir(COD) complexes were weakly flourescent. On the other hand, upon reaction with dihydrogen in the presence of pyridine, NHC complexes of the type $\left[(\mathbf{3 1 3}) \operatorname{Ir}(\mathrm{H})_{2}(\mathrm{py})_{3}\right][\mathrm{X}]$ were formed and showed strongly fluorescent properties. A filter paper impregnated with a solution of $[(\mathbf{3 1 3}) \operatorname{Ir}(\mathrm{COD})(\mathrm{py})][\mathrm{OTf}]$ was suitable for dihydrogen detection at 4 vol\% concentration. Furthermore, it was demonstrated that these molecular probes are capable of operating during olefin hydrogenation catalysis (vide infra).
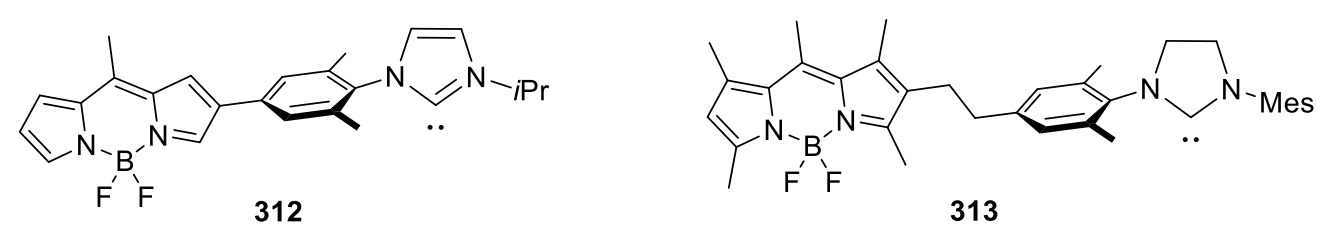

Figure 21. Bodipy-tagged NHCs for $\mathrm{CO}(\mathbf{3 1 2})$ and $\mathrm{H}_{2}(\mathbf{3 1 3})$ detection.

A series of luminescent iridium(III) complexes featuring tetradentate trianionic ligands were prepared by Che et al. ${ }^{159}$ The luminescent properties of such complexes were strongly affected by the ligands (N, P or C donors) in the axial positions, and the best performance was achieved with NHC ligands. Compound 314a, which had the highest emission quantum yield in thin film, was incorporated into an OLED. Interestingly, in solution complex 314 goes through slow dimerization to afford compound 315 (Scheme 105).

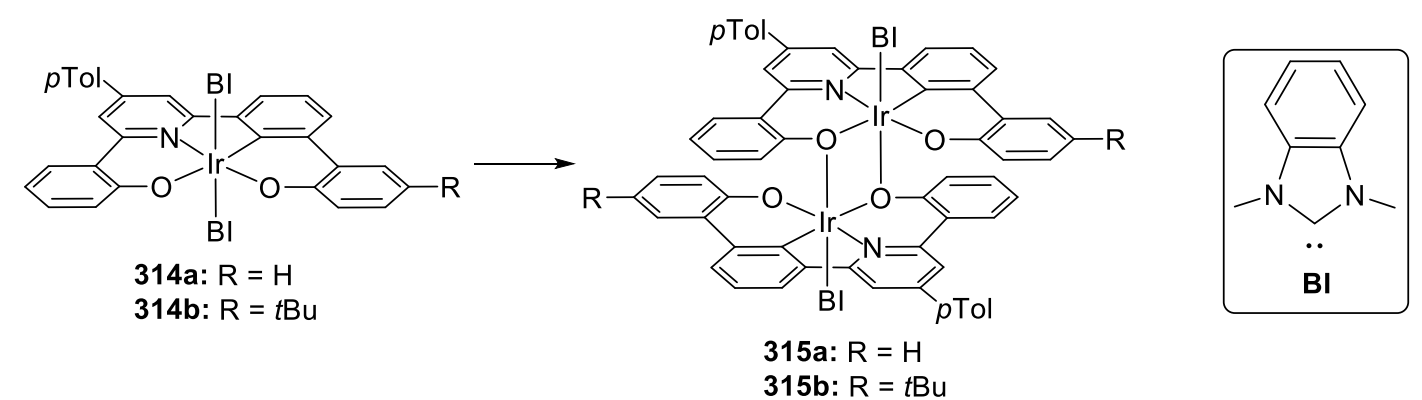

Scheme 105. Dimerization of luminescent iridium(III) complexes 314.

\section{Non-enantioselective NHC-iridium catalysis}

As outlined in the introduction, the application of NHCs as ancillary ligands in transition metal catalysis was launched by Herrmann's group, ${ }^{7}$ shortly after Arduengo's discovery of a stable free NHC. ${ }^{6}$ In this first article on the use of NHC-M catalysts, Herrmann et al. described results on NHC-Pd catalyzed Heck reactions, where they saw that monodentate (and chelating) NHC ligands can not only bind to palladium to give $(\mathrm{NHC})_{2} \mathrm{PdI}_{2}$ precatalysts, but that the resulting species showed unusually high reactivity and robustness during catalysis. This report set the stage to remarkable and extremely rapid developments within this research field with the most prominent examples coming from developments in NHC-Ru catalysis for olefin metathesis and the discovery of various cross-coupling catalysts incorporating NHC ligands. ${ }^{12}$ The chapter that follows shows how these new monodentate ancillary ligands have been applied in various fields of NHC-Ir catalysis and how both improved and new reactivity is starting to emerge. 


\subsection{Hydrogenation with dihydrogen}

We already mentioned Crabtree's catalyst in the introduction as being one of the most well-known iridium catalysts. $\left[\left(\mathrm{PCy}_{3}\right) \operatorname{Ir}(\mathrm{COD})(\mathrm{py})\right]\left[\mathrm{PF}_{6}\right](316)$ is effective for the hydrogenation of simple alkenes and is, in particular, productive in the hydrogenation of hindered substrates (e.g. 1-methyl-1-cyclohexene, 2,3dimethyl-2-butene) where the rhodium-based Wilkinson's catalyst or the Schrock-Osborn catalyst fail. ${ }^{8,160}$ Catalyst $\mathbf{3 1 6}$ is reactive and robust at room temperature, however it suffers from thermal instability.

When it became clear that NHCs might be able to replace phosphine ligands, homogeneous hydrogenation catalysts based on rhodium and iridium were of the first systems to be targeted. In their seminal work, Nolan and coworkers exchanged $\mathrm{PCy}_{3}$ with various NHC ligands and employed these cationic NHC-Ir complexes for the hydrogenation of alkenes. When comparing reactivity to Crabtree's catalyst, $[(\mathrm{SIMes}) \operatorname{Ir}(\mathrm{COD})(\mathrm{py})]\left[\mathrm{PF}_{6}\right]$ (23a) showed lesser activity at room temperature and at atmospheric pressure. On the other hand, due to the improved thermal stability of 23a, the NHC-Ir analogue displayed higher reactivity under mild pressure at $50^{\circ} \mathrm{C}$ (Table 1$) .^{41 \mathrm{a}}$

Table 1. Hydrogenation with Crabtree's catalyst (316) and Nolan's 23a.

\begin{tabular}{|c|c|c|c|c|c|c|}
\hline subs. & cat. formula & cat. & time / h & $\mathrm{T} /{ }^{\circ} \mathrm{C}$ & $\mathrm{H}_{2} / \mathrm{atm}$ & yield / \% \\
\hline & {$\left[\left(\mathrm{PCy}_{3}\right) \operatorname{Ir}(\mathrm{COD})(\mathrm{py})\right]\left[\mathrm{PF}_{6}\right]$} & 316 & $<0.5$ & 25 & 1 & 100 \\
\hline & {$[($ SIMes $) \operatorname{Ir}(\mathrm{COD})(\mathrm{py})]\left[\mathrm{PF}_{6}\right]$} & $23 a$ & 2 & 25 & 1 & 100 \\
\hline & & 316 & 28 & 25 & 1 & 77 \\
\hline & & 316 & 7 & 50 & 4 & 34 \\
\hline & & $23 a$ & 16 & 25 & 1 & 44 \\
\hline & & $23 a$ & 7 & 50 & 4 & 100 \\
\hline
\end{tabular}

Conditions: olefin (1 mmol), cat $(0.01 \mathrm{mmol}), \mathrm{CH}_{2} \mathrm{Cl}_{2}$.

Buriak et al. took a different approach by replacing the pyridine ligand with an NHC and leaving the trialkylphosphine ligand intact. ${ }^{74,161}$ Some of these cationic $\left[(\mathrm{NHC}) \operatorname{Ir}(\mathrm{COD})\left(\mathrm{PR}_{3}\right)\right]\left[\mathrm{PF}_{6}\right]$ complexes showed comparable activity to Crabtree's catalyst when mono-, di-, tri-, and tetra-substituted olefins were subjected to their standard hydrogenation conditions (Table 2). For the hydrogenation of 1-octene and cyclohexene, [(IMes) $\left.\operatorname{Ir}(\mathrm{COD})\left\{\mathrm{P}(n \mathrm{Bu})_{3}\right\}\right]\left[\mathrm{PF}_{6}\right](\mathbf{6 8})$ featuring a bulky NHC ligand and a relatively small trialkylphosphine proved to be the best alternative to Crabtree's catalyst. In contrast, for more hindered substrates, better results were obtained with a catalyst incorporating a smaller NHC ligand, [(IMe) $\left.\operatorname{Ir}(\mathrm{COD})\left\{\mathrm{P}(n \mathrm{Bu})_{3}\right\}\right]\left[\mathrm{PF}_{6}\right](\mathbf{6 7 c})$. Complexes with saturated NHCs, e.g. [(SIMes) $\left.\operatorname{Ir}(\mathrm{COD})\left\{\mathrm{P}(n \mathrm{Bu})_{3}\right\}\right]\left[\mathrm{PF}_{6}\right](\mathbf{3 1 7})$, showed similar reaction rates, but improved stability providing the opportunity for catalyst recycling. Significant improvement in reactivity was achieved by switching the counteranion from $\mathrm{PF}_{6}$ to $\mathrm{BAr}_{4}^{f}$, as seen in $\left[\left(\mathrm{PCy}_{3}\right) \operatorname{Ir}(\mathrm{COD})(\mathrm{py})\right]\left[\mathrm{BAr}_{4}{ }_{4}\right]$ (318) and $\left[(\mathrm{NHC}) \operatorname{Ir}(\mathrm{COD})\left(\mathrm{PR}_{3}\right)\right]\left[\mathrm{BAr}_{4}{ }_{4}\right]$ complexes. From the latter type $\left[(\mathrm{IMe}) \operatorname{Ir}(\mathrm{COD})\left\{\mathrm{P}(n \mathrm{Bu})_{3}\right\}\right]\left[\mathrm{BAr}_{4}{ }_{4}\right](\mathbf{3 1 9})$ proved to be the most efficient, although reaction rates were lower than those of $\mathbf{3 1 8}$.

Table 2. Hydrogenations with Buriak's complexes. 


\begin{tabular}{|c|c|c|c|c|c|}
\hline subs. & cat. formula & cat. / mol $\%$ & time / min & yield / \% & rate \\
\hline & {$\left[\left(\mathrm{PCy}_{3}\right) \operatorname{lr}(\mathrm{COD})(\mathrm{py})\right]\left[\mathrm{PF}_{6}\right]$} & $316(0.1)$ & 36 & 99 & 2290 \\
\hline & {$\left[(\mathrm{IMes}) \operatorname{Ir}(\mathrm{COD})\left\{\mathrm{P}(n \mathrm{Bu})_{3}\right\}\right]\left[\mathrm{PF}_{6}\right]$} & $68(0.1)$ & 75 & 100 & 1963 \\
\hline & {$\left[(\mathrm{IMe}) \operatorname{Ir}(\mathrm{COD})\left\{\mathrm{P}(n \mathrm{Bu})_{3}\right\}\right]\left[\mathrm{PF}_{6}\right]$} & $67 c(0.1)$ & 100 & $>99$ & 1168 \\
\hline & {$\left[(\mathrm{SIMes}) \operatorname{Ir}(\mathrm{COD})\left\{\mathrm{P}(n \mathrm{Bu})_{3}\right\}\right]\left[\mathrm{PF}_{6}\right]$} & $317(0.1)$ & 190 & 100 & 964 \\
\hline & {$\left[\left(\mathrm{PCy}_{3}\right) \operatorname{Ir}(\mathrm{COD})(\mathrm{py})\right]\left[\mathrm{BAr}_{4}{ }_{4}\right]$} & $318(0.1)$ & 26 & 100 & 3398 \\
\hline & {$\left[(\mathrm{IMe}) \operatorname{Ir}(\mathrm{COD})\left\{\mathrm{P}(n \mathrm{Bu})_{3}\right\}\right]\left[\mathrm{BAr}_{4}{ }_{4}\right]$} & $319(0.1)$ & 47 & 100 & 1602 \\
\hline & & $316(0.1)$ & 60 & 70 & 1496 \\
\hline & & $68(1)$ & 180 & 100 & 43 \\
\hline & & $67 c(0.1)$ & 130 & 71 & 649 \\
\hline & & $317(1)$ & 121 & 100 & 60 \\
\hline & & $318(0.1)$ & 60 & 78 & 1396 \\
\hline & & $319(0.1)$ & 86 & 100 & 850 \\
\hline & & $319(0.01)$ & 400 & $>90$ & n.d. \\
\hline & & $316(0.1)$ & 50 & 49 & 1057 \\
\hline & & $68(1)$ & 220 & 19 & 30 \\
\hline & & $67 \mathrm{c}(0.1)$ & 30 & 5 & 70 \\
\hline & & 317 (1) & 240 & 8 & 2 \\
\hline & & $318(0.1)$ & 65 & 51 & 788 \\
\hline & & $319(0.1)$ & 120 & 100 & 493 \\
\hline
\end{tabular}

Conditions: $\mathrm{CH}_{2} \mathrm{Cl}_{2}, 25^{\circ} \mathrm{C}, 1$ atm $\mathrm{H}_{2}$. rate $=(\mathrm{mol}$ substrate reduced $)(\mathrm{mol} \text { of catalyst })^{-1} \mathrm{~h}^{-1}$

Bennie et al. showed that $\left[(\mathrm{IMes}) \operatorname{Ir}(\mathrm{COD})\left(\mathrm{PBn}_{3}\right)\right]\left[\mathrm{PF}_{6}\right](\mathbf{3 2 0})$ is a potent catalyst in the reduction of $\alpha, \beta-$ unsaturated ketones (Scheme 106). This complex was also active in the hydrogenation of 4-bromostyrene and an internal alkyne. However, it failed to hydrogenate sterically encumbered substrates, such as 1-methyl1-cyclohexene and 2,3-dimethyl-2-butene. ${ }^{162}$ In 2016, Kerr et al. developed [(IMes) $\left.\operatorname{Ir}(\mathrm{COD})\left(\mathrm{PMe}_{2} \mathrm{Ph}\right)\right]\left[\mathrm{BAr}_{4}^{f}\right](\mathbf{3 2 1})$, which was capable of hydrogenating a variety of electron-poor olefins in enones, including $\alpha$ - and $\beta$-disubstituted enones (Scheme 107). Substrates with a wide range of oxygen containing directing groups (e.g. $\mathrm{OCO}_{2} \mathrm{Me}, \mathrm{CO}_{2} \mathrm{R}, \mathrm{C}(\mathrm{O}) \mathrm{NEt}_{2}, \mathrm{NO}_{2}$ ) were reduced by 321 with good efficiency. The catalyst system tolerated a large range of solvents. Together with a judicious choice of the directing group used, the authors showed that chemoselective hydrogenation of these $\alpha, \beta$-unsaturated ketones/amides over simple stilbene can be achieved. ${ }^{163}$

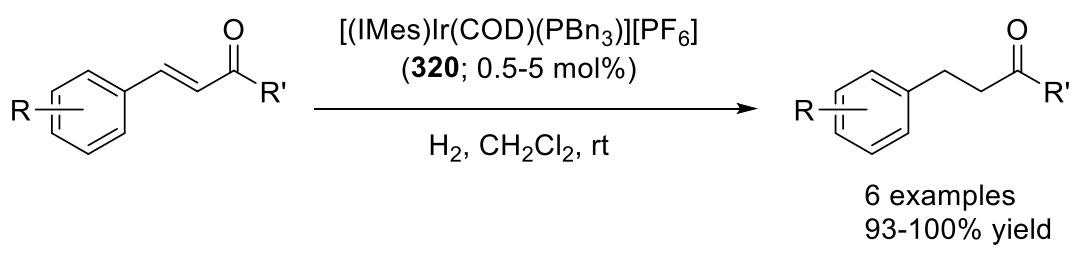

Scheme 106. Hydrogenation of enones with [(IMes) $\left.\operatorname{Ir}(\mathrm{COD})\left(\mathrm{PBn}_{3}\right)\right]\left[\mathrm{PF}_{6}\right](\mathbf{3 2 0})$. 


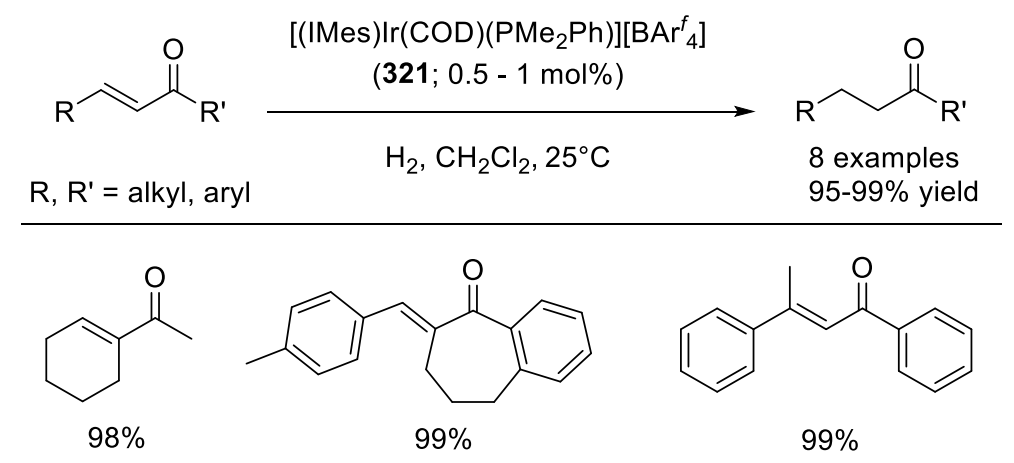

Scheme 107. Hydrogenation of enones with [(IMes) $\left.\operatorname{Ir}(\mathrm{COD})\left(\mathrm{PMe}_{2} \mathrm{Ph}\right)\right]\left[\mathrm{BAr}{ }_{4}\right](\mathbf{3 2 1})$.

Neutral (IMe) $\operatorname{Ir}(\mathrm{COD}) \mathrm{Cl}(\mathbf{2 1})$ and (IMe) $\operatorname{Ir}(\mathrm{COD}) \mathrm{I}(\mathbf{6 6})$ showed moderate activity in the hydrogenation and isomerization of 1-octene. The iodo complex $\mathbf{6 6}$ showed low selectivity in the hydrogenation of 1-octene. In contrast, full conversion to octane was reached within four hours using the chloro complex $21{ }^{161}$

In other studies, [(IMes)Ir(COD)Cl] (22g) and [(IMes) $\left.\operatorname{Ir}(\mathrm{COD})\left(\mathrm{OSiMe}_{3}\right)\right]$ were shown to be competent catalysts in the hydrogenation of cyclooctene and stilbene. ${ }^{58}$ Plenio's bodipy-tagged NHC ligand was employed with iridium $\left\{[(\mathbf{3 1 3}) \operatorname{Ir}(\mathrm{COD})][\mathrm{X}]\left(\mathrm{X}=\mathrm{OTf}, \mathrm{BAr}_{4}^{f}\right)\right\}$ for the hydrogenation of allylbenzene, styrene, cyclohexene and $\alpha$-terpinene. ${ }^{158}$ Complexes 322-324 with a phenanthroline-derived NHC ligand (Scheme 108) showed moderate activity in the hydrogenation of 2-acetamidoacrylate. ${ }^{164}$

$$
\mathrm{MeO}_{2} \mathrm{C} \prod^{\mathrm{NHAc}} \stackrel{[\mathrm{Ir}](\mathrm{mol} \%), \mathrm{H}_{2}(\mathrm{bar})}{\underset{\mathrm{CH}_{2} \mathrm{Cl}_{2}, \mathrm{rt}, 72 \mathrm{~h}}{\longrightarrow}} \mathrm{MeO}_{2} \mathrm{C} Y^{\mathrm{NHAc}}
$$

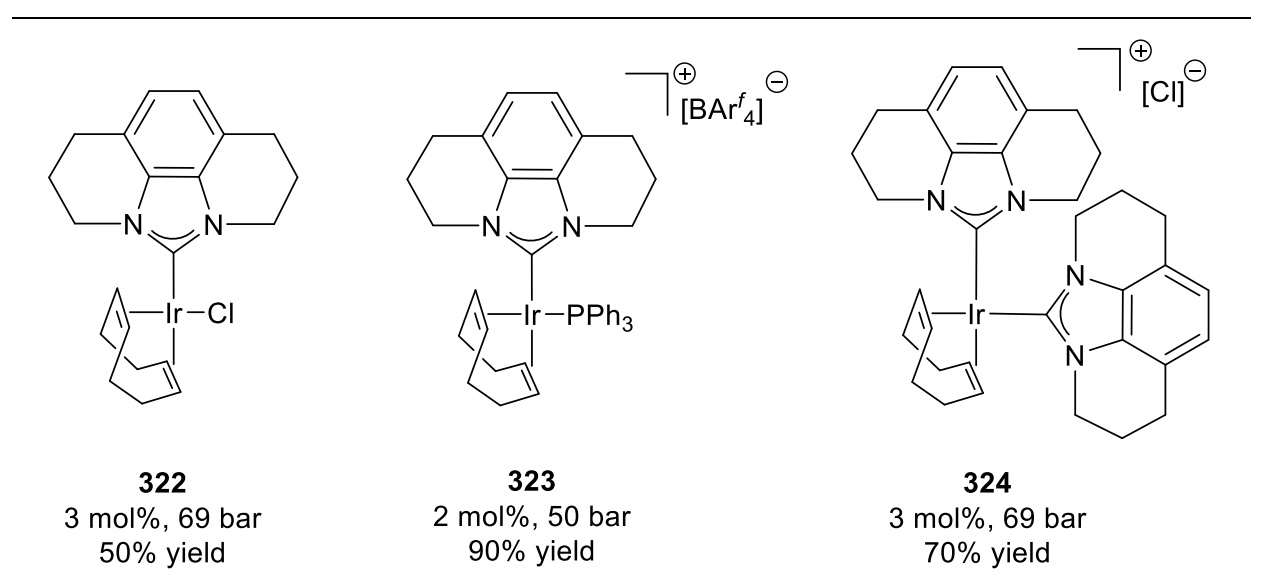

Scheme 108. Hydrogenation of 2-acetamidoacrylate.

In a study on the utility of expanded ring NHC structures, complexes of NHC-iridium such as $\mathbf{3 2 5}$ were synthesized and evaluated in hydrogenation catalysis. ${ }^{137,165}$ Non-hindered alkenes were reduced with good efficiency, but lower conversions were observed for internal olefins (Scheme 109). Reduction of 1-methyl-1cyclohexene and trans-stilbene failed under the reaction conditions used (room temperature and $0.01 \mathrm{~mol} \%$ of 325). 


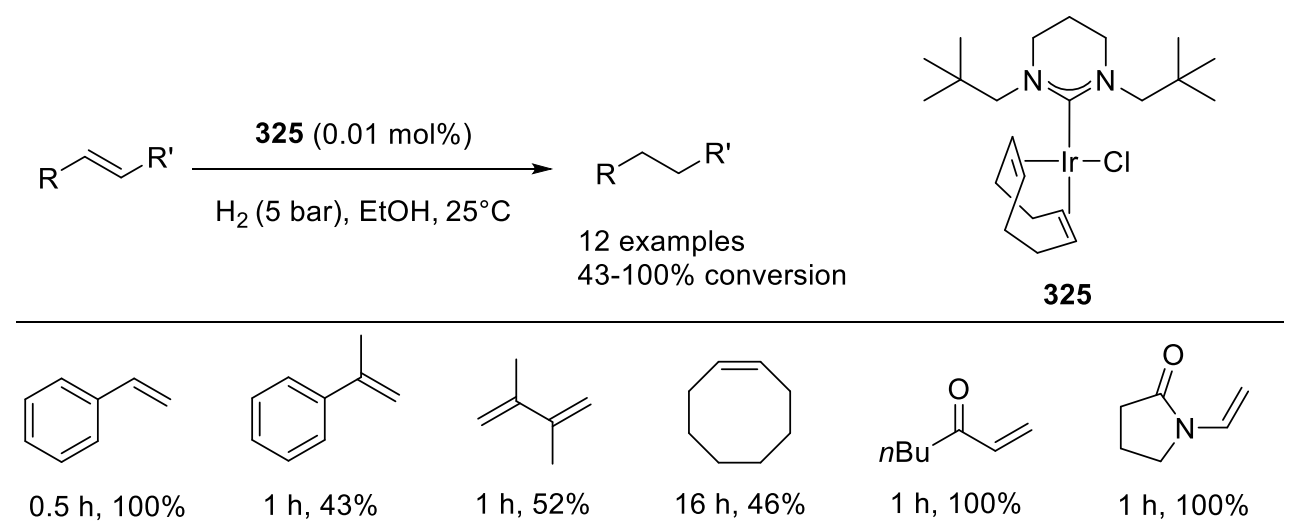

Scheme 109. Expanded ring NHCs in hydrogenations.

Earlier, we mentioned the stoichiometric reactivity of $\mathbf{1 0 4 b}$ towards dihydrogen (Scheme 44$).{ }^{17}$ This complex, when applied as a catalyst, showed excellent performance in the hydrogenation of simple alkenes. For example, an impressive TOF of $42,545 \mathrm{~h}^{-1}$ was measured for 1-octene and even the challenging 2,3dimethyl-2-butene was rapidly $(30 \mathrm{~min})$ hydrogenated at $70^{\circ} \mathrm{C}$ with $0.1 \mathrm{~mol} \%$ [ Ir] in cyclohexane. Neat alkenes were converted to the corresponding alkanes at 8 bar $\mathrm{H}_{2}$ pressure and at 0.01 or $0.1 \mathrm{~mol} \%$ catalyst loading (Scheme 110). Full conversion of cyclooctene was achieved at $10 \mathrm{ppm}$ [Ir]. Finally, hydrogenation of 4-terpinol in cyclohexane took place with excellent diastereoselectivity ( $>99: 1$ in cyclohexane solvent, 96:4 in neat alkene).

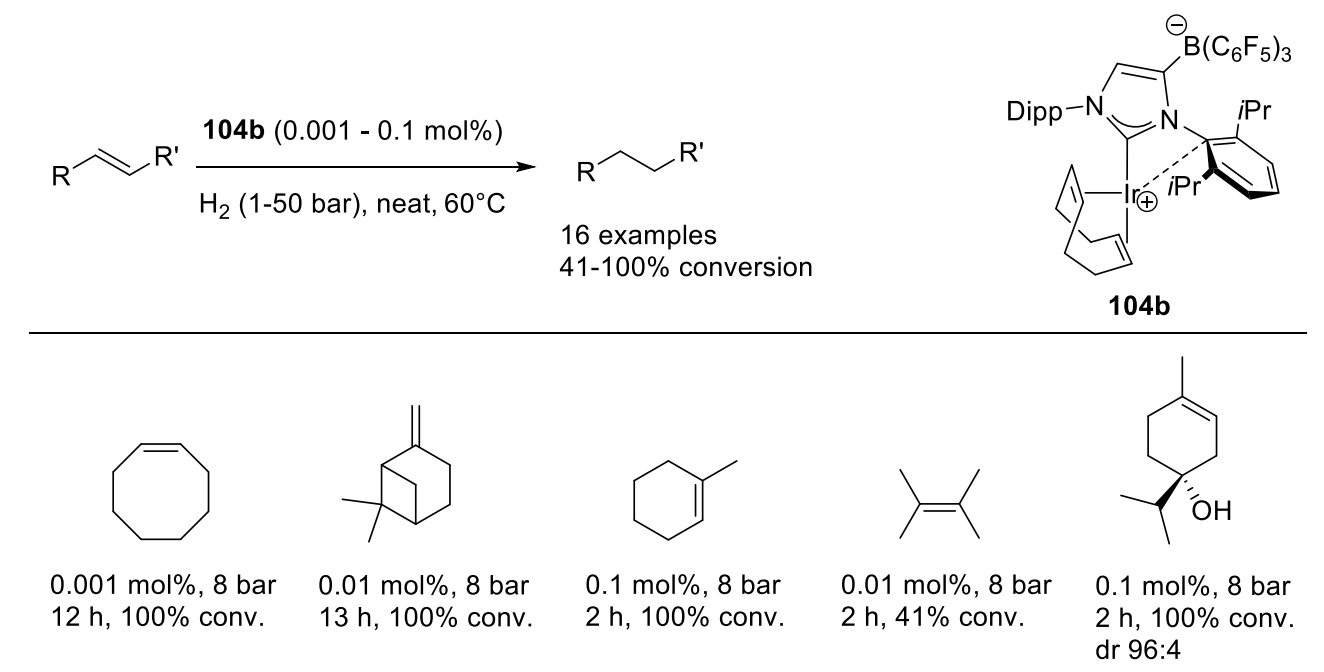

Scheme 110. Selected examples of hydrogenation catalyzed by $\mathbf{1 0 4 b .}$

A recent contribution from Lacôte, Thieuleux and coworkers introduced well-defined, single-site NHC-Ir(I) based hybrid catalysts which were then tested in the heterogeneous hydrogenation of styrenes, stilbene and limonene. ${ }^{166}$ Hydrogenation of trans-stilbene catalyzed by the hybrid precatalyst $\mathbf{3 2 6}$ reached full conversion after 18 hours at $0.1 \mathrm{~mol} \%$ [ Ir] loading under 3 bar $\mathrm{H}_{2}$ pressure at $40{ }^{\circ} \mathrm{C}$ in toluene (Table 3). Efficiency of the hybrid material proved to be significantly superior compared to that of its homogeneous counterpart $\mathbf{3 2 7}$ and of a cationic species generated in situ from 327 and $\mathrm{AgBF}_{4}$.

Table 3. Iridium-NHC hybrid material for the hydrogenation of trans-stilbene. 


\begin{tabular}{|c|c|c|}
\hline$\leadsto \mathrm{Ph} \frac{\mathrm{H}_{2}}{\text { tolu }}$ & $\underset{\text { bar), } 40^{\circ} \mathrm{C}}{\stackrel{\text { br] }}{\longrightarrow}}$ & \\
\hline cat. / mol\% & time & conv. $/ \%$ \\
\hline $326(0.1)$ & $18 \mathrm{~h}$ & 100 \\
\hline $326(0.01)$ & 25 days & 80 \\
\hline $327(0.1)$ & 80 days & ca. 80 \\
\hline $327+\mathrm{AgBF}_{4}(0.1)$ & 60 days & ca. 90 \\
\hline
\end{tabular}
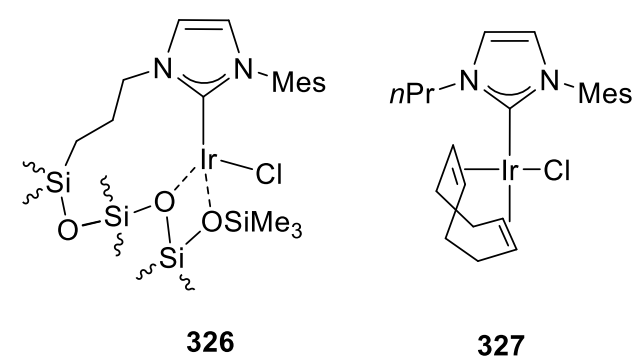

$\mathrm{Tu}$ and coworkers realized a highly efficient hydrogenation of oxoacids (such as levulinic acid) to lactones using NHC-iridium coordination polymers as solid molecular catalysts. ${ }^{167}$ Another approach to rendering these iridium catalyzed hydrogenation runs more practical saw the development of a series of water-soluble mixed NHC-iridium phosphine complexes (Figure 22). When using complex $\mathbf{3 2 8}$ as the precatalyst, $\mathrm{C}=\mathrm{C}$ and $\mathrm{C}=\mathrm{O}$ bonds of unsaturated aliphatic acids were hydrogenated using water as the reaction medium. Substrates with highly substituted $\mathrm{C}=\mathrm{C}$ bonds such as methylmaleic and methylfumaric acid, were also susceptible to reduction (Table 4). ${ }^{168}$ This paper follows earlier work where in a single entry, acetophenone was hydrogenated by a water-soluble NHC-Ir complex with low efficiency. ${ }^{169}$

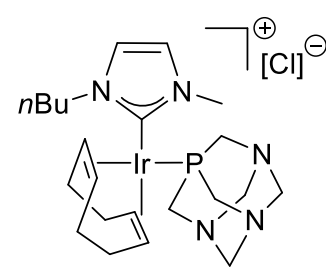

328

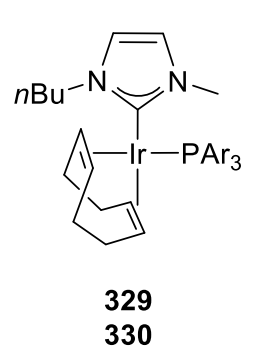

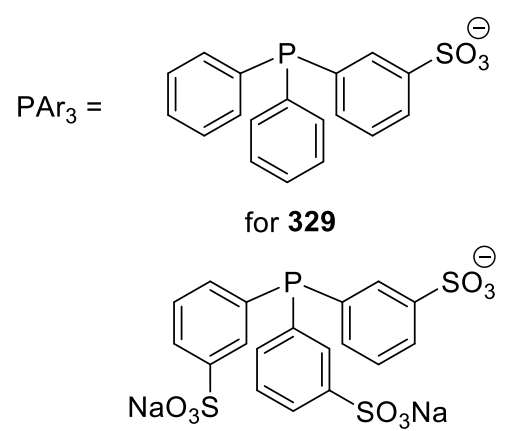

for 330

Figure 22. Water-soluble iridium-NHC complexes 328-330.

Table 4. Hydrogenation of unsaturated acids by catalyst $\mathbf{3 2 8}$.

\begin{tabular}{lllll}
\hline substrate & $\mathbf{3 2 8} / \mathbf{m o l} \%$ & time $/ \mathrm{h}$ & conv $/ \%$ & TOF $/ \mathrm{h}^{-1}$ \\
\hline itaconic acid & 3.3 & 1.5 & 100 & 20 \\
Na-pyruvate & 2 & 1 & 60 & 30 \\
methylmaleic acid & 2 & 1 & 31 & 15 \\
methylfumaric acid & 4 & 1 & 39 & 10 \\
K-sorbate $^{\text {a }}$ & 4 & 6.5 & 100 & 7.7 \\
\hline
\end{tabular}

Conditions: $\mathrm{H}_{2} \mathrm{O}, \mathrm{H}_{2}$ (0.8 bar). ${ }^{a}$ Both $\mathrm{C}=\mathrm{C}$ double bonds were hydrogenated.

In an interesting recent contribution by Crabtree et al., six NHC-iridium phosphine complexes were screened and shown to catalyze quinoline hydrogenations under mild conditions. Precatalyst 331, in combination with triphenyl phosphine, proved to be the optimal system. Several quinolines were hydrogenated at 1 atm $\mathrm{H}_{2}$ pressure at $35^{\circ} \mathrm{C}$ in toluene (Scheme 111). Interestingly, less hindered substrates required higher pressures of dihydrogen for high conversion to occur. Mechanistic studies revealed that the additional amount of triphenyl phosphine is required to generate the catalytically active species. Intermediates in the catalytic 
cycle were either isolated $(\mathbf{3 3 2}, \mathbf{3 3 3})$ or spectroscopically characterized $(\mathbf{1 5})$, giving a detailed picture of the overall reaction mechanism. As can be seen, the reaction seems to proceed via a stepwise outer-sphere mechanism (Scheme 112). ${ }^{28}$ More recently, Crabtree's group showed that the same catalyst is able to dehydrogenate the tetrahydroquinoline product. ${ }^{170}$
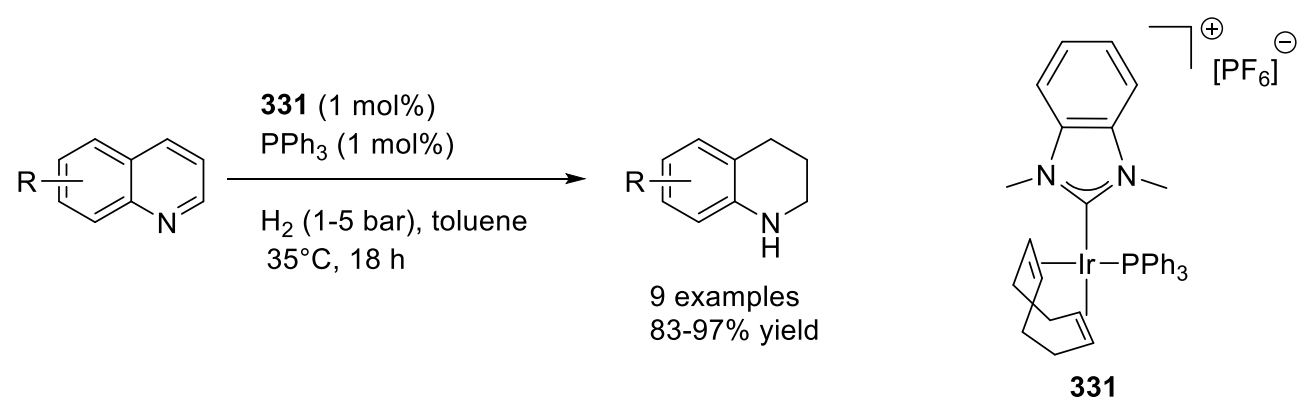

Scheme 111. Quinoline hydrogenation with 331.
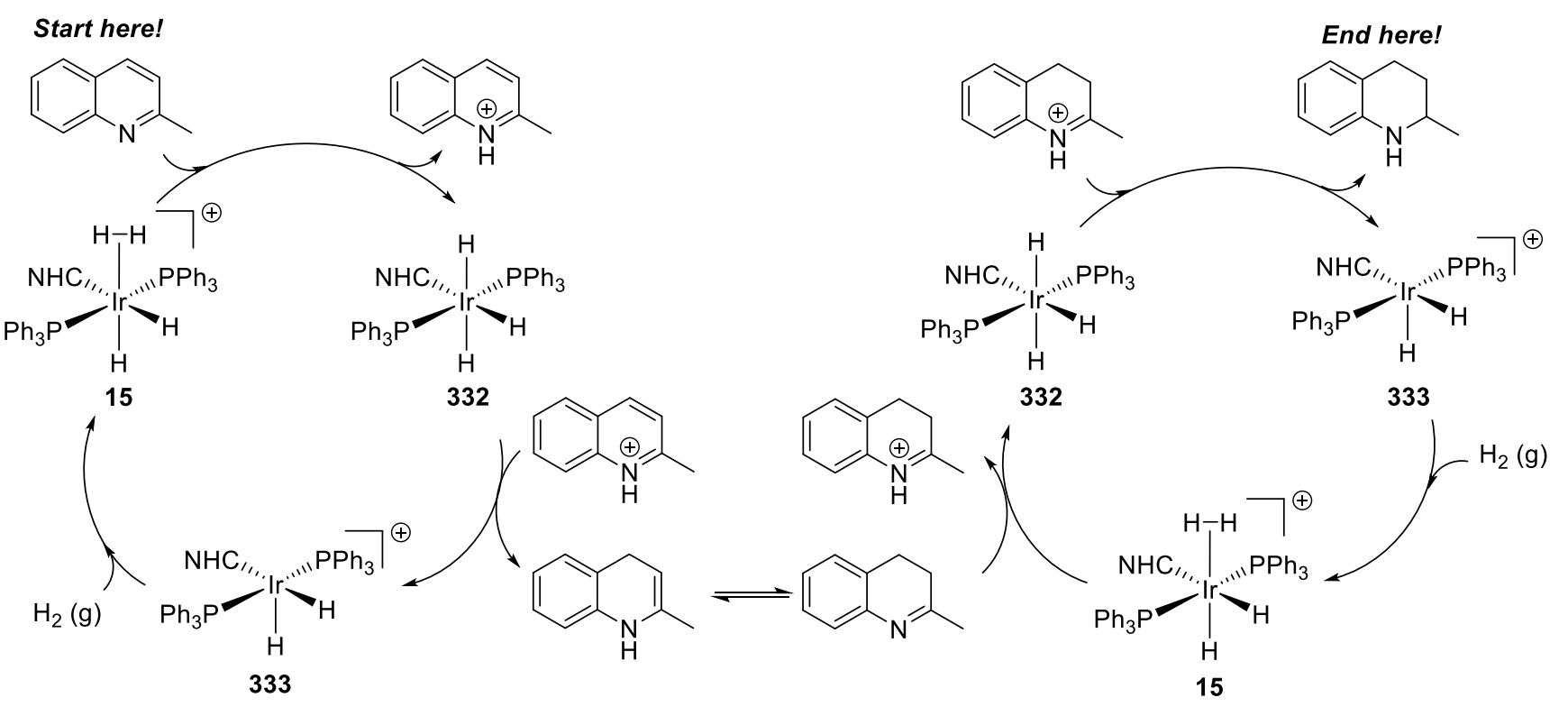

Scheme 112. Stepwise outer-sphere mechanism for the hydrogenation of quinolines.

\subsection{Transfer hydrogenation}

Transfer hydrogenation (TH) with NHC-Ir catalysts was first reported by Nolan and coworkers during their investigation on the use of $[(\mathrm{NHC}) \operatorname{Ir}(\mathrm{COD})(\mathrm{py})]\left[\mathrm{PF}_{6}\right]\{\mathrm{NHC}=$ SIMes (23a), IMes (23b), IPr (23c), ICy (23d) $\}$ complexes as catalysts. ${ }^{41 \mathrm{~b}}$ These complexes generally showed higher activity than Crabtree's catalyst and complexes with diazabutadiene ligands. Compound 23d was found to be the optimal catalyst. Using this complex, a variety of simple ketones and olefins were reduced efficiently in an $i \mathrm{PrOH} / \mathrm{KOH}$ mixture (Scheme 113). The reduction of diolefins was only partially achieved and while moderate reactivity was shown for the reduction of 2,6-dimethylnitrobenzene, no reactivity was observed for the $\mathrm{TH}$ of imines, nitriles and acetylenes. 


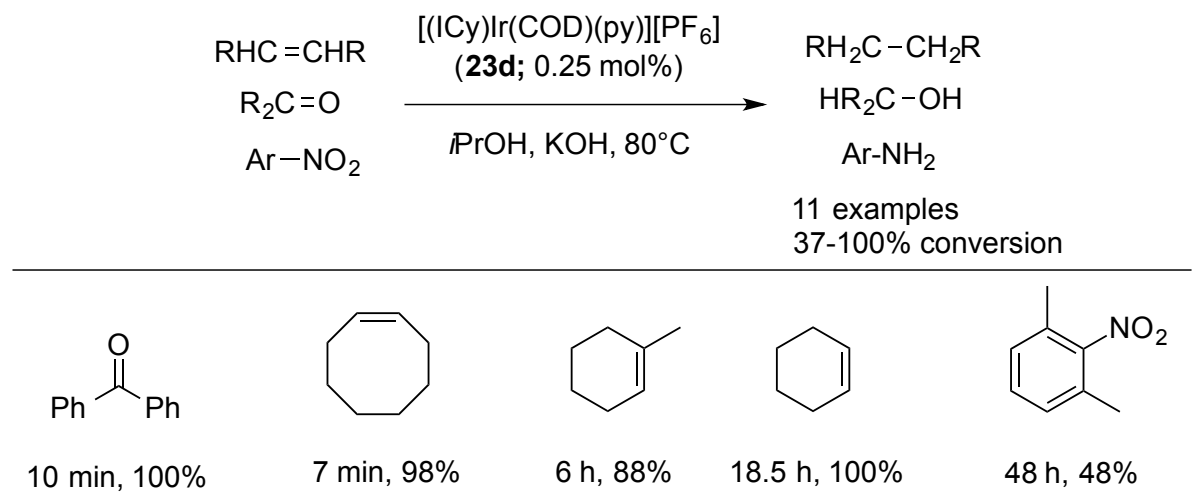

Scheme 113. Selected examples for transfer hydrogenations with $[(\mathrm{ICy}) \operatorname{Ir}(\mathrm{COD})(\mathrm{py})]\left[\mathrm{PF}_{6}\right](\mathbf{2 3 d})$.

In more recent research and again using $i \mathrm{PrOH}$ as the hydrogen source and $\mathrm{KOH}$ as the base, complexes 247 and 248 (Scheme 87) were tested in the transfer hydrogenation reaction of cyclohexanone to cyclohexanol. ${ }^{112 a}$ Neutral, monodentate as well as cationic, chelating pyridinyl-NHC complexes of iridium(I) displayed catalytic activity for the TH of carbonyl and nitro functionalities. ${ }^{119}$ Other studies probing catalytic activities in TH include the donor-functionalized NHC complex 277d (Scheme 94), which showed excellent performance in the TH of acetophenone, ${ }^{123}$ electronically tuned NHC complexes of iridium(I), ${ }^{138}$ and the siloxide substituted (IMes) $\operatorname{Ir}(\mathrm{COD})\left(\mathrm{OSiMe}_{3}\right)$, which showed comparable activity to (IMes) $\operatorname{Ir}(\mathrm{COD}) \mathrm{Cl}(\mathbf{2 2 g})$ as a catalyst for the $\mathrm{TH}$ of acetophenone. ${ }^{58}$ Conversion of acetophenone to 1-phenylethanol and cyclohexanone to cyclohexanol with good efficiency at only $0.02 \mathrm{~mol} \%$ catalyst loading was achieved using non-symmetrically substituted NHC ligands as their (NHC) $\operatorname{Ir}(\mathrm{COD})(\mathrm{Br})$ complexes. ${ }^{171}$

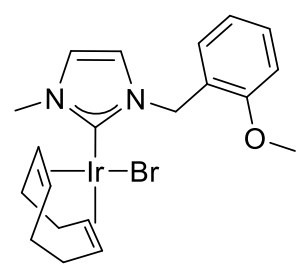

334

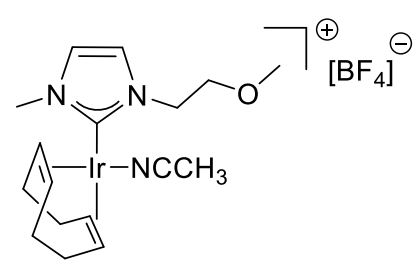

335

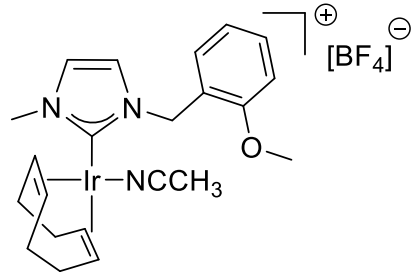

336

Figure 23. Methoxy functionalized NHC complexes 334-336.

With the intent to understand whether hemilability plays a role in the TH with NHC-Ir catalysts, Jiménez et al. prepared a large range of NHC ligands with pendant $\mathrm{N}$ - or O-donor groups and isolated their (NHC) $\operatorname{Ir}(\mathrm{COD}) \mathrm{Cl}$ complexes. Cationic compounds were accessed by silver salt metathesis. While aminefunctionalized NHC ligands gave cationic complexes where the ligand acted as a chelate, addition of acetonitrile was required in order to occupy the fourth coordination site when the NHC ligand featured a pendant methoxy group. These iridium compounds, and in particular 334, 335, and 336 (Figure 23) showed good efficiency in the TH of cyclohexanone and reduction of ketones, aldehydes, olefins and imines was successful at $0.1 \mathrm{~mol} \%$ [Ir] loading. However, activities were only moderate with non-activated olefins. Mechanistic studies indicated that the pendant O-functionality fills a role by assisting the forward and backward hydrogen transfer steps (Scheme 114). ${ }^{23}$ 


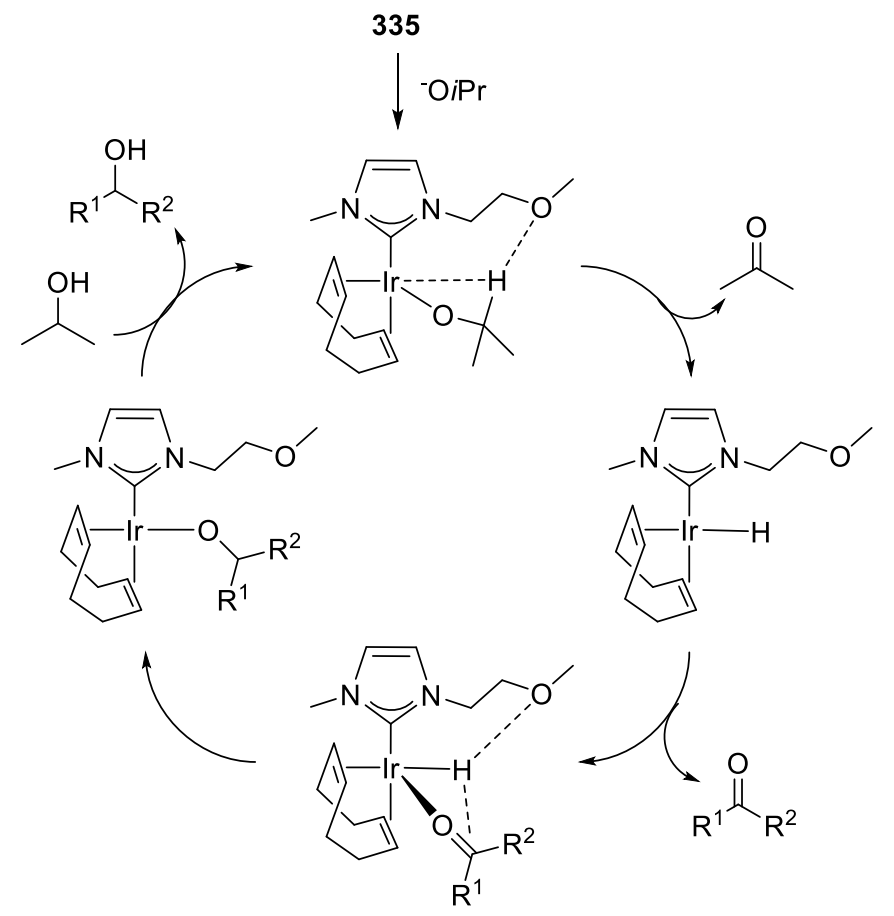

Scheme 114. Proposed mechanism for the TH with O-functionalized NHC-Ir(I) catalyst 335.

$\left[(\mathrm{NHC})_{2} \operatorname{Ir}(\mathrm{COD})\right]^{+}$featuring similar hemilabile NHC ligands with pendant $\mathrm{O}$ - or $\mathrm{N}$-functionalities showed moderate activity in the TH of cyclohexanone. ${ }^{120}$ In related studies on using NHCs with potentially chelating second binding sites, Sun et al. employed quinoline-tethered NHC-Ir(I) complexes for the TH reaction of ketones. Complex 271a (Scheme 92) provided high TOFs at low catalyst loading (Scheme 115). ${ }^{121}$
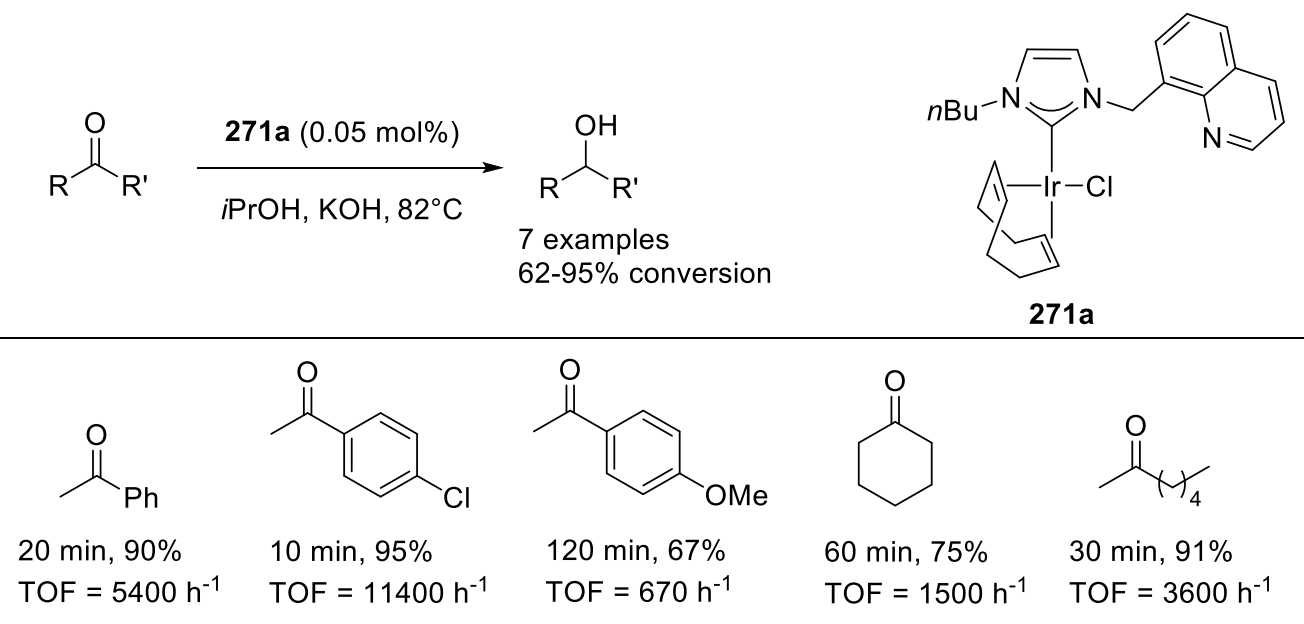

Scheme 115. Transfer hydrogenation with 271a.

In an effort to understand how the Ir-catalyst architecture affects reactivity in these TH reactions, Herrmann, Kühn et al. systematically varied both $\mathrm{NHC}$ and $\mathrm{X}$ ligands in [(NHC) $\operatorname{Ir}(\mathrm{COD}) \mathrm{X}]$ complexes. It was shown that NHCs with weaker donor strength seem to increase the activity and shorten the induction period. Furthermore, NHC ligands that have a combination of both small and sterically demanding N-substituents offer increased performance. ${ }^{172}$ 


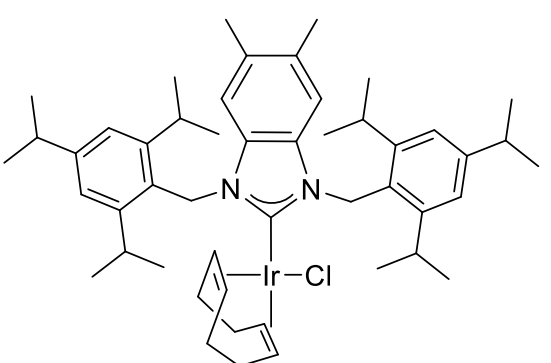

337

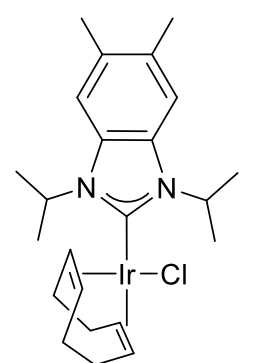

338

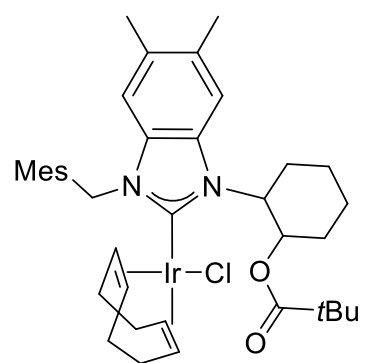

339

Figure 24. Transfer hydrogenation catalysts 337-339.

In related studies on the impact of the N-substitution in these NHC ligands, Gülcemal and coworkers employed (NHC) Ir(COD)Cl complexes (Figure 24) for the TH of ketones, aldehydes and imines. Choosing the right wingtip substitution had a more profound effect on reactivity than modifications of the Nheterocyclic backbone. Complex 337 offered exceptionally high TOF numbers of up to $24,000 \mathrm{~h}^{-1}$ for the TH of ketones. However, the reduction of imines occurred at much lower rates. Remarkably, this catalyst was recyclable for up to four catalytic cycles without loss in reactivity (Scheme 116). Additionally, the reduction of aldehydes was realized with catalyst $\mathbf{3 3 8}$ and with the ester-functionalized NHC found in complex 339. ${ }^{139,173}$

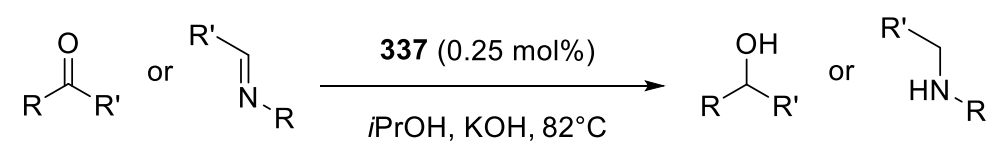

13 examples

$>99 \%$ conversion

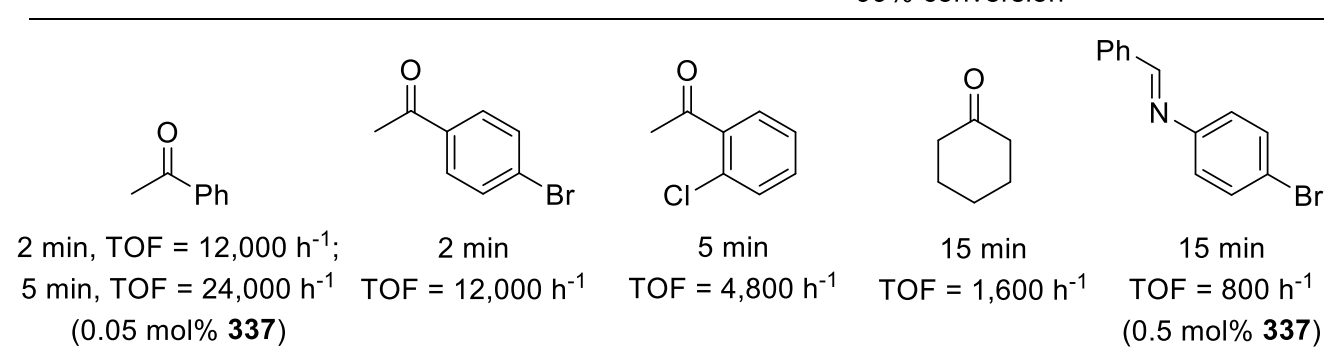

Scheme 116. Transfer hydrogenation of ketones with 337.

Expanded-ring NHC-Ir(I) and NHC-Rh(I) complexes were also tested in the $\mathrm{TH}$ reaction of 4bromoacetophenone. While the rhodium complexes showed no or low activity, all tested iridium compounds were able to provide full conversion at $1 \mathrm{~mol} \%$ loading. Catalysts with $o$-methoxyphenyl wingtipped NHCs performed better, with complex 340a and 340b affording $82 \%$ and $86 \%$ conversion of the parent acetophenone, respectively (Scheme 117). ${ }^{174}$

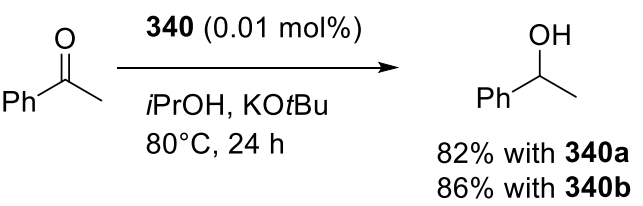

$86 \%$ with $340 \mathrm{~b}$

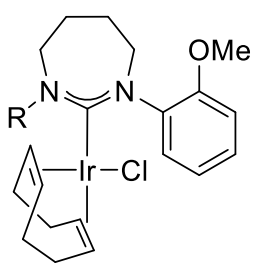

340a: $R=$ Mes

340b: $R=$ Dipp 
Scheme 117. OMe-functionalized NHCs in the TH of acetophenone.

Ruiz-Botella and Peris showed that $\pi$-stacking interactions influence the catalytic activity of pyrene-tagged NHC-Ir complexes in TH reactions. Partial catalyst inhibition was induced by the addition of external pyrene, but only when a pyrene-tagged NHC in combination with an aromatic substrate was employed. ${ }^{175}$ In another contribution on catalytic TH reactions that was discussed above in terms of catalyst systems used, the redox isomerization of allylic alcohols (intramolecular TH) was catalyzed by $\mathbf{3 3 0}$ (Figure 22) in an aqueous biphasic system (Scheme 118). ${ }^{168}$ A similar isomerization process of 1-octen-3-ol was carried out using Zr-MOFs (MOF = metal-organic framework) that contained an NHC-Ir metallolinker. ${ }^{176}$

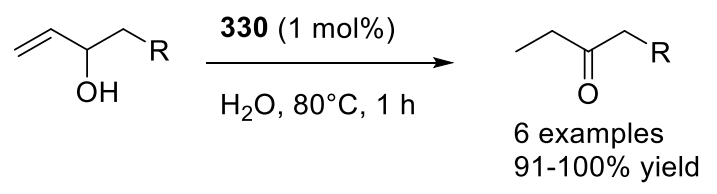

Scheme 118. Iridium-catalyzed redox isomerization of allylic alcohols with water-soluble

$(\mathrm{NHC}) \operatorname{Ir}(\mathrm{COD})\left(\mathrm{PAr}_{3}\right)$ (330 in Figure 22).

Transfer hydrogenation reactions were also carried out with NHC-Ir(III) complexes. A catalyst system consisting of $(\mathrm{I} n \mathrm{Bu}) \operatorname{Ir}\left(\mathrm{Cp}^{*}\right) \mathrm{Cl}_{2}$ (341) and AgOTf was able to catalyze the TH of ketones, aldehydes and imines. The major advantage of this system is its base-free nature, which allows hydrogenation of sensitive substrates, such as deoxybenzoin or benzaldehyde (Table 5). ${ }^{34}$ In a more recent study with NHC-Ir(III) catalysts, $\mathrm{Zhu}$ et al. employed ( $\mathrm{NHC}) \operatorname{Ir}\left(\mathrm{Cp}^{*}\right) \mathrm{Cl}_{2}$ compounds together with $\mathrm{KO} t \mathrm{Bu}$ for the $\mathrm{TH}$ of simple ketones and imines. ${ }^{177}$ Using glycerol as both hydrogen donor and solvent, the reactions were carried out with conventional heating (i.e. in an oil bath), under microwave conditions as well as employing an ultrasound activation procedure. ${ }^{178}$ Carborane-tagged NHC-Ir(III) complexes showed low activity in the TH reaction. ${ }^{107}$

Table 5. Base-free transfer hydrogenation with $(\mathrm{I} n \mathrm{Bu}) \operatorname{Ir}\left(\mathrm{Cp}^{*}\right) \mathrm{Cl}_{2}(\mathbf{3 4 1}) / \mathrm{AgOTf}$.

\begin{tabular}{llll}
\hline substrate & $\mathbf{3 4 1 / \mathrm { mol } \%}$ & time / h & yield / \% \\
\hline 2-butanone & 2 & 2 & $>99$ \\
2-butanone & 0.1 & 22 & 73 \\
deoxybenzoin & 2 & 0.25 & $>99$ \\
benzaldehyde & 2 & 0.5 & $>99$ \\
N-benzylideneaniline & 0.1 & 48 & $>99$ \\
\hline
\end{tabular}

Conditions: 341/AgOTf 1:3, iPrOH, rt.

Chiral-at-metal NHC-Ir(III) complexes with a stereogenic carbon center at the benzylamine ligand were developed by Mata et al. ${ }^{179}$ The syntheses of these complexes were diastereoselective, meaning that racemic mixtures of only one diastereomer were obtained from racemic 1-(naphthalen-1-yl)ethanamine (Scheme 119). Complex 342 showed good activity in the transfer hydrogenation of various ketones under relatively mild conditions (Scheme 120). 


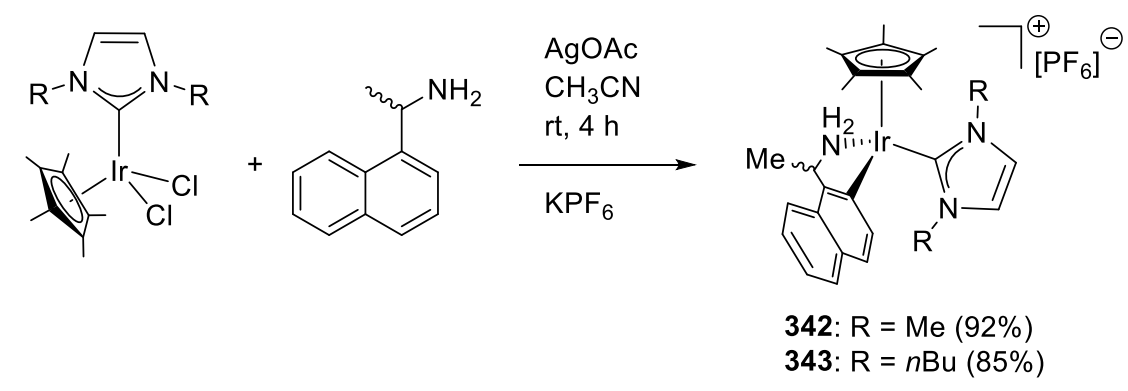

Scheme 119. The synthesis of chiral-at-metal NHC-Ir(III) complexes.

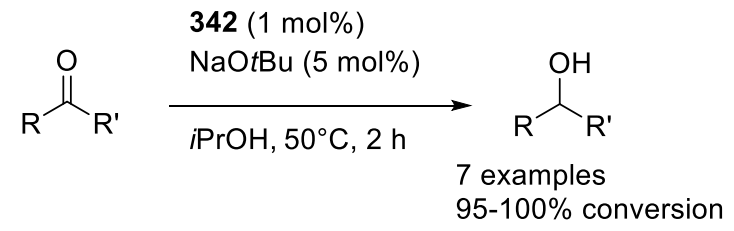

Scheme 120. Transfer hydrogenation with precatalyst 342.

Hintermair, Crabtree and coworkers tested fourteen $\mathrm{Cp} * \operatorname{Ir}(\mathrm{III})$ complexes bearing various combinations of ligands for use in the TH reaction. ${ }^{180,32}$ Both monodentate and chelating C-donor NHC and N-donor pyridine analogues were employed as spectator ligands. The most efficient transfer hydrogenation catalyst $\left[(\mathrm{IMe})_{2} \operatorname{Ir}\left(\mathrm{Cp}^{*}\right) \mathrm{Cl}\right]\left[\mathrm{BF}_{4}\right](\mathbf{3 4 4})$ was able to reduce a variety of aryl and alkyl ketones with $1 \mathrm{~mol} \%$ [Ir] loading at $60^{\circ} \mathrm{C}$ in $i \mathrm{PrOH}$ in the prescence of $\mathrm{KOH}$ (Scheme 121). When moving to conjugated $\alpha, \beta$-unsaturated ketones, the authors found that these substrates were fully reduced to saturated alcohols with TONs of up to 3100 at $0.01 \mathrm{~mol} \%$ [Ir]. The complex kinetics of the reaction led the authors to assume that the reaction catalyzed by 344 might not proceed according to one of the classical monohydride routes (inner- or outersphere). ${ }^{180}$ Indeed, detailed investigations showed that from sterically encumbered $\left[(\mathrm{NHC})_{2} \operatorname{Ir}(\mathrm{Cp} *) \mathrm{Cl}\right][\mathrm{X}]$ complexes, catalytically competent polyhydride species are formed by $\mathrm{Cp}^{*}$ ring loss. On the other hand, when more labile ligands, such as pyridine, are present in the $\operatorname{Ir}(\mathrm{III})$ complexes, transfer hydrogenation reactions seem to follow one of the common monohydride mechanisms. ${ }^{32}$

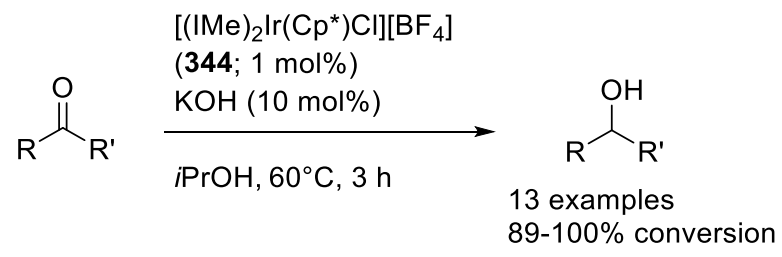

Scheme 121. Transfer hydrogenation with precatalyst [(IMe $\left.)_{2} \operatorname{Ir}(\mathrm{Cp} *) \mathrm{Cl}\right]\left[\mathrm{BF}_{4}\right](\mathbf{3 4 4})$.

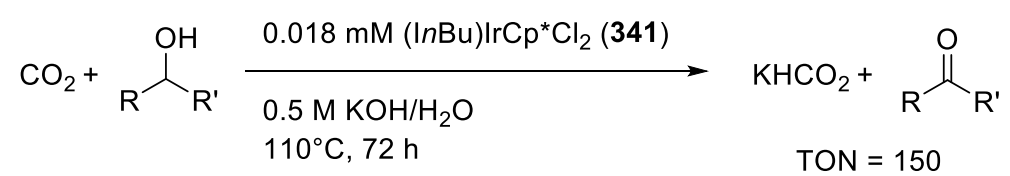

Scheme 122. $\mathrm{CO}_{2}$ reduction by 341 .

In another development using the TH reaction with NHC-Ir(III) compounds, $(\operatorname{In} \mathrm{Bu}) \operatorname{Ir}\left(\mathrm{Cp}^{*}\right) \mathrm{Cl}_{2}(\mathbf{3 4 1})$ was found to be a potent catalyst for the reduction of $\mathrm{CO}_{2}$ to formate (Scheme 122). ${ }^{181}$ The TH reaction was 
carried out in a variety of alcohols ( $i \mathrm{PrOH}$, cyclohexanol, 1-phenylethanol) and TONs of up to 150 were reached. Finally, the TH reaction was briefly tested with resin-, ${ }^{182}$ polyoxometalate-, ${ }^{183}$ carbon nanotube, ${ }^{184,185}$ porous polymeric aromatic framework-, ${ }^{186}$ and graphene-supported, ${ }^{187,188}$ NHC-iridium hybrid materials as catalysts. For further reading on the topic of transfer hydrogenation catalysis, we refer the reader to an excellent recent review by Wang and Astruc. ${ }^{189}$

\subsection{Hydrogen isotope exchange (HIE)}

A catalytic application where the inherent propensity of iridium complexes to undergo C-H activation can be used is represented by the hydrogen isotope exchange reaction. ${ }^{190}$ Peris and coworkers reported that $\mathrm{Cp}^{*}$ ligated (NHC) Ir(III) complexes are able to catalyze H/D exchange reactions. ${ }^{35,191}$ For example, complexes 217a-b (Scheme 79), $(\mathrm{I} n \mathrm{Bu}) \operatorname{Ir}\left(\mathrm{Cp}^{*}\right) \mathrm{Cl}_{2}(\mathbf{3 4 1})$ and $\left(\mathrm{I} n \mathrm{Bu}^{\mathrm{Cl}}\right) \operatorname{Ir}\left(\mathrm{Cp}^{*}\right) \mathrm{Cl}_{2}$ were tested in the HIE reaction on various substrates (e.g. diethyl ether, THF, acetophenone, styrene, 2-propanol etc.), and the results were benchmarked against Bergman's $\mathrm{Cp}^{*} \mathrm{IrCl}_{2}\left(\mathrm{PMe}_{3}\right)$ catalyst. Overall, complex 341 provided the most efficient system and the results surpassed the ones obtained with $\mathrm{Cp} * \mathrm{IrCl}_{2}\left(\mathrm{PMe}_{3}\right)$.

Ison et al. studied H/D exchange reactions between benzene and various deuterium sources (methanol- $d_{4}$, acetic acid- $d_{4}$, trifluoroacetic acid- $d_{1}$, etc.) catalyzed by $\mathrm{Cp} * \operatorname{Ir}(\mathrm{III})$ complexes. ${ }^{87,88}$ Amongst the catalysts tested, Ir(III) systems featuring NHC ligands displayed good efficiencies. The mechanism, and therefore the outcome of the reaction, depends both on the nature of ancillary ligands (e.g. strongly donating NHC $v s$ weak donor $\mathrm{H}_{2} \mathrm{O}$ ) and on the choice of the solvent.

NHC-Ir(III)-based nanostructured hybrid materials, developed by Thieuleux and coworkers, were also investigated as catalysts for H/D exchange reactions. ${ }^{55}$ Heterogeneous catalysts with different pore sizes and with different local steric characteristics were compared to their homogeneous homologues. Selective deuteration of the acetyl groups in activated substrates (e.g. in acetophenone and 9-acetylanthracene) took place.

Deuterosilanes were prepared using [(It Bu)(ItBu') $\operatorname{Ir}(\mathrm{H}) \mathrm{Cl}]$ or [( $\left.\left(\mathrm{I} \mathrm{Bu}^{\prime}\right)_{2} \mathrm{IrCl}\right](\mathbf{1 7 3}$ and $\mathbf{1 7 4}$ in Scheme 66, respectively) as a catalyst, with the conversion of $\mathrm{HSiR}_{3}$ to $\mathrm{DSiR}_{3}$ occurring under mild conditions ( $0.5 \mathrm{~atm}$ $\mathrm{D}_{2}$, room temperature, $1 \mathrm{~mol} \%$ [Ir]). ${ }^{192,60}$ Both DFT calculations and experimental work were used to clarify the mechanism of the reversible ortho-metallation, as well as the interconversion between 173, 174 and $\left[\operatorname{Ir}(\mathrm{H})_{2}(\mathrm{I} t \mathrm{Bu})_{2} \mathrm{Cl}\right]$. Complex 173 was also shown to be capable of catalyzing the deuteration of boronic esters under mild conditions. ${ }^{193}$ Deuterated DBpin was produced with $94 \%$ conversion in 48 hours using only 300 ppm of catalyst 173. Unfortunately, the same catalyst system was inactive in the deuteration of boranes.

HIE reactions catalyzed by square planar NHC-iridium(I) compounds were investigated in detail by Kerr, Nilsson, Tuttle and coworkers. ${ }^{194,195}$ In their first contribution, the authors screened [(NHC)Ir(COD) $\left.\left(\mathrm{PR}_{3}\right)\right]\left[\mathrm{PF}_{6}\right]$ complexes for catalytic, ortho-directed $\mathrm{H} / \mathrm{D}$ exchange of various aromatic substrates. The combination of sterically encumbered $\mathrm{NHC}$ and $\mathrm{PR}_{3}$ ligands seemed to be important for reactivity. Furthermore, IMes proved to be more suitable than the saturated SIMes counterpart. Complexes with 
phosphine ligands $\mathrm{PPh}_{3}, \mathrm{PBn}_{3}$ and $\mathrm{PMe}_{2} \mathrm{Ph}$ showed similar performance, meaning that steric factors seem to outplay electronic differences. In terms of aromatic substrates used, O- and N-donor directing groups (ketones, amides, N-heterocycles, nitro arenes) were successfully used (Scheme 123). Mechanistic investigations pointed towards a key $\mathrm{Ir}(\mathrm{III})$ species featuring the $\mathrm{NHC}$ and the phosphine ligand in a trans configuration (Scheme 124). ${ }^{195}$ The scope of HIE of complex [(IMes) $\left.\operatorname{Ir}(\mathrm{COD})\left(\mathrm{PBn}_{3}\right)\right]\left[\mathrm{PF}_{6}\right]$ (320) was expanded using industrially more benign ethereal solvents. ${ }^{196}$ In line with other catalytic studies employing cationic iridium complexes, the analogous catalyst with the $\mathrm{BAr}_{4}^{f}$ anion displayed better performance with an even broader solvent scope. ${ }^{197}$ Deuterium or tritium labeling of pharmacological targets, such as Nilutamide or Celexocib was also achieved. ${ }^{195,198,199}$ Reactions with tritium gas proceeded with low efficiency; nevertheless, compound $\mathbf{3 2 0}$ and similar complexes outperformed Crabtree's catalyst in the H/T exchange reaction. ${ }^{195,198,200}$ Pharmaceutically relevant heterocycles (e.g. pyrimidine, imidazole, thiazole, etc.) were also suitable ortho-directing groups. ${ }^{201}$

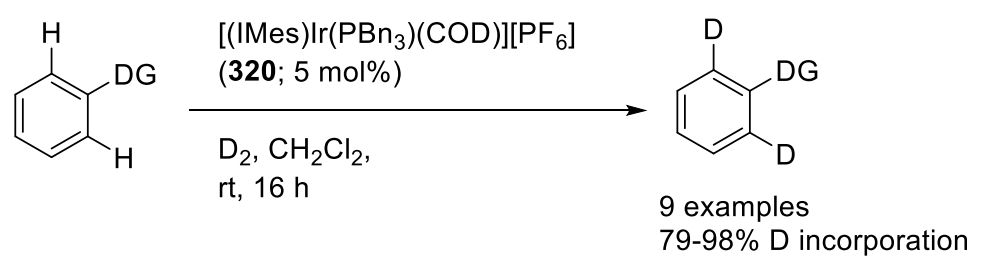

Scheme 123. A mixed NHC/PR 3 iridium complex as catalyst in the ortho-directed HIE.

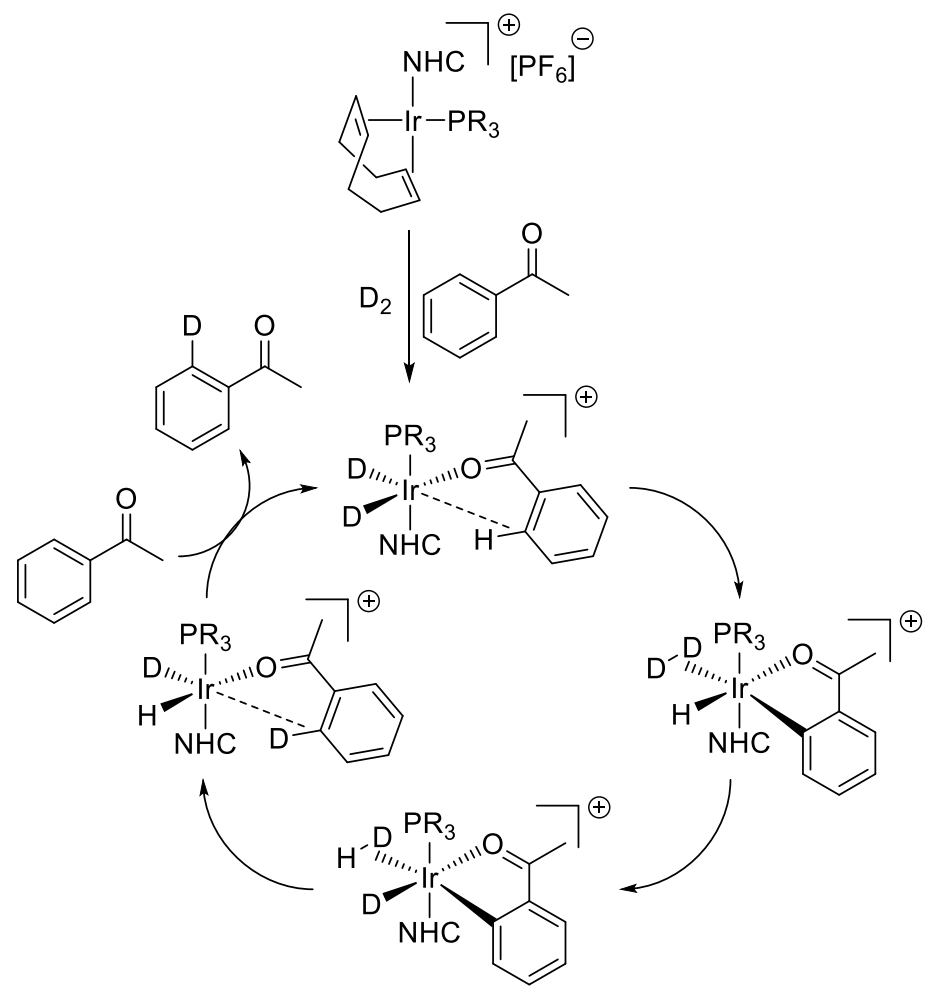

Scheme 124. Proposed catalytic cycle for mixed NHC/PR 3 iridium-catalyzed HIE.

Notably, the use of $\left[(\mathrm{IMes}) \operatorname{Ir}(\mathrm{COD})\left(\mathrm{PPh}_{3}\right)\right]\left[\mathrm{PF}_{6}\right]$ (345) allowed $\mathrm{HIE}$ at the $\beta$-position of $\alpha, \beta$-unsaturated compounds (Scheme 125). Mostly ketones were applied but it was demonstrated that amido and nitro groups 
were tolerated as well. In order to avoid reduction of the double bond, it was crucial to keep the catalyst loading at low levels $(0.1 \mathrm{~mol} \%){ }^{202}$

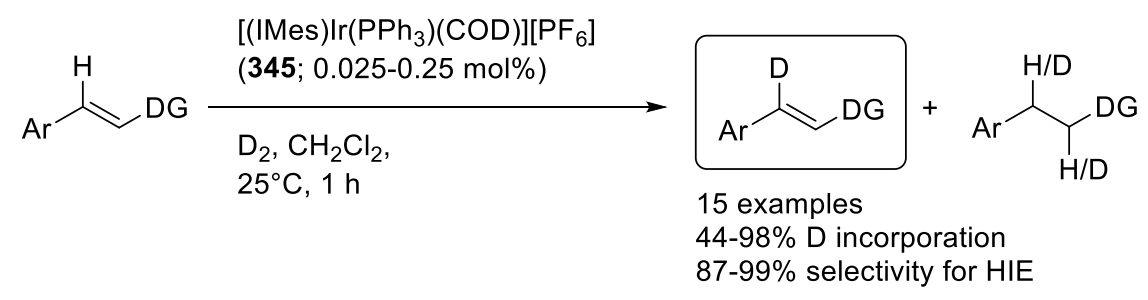

Scheme 125. Regioselective HIE of non-aromatic unsaturated substrates.

Recently, the ortho-selective HIE of unprotected 2-aryltetrazoles was also realized (Scheme 126). ${ }^{203}$ Contrary to previous work by Kerr and coworkers, this process required the use of a base. In the same contribution, the deuteration and tritiation of Valsartan (an angiotensin receptor blocker containing a 2aryltetrazole motif) was carried out with excellent efficiency.

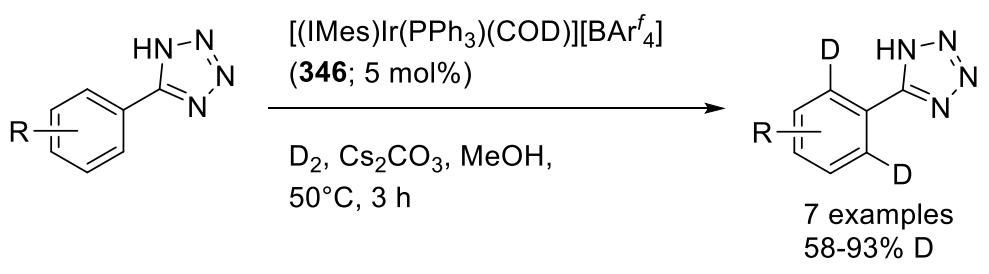

Scheme 126. C-H activation of unprotected 2-aryltetrazoles.

Very recently, Kerr et al. showed that cationic [(SIMes) $\operatorname{Ir}(\mathrm{COD})(\mathrm{py})]\left[\mathrm{PF}_{6}\right]$ (23a) was a competent catalyst in the ortho-directed HIE of aryl ketones, benzamide derivatives and substrates with N-heterocyclic directing groups. ${ }^{204}$ In another contribution by the same authors, it was shown that neutral (IMes) $\operatorname{Ir}(\mathrm{COD}) \mathrm{Cl}(\mathbf{2 2 g})$ is a highly active catalyst in the HIE of aryl ketones. Nitrogen-based heterocycles were also tolerated as directing groups. However, amides failed to deliver high percentages of deuterium incorporation. ${ }^{205}$ The neutral $\left(\mathrm{IMes}^{\mathrm{Me}}\right) \operatorname{Ir}(\mathrm{COD}) \mathrm{Cl}$ (347) complexes featuring an electron-rich NHC ligand showed good activity in the deuterium labeling of primary sulfonamides. ${ }^{206}$ Of great pharmaceutical interest, the selective orthodeuteration of COX-2 inhibitors, Celecoxib (348) and Mavacoxib (349), was achieved by a simple catalyst switch between (IMes) Ir(COD)Cl (22g) and $\left(\mathrm{IMes}^{\mathrm{Me}}\right) \operatorname{Ir}(\mathrm{COD}) \mathrm{Cl}(\mathbf{3 4 7})$ (Scheme 127). ${ }^{206}$ HIE reaction of secondary and tertiary sulfonamides and sulfonylureas was carried out with good efficiency using either (IMes) $\operatorname{Ir}(\mathrm{COD}) \mathrm{Cl}(\mathbf{2 2 g})$ or the commercially available Burgess catalyst. ${ }^{207}$ 

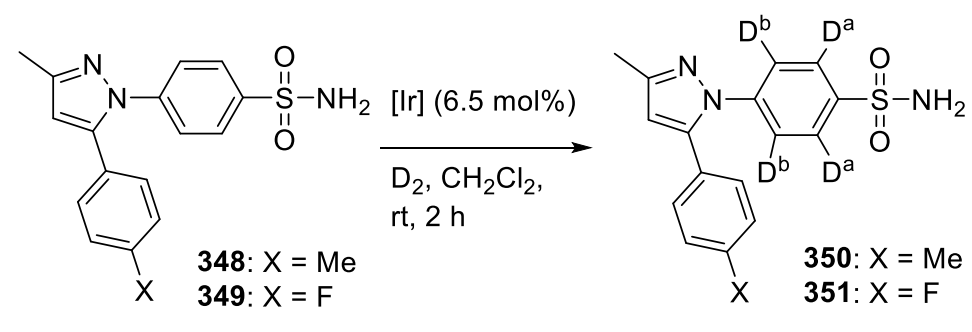

\begin{tabular}{|c|c|c|c|}
\hline cat. & $\mathrm{x}$ & $\% D^{a}$ & $\% D^{b}$ \\
\hline (IMes) $\operatorname{Ir}(\mathrm{COD}) \mathrm{Cl}(\mathbf{2 2 g})$ & $\mathrm{Me}$ & 16 & 95 \\
\hline (IMes $\left.^{\mathrm{Me}}\right) \operatorname{Ir}(\mathrm{COD}) \mathrm{Cl}(\mathbf{3 4 7})$ & $\mathrm{Me}$ & 97 & 11 \\
\hline (IMes)Ir(COD)CI (22g) & $\mathrm{F}$ & 7 & 89 \\
\hline (IMes $\left.^{\mathrm{Me}}\right) \operatorname{Ir}(\mathrm{COD}) \mathrm{Cl}(\mathbf{3 4 7})$ & $\mathrm{F}$ & 98 & 11 \\
\hline
\end{tabular}

Scheme 127. Chemoselective deuterium labeling of Celecoxib (348) and Mavacoxib (349).

Most recently, a method for the formyl-selective deuteration of aldehydes was developed by Kerr, Reid and Tuttle. ${ }^{208}$ The authors reasoned that careful steric tuning of the ancillary ligand environment can lead to a situation where deuteration of the formyl group is favored over ortho $\mathrm{C}-\mathrm{H}$ activation of the aryl motif. Indeed, a large/small ligand combination in NHC/chloro complex 352 lead to excellent performance (Scheme 128). The excellent formyl selectivity of the reaction was rationalized through advanced DFT calculations.
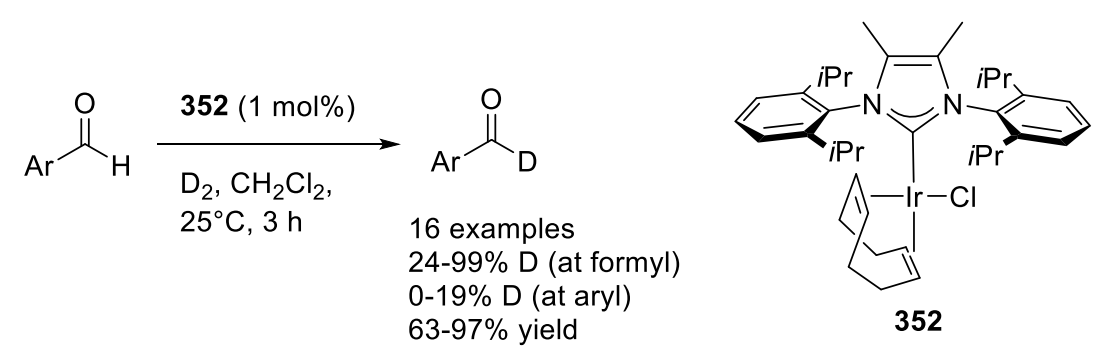

Scheme 128. Formyl-selective deuteration of aldehydes.

\subsection{Dehydrogenation}

Half-sandwich $\operatorname{Ir}(\mathrm{III})$ complexes are frequently used in oxidative transformations, such as the Oppenauertype oxidation of alcohols. ${ }^{209}$ The Yamaguchi group achieved good results with $\left[\left(\mathrm{IMe}^{\mathrm{Me}}\right) \operatorname{Ir}\left(\mathrm{Cp}^{*}\right)\left(\mathrm{CH}_{3} \mathrm{CN}\right)_{2}\right][\mathrm{OTf}]_{2}(\mathbf{1 2 7} \mathbf{b}$, Scheme 51) in the oxidation of primary and secondary alcohols (Scheme 129). ${ }^{47}$ Catalyst $\mathbf{1 2 7 b}$ provided TONs of up to 6,640 when the substrate was a secondary alcohol. Clearly lower activity (TON $=108-196)$ was observed in case of primary alcohol substrates. When a pendant amine functionality was built into the $\mathrm{Cp}^{*}$ framework of the precatalyst (Figure 25), the addition of external base to the catalytic reaction was not necessary anymore. ${ }^{210}$
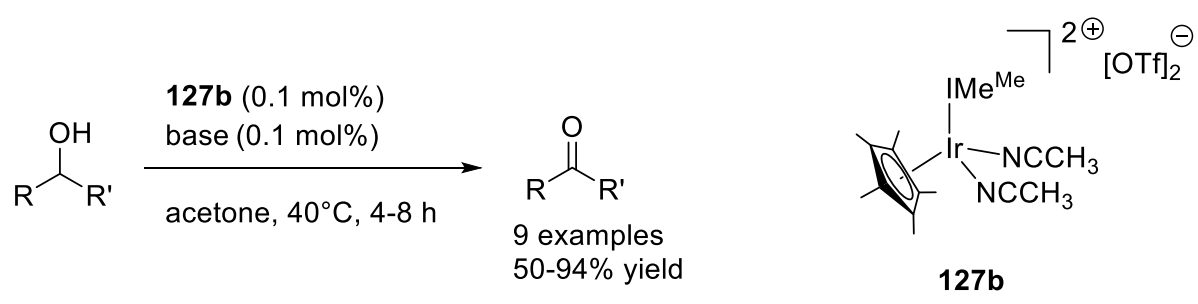
Scheme 129. Oppenauer-type oxidation of secondary alcohols.

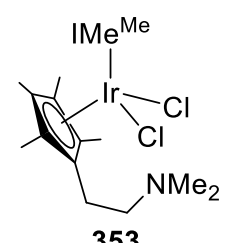

353

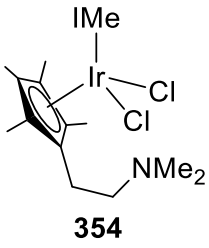

354

Figure 25. Precatalysts for the oxidation of alcohols with internal base.

Very recently, the acceptorless dehydrogenative oxidation of an impressive range of secondary alcohols was reported using catalyst $\mathbf{3 5 5}$ in 2,2,2-trifluoroethanol (TFE, Scheme 130). ${ }^{211}$ The acceptorless dehydrogenation of primary alcohols did not proceed with good efficiency, since catalyst $\mathbf{3 5 5}$ was able to promote the reverse hydrogenation pathways as well. Nevertheless, the authors showed that the dehydrogenation of primary alcohols is possible when a suitable functional group is available to intercept the newly formed aldehyde (Scheme 131).
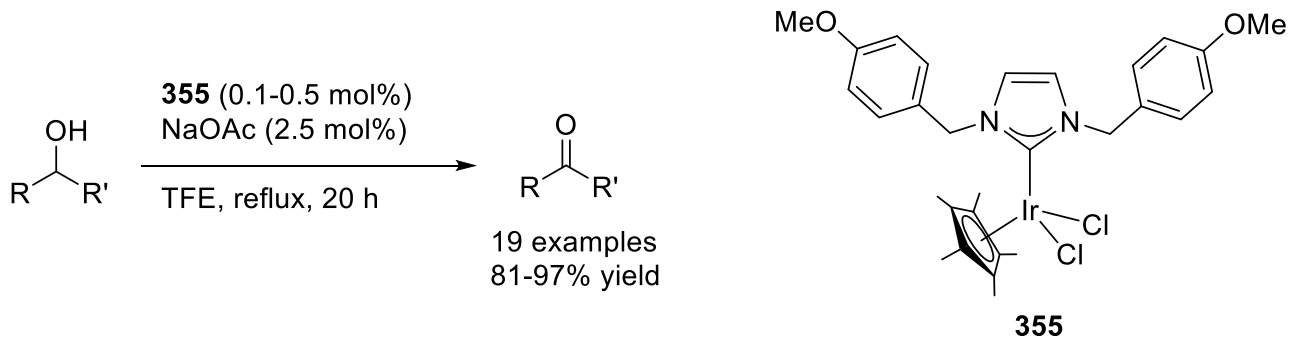

Scheme 130. Acceptorless dehydrogenation catalyzed by 355 .

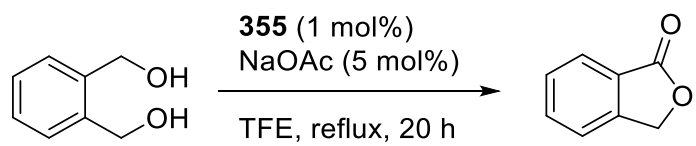

Scheme 131. Acceptorless dehydrogenation of 1,2-phenylenedimethanol.

Most recently, Martín-Matute et al. demonstrated that bifunctional Ir-complexes bearing NHC ligands functionalized with hydroxy groups show excellent activity in the acceptorless dehydrogenation of primary and secondary alcohols (Scheme 132), and diols. ${ }^{176}$
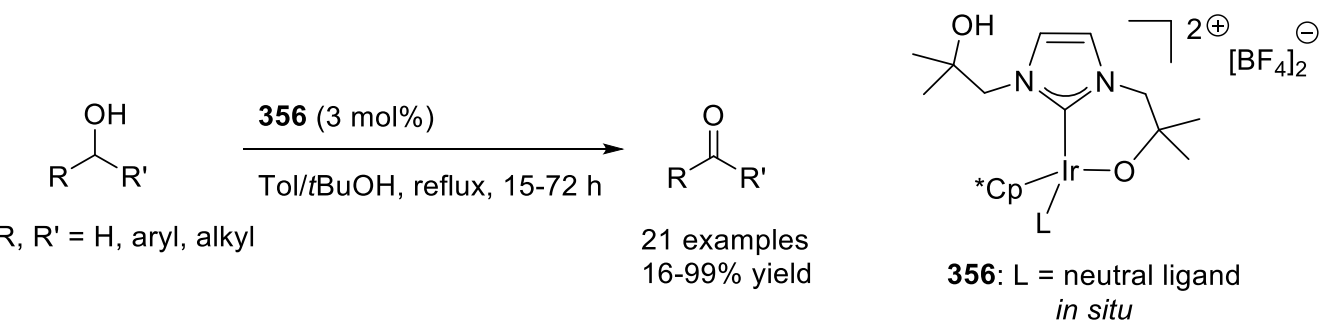

Scheme 132. Acceptorless dehydrogenation of primary and secondary alcohols catalyzed by $\mathbf{3 5 6}$.

Moving to cationic NHC-Ir(I) and NHC-Ir(III) species as the catalysts in these dehydrogenation events, various complexes featuring small IMe ligands showed significant activity in the reactions (Figure 26). ${ }^{30}$ The efficient conversion of glycerol, which is a cheap byproduct from biodiesel production, to lactic acid was 
first realized by Crabtree and coworkers. ${ }^{30}$ Among the iridium complexes screened, the best result was provided by $\left[(\mathrm{IMe})_{2} \operatorname{Ir}(\mathrm{CO})_{2}\right]\left[\mathrm{BF}_{4}\right](357$, Scheme 133). Excellent selectivities (>95\%) and TONs of up to 30,000 were reached. This, at that time, made the process superior compared to any other existing systems, including heterogeneous processes. The reaction could be performed under air, in neat glycerol and at catalyst loadings as low as $0.003 \mathrm{~mol} \%$. Even the dehydrogenation of crude glycerol waste proceeded with high selectivity, albeit with somewhat lower activity. More recently, the scope has been extended to the oxidation of other sugar alcohols (e.g. sorbitol, xylitol). ${ }^{212}$ In another approach, Sun et al. showed that iridium coordination polymers featuring a bis-benzimidazolidine motif are able to provide excellent results for the conversion of glycerol to potassium lactate. ${ }^{213}$ In a similar vein, a half-sandwich NHC-iridium complex was shown to catalyze the hydrogen transfer initiated dehydration of 1,3-propanediol to aldehydes in ionic liquid reaction media. ${ }^{214}$

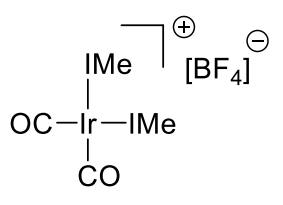

357

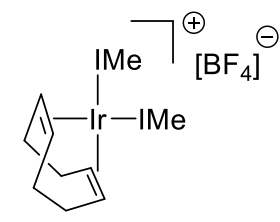

358

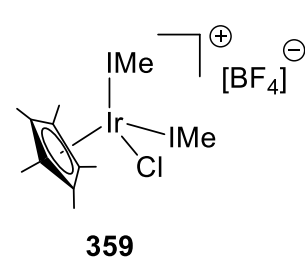

359

Figure 26. Efficient bis-NHC-iridium complexes for dehydrogenations.

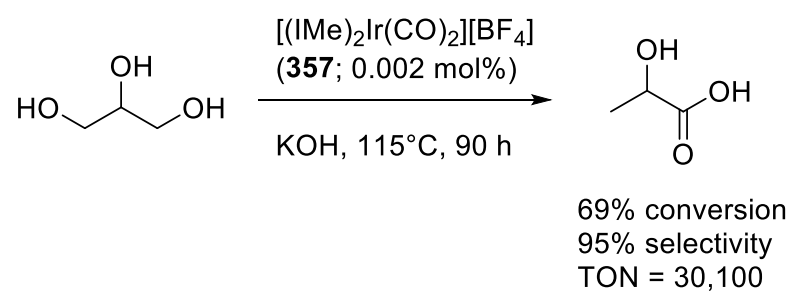

Scheme 133. [(IMe $\left.)_{2} \operatorname{Ir}(\mathrm{CO})_{2}\right]\left[\mathrm{BF}_{4}\right](\mathbf{3 5 7})$ catalyzed glycerol oxidation to lactic acid.

Complex $\mathbf{3 5 7}$ was able to efficiently catalyze the challenging acceptorless dehydrogenation of methanol to formate (Scheme 134). ${ }^{215}$ The usefulness of this process was furthermore demonstrated in transfer hydrogenation and N-alkylation reactions. ${ }^{215}$ Dehydrogenation of sodium formate was also investigated using water-soluble, mixed NHC-iridium phosphine complexes. ${ }^{216}$ The catalyst was able to convert sodium formate into dihydrogen gas and bicarbonate with high efficiency.

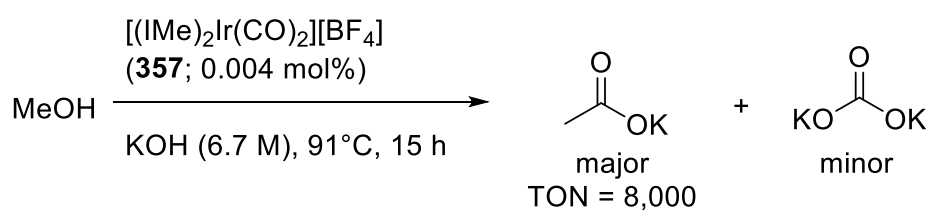

Scheme 134. Acceptorless methanol oxidation.

In related dehydrogenation chemistry, cyclooctadiene-iridium complexes having NHC ligands with an O- or $\mathrm{N}$-functionalized wingtip group were investigated as catalysts for the Oppenauer-type oxidation of primary and secondary alcohols in the presence of a base and a sacrificial hydrogen acceptor. ${ }^{217}$ Further developments more recently also led to their use in a $\beta$-akylation reaction (vide infra in Section 9.6). 
Within the field of dehydrogenation, a particular focus in the last decade has centered on hydrogen storage and subsequent gas liberation from ammonia-borane and amine-boranes. ${ }^{218}$ We have discussed the reactivity of various bis-NHC-Ir(III) compounds towards amine-boranes from the perspective of the formed metalcontaining species in detail. Herein, we focus on the catalytic aspects of the same transformation.

Tertiary amine-boranes without N-H bonds are not suitable for dehydrogenation purposes and only adduct formation occurs as was seen in 191 for instance (Scheme 72). Treatment of $\mathrm{R}_{2} \mathrm{NH} \cdot \mathrm{BH}_{3}(\mathrm{R}=i \mathrm{Pr}, \mathrm{Cy}$ ) with 2 mol\% 187 in fluorobenzene resulted in the generation of monomeric $\mathrm{R}_{2} \mathrm{NBH}_{2}$ and gave complexes with unsaturated aminoborane ligands (Scheme 72, Figure 27). ${ }^{99,100}$ Compared to the reactivity of 187 in fluorobenzene, both 190 and the in situ generated $186 / \mathrm{NaBAr}_{4}^{f}$ catalyst system showed diminished performance in THF for the dehydrogenation of $i \mathrm{Pr}_{2} \mathrm{NH} \cdot \mathrm{BH}_{3}{ }^{101}$ Reaction of the less bulky $\mathrm{Me}_{2} \mathrm{NH} \cdot \mathrm{BH}_{3}$ with $\mathbf{1 8 6} / \mathrm{NaBAr}_{4}^{f}(5 \mathrm{~mol} \%)$ in fluorobenzene afforded the $\left[\mathrm{Me}_{2} \mathrm{NBH}_{2}\right]_{2}$ dimer as the non-metallic product. ${ }^{102}$ The in situ prepared $\left[(\mathrm{SIMes})_{2} \operatorname{Ir}(\mathrm{H})_{2}\right]^{+}$complex was also able to catalyze this transformation in THF. ${ }^{103 \mathrm{c}}$ The rhodium analogue of $\mathbf{1 8 7}$ showed activity in the catalytic dehydrogenation of $\mathrm{H}_{3} \mathrm{~N} \cdot \mathrm{BH}_{3}$, but its use is limited due to decomposition of the metal complex during catalysis. ${ }^{99,100}$

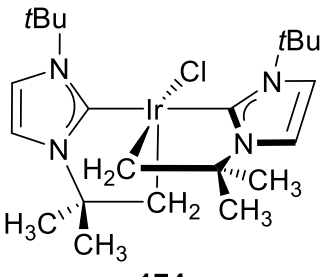

174

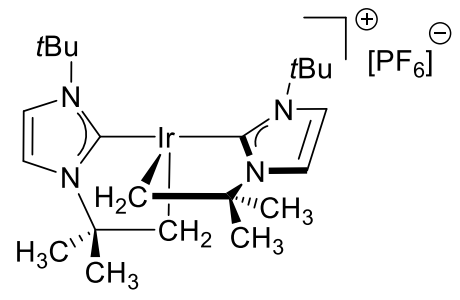

175<smiles>CC(C)C[In](C)C(C)C</smiles>

176

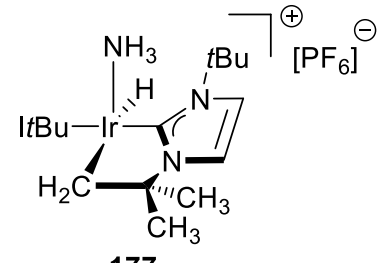<smiles>C[Mg][I-](C)(C)Cl</smiles>

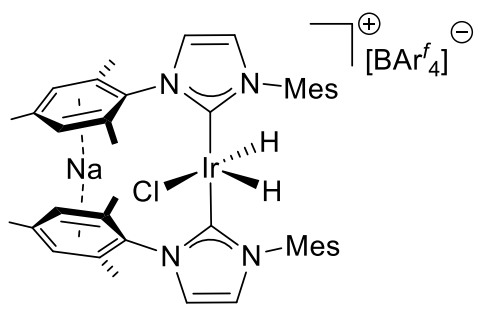

187

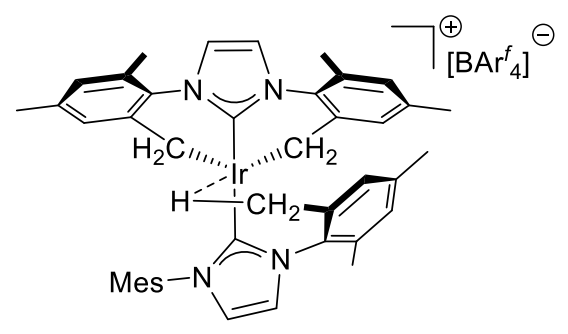

190

Figure 27. A range of NHC-Ir complexes employed in amine-borane dehydrogenation catalysis.

The cyclometallated 174 and 175 species, developed by the Nolan group (Scheme 66, Figure 27), are competent catalysts in ammonia-borane solvolysis. ${ }^{219} \mathrm{~A}$ remarkable TOF of $173,000 \mathrm{~h}^{-1}$ was reached with catalyst 175 at $24^{\circ} \mathrm{C}$ and at $500 \mathrm{ppm}$ [Ir] loading in a $\mathrm{H}_{2} \mathrm{O}$ /THF mixture. Interestingly, one equivalent of the evolved $\mathrm{H}_{2}$ is obtained from water and not from the ammonia-borane substrate. The authors suggested that 
the reaction might proceed according to Scheme 135. Related complexes 176 and 177 (Scheme 67, Figure 27) were identified from stoichiometric studies and were as active as $\mathbf{1 7 5}$ in the transformation. Superior catalytic results were achieved by using dihydride complex $\left[(\mathrm{I} t \mathrm{Bu})_{2} \mathrm{I}\left(\mathrm{H}(\mathrm{H})_{2}\right]\left[\mathrm{BAr}{ }_{4}^{f}\right]\right.$, that reached an exceptional TON over $5 \times 10^{5}$ in catalyst recycling studies. ${ }^{220}$ Complex $\left[(\mathrm{I} t \mathrm{Bu})_{2} \operatorname{Ir}(\mathrm{H})_{2}\right]\left[\mathrm{BAr}{ }_{4}\right]$ was able to operate under aerobic conditions using technical grade THF and tap water to provide ca. $85 \%$ conversion of $\mathrm{H}_{3} \mathrm{~N} \cdot \mathrm{BH}_{3}$ at $50 \mathrm{ppm}$ catalyst loading.

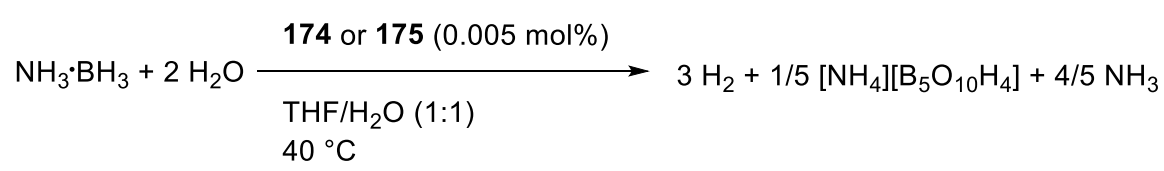

Scheme 135. Ammonia-borane dehydrogenation by ItBu complexes 174 and 175 .

\subsection{Hydrosilylation}

To the best of our knowledge, the first NHC-Ir catalyzed hydrosilylation reactions employed bimetallic Ircomplexes with tripodal NHC ligands. ${ }^{221}$ However, these complexes showed low catalytic activity in the hydrosilylation reaction of alkynes. In follow-up work by the same group, Peris and coworkers synthesized $\mathrm{Rh}$ and Ir complexes of NHC ligands with a pendant pyridine group. Originally, it was assumed that chelation of the pyridine moiety would result in the formation of a cationic species. ${ }^{222}$ However, X-ray crystallography revealed that this is not the case in the NHC-Ir(I) species. ${ }^{223}$ The monodentate NHC-Ir complex 360 showed low activity in the hydrosilylation of alkynes (Scheme 136). ${ }^{222}$ Mechanistic exploration using electrospray ionisation mass spectrometry led to the proposal of a plausible mechanistic scenario for the hydrosilylation reaction of these alkynes. ${ }^{223}$

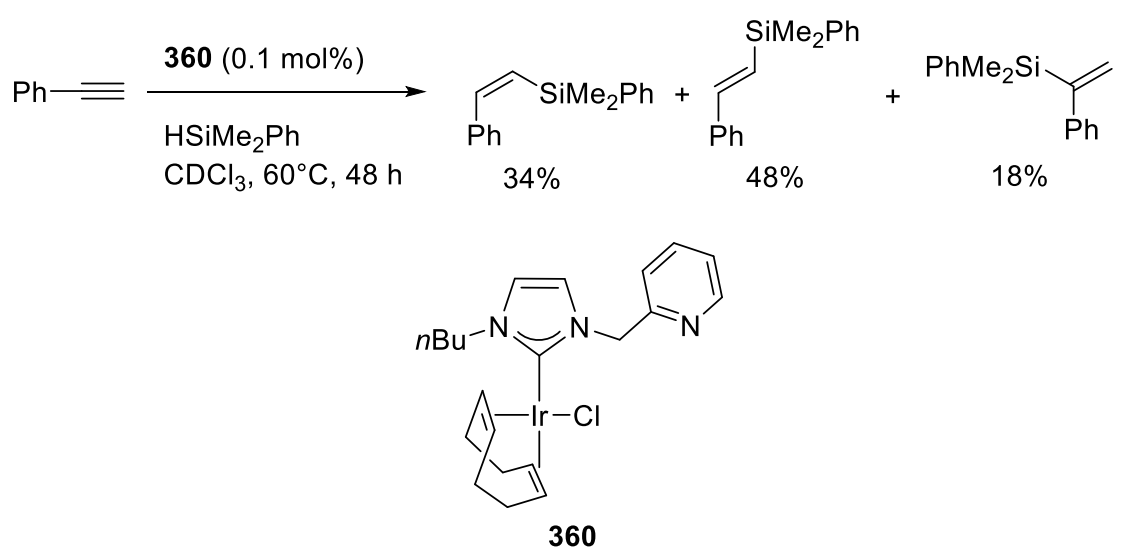

Scheme 136. Hydrosilylation of phenylacetylene by $\mathbf{3 6 0}$.

Table 6. Alkyne hydrosylilation with 247. 


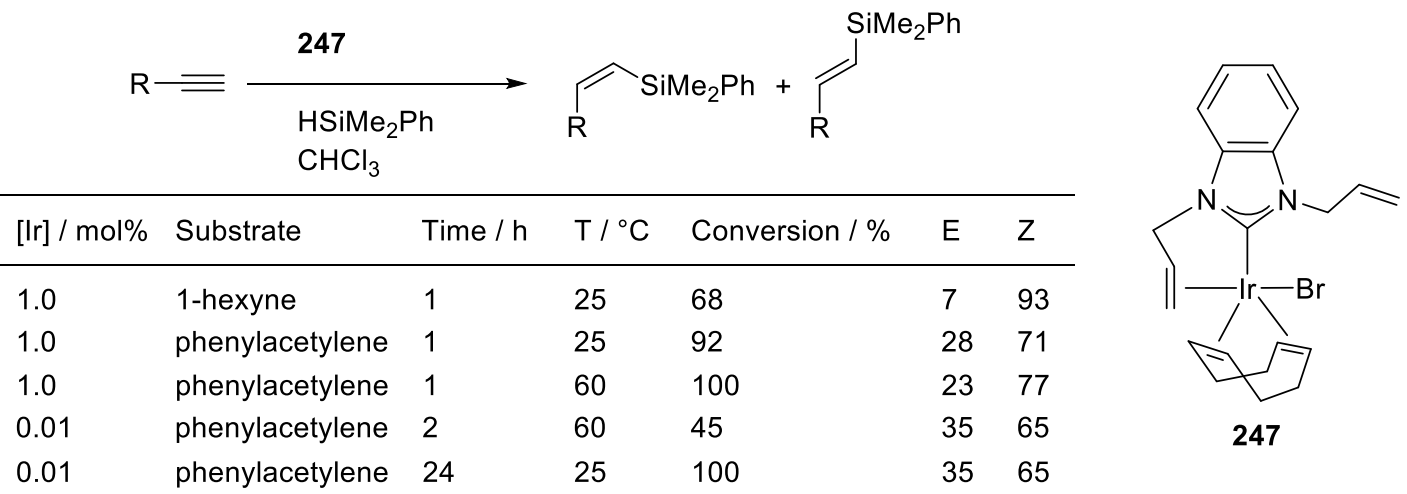

Alkenyl-functionalized NHC-Ir complexes 247 (Scheme 87), 249 (Scheme 88) and 253-255 (Figure 14) displayed good activity and selectivity in the hydrosilylation of terminal alkynes. ${ }^{113}$ The best performance was achieved with compound 247 (Table 6). Moving to other hydrosilylation substrates, Shi et al. have synthesized a series of monodentate and chelating NHC ligands derived from 2,2'-diaminophenyl. These were then used in NHC-Rh(I) and NHC-Ir(I) complexes and their activity as catalysts in the hydrosilylation of acetophenone showed that the NHC-Ir complexes were significantly less active. ${ }^{224}$ In related studies, $(\mathrm{NHC}) \operatorname{Ir}(\mathrm{COD}) \mathrm{Cl}$ complexes with flexible, bowl-shaped carbene ligands were tested in the hydrosilylation of ketones by Chianese and coworkers. ${ }^{225}$ Studies by Tapu et al. are noteworthy as these show that within complexes of formula ( $\mathrm{NHC}) \mathrm{M}(\mathrm{COD}) \mathrm{Cl}$ (where the $\mathrm{NHC}$ is $\mathbf{3 0 3}$ or $\mathbf{3 6 1}$, and $\mathrm{M}=\mathrm{Rh}$, $\mathrm{Ir}$ ), the corresponding iridium compound showed higher activity in the reaction (Scheme 137). ${ }^{151,226}$
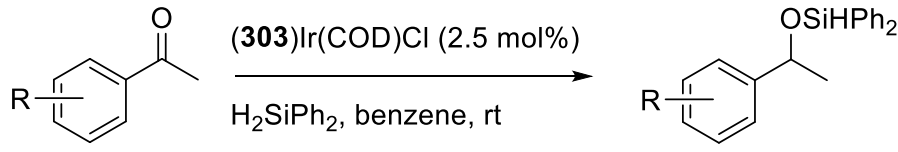

9 examples $88-100 \%$ conversion<smiles>CCCCN1CN(CCCC)c2cc3nc4c5ccccc5c5ccccc5c4nc3cc21</smiles>

303<smiles>CC(C)(C)CCCN1CN(CC(C)(C)C)c2cc3nsnc3cc21</smiles>

Scheme 137. Hydrosilylation of acetophenone derivatives.

\subsection{NHC-iridium catalysts for $\mathrm{C}-\mathrm{X}$ bond $(\mathrm{X}=\mathrm{B}, \mathrm{C}, \mathrm{N}, \mathrm{O}, \mathrm{Si})$ formation}

\subsubsection{C-B bond formation}

A decade ago, Herrmann and coworkers showed that direct borylation of benzene derivatives was possible employing [(IMe $\left.)_{2} \operatorname{Ir}(\mathrm{COD})\right]\left[\mathrm{CF}_{3} \mathrm{CO}_{2}\right]$ and $\left[(\mathrm{ICy})_{2} \operatorname{Ir}(\mathrm{COD})\right]\left[\mathrm{CF}_{3} \mathrm{CO}_{2}\right]$ (362 and 363, respectively) as the catalysts (Scheme 138). Comparing these with complexes featuring a single chelating biscarbene ligand showed that they had very similar activity under the tested reaction conditions. ${ }^{39}$ Improved results were later achieved using a chelating NHC-Ir complex in combination with microwave heating. ${ }^{227}$ More recently, an in 
situ formed iridium catalyst having NHC ligands with pendant pyridine functionality was shown to be moderately active in the borylation of 2,6-dichloropyridine with $\mathrm{B}_{2} \mathrm{pin}_{2}{ }^{228}$

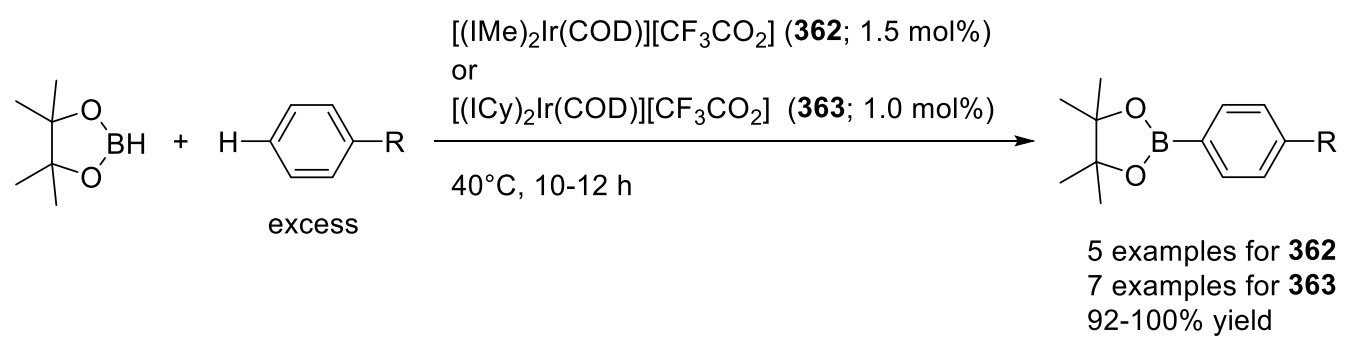

Scheme 138. NHC-Ir catalyzed C-H borylation reaction.

In very recent work, catalytic C-H borylation of heteroarenes was reported with an in situ generated NHC-Ir catalyst system (Scheme 139). ${ }^{229}$ The aminoborylated product that formed during the reaction was unstable and protection with pinacol had to be carried out in a one-pot procedure. Unfortunately, high catalyst loadings were required and borylation of benzene derivatives proved to be sluggish.

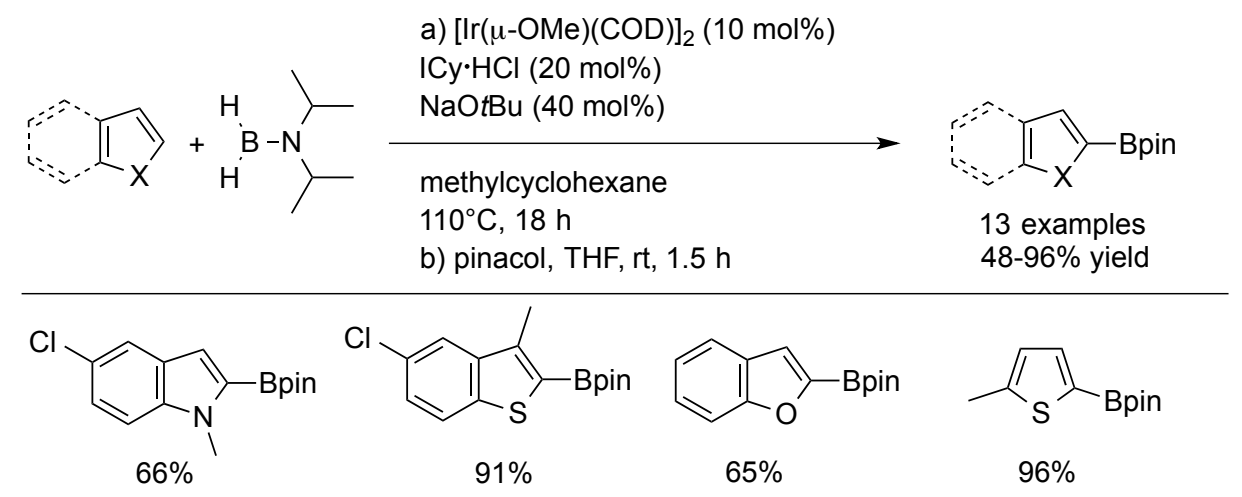

Scheme 139. C-H borylation of heteroarenes by an ICy-Ir catalyst system.

\subsection{2. $C$-C bond formation}

A fascinating NHC-iridium catalyzed intramolecular cross-coupling between $\mathrm{sp}^{3} \mathrm{C}-\mathrm{H}$ bonds and alkenes was described by Sames and coworkers. ${ }^{43}$ The in situ generated $\left[\operatorname{Ir}(\mathrm{COE})_{2} \mathrm{Cl}\right]_{2} / \mathrm{IPr}$ catalyst was found to facilitate the cyclization of 364 (Scheme 140). The $(\operatorname{IPr})_{2} \operatorname{Ir}(\mathrm{H})_{2} \mathrm{Cl}(\mathbf{1 8 1})$ complex was inactive for the same transformation. In an effort to elucidate the reaction mechanism, complex 368 was prepared in a stoichiometric reaction. Upon heating, cyclization of the bound substrate occurred, leading to product $\mathbf{3 6 5}$ in $63 \%$ yield (Scheme 141). Complex 368 was in fact also shown to be a catalytically competent species for the transformation shown in Scheme 140.

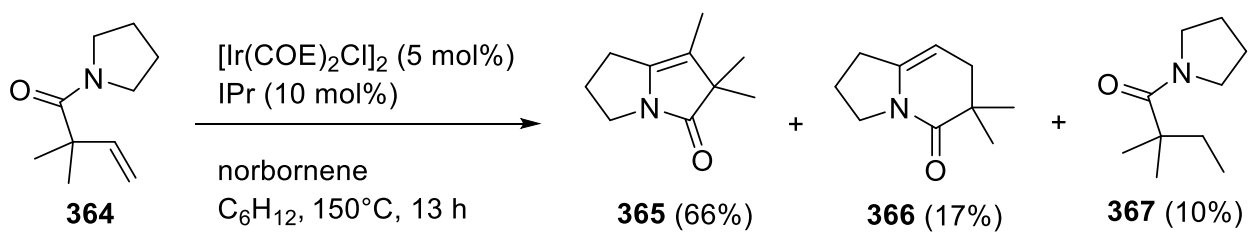

Scheme 140. Intramolecular cross-coupling with $\left[\operatorname{Ir}(\mathrm{COE})_{2} \mathrm{Cl}\right]_{2} / \mathrm{IPr}$. 


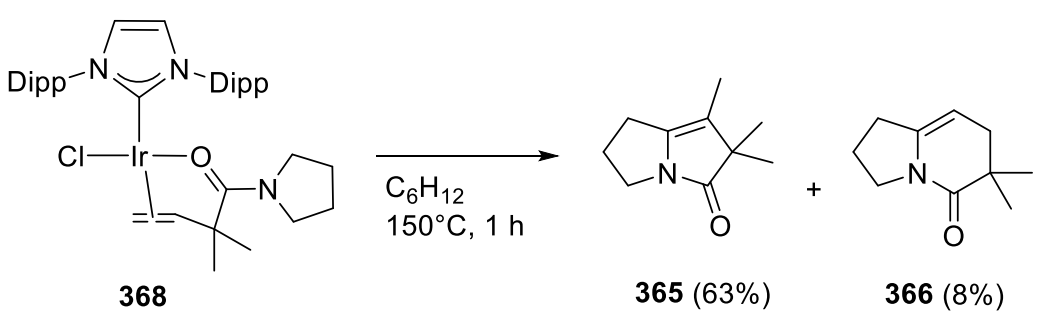

Scheme 141. Thermolysis of 368 .

A more classical approach to $\mathrm{C}-\mathrm{C}$ bond formation consists of catalyzing the nucleophilic attack and ensuing $\mathrm{C}-\mathrm{C}$ bond formation events of carbonyl compounds. Within this category, addition of arylboronic acids to benzaldehydes were shown to be catalyzed by complexes $(6 \mathrm{Mes}) \operatorname{Ir}(\mathrm{COD}) \mathrm{Cl}(\mathbf{6 9})$ and $(6 i \mathrm{Pr}) \operatorname{Ir}(\mathrm{COD}) \mathrm{Br}(\mathbf{7 0}$; Scheme 31), showing overall low catalytic activity (Scheme 142). ${ }^{76}$ The analogous NHC-Rh complexes displayed clearly superior reactivity. Unfortunately, none of the tested complexes revealed obvious selectivity towards the alcohol or the ketone coupling product.

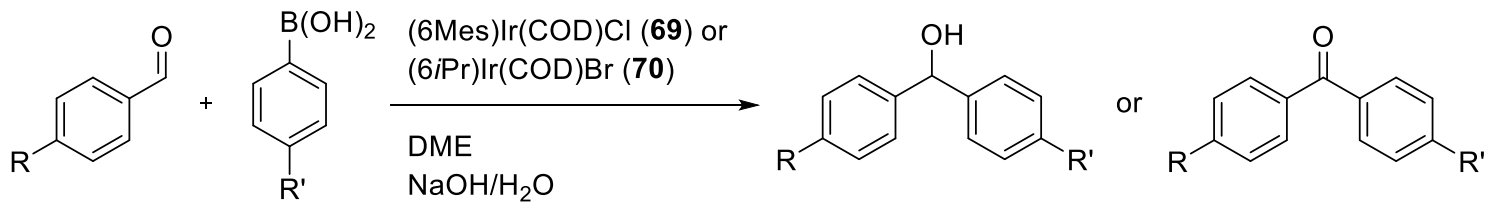

Scheme 142. Arylation of aldehydes with boronic acids.

Tsuji and coworkers described the Ir-catalyzed addition between acid chlorides and terminal alkynes. ${ }^{230}$ Distinct reactivity patterns were observed for complexes with NHC or phosphine ligands. Namely, (IPr) $\operatorname{Ir}(\mathrm{COD}) \mathrm{Cl}$ (22d) was applicable for the coupling of aroyl chlorides and terminal alkynes (Scheme 143), but was inefficient for aliphatic acid chlorides. The latter type of substrates was conveniently coupled by $\left[\operatorname{Ir}(\mathrm{COD}) \mathrm{Cl}_{2} / \mathrm{PCy}_{2}(o-\mathrm{Tol})\right.$. The same authors noticed that furans can be obtained at high temperatures if a terminal alkyne bearing a methylene unit adjacent to the triple bond is used (Scheme 144).

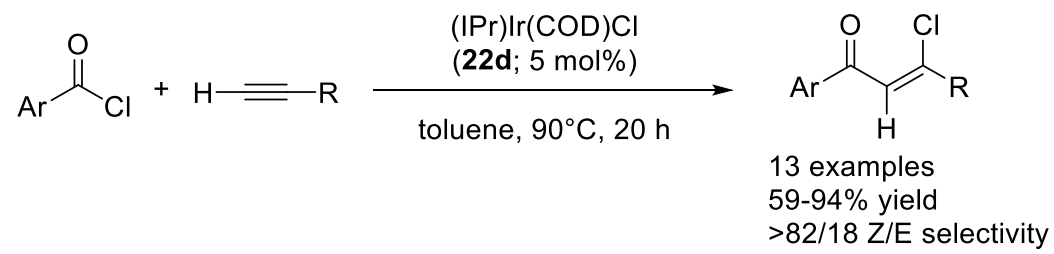

Scheme 143. (IPr) $\operatorname{Ir}(\mathrm{COD}) \mathrm{Cl}$ (22d) catalyzed oxidative coupling.

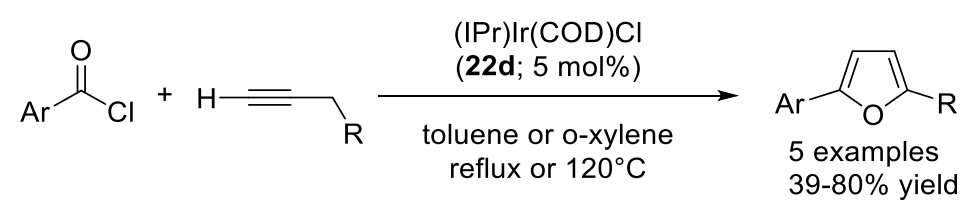

Scheme 144. Furane synthesis via NHC-Ir catalysis.

In a related application, the homodimerization of alkynes with Z-selectivity was described using the cationic NHC-phosphine catalyst [(IMes) $\left.\operatorname{Ir}(\mathrm{COD})\left(\mathrm{PBn}_{3}\right)\right]\left[\mathrm{PF}_{6}\right](\mathbf{3 2 0}){ }^{231}$ Recently, the unusual $\operatorname{Ir}(\mathrm{II})$-complex 8 (Figure 3) was shown to catalyze the hydroalkynylation of imines (Scheme 145). A broad variety of alkyne 
substrates (e.g. ethynylsilanes, aryl alkynes, aliphatic alkynes) were tolerated, allowing the synthesis of several propargylamines. Experimental studies and DFT calculations supported a previously unprecedented Ir(II)-based mechanism (Scheme 146). ${ }^{20}$

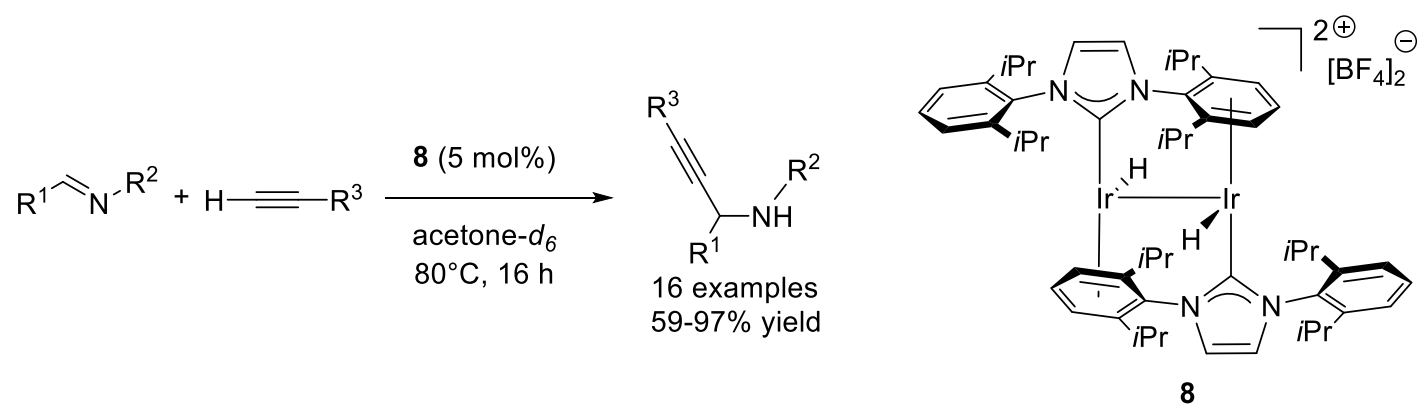

Scheme 145. NHC-Ir(II) catalyzed hydroalkynylation of imines.

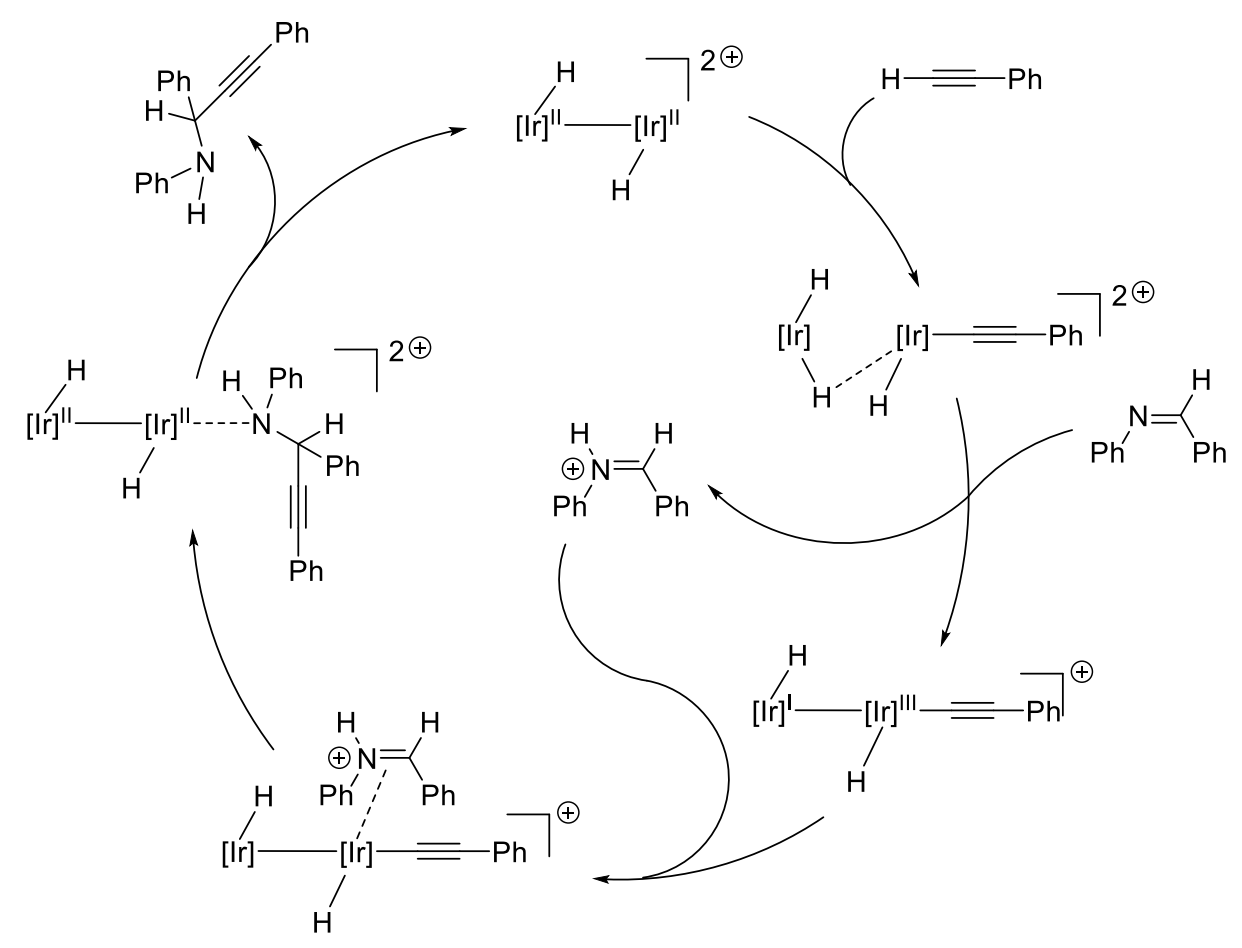

Scheme 146. Proposed catalytic cycle for the Ir(II)-catalyzed hydroalkynylation of imines.

Moving on to more complex reaction sequences catalyzed by NHC-Ir complexes, the B-alkylation of secondary alcohols with primary alcohols is a tandem process that is initiated by an Oppenauer-type oxidation of both reactants. In the next step the formed ketone and aldehyde engage in a cross-aldol condensation to afford an $\alpha, \beta$-unsaturated ketone, which is finally reduced through a transfer hydrogenation reaction. This borrowing hydrogen methodology was utilized by Jiménez et al. employing NHC-iridium(I) complexes as catalysts. ${ }^{217} \mathrm{~A}$ wide range of secondary and primary alcohols were coupled employing either complex 334 or 336 (Figure 23, Scheme 147). The reaction generally proceeded with only moderate selectivity. However, in some cases addition of a larger amount of base (1.5 equiv compared to the secondary alcohol) led to exclusive formation of the alcohol product. In a closely related examples, Peris and coworkers demonstrated that both (NHC)Ir(COD)Br and NHC-Ir(III) half-sandwich complexes are able to 
catalyze the B-alkylation of 1-phenyethanol with primary alcohols via the borrowing hydrogen methodology. ${ }^{175,191}$

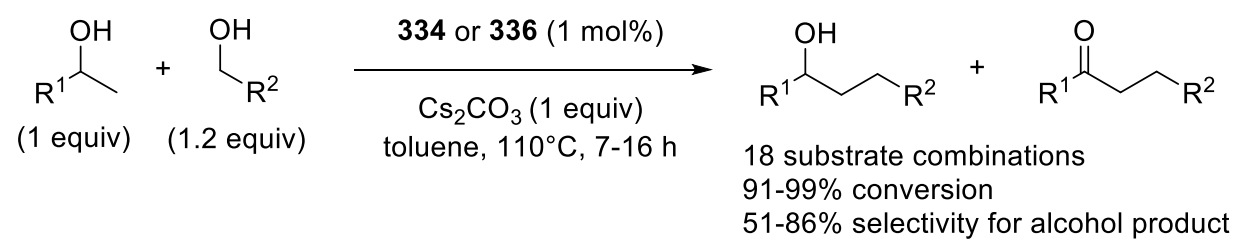

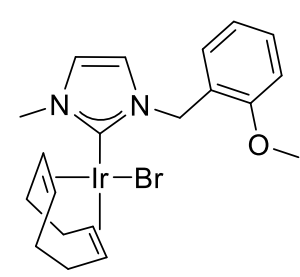

334

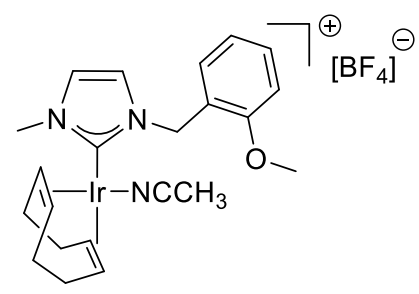

336

Scheme 147. ß-alkylation of secondary alcohols with primary alcohols.

\subsection{3. $C-N$ bond formation}

Most of the C-N bond formation reactions with NHC-Ir complexes are based on the above mentioned borrowing hydrogen methodology. ${ }^{232} \mathrm{~N}$-alkylation reactions were accomplished by a $(\mathrm{I} t \mathrm{Bu}) \operatorname{Ir}\left(\mathrm{Cp}^{*}\right) \mathrm{Cl}_{2}$ (369)/AgOTf catalyst system, where the reaction of anilines with aliphatic amines afforded secondary amines in moderate to excellent yields (Scheme 148). ${ }^{233}$ When primary amines were treated with primary or secondary alcohols, the selectivity towards secondary or tertiary amines was highly dependent on the actual coupling partners. With the exception of benzylmethylaniline, secondary amines (dibutylamine, diethylamine, diallylamine) did not engage in the reaction with benzyl alcohol. Applicability of $\mathbf{3 6 9}$ in the preparation of imines through a tandem process was demonstrated in a single entry. ${ }^{234}$

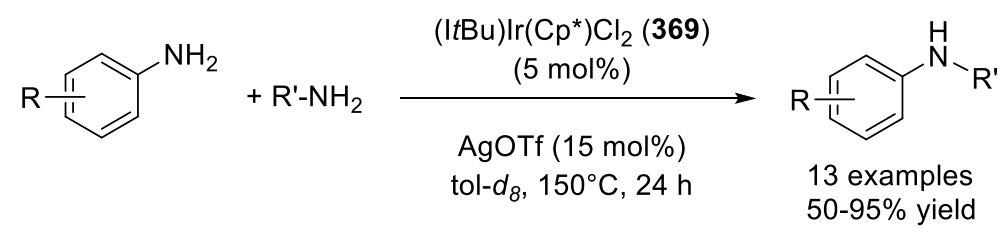

Scheme 148. N-alkylation of anilines with aliphatic amines.

The mixed NHC-phosphine complex $(\mathrm{SIBn}) \operatorname{Ir}\left(\mathrm{PPh}_{3}\right)(\mathrm{CO}) \mathrm{Cl}(\mathbf{5 1 b}$; Scheme 22) was able to facilitate the Nalkylation reaction of primary amines. Selective formation of the monoalkylated products occurred, and unreduced imines were identified as intermediates. Satisfactory results were obtained for the coupling of anilines with benzyl alcohol derivatives and 2-(hydroxymethyl)pyridine (Scheme 149). Aliphatic amines and alcohols generally afforded low reactivity. ${ }^{62 a}$ Oxidative cyclization of 2-(o-aminophenyl)ethanol to give indole $\left(100 \%{ }^{1} \mathrm{H}\right.$ NMR yield) was achieved when using $1 \mathrm{~mol} \%$ of $(\mathrm{SIEt}) \operatorname{Ir}(\mathrm{CO}){ }_{2} \mathrm{Cl}$ (49a; Scheme 22) catalyst in the presence of $\mathrm{CsOH}$ in toluene at $100^{\circ} \mathrm{C} .{ }^{62 \mathrm{~b}}$ 

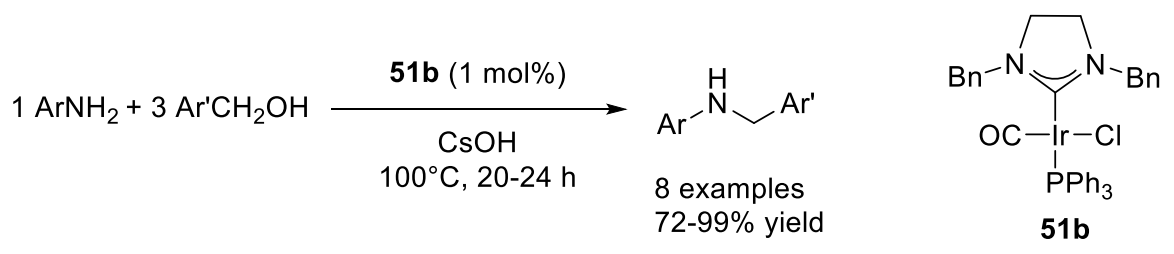

Scheme 149. N-alkylation reaction catalyzed by complex $\mathbf{5 1 b}$.

Complex 268a (Scheme 91) showed remarkable activity in the N-alkylation of amines with alcohols. ${ }^{117}$ Both primary and secondary aromatic amines were alkylated in good to excellent yields (Scheme 150), with various primary and secondary alcohols used as the coupling partners. Aliphatic amines however showed low reactivity with conversions of less than $10 \%$. In general, an ideal one to one ratio of amine and alcohol substrates was adequate and sufficient for the reaction to occur and some reactions could be performed at low catalyst loadings $(1 \mathrm{~mol} \%)$ and mild reaction conditions $\left(50^{\circ} \mathrm{C}\right) .{ }^{117 \mathrm{a}}$ Mechanistic investigations revealed that 268a operates as a bifunctional catalyst (Scheme 151). ${ }^{117 \mathrm{~b}}$ Related (NHC) $\operatorname{Ir}\left(\mathrm{Cp}^{*}\right) \mathrm{Cl}_{2}$ complexes reported by Zhu et al. were also briefly evaluated in the N-alkylation of aniline with benzyl alcohol. ${ }^{177}$ In a parallel development, the N-alkylation of anilines with methanol was developed by Crabtree and coworkers. ${ }^{215}$ Furthermore, the Marr group showed that piano-stool complexes 216 (Scheme 79) and (bmim) $\operatorname{Ir}\left(\mathrm{Cp}^{*}\right) \mathrm{Cl}_{2}$ (bmim $=1$-butyl-3-methyl-imidazolium) can be applied for the amination of 1,3-propanediol. However, this amination reaction was often accompanied by dehydration of the 1,3-propanediol starting material to 2methyl-2-pentenal and acrolein dimer products. ${ }^{235}$

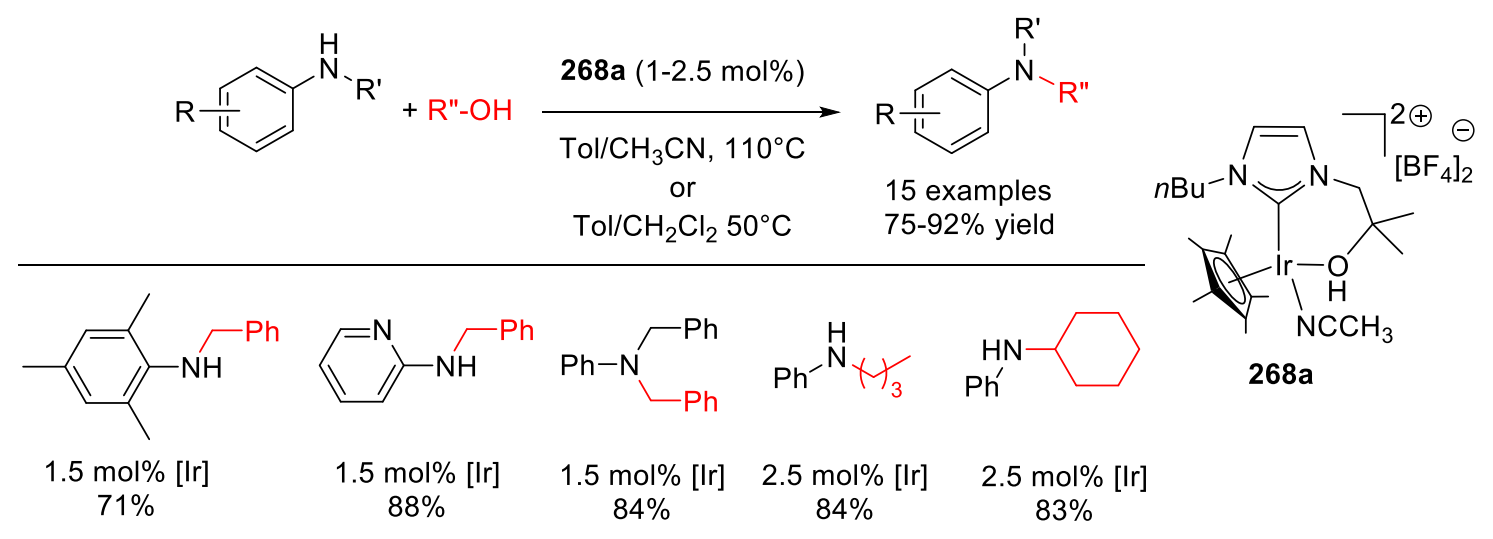

Scheme 150. N-alkylation with catalyst 268 a.

The efficiency of porous polymeric aromatic framework supported NHC-Ir catalysts were probed in the Nalkylation reaction of anilines with benzyl alcohol derivatives. ${ }^{186}$

Hemilabile interactions were also found to be important in a more classical C-N bond-forming scheme, namely the intramolecular hydroamination reaction. ${ }^{236}$ Grotjahn et al. showed that the aforementioned $\operatorname{Ir}(\mathrm{III})$ complexes 280c-d and $\mathbf{2 8 1}$ (see Figure 15) display appreciable catalytic activity (Scheme 152), while the tightly bound 280a remains virtually inactive in the hydroamination/cyclization of simple amino alkenes. ${ }^{124}$

More recently, the Dorta group showed that the highly unsaturated NHC-Ir(I) compound 107[ $\left.\mathrm{PF}_{6}\right]$ displays excellent reactivity in the hydroamination/cyclization of unactivated aminoalkenes under mild conditions (Scheme 153). ${ }^{82 \mathrm{a}}$ The low catalyst loadings (as low as $0.25 \mathrm{~mol} \%$ ) and high turnover frequencies (up to 3500 
$\mathrm{h}^{-1}$ ) achieved render compound $\mathbf{1 0 7}\left[\mathrm{PF}_{6}\right]$ one of the most active intramolecular hydroamination catalysts reported to date.

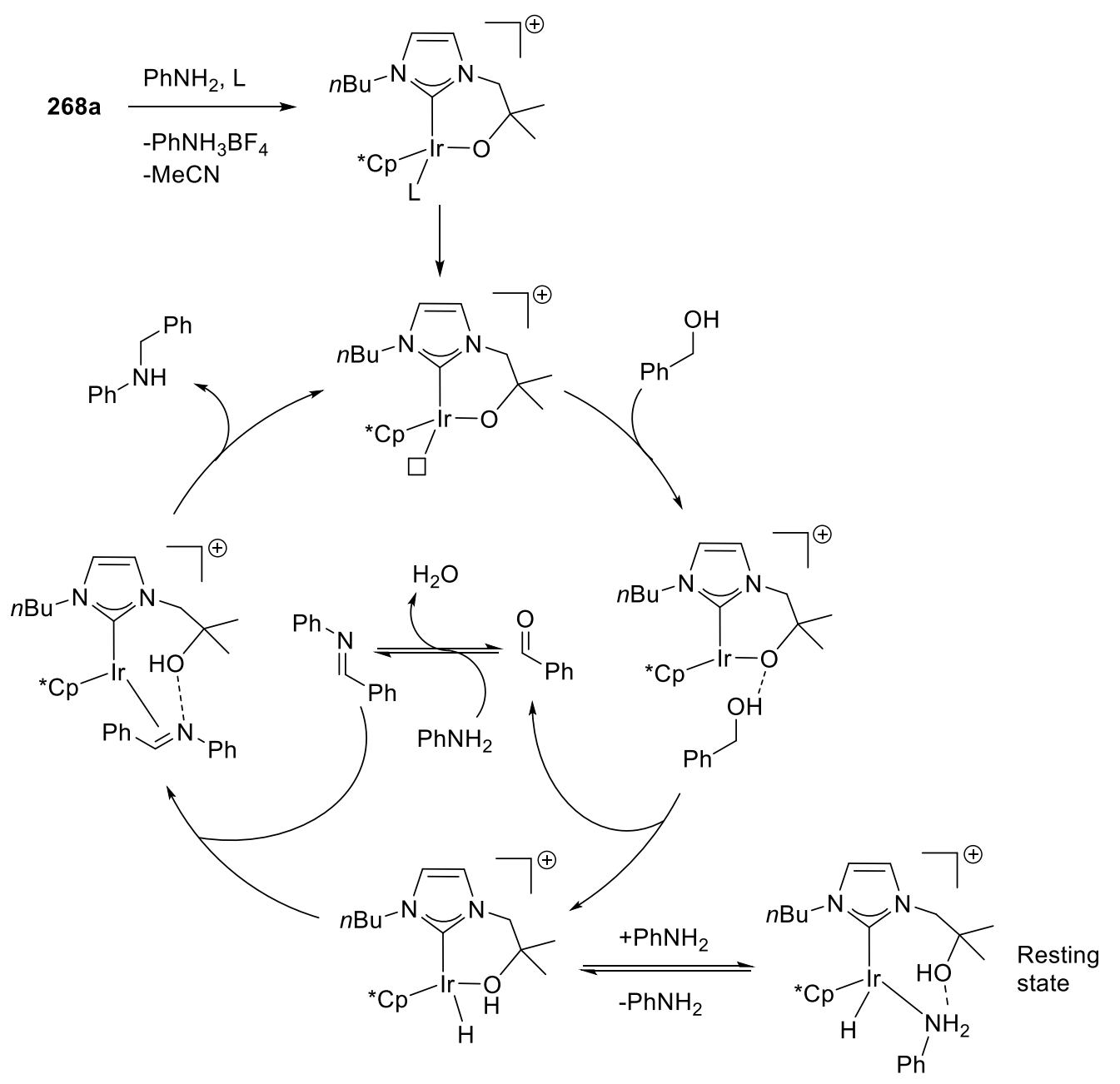

Scheme 151. Plausible mechanism for N-alkylation of amines with in situ activated catalyst $\mathbf{2 6 8 a}$ as suggested by Martín-Matute et al.

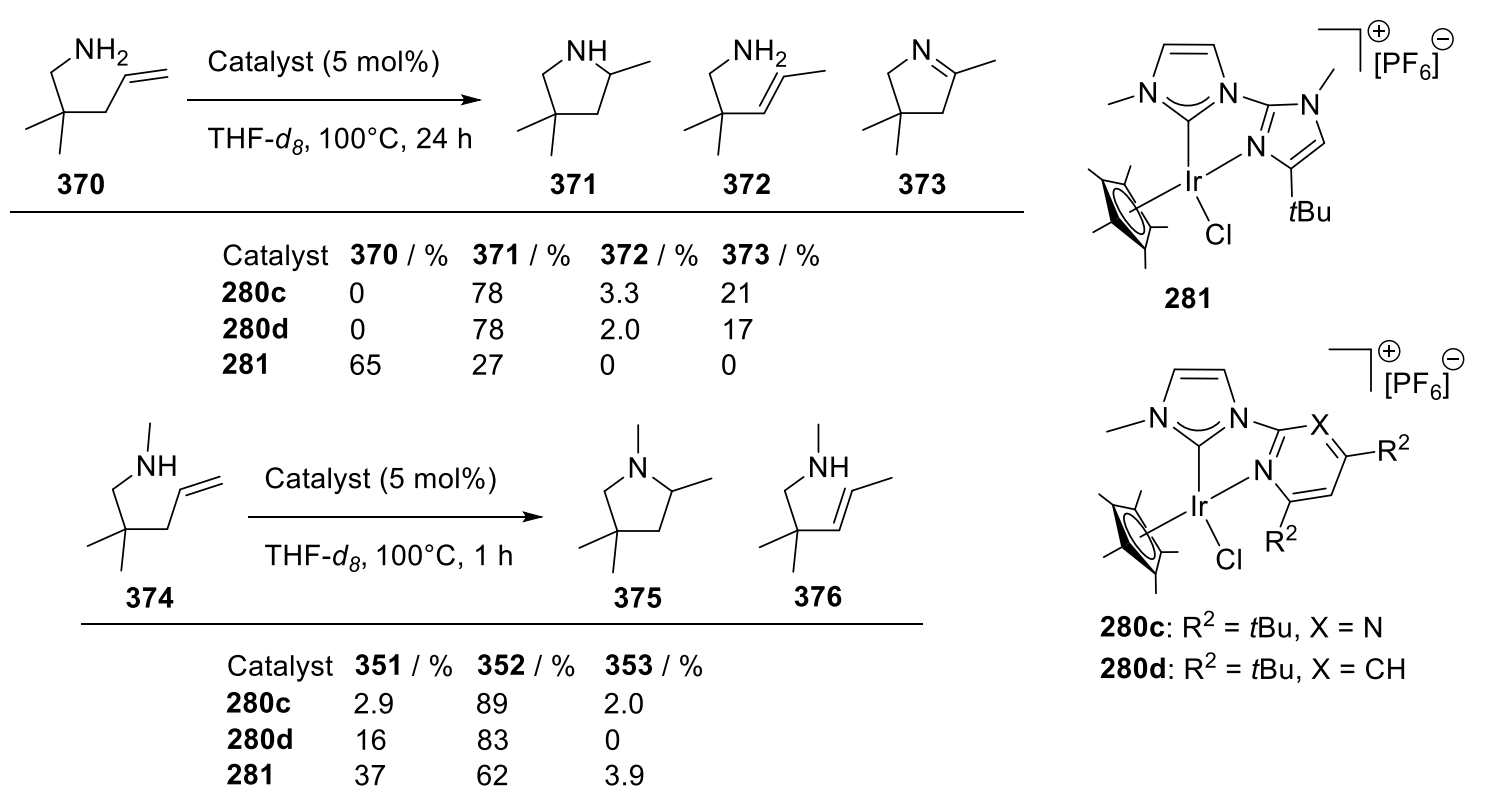

Scheme 152. Hydroamination reaction with NHC-Ir complexes developed by Grotjahn. 

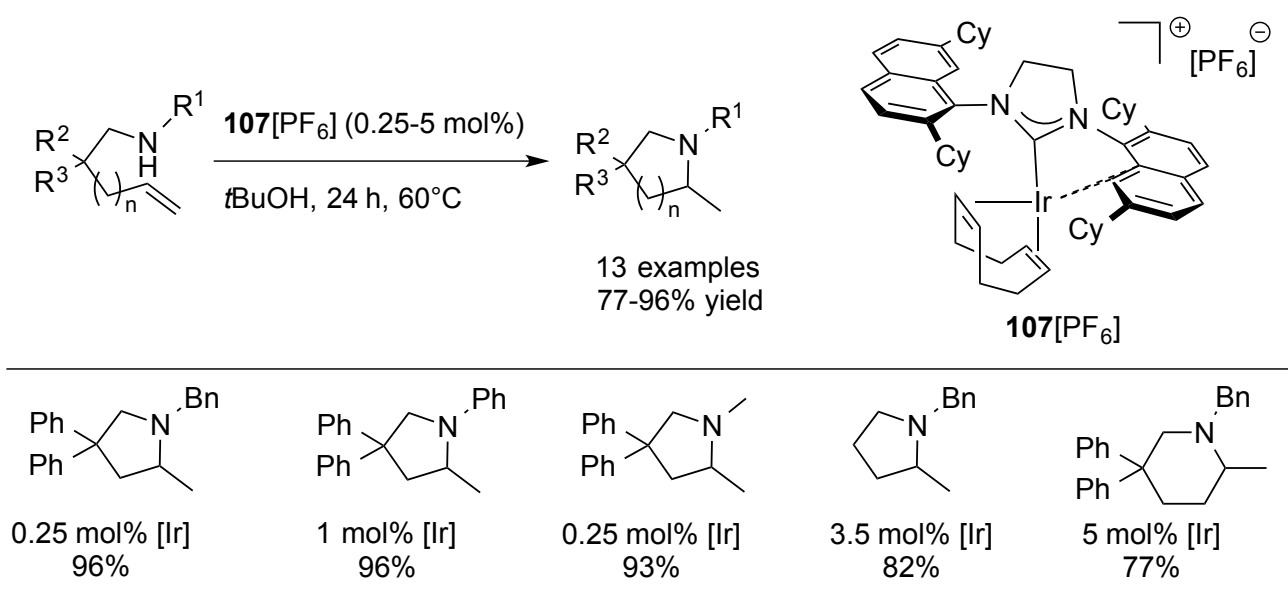

Scheme 153. Unusual NHC-Ir(I) complex $107\left[\mathrm{PF}_{6}\right]$ in the hydroamination reaction.

\subsection{4. $C$-O bond formation}

We are aware of only two reports on NHC-Ir catalyzed C-O bond forming reactions, both reported by the Peris group. Cross-coupling of benzyl alcohol with primary and secondary alcohols to afford unsymmetrical ethers was realized using $(\mathrm{I} t \mathrm{Bu}) \operatorname{Ir}\left(\mathrm{Cp}^{*}\right) \mathrm{Cl}_{2}$ (369) in combination with AgOTf (Scheme 154). ${ }^{233}$ On the other hand, the NHC-Ir(I) complex 360 (Scheme 136) was not only employed in the hydrosilylation reaction, but also displayed activity for the intramolecular cyclization of 4-pentynoic and 5-hexynoic acids. ${ }^{222}$

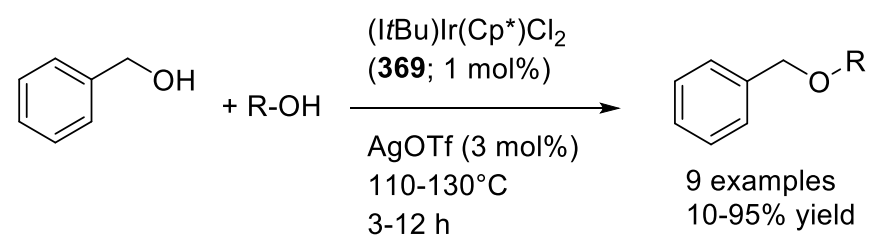

Scheme 154. C-O cross-coupling catalyzed by $(\mathrm{I} t \mathrm{Bu}) \operatorname{Ir}\left(\mathrm{Cp}^{*}\right) \mathrm{Cl}_{2}(\mathbf{3 6 9})$.

\subsubsection{C-Si bond formation}

The only example of C-Si bond formation we are aware of was reported by Mashima and coworkers, who realized the dehydrogenative silylation of arenes catalyzed by 169 (Scheme 65, Scheme 155). ${ }^{95}$ Triethylsilane served as an EtSi source, and the addition of norbornene as a hydrogen scavenger was required in order to achieve high catalytic activity.

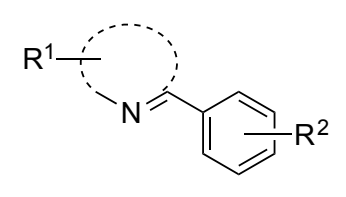

a) $169(5 \mathrm{~mol} \%)$ norbornene toluene, $\Delta, 3 \mathrm{~h}$

b) $\mathrm{Et}_{3} \mathrm{SiH}, 24 \mathrm{~h}$

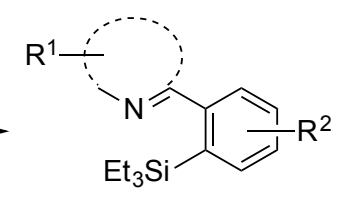

15 examples $5-99 \%$ yield

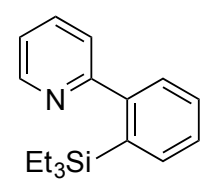

$98 \%$<smiles>CC[SiH2]c1cccc(C)c1-c1ccccn1</smiles>

$5 \%$<smiles>CCOc1ccccc1-n1cccn1</smiles>

$64 \%$<smiles>CC[SiH2]c1ccccc1/C=N/c1ccccc1</smiles>

$87 \%$<smiles>Cc1cc(C)cc(N2c3cccc4cccc(c34)N(C)C2[I-]2(OC(=O)O)C3CCC2CC3)c1</smiles>

169 
Scheme 155. The dehydrogenative silylation of arenes.

\subsection{Miscellaneous}

The first retro-hydroformylation of an aldehyde was reported recently by Nozaki and coworkers. The process was catalyzed by half-sandwich NHC-Ir(III) complexes featuring hydroxytetraphenylcyclopentadienyl ligands (Scheme 156). Control experiments illustrated that the reaction is likely to proceed through a retrohydroformylation rather than sequential decarbonylation-dehydrogenation or dehydrogenationdecarbonylation pathways. ${ }^{237}$

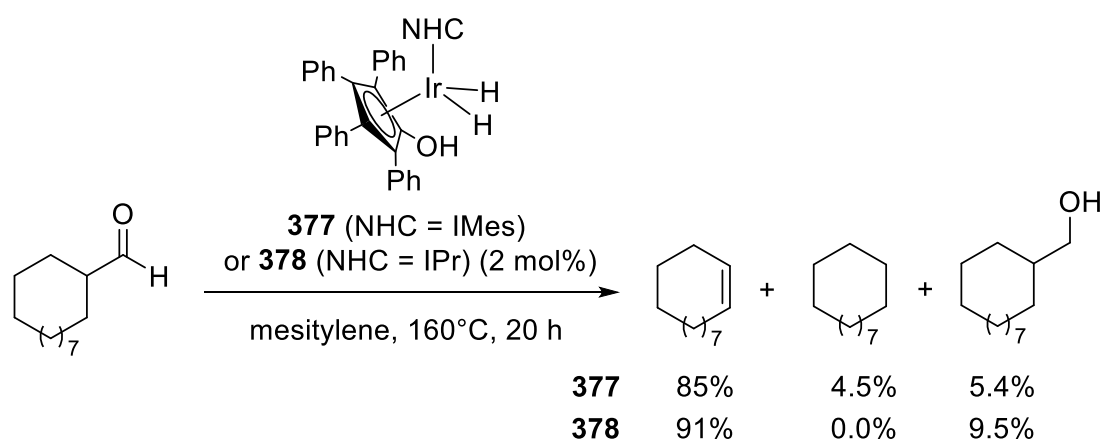

Scheme 156. The first retro-hydroformylation reaction.

The Nolan group showed that $(\operatorname{Ii} \operatorname{Pr}) \operatorname{Ir}(\mathrm{COD})(\mathrm{OH})$ (46f; Scheme 20) is a competent catalyst for the rearrangement of allylic alcohols to ketones. At first, the reaction was carried out at $0.25 \mathrm{~mol} \%$ [Ir] under conventional heating conditions. Next, it was shown that both the reaction time and the catalyst loading can be significantly lowered when microwave irradiation is used for heating (Scheme 157). ${ }^{238}$

Ott et al. found that in imidazolium-based ionic liquids, N-heterocyclic carbene formation and ligation to $\operatorname{Ir}(0)$ nanoclusters can occur. ${ }^{239}$ Half-sandwich iridium complexes showed excellent activity as water oxidation catalysts. ${ }^{240,241}$

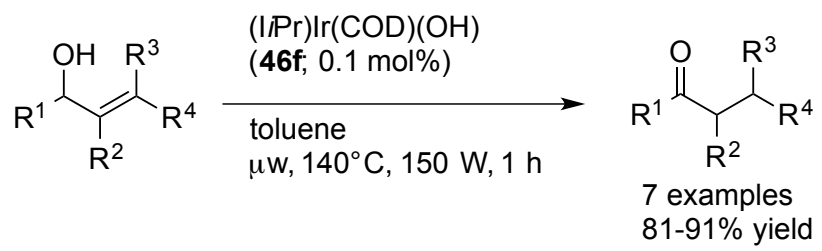

Scheme 157. Rearrangement of allylic alcohols to ketones catalyzed by $\mathbf{4 6 f}$.

Compound (6Mes) $\operatorname{Ir}(\mathrm{COD})\left(\mathrm{CF}_{3} \mathrm{COO}\right)$ (71; Scheme 32) together with other Ir, $\mathrm{Rh}$ and $\mathrm{Ru}$ complexes were tested in the polymerization of phenylacetylene. In contrast to the Rh systems, 71 showed high transselectivity, but generally low activity (maximum 11\% yield). The other iridium systems tested in the study were even less active. ${ }^{77}$

Achiral half-sandwich NHC-Ir(III) compounds were found to catalyze the racemization of secondary alcohols under base-free conditions. When these complexes were combined with an enzyme, which catalyzed the asymmetric esterification with isopropenyl acetate, dynamic kinetic resolution took place. ${ }^{242}$ 


\subsection{Magnetization transfer catalysis}

NMR and MRI are important techniques in chemistry, biochemistry and medicine. However, their application is somewhat limited due to the inherently low sensitivity of these methods. By redistributing the nuclear spin state populations, hyperpolarization techniques offer a way to enhance sensitivity. ${ }^{243}$ In particular, Duckett et al. developed polarization transfer from para- $\mathrm{H}_{2}$ without actual chemical modification of the substrate. This technique, called signal amplification by reversible exchange (SABRE) was first exemplified by employing Crabtree's complex as a precatalyst. ${ }^{244}$ Not much later, the same group found that (IMes) $\operatorname{Ir}(\mathrm{COD}) \mathrm{Cl}(\mathbf{2 2 g})$ is an even more efficient magnetization transfer precatalyst. The catalytically active species $\mathbf{3 8 0}$ was formed by treating $\mathbf{2 2 g}$ with para- $\mathrm{H}_{2}$ and excess pyridine (Scheme 158). ${ }^{24,245}$ Variations on the ligand sphere of iridium were examined, ${ }^{25,246}$ and a heterogeneous SABRE system was also described. ${ }^{247}$ Research considering specific aspects related to in vivo applications is under continuous and rapid development. $^{248}$

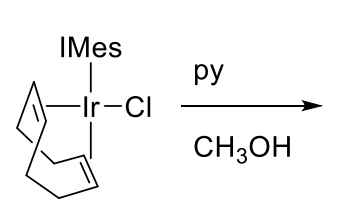

$22 \mathrm{~g}$

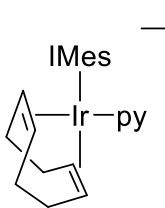

379

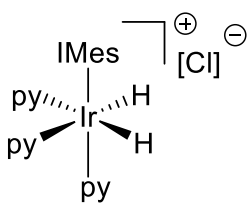

380

Scheme 158. Formation of $\mathbf{3 8 0}$ for magnetization transfer.

\section{Enantioselective catalysis with NHC-iridium catalysts}

Early on in 1996, Herrmann's group demonstrated the potential of enantiopure monodentate NHCs as ligands in asymmetric catalysis. ${ }^{249}$ A rhodium complex with a chiral monodentate NHC ligand was able to facilitate the asymmetric hydrosilylation of acetophenone, albeit with low enantioselectivities (up to $32 \%$ ee). The first truly efficient chiral ligand system featuring an NHC, although within a chelating framework, was described by Burgess et al. five years later (Ir hydrogenation catalyst). ${ }^{250}$ Even though the past two decades have witnessed continuous and successful developments in the field of NHC-iridium catalyzed applications, efficient enantioselective systems remain scarce, in particular ones that feature monodentate NHC ligands. In the following section we review the state-of-the-art of the few available chiral monodentate NHC-Ir catalysts. 


\subsection{Asymmetric hydrogenation with dihydrogen}

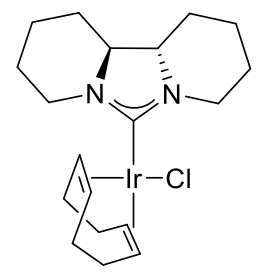

381

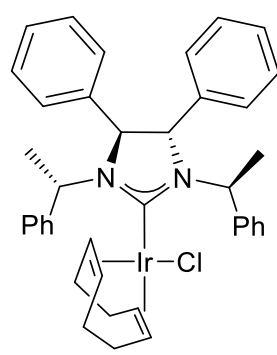

384

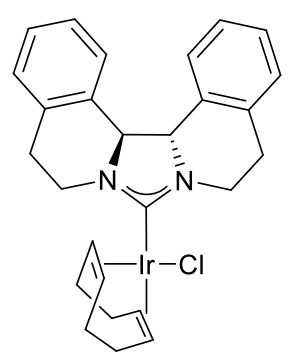

382

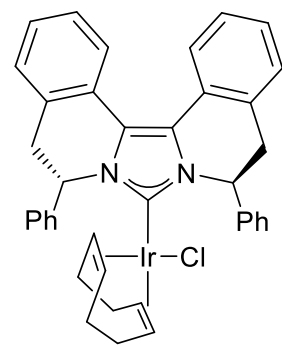

385

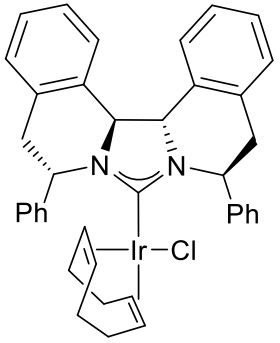

383

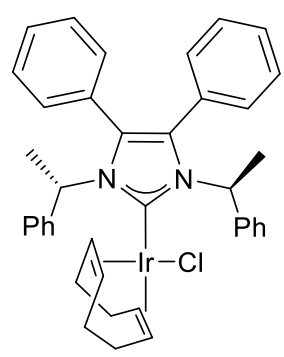

386

Figure 28. Chiral $\operatorname{Ir}(\mathrm{I})-\mathrm{NHC}$ complexes developed by Herrmann.

Herrmann has evaluated the performance of a whole series of complexes (381-386) in asymmetric hydrogenation catalysis (Figure 28, Scheme 159). ${ }^{251}$ Complexes 381 and 382 both proved to be efficient catalysts for the transformation, providing full conversion in the asymmetric hydrogenation of methyl-2acetamidoacrylate. Unfortunately, enantioinduction was not observed with $\mathbf{3 8 1}$ and enantioselectivity values recorded with $\mathbf{3 8 2}$ were very low ( $22 \%$ ee). These complexes were also shown to be active in the asymmetric hydrosilylation and transfer hydrogenation of acetophenone, but again enantioselection was negligible $(<24 \%$ ee $) .{ }^{251 a}$ Improved results were achieved by incorporating additional substituents on the methylene carbon adjacent to the nitrogen atoms as seen in $\mathbf{3 8 3 - 3 8 6 .}{ }^{251 b}$ This more bulky ligand framework with appropriately protruding phenyl groups led to results that showed optical purities of up to $67 \%$ ee (Scheme 159).

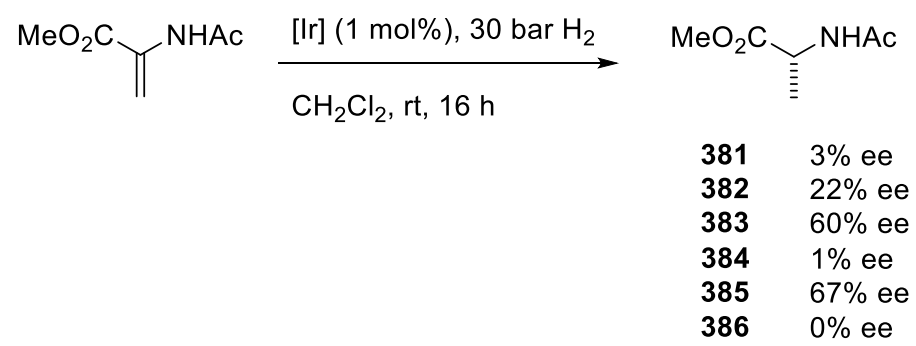

Scheme 159. Asymmetric hydrogenation of methyl-2-acetamidoacrylate.

In 2009, Metallinos and $\mathrm{Du}$ were able to achieve enantioselectivities of up to $81 \%$ ee in the asymmetric hydrogenation of the same class of acetamidoacrylate substrates (Scheme 160). ${ }^{164}$ The NHC ligand structure was overall very similar to the structures reported by Herrmann, but the authors noticed that substituting the two protruding phenyl groups with ferrocenyl moieties led to a clear increase in reactivity and 
enantioselectivity (387 vs 388). A cationic precatalyst (389) was also tested in their study. In a more recent contribution, Metallinos et al. more directly incorporated the ferrocene fragment into the NHC ligand design and described the preparation of novel chiral, cationic N-ferrocenyl-NHC-iridium complexes such as 390 (Scheme 161). ${ }^{252}$ The group then went on to test these catalysts in the asymmetric catalytic hydrogenation of quinolines, a reaction where previous work by Crabtree et al. (see section 9.1) had established NHC-Ir systems showing high reactivity under mild reaction conditions. ${ }^{28}$ Catalyst $\mathbf{3 9 0}$ was able to hydrogenate several 2-substituted quinolines with moderate to high yields and enantioselectivities (38-80\% ee). In separate work, complex 259, reported by Chung et al. (Scheme 89), showed no activity in the hydrogenation of dimethyl itaconate. ${ }^{115 a}$

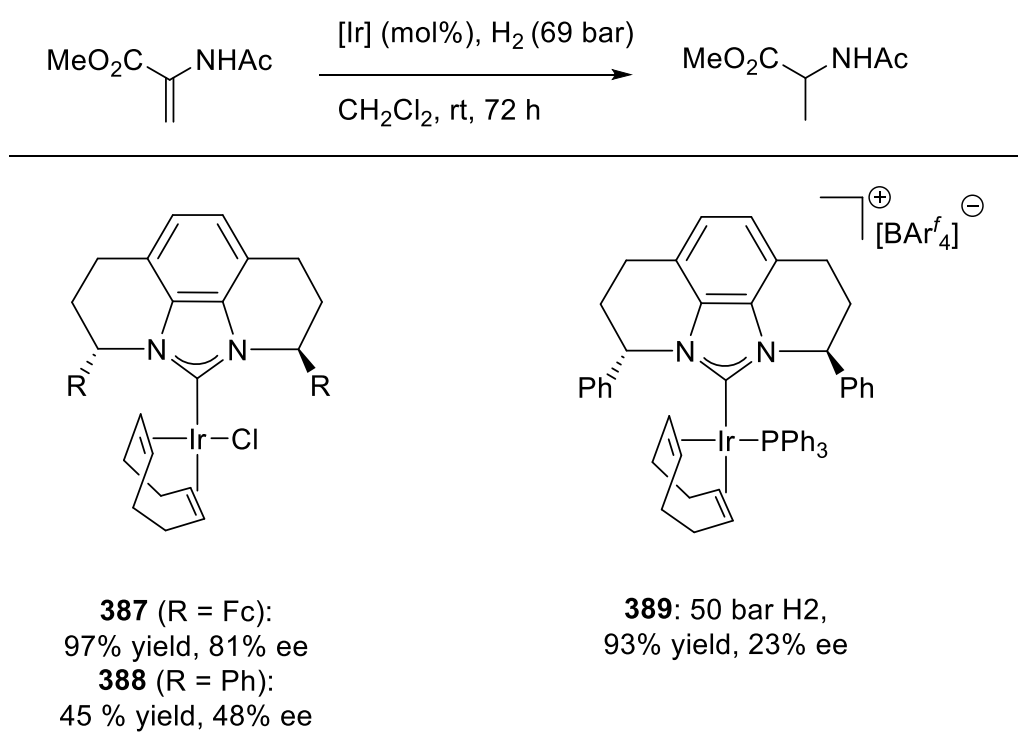

Scheme 160. Asymmetric hydrogenation of methyl-2-acetamidoacrylate.
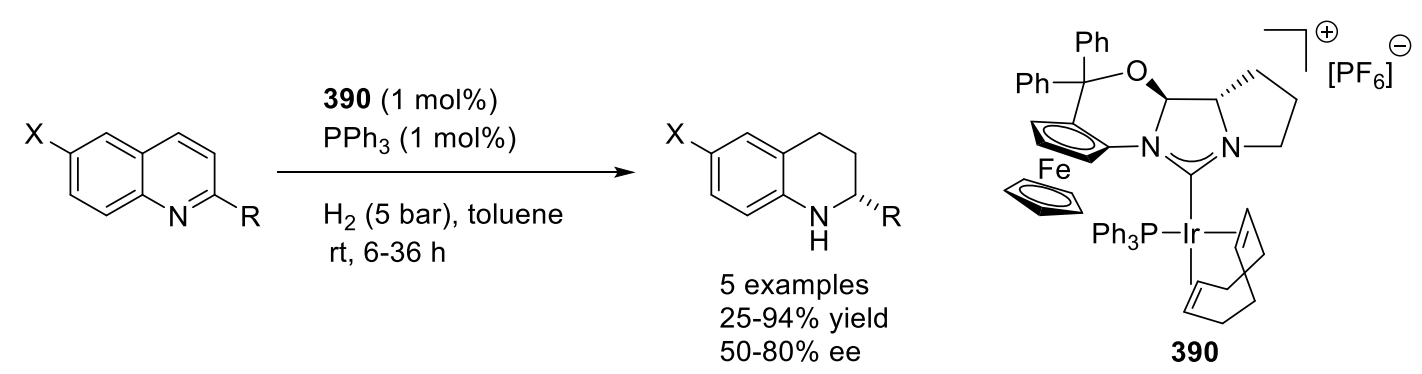

Scheme 161. Asymmetric hydrogenation of quinolines with complex 390. 


\subsection{Asymmetric transfer hydrogenation}

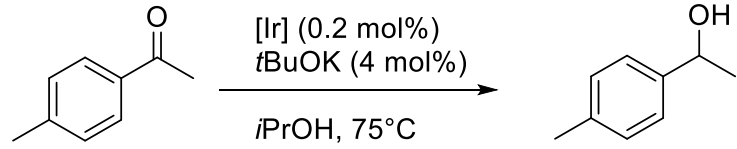

391: $>99 \%$ yield, $14 \%$ ee

392: $98 \%$ yield, $53 \%$ ee

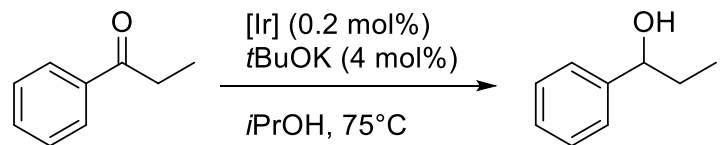

391: $>99 \%$ yield, $22 \%$ ee

392: $98 \%$ yield, $32 \%$ ee

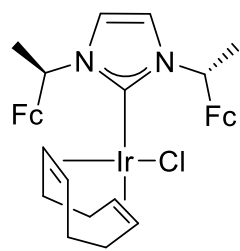

391

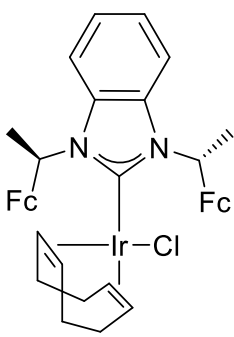

392

Scheme 162. Asymmetric transfer hydrogenation with complexes 391 and 392.

Transfer hydrogenation has been the subject of some studies that tried to employ chiral, monodentate NHCIr systems. The first report, by the Chung group, ${ }^{115 \mathrm{~b}}$ presented chiral NHC ligands where the chirality resided on the two $\alpha$-carbon positions of the N-substituents. The NHC-iridium complexes 391 and 392 (Scheme 162) were tested in the TH of acetophenone derivatives, where good conversions were achieved with surprisingly low catalyst loadings $(0.2 \mathrm{~mol} \%)$, but where enantioselectivities remained very low.

More recently, the NHC-Ir(III) complex 393 (Figure 29) was used in the asymmetric transfer hydrogenation of acetophenone to give $46 \%$ yield and $18 \%$ ee of the reduced alcohol product. A catalyst system in situ generated from $\left[\mathrm{Cp}^{*} \mathrm{IrCl}_{2}\right]$ and ligand precursor 394 provided improved results with up to $60 \%$ ee. Although the NHC ligand shows monodentate coordination in precatalyst complex $\mathbf{3 9 3}$, it is more than likely that during catalysis, deprotonation of the ligand by $\mathrm{KOH}$ leads to a $\kappa^{2}-\mathrm{C}, \mathrm{N}$ NHC chelate that supports the catalytically active species. ${ }^{253}$ The chiral-at-metal complex 395, the enantiopure analogue of 343 (Scheme 119), was able to provide enantioselectivities up to $55 \%$ when acetophenone was used as a substrate (Scheme 133). ${ }^{179}$

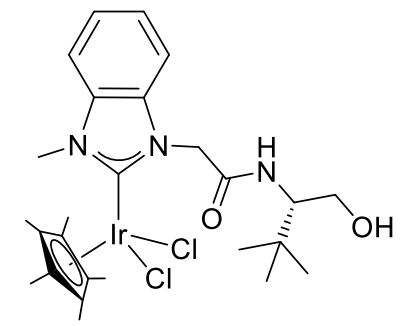

393<smiles></smiles>

394

Figure 29. Enantiopure NHC-Ir(III) complex 393 and NHC ligand 394. 

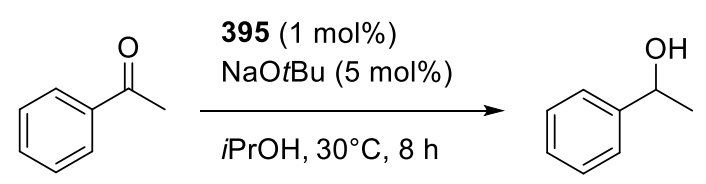

$99 \%$ yield $55 \%$ ee

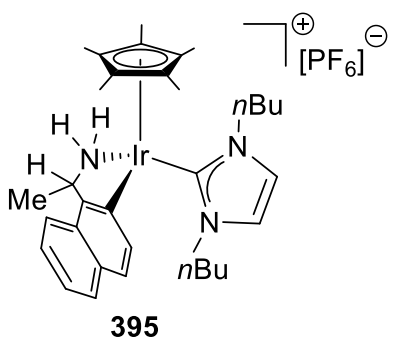

Scheme 163. Enantioselective catalysis with chiral-at-metal 395.

It was only in 2015 that excellent enantioselectivities were obtained for the first time with a monodentate NHC-Ir system. Yoshida et al. prepared a series of chiral bicyclic NHC-Ir(I) and NHC-Ir(III) complexes. ${ }^{254}$ Complex 396 was found to be an excellent precatalyst for the asymmetric transfer hydrogenation of ketones (Scheme 164). Remarkable ee values of up to $98 \%$ and high TONs (up to 4,500) were achieved. Interestingly, lower catalyst loadings provided significantly higher enantioselectivities. Sterically crowded NHC ligands with restricted rotation around the $\mathrm{NHC}(\mathrm{C})$-Ir bond were superior compared to ones where this rotation was allowed.
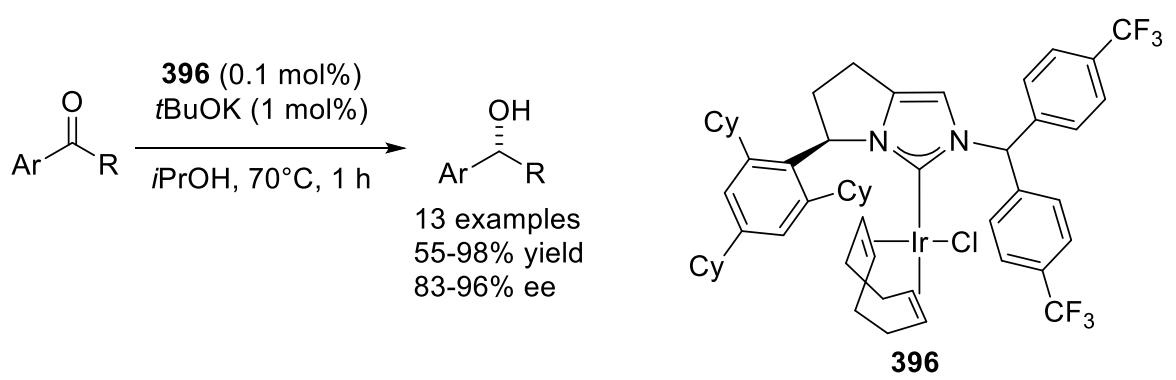

Scheme 164. Asymmetric transfer hydrogenation with 396.

\subsection{Asymmetric hydrosilylation}

Iridium(I) complexes of the hydroxy-amide functionalized NHC ligands (similar to 394 in Figure 29) were also successfully employed in the asymmetric hydrosilylation of ketones. While it is again more than likely that asymmetric induction originates from the fact that the NHC ligand chelates to the iridium during catalysis, the reaction is noteworthy as it provides the alcohol product with up to $96 \%$ ee (Scheme 165). ${ }^{255}$
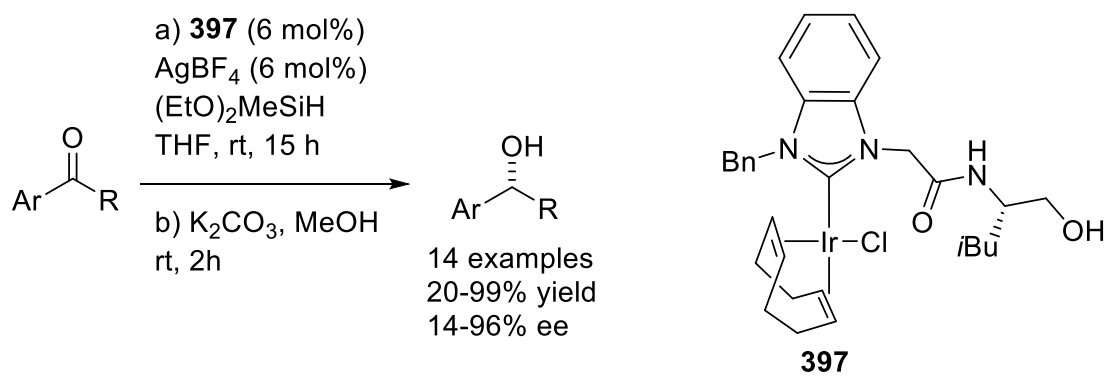

Scheme 165. Asymmetric hydrosilylation of ketones. 


\subsection{Asymmetric C-N bond formations}

Very recently, Dorta et al. introduced chiral, cationic NHC-Ir(I) complexes as catalysts for the intramolecular hydroamination reaction of unactivated aminoalkenes. ${ }^{82 a, c}$ Complex 398, which is the enantiopure version of $\mathbf{1 0 7}$ (see Scheme 45), was prepared using three different gegenions, $\mathrm{PF}_{6}, \mathrm{NTf}_{2}$ and $\mathrm{BAr}_{4}^{f}$ respectively. The $\mathbf{3 9 8}\left[\mathrm{NTf}_{2}\right]$ complex showed the best overall performance in catalysis. Highly enantioenriched pyrrolidines, piperidines and indoles were produced at low catalyst loadings and under mild conditions (Scheme 166). The system showed good tolerance towards a range of functional groups ( $t \mathrm{BuOH}$ solvent, amines, esters, halides, ethers, nitro group). Limitations however remain, with cyclization of the parent N-benyzl-pent-4-en-1-amine, a substrate where the Thorpe-Ingold effect is not operative, giving acceptable yields but low enantiopurity ( $20 \%$ ee). Nevertheless, the fact that virtually optically pure pyrrolidines were obtained and that other iridium systems (e.g. with phosphines or other chiral ligands) are unknown for this transformation bodes well for future applications of this group of chiral NHC ligands. The proposed catalytic cycle the authors put forth (Scheme 167) is in line with their experimental observations and follows a pathway where olefin coordination is followed by external attack of the amine to generate the carbon-nitrogen bond, which after hydrogen migration yields the product and regenerates the active catalyst species.

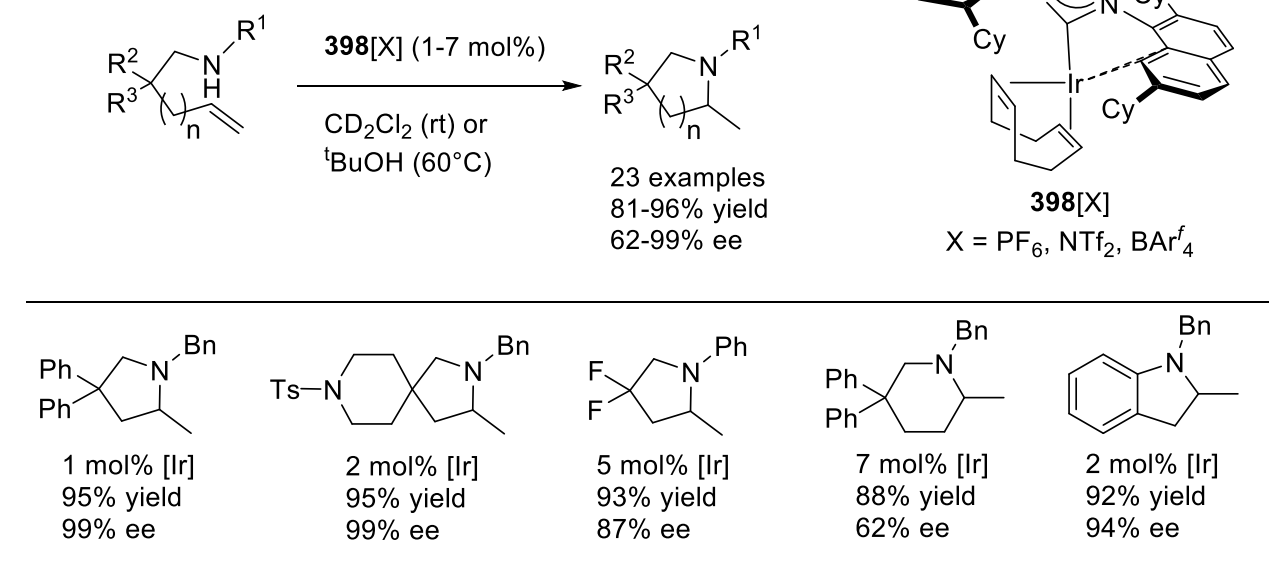

Scheme 166. Asymmetric intramolecular hydroamination by Dorta et al. 

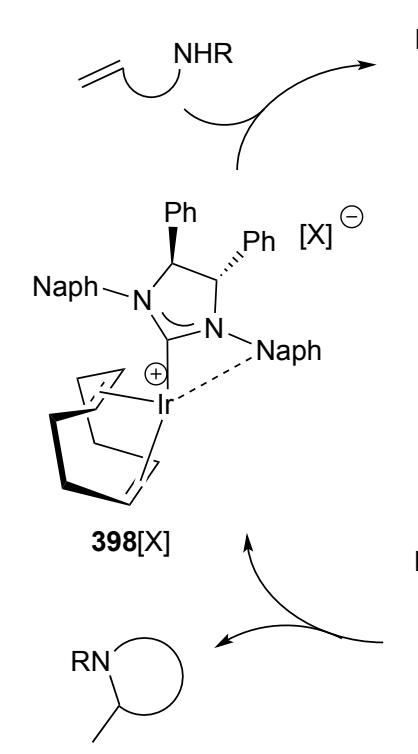
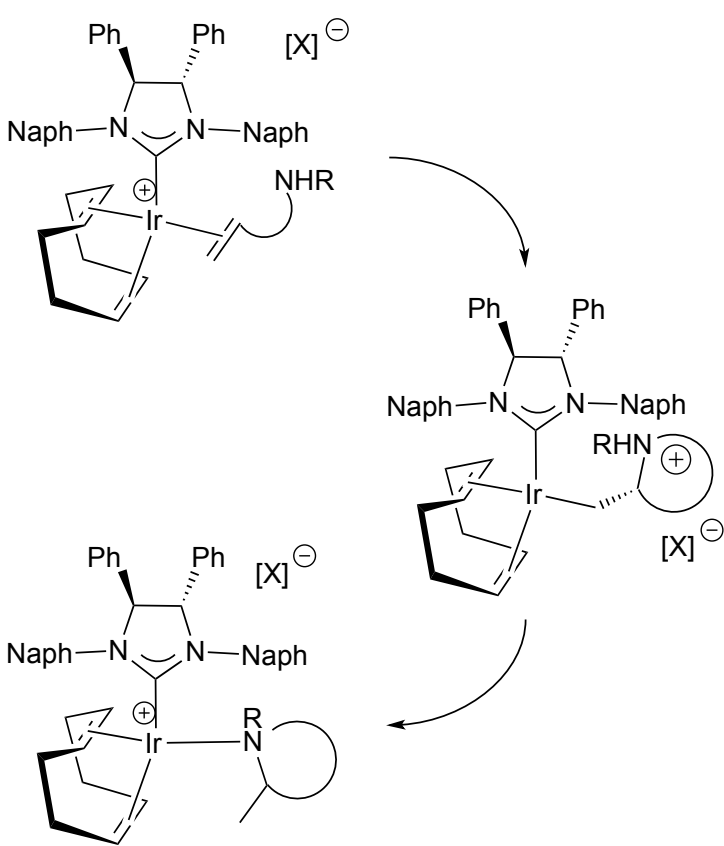

Scheme 167. Proposed catalytic cycle for the asymmetric intramolecular hydroamination catalyzed by

$398[\mathrm{X}]$.

The last example in this overview on asymmetric applications of NHC-Ir complexes is again not strictly falling into the scope of this review as it shows an example where a chiral triazolium salt (399) was used as an ancillary ligand in an iridium-catalyzed reaction scheme and where the NHC is effectively functioning as a chelate ligand. The group of You has very recently been successful in developing the first NHC-Ir catalyzed asymmetric intramolecular allylic amination reaction. ${ }^{256,257}$ Triazolium salts combined with $[\operatorname{Ir}(\mathrm{COD}) \mathrm{Cl}]_{2}$ in the presence of a base provided an array of cyclized indole products with good to excellent yields and high ee values (Scheme 168). The reaction was limited to the formation of six-membered rings and the allylic amination of pyrroles proved to be more challenging. Mechanistic studies revealed that not unlike what has been proposed with ligand 394, the catalytically active species presents a chelating ligand framework where the ortho $\mathrm{C}-\mathrm{H}$ position of the N-phenyl group of the ligand has undergone cyclometallation. Indeed, treatment of $\mathbf{4 0 0}$ with $\mathrm{AgBF}_{4}$ and allyl methyl carbonate afforded the catalytically active 401 (Scheme 169). It should be pointed out that this scenario has been observed before in such allylic amination reactions when employing Monophos-type ligands. ${ }^{258}$
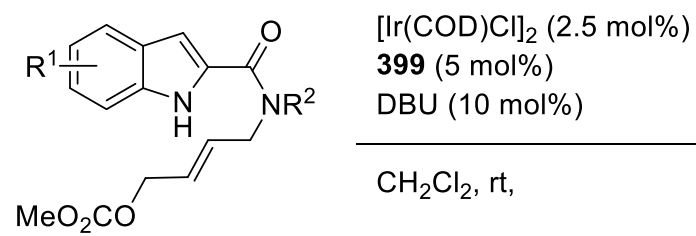

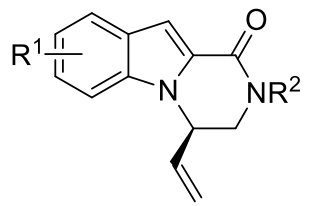

12 examples

$74-91 \%$ yield $96-99 \%$ ee<smiles>CC(C)(C)[C@H]1COc2n[n+](-c3ccccc3)cn21</smiles>

$\mathrm{BF}_{4}$

399

Scheme 168. Asymmetric allylic amination. 
<smiles></smiles>

400

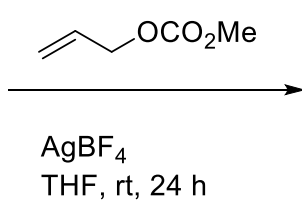

THF, rt, $24 \mathrm{~h}$

Scheme 169. Cyclometallation of $\mathbf{4 0 0}$.

\section{Bioactivity of monodentate NHC-Ir complexes}

There is significant interest in the development of NHC metal complexes as potential anti-tumor agents. ${ }^{259}$ Nonetheless, the exploration of corresponding iridium complexes as therapeutic agents only started to develop in recent years. NHC-rhodium and -iridium complexes decorated with anionic (sulfonate) or cationic (phosponium) pendant groups were tested for their antibacterial, antiparasitic and anticancer activity. The phosphonium complexes $\mathbf{4 0 2}$ and $\mathbf{4 0 3}$ (Figure 30) showed moderate to high activity, though accompanied with a general toxicity on mammalian cell lines. ${ }^{260}$ Complex 404 showed moderate antiproliferative activity in vitro. Reactivity studies between $\mathbf{4 0 4}$ and cytochrome c indicated an unusual oxidative binding mechanism. ${ }^{261}$ Very recently, these investigations were extended to a greater number of neutral and cationic iridium(I) complexes. ${ }^{262}$ Tamm, Neda and coworkers prepared and tested trifluormethylated NHC-M(I) $(\mathrm{M}=$ $\mathrm{Au}, \mathrm{Rh}, \mathrm{Ir}$ ) complexes for their antitumor activity; unfortunately, the iridium compounds showed low activity. ${ }^{263}$
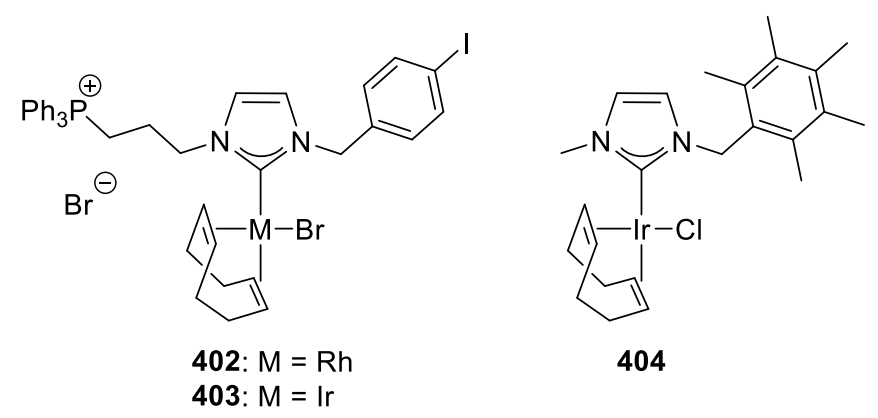

Figure 30. Iridium-complexes with biological activity.

\section{Summary and outlook}

Easily accessible iridium complexes with monodentate NHC ligands show an impressive array of structural diversity. Early reports explored the underlying chemical properties of such systems. These developments led to more recent work, which for example, readily utilizes the high tendency of iridium to engage in $\mathrm{C}-\mathrm{H}$ oxidative addition reactions. These processes are frequently reversible and/or catalytically exploitable as seen in hydrogenation or amine-borane dehydrogenation reactions. 
Unusual reactivity pathways have been discovered as well recently. In particular, Crabtree and co-workers' work related to the outer-sphere hydrogenation of quinolines or the glycerol dehydrogenation reaction offer pathways for further innovation when employing NHC-Ir systems. Other freshly developed reactions such as the retro-hydroformylation reaction catalyzed by NHC-Ir complexes, or the intramolecular hydroamination reaction with cationic NHC-Ir complexes show great promise as they underline the unique properties these NHC ligands can impart to their metal catalysts.

At the same time, the introduction of the well-known (IMes) $\operatorname{Ir}(\mathrm{COD}) \mathrm{Cl}$ and derivatives as magnetization transfer catalysts has led to an impressive number of reports. Because of the high interest in MRI imaging, this field of research is expected to grow further reaching in vivo applications.

Despite the large body of work carried out on monodentate NHC-iridium complexes during the last two decades, reports of asymmetric catalysis with monodentate NHC-Ir complexes remain sporadic and results are generally disappointing. Obviously, the particular three-dimensional shape of NHCs and high steric bulk that needs to be incorporated into the chiral ligand design poses particular challenges and inter alia means that protruding ligand groups will necessarily be placed within reach of the metal center. As a consequence, most catalytic results with iridium that show success with chiral monodentate NHCs come where these metallation events can be reversed (hydrogenation and similar Ir-hydride forming events) or are indeed part of the catalytically active species (Scheme 168). In the coming years, we can nevertheless expect to see first systems appear in the literature where these current limitations will be overcome (see also first promising results within this review). Such a development would again mirror a similar trend observed for chiral phosphorus based systems, where bulky monodentate ligands have seen a resurgence in the last decade and are becoming more and more predominant in catalytic asymmetric synthesis. ${ }^{264}$

\section{Acknowledgements:}

G.S. thanks UWA for an International Postgraduate Research Scholarship (IPRS). R.D. thanks the Australian Research Council (ARC) for generous funding (FT130101713). 


\section{References}

${ }^{1}$ a) H. W. Wanzlick, Angew. Chem. Int. Ed. 1 (1962) 75-80; b) H. W. Wanzlick, H. J. Schönherr, Angew. Chem. Int. Ed. 7 (1968) 141-142; c) K. Öfele, J. Organomet. Chem. 12 (1968) P42-P43.

2 a) B. Cetinkaya, P. Dixneuf, M. F. Lappert, J. Chem. Soc., Dalton Trans. (1974) 1827-1833; b) P. B. Hitchcock, M. F. Lappert, P. Terreros, J. Organomet. Chem. 239 (1982) C26-C30.

${ }^{3}$ a) G. R. Clark, W. R. Roper, A. H. Wright, J. Organomet. Chem. 236 (1982) C7-C10; b) J. Müller, C. Hänsch, J. Pickardt, J. Organomet. Chem. 259 (1983) C21-C25.

${ }^{4}$ Early reviews on metal-carbene complexes: a) D. J. Cardin, B. Cetinkaya, M. F. Lappert, Chem. Rev. 72 (1972), 545574; b) M. F. Lappert, J. Organomet. Chem. 358 (1988) 185-214.

${ }^{5}$ A. Igau, H. Grutzmacher, A. Baceiredo, G. Bertrand, J. Am. Chem. Soc. 110 (1988) 6463-6466.

${ }^{6}$ a) A. J. Arduengo, R. L. Harlow, M. Kline, J. Am. Chem. Soc. 113 (1991) 361-363; b) A. J. Arduengo, H. V. Rasika Dias, R. L. Harlow, M. Kline, J. Am. Chem. Soc. 114 (1992) 5530-5534; c) A. J. Arduengo, J. R. Goerlich, W. J. Marshall, J. Am. Chem. Soc. 117 (1995) 11027-11028.

${ }^{7}$ W. A. Herrmann, M. Elison, J. Fischer, C. Köcher, G. R. J. Artus, Angew. Chem. Int. Ed. 34 (1995) 2371-2374.

${ }^{8}$ a) R. H. Crabtree, H. Felkin, G. E. Morris, J. Organomet. Chem. 141 (1977) 205-215; b) R. H. Crabtree, H. Felkin, T. Fillebeen-Kahn, G. E. Morris, J. Organomet. Chem. 168 1979 183-195.

${ }^{9}$ We do not discuss triazolediylidenes such as: a) E. Mas-Marzá, J. A. Mata, E. Peris, Angew. Chem. Int. Ed. 46 (2007) 3729-3731; b) A. Zanardi, J. A. Mata, E. Peris, J. Am. Chem. Soc. 131 (2009) 14531-14537. For a recent phosphazane/NHC see: c) T. Roth, V. Vasilenko, C. G. M. Benson, H. Wadepohl, D. S. Wright, L. H. Gade, Chem. Sci. 6 (2015) 2506-2510. Examples with abnormal carbenes: d) L. N. Appelhans, D. Zuccaccia, A. Kovacevic, A. R. Chianese, J. R. Miecznikowski, A. Macchioni, E. Clot, O. Eisenstein, R. H. Crabtree, J. Am. Chem. Soc. 127 (2005) 16299-16311; e) V. Lavallo, Y. Canac, C. Präsang, B. Donnadieu, G. Bertrand, Angew. Chem. Int. Ed. 44 (2005) 57055709.

${ }^{10}$ D. J. Nelson, S. P. Nolan, Chem. Soc. Rev. 42 (2013) 6723-6753.

${ }^{11}$ R. Visbal, M. C. Gimeno, Chem. Soc. Rev. 43, 2014, 3551-3574.

12 a) N-Heterocyclic Carbenes in Synthesis (Ed.: S. P. Nolan) (2006), Wiley-VCH: Weinheim; b) N-Heterocyclic Carbenes in Transition Metal Catalysis (Eds.: F. Glorius, S. Bellemin-Laponnaz) (2007), Springer: Berlin; c) NHeterocyclic Carbenes in Transition Metal Catalysis and Organocatalysis (Ed.: C. S. J. Cazin), (2010), Springer: Berlin; d) N-Heterocyclic Carbenes: From Laboratory Curiosities to Efficient Synthetic Tools (Ed.: S. Díez-González) (2011), RSC: Cambridge; e) N-Heterocyclic Carbenes (Ed.: S. P. Nolan) (2014), Wiley-VCH: Weinheim; For a short account, see: f) M. N. Hopkinson, C. Richter, M. Schedler, F. Glorius, Nature 510 (2014) 485-496.

${ }^{13}$ a) S. Díez-Gonzalez, N. Marion, S. P. Nolan, Chem. Rev. 109 (2009) 3612-3676; b) G. C. Vougioukalakis, R. H. Grubbs, Chem. Rev. 110 (2010) 1746-1787; c) F. Wang, L. J. Liu, W. Wang, S. Li, M. Shi, Coord. Chem. Rev. 256 (2012) 804-853; NHC synthesis: d) P. de Frémont, N. Marion, S. P. Nolan, Coord. Chem. Rev. 253 (2009) 862-892; e) L. Benhamou, E. Chardon, G. Lavigne, S. Bellemin-Laponnaz, V. César, Chem. Rev. 111 (2011) 2705-2733; NHC stability and reactivity: f) C. M. Crudden, D. P. Allen, Coord. Chem. Rev. 248 (2004) 2247-2273; M-NHC bond: g) H. Jacobsen, A. Correa, A. Poater, C. Costabile, L. Cavallo, Coord. Chem. Rev. 253 (2009) 687-703; NMR spectroscopy of the M-NHC bond: h) L. Falivene, L. Cavallo, Coord. Chem. Rev. 344 (2017) 101-114.

${ }^{14}$ M. Prinz, L. F. Veiros, M. J. Calhorda, C. C. Ramão, E. Herdtweck, F. E. Kühn, W. A. Herrmann, J. Organomet. Chem. 691 (2006) 4446-4458.

${ }^{15}$ A. T. Termaten, M. Schakel, A. W. Ehlers, M. Lutz, A. L. Spek, K. Lammertsma, Chem. Eur. J. 9 (2003) 3577-3582. 
${ }^{16}$ B. Hildebrandt, S. Raub, W. Frank, C. Ganter, Chem. Eur. J. 18 (2012) 6670-6678.

${ }^{17}$ E. L. Kolychev, S. Kronig, K. Brandhorst, M. Freytag, P. G. Jones, M. Tamm, J. Am. Chem. Soc. 135 (2013) $12448-$ 12459

${ }^{18}$ C. Y. Tang, J. Lednik, D. Vidovic, A. L. Thompson, S. Aldridge, Chem. Commun. 47 (2011) 2523-2525.

${ }^{19}$ B. J. Truscott, D. J. Nelson, A. M. Z. Slawin, S. P. Nolan, Chem. Commun. 50 (2014) 286-288.

${ }^{20}$ L. Rubio-Pérez, M. Iglesias, J. Munárriz, V. Polo, P. J. S. Miguel, J. J. Pérez-Torrente, L. A. Oro, Chem. Commun. 51 (2015) 9860-9863.

${ }^{21}$ J. Campos, L. S. Sharninghausen, R. H. Crabtree, D. Balcells, Angew. Chem. Int. Ed. 53 (2014) 12808-12811.

${ }^{22}$ O. Torres, M. Martín, E. Sola, Organometallics 28 (2009) 863-870.

${ }^{23}$ M. V. Jiménez, J. Fernández-Tornos, J. J. Pérez-Torrente, F. J. Modrego, S. Winterle, C. Cunchillos, F. J. Lahoz, L. A. Oro, Organometallics 30 (2011) 5493-5508.

${ }^{24}$ M. J. Cowley, R. W. Adams, K. D. Atkinson, M. C. R. Cockett, S. B. Duckett, G. G. R. Green, J. A. B. Lohman, R. Kerssebaum, D. Kilgour, R. E. Mewis, J. Am. Chem. Soc. 133 (2011) 6134-6137.

${ }^{25}$ M. Fekete, O. Bayfield, S. B. Duckett, S. Hart, R. E. Mewis, N. Pridmore, P. J. Rayner, A. Whitwood, Inorg. Chem. 52 (2013) 13453-13461.

${ }^{26}$ J. Fawcett, D. A. J. Harding, E. G. Hope, K. Singh, G. A. Solan, Dalton Trans. 39 (2010) 10781-10789.

${ }^{27}$ L. Rubio-Pérez, E. A. Jaseer, N. García, V. Polo, M. Iglesias, L. A. Oro, Organometallics 35 (2016) 569-578.

${ }^{28}$ G. E. Dobereiner, A. Nova, N. D. Schley, N. Hazari, S. J. Miller, O. Eisenstein, R. H. Crabtree, J. Am. Chem. Soc. 133 (2011) 7547-7562.

${ }^{29}$ N. M. Scott, V. Pons, E. D. Stevens, D. M. Heinekey, S. P. Nolan, Angew. Chem. Int. Ed. 44 (2005) 2512-2515.

${ }^{30}$ L. S. Sharninghausen, J. Campos, M. G. Manas, R. H. Crabtree, Nature Comm. 5 (2014) 5084.

${ }^{31}$ S. A. Hauser, R. Tonner, A. B. Chaplin, Organometallics 34 (2015) 4419-4427.

${ }^{32}$ J. Campos, U. Hintermair, T. P. Brewster, M. K. Takase, R. H. Crabtree, ACS Catal. 4 (2014) 973-985.

${ }^{33}$ L. S. Sharninghausen, B. Q. Mercado, R. H. Crabtree, D. Balcells, J. Campos, Dalton Trans. 44 (2015) 18403-18410.

${ }^{34}$ R. Corberán, E. Peris, Organometallics 27 (2008) 1954-1958.

${ }^{35}$ R. Corberán, M. Sanaú, E. Peris, J. Am. Chem. Soc. 128 (2006) 3974-3979.

${ }^{36}$ N. Phillips, L. Treasure, N. H. Rees, R. Tirfoin, J. E. McGrady, S. Aldridge, Eur. J. Inorg. Chem. (2014) 4877-4885.

${ }^{37}$ E. Peris, Top. Organomet. Chem. 21 (2007) 83-116.

${ }^{38}$ W. A. Herrmann, M. Elison, J. Fischer, C. Köcher, G. R. J. Artus, Chem. Eur. J. 2 (1996) 772-780.

${ }^{39}$ G. D. Frey, C. F. Rentzsch, D. von Preysing, T. Scherg, M. Mühlhofer, E. Herdtweck, W. A. Herrmann, J. Organomet. Chem. 691 (2006) 5725-5738.

${ }^{40}$ R. A. Kelly, H. Clavier, S. Giudice, N. M. Scott, E. D. Stevens, J. Bordner, I. Samardjiev, C. D. Hoff, L. Cavallo, S. P. Nolan, Organometallics 27 (2008) 202-210.

${ }^{41}$ a) H. M. Lee, T. Jiang, E. D. Stevens, S. P. Nolan, Organometallics 20 (2001) 1255-1258; b) A. C. Hillier, H. M. Lee, E. D. Stevens, S. P. Nolan, Organometallics 20 (2001) 4246-4252.

${ }^{42}$ N. M. Scott, R. Dorta, E. D. Stevens, A. Correa, L. Cavallo, S. P. Nolan, J. Am. Chem. Soc. 127 (2005) 3516-3526.

${ }^{43}$ B. DeBoef, S. J. Pastine, D. Sames, J. Am. Chem. Soc. 126 (2004) 6556-6557.

${ }^{44}$ C. Y. Tang, W. Smith, A. L. Thompson, D. Vidovic, S. Aldridge, Angew. Chem. Int. Ed. 50 (2011) 1359-1362.

${ }^{45}$ M. Prinz, M. Grosche, E. Herdtweck, W. A. Herrmann, Organometallics 19 (2000) 1692-1694.

${ }^{46}$ N. Kuhn, T. Kratz, Synthesis (1993) 561-562.

${ }^{47}$ a) F. Hanasaka, K. Fujita, R. Yamaguchi, Organometallics 23 (2004) 1490-1492; b) F. Hanasaka, K. Fujita, R. Yamaguchi, Organometallics 24 (2005) 3422-3433. 
${ }^{48}$ C. Köcher, W. A. Herrmann, J. Organomet. Chem. 532 (1997) 261-265.

${ }^{49}$ R. Savka, H. Plenio, Dalton Trans. 44 (2015) 891-893.

${ }^{50}$ A. R. Chianese, X. Li, M. C. Janzen, J. W. Faller, R. H. Crabtree, Organometallics 22 (2003) 1663-1667.

${ }^{51}$ H. M. J. Wang, I. J. B. Lin, Organometallics 17 (1998) 972-975.

${ }^{52}$ U. Hintermair, U. Englert, W. Leitner, Organometallics 30 (2011) 3726-3731.

${ }^{53}$ K.Y. Wan, A.J. Lough, R.H. Morris, Organometallics 35 (2016) 1604-1612.

${ }^{54}$ Y. Tanabe, F. Hanasaka, K. Fujita, R. Yamaguchi, Organometallics 26 (2007) 4618-4626.

55 a) T. K. Maishal, J. Alauzun, J.-M. Basset, C. Copéret, R. J. P. Corriu, E. Jeanneau, A. Mehdi, C. Rezé, L. Veyre, C. Thieuleux, Angew. Chem. Int. Ed. 47 (2008) 8654-8656; b) T. K. Maishal, M. Boualleg, M. Bouhrara, C. Coperét, E. Jeanneau, L. Veyre, C. Thieuleux, Eur. J. Inorg. Chem. (2010) 5005-5010; c) I. Romanenko, S. norsic, L. Veyre, R. Sayah, F. D’Agosto, J. Raynaud, C. Boisson, E. Lacôte, C. Thieuleux, Adv. Synth. Catal. 358 (2016) 2317-2323.

${ }^{56}$ T. K. Maishal, J.-M. Basset, M. Boualleg, C. Copéret, L. Veyre, C. Thieuleux, Dalton Trans. (2009) 6956-6959.

${ }^{57}$ L. N. Appelhans, C. D. Incarvito, R. H. Crabtree, J. Organomet. Chem. 693 (2008) 2761-2766.

${ }^{58}$ I. Kownacki, M. Kubicki, K. Szubert, B. Marciniec, J. Organomet. Chem. 693 (2008) 321-328.

${ }^{59}$ B. J. Truscott, D. J. Nelson, C. Lujan, A. M. Z. Slawin, S. P. Nolan, Chem. Eur. J. 19 (2013) 7904-7916.

${ }^{60}$ D. J. Nelson, B. J. Truscott, A. M. Z. Slawin, S. P. Nolan, Inorg. Chem. 52 (2013) 12674-12681.

${ }^{61}$ S. Kaufhold, L. Petermann, D. Sorsche, S. Rau, Chem. Eur. J. 23 (2017) 2271-2274.

${ }^{62}$ a) Y.-H. Chang, C.-F. Fu, Y.-H. Liu, S.-M. Peng, J.-T. Chen, S.-T. Liu, Dalton Trans. (2009) 861-867; b) C.-F. Fu, Y.-H. Chang, Y.-H. Liu, S.-M. Peng, C. J. Elsevier, J.-T. Chen, S.-T. Liu, Dalton Trans. (2009) 6991-6998.

${ }^{63}$ Y. D. Bidal, O. Santoro, M. Melaimi, D. B. Cordes, A. M. Z. Slawin, G. Bertrand, C. S. J. Cazin, Chem. Eur. J. 22 (2016) 9404-9409.

${ }^{64}$ M. Scholl, S. Ding, C. W. Lee, R. H. Grubbs, Org. Lett. 1 (1999) 953-956.

${ }^{65}$ K. Denk, P. Sirsch, W. A. Herrmann, J. Organomet. Chem. 649 (2002) 219-224.

${ }^{66}$ G. W. Nyce, Sz. Csihony, R. M. Waymouth, J. L. Hedrick, Chem. Eur. J. 10 (2004) 4073-4079.

${ }^{67}$ R. Savka, Synlett 2013, 24 1735-1736.

${ }^{68}$ A. P. Blum, T. Ritter, R. H. Grubbs, Organometallics 26 (2007) 2122-2124.

${ }^{69}$ a) A. M. Voutchkova, L. N. Appelhans, A. R. Chianese, R. H. Crabtree, J. Am. Chem. Soc. 127 (2005) 17624-17625; b) A. M. Voutchkova, M. Feliz, E. Clot, O. Eisenstein, R. H. Crabtree, J. Am. Chem. Soc. 129 (2007) 12834-12846.

${ }^{70}$ Reported: "[ $\left.\operatorname{Ir}(\mathrm{COD}) \mathrm{Cl}\right]_{2}(162 \mathrm{mg}, 162 \mu \mathrm{mol})$ ". In contrast, the molecular weight of $[\operatorname{Ir}(\mathrm{COD}) \mathrm{Cl}]_{2}$ is $671.70 \mathrm{~g} / \mathrm{mol}$, therefore $162 \mathrm{mg}$ would correspond to $0.241 \mathrm{mmol}$. Furthermore, the authors reported that $0.4 \mathrm{mmol}$ of $\mathbf{5 4}$ was used, this maximizes the yield in $0.2 \mathrm{mmol}$ for $\mathbf{5 5}$. However, the reported yield $(157 \mathrm{mg}$ ) for $\mathbf{5 5}$ corresponds to $0.285 \mathrm{mmol}$.

${ }^{71}$ a) M. Viciano, E. Mas-Marzá, M. Poyatos, M. Sanaú, R. H. Crabtree, E. Peris, Angew. Chem. Int. Ed. 44 (2005) $444-$ 447; b) M. Viciano, M. Poyatos, M. Sanaú, E. Peris, A. Rossin, G. Ujaque, A. Lledós, Organometallics 25 (2006) 11201134.

72 a) M. Raynal, C. S. J. Cazin, C. Vallée, H. Olivier-Bourbigou, P. Braunstein, Organometallics 28 (2009) 2460-2470; b) M. Raynal, C. S. J. Cazin, C. Vallée, H. Olivier-Bourbigou, P. Braunstein, Dalton Trans. (2009) 3824-3832.

${ }^{73}$ A. Prades, M. Poyatos, J. A. Mata, E. Peris, Angew. Chem. Int. Ed. 50 (2011) 7666-7669.

${ }^{74}$ L. D. Vázquez-Serrano, B. T. Owens, J. M. Buriak, Chem. Commun. (2002) 251-2519.

${ }^{75}$ P. V. Simpson, K. Radacki, H. Braunschweig, U. Schatzshneider, J. Organomet. Chem. 782 (2015) 116-123

${ }^{76}$ N. Imlinger, M. Mayr, D. Wang, K. Wurst, M. R. Buchmeiser, Adv. Synth. Catal. 346 (2004) 1836-1843.

${ }^{77}$ Y. Zhang, D. Wang, K. Wurst, M. R. Buchmeiser, J. Organomet. Chem. 690 (2005) 5728-5735.

${ }^{78}$ B. J. Truscott, F. Nahra, A. M. Z. Slawin, D. B. Cordes, S. P. Nolan, Chem. Commun. 51 (2015) 62-65. 
79 a) B. J. Truscott, H. Kruger, P. B. Webb, M. Bühl, S. P. Nolan, Chem. Eur. J. 21 (2015) 6930-6935; b) S. V. C. Vummaleti, G. Talarico, S. P. Nolan, L. Cavallo, A. Poater, Eur. J. Inorg. Chem. (2015) 4653-4657; c) S. V. C. Vummaleti, G. Talarico, S. P. Nolan, L. Cavallo, A. Poater, Org. Chem. Front. 3 (2016) 19-23.

${ }^{80}$ a) G. E. Dobereiner, C. A. Chamberlin, N. D. Schley, R. H. Crabtree, Organometallics 29 (2010) 5728-5731; b) G. Song, Y. Su, R. A. Periana, R. H. Crabtree, K. Han, H. Zhang, X. Li, Angew. Chem. Int. Ed. 49 (2010) 912-917.

${ }^{81}$ L. Rubio-Pérez, E. A. Jaseer, N. García, V. Polo, M. Iglesias, L. A. Oro, Organometallics 35 (2016) 569-578.

82 a) G. Sipos, A. Ou, B.W. Skelton, L. Falivene, L. Cavallo, R. Dorta, Chem. Eur. J. 22 (2016) 15818-15827; b) G. Sipos, P. Gao, D. Foster, B.W. Skelton, A.N. Sobolev, R. Dorta, Organometallics 36 (2017) 801-817; c) P. Gao, G. Sipos, D. Foster, ACS Catal. 7 (2017) 6060-6064

${ }^{83}$ Organotransition Metal Chemistry (Ed.: J. Hartwig) (2010), University Science Books, Sausalito.

${ }^{84}$ a) A. B. Chaplin, Organometallics 33 (2014) 3069-3077; b) A. B. Chaplin, Organometallics 33 (2014) 624-626.

${ }^{85}$ S. A. Hauser, I. Prokes, A. B. Chaplin, Chem. Commun. 51 (2015) 4425-4428.

${ }^{86}$ B. J. Anding, A. Ellern, L. K. Woo, Organometallics 33 (2014) 2219-2229.

${ }^{87}$ Y. Feng, B. Jiang, P. A. Boyle, E. A. Ison, Organometallics 29 (2010) 2857-2867.

${ }^{88}$ M. C. Lehman, J. B. Gray, P. D. Boyle, M. S. Sanford, E. A. Ison, ACS Catal. 3 (2013) 2304-2310.

${ }^{89}$ M. C. Lehman, P. D. Boyle, R. D. Sommer, E. A. Ison, Organometallics 33 (2014) 5081-5084.

${ }^{90}$ M. C. Lehman, D. R. Pahls, J. M. Meredith, R. D. Sommer, D. M. Heinekey, T. R. Cundari, E. A. Ison, J. Am. Chem. Soc. 137 (2015) 3574-3584.

${ }^{91}$ X. Wang, H. Chen, X. Li, Organometallics 26 (2007) 4684-4687.

${ }^{92}$ W. B. Cross, S. Razak, K. Singh, A. J. Warner, Chem. Eur. J. 20 (2014) 13203-13209.

${ }^{93}$ H. Aktas, J. C. Slootweg, A. W. Ehlers, M. Lutz, A. L. Spek, K. Lammertsma, Organometallics 28 (2009) 5166-5172.

${ }^{94}$ J. Navarro, O. Torres, M. Martín, E. Sola, J. Am. Chem. Soc. 133 (2011) 9738-9740.

${ }^{95}$ G. Choi, H. Tsuguri, K. Mashima, J. Am. Chem. Soc. 135 (2013) 13149-13161.

${ }^{96}$ R. Dorta, E. D. Stevens, S. P. Nolan, J. Am. Chem. Soc. 126 (2004) 5054-5055.

${ }^{97}$ G. C. Fortman, A. M. Z. Slawin, S. P. Nolan, Organometallics 30 (2011) 5487-5492.

${ }^{98}$ C. Y. Tang, W. Smith, D. Vidovic, A. L. Thompson, A. B. Chaplin, S. Aldridge, Organometallics 28 (2009) $3059-$ 3066.

${ }^{99}$ C. Y. Tang, A. L. Thompson, S. Aldridge, J. Am. Chem. Soc. 132 (2010) 10578-10591.

${ }^{100}$ C. Y. Tang, A. L. Thompson, S. Aldridge, Angew. Chem. Int. Ed. 49 (2010) 921-925.

${ }^{101}$ C. Y. Tang, N. Phillips, M. J. Kelly, S. Aldridge, Chem. Commun. 48 (2012) 11999-12001.

${ }^{102}$ C. Y. Tang, N. Phillips, J. I. Bates, A. L. Thompson, M. J. Gutmann, S. Aldridge, Chem. Commun. 48 (2012) $8096-$ 8098

103 a) N. Phillips, J. Rowles, M. J. Kelly, I. Riddlestone, N. H. Rees, A. Dervisi, I. A. Fallis, S. Aldridge, Organometallics 31 (2012) 8075-8078; b) N. Phillips, R. Tirfoin, S. Aldridge, Chem. Eur. J. 20 (2014) 3825-3830; c) N. Phillips, C. Y. Tang, R. Tirfoin, M. J. Kelly, A.L. Thompson, M. J. Gutmann, S. Aldridge, Dalton Trans. 43 (2014) 12288-12298.

${ }^{104}$ H.P. Thomas, Y.-M. Wang, F. Lorenzini, S.J. Coles, P.N. Horton, A.C. Marr, G.C. Saunders, Organometallics 36 (2017) 960-963.

${ }^{105}$ R. Corberán, M. Sanaú, E. Peris, Organometallics 25 (2006) 4002-4008.

${ }^{106}$ F. Hanasaka, Y. Tanabe, K. Fujita, R. Yamaguchi, Organometallics 25 (2006) 826-831.

${ }^{107}$ J. Holmes, C.M. Pask, C.E. Willans, Dalton Trans. 45 (2016) 15818-15827. 
108 J. M. Meredith, R. Robinson Jr, K. I. Goldberg, W. Kaminsky, D. M. Heinekey, Organometallics 31 (2012) 18791887.

${ }^{109}$ J. M. Meredith, K. I. Goldberg, W. Kaminsky, D. M. Heinekey, Organometallics 31 (2012) 8459-8462.

110 a) B. A. Arndtsen, R. G. Bergman, Science 270 (1995), 1970-1973; b) B. A. Arndtsen, R. G. Bergman, T. A. Mobley, T. H. Peterson, Acc. Chem Res. 28 (1995) 154-162; c) R. G. Bergman, Nature 446 (2007) 391-393.

111 a) M. Albrecht, J. R. Miecznikowski, A. Samuel, J. W. Faller, R. H. Crabtree, Organometallics 21 (2002) 35963604; b) For a similar $\operatorname{Ir}(\mathrm{III})$-intermediate with a bis-carbene ligand, see: M. Vogt, V. Pons, D. M. Heinekey, Organometallics 24 (2005) 1832-1836.

112 a) F. E. Hahn, C. Holtgrewe, T. Pape, M. Martin, E. Sola, L. A. Oro, Organometallics 24 (2005) 2203-2209; b) F. E. Hahn, B. Heidrich, T. Pape, A. Hepp, M. Martin, E. Sola, L. A. Oro, Inorg. Chim. Acta 359 (2006) 4840-4846.

${ }^{113}$ A. Zanardi, E. Peris, J. A. Mata, New J. Chem. 32 (2008) 120-126.

${ }^{114}$ R. Corberán, M. Sanaú, E. Peris, Organometallics 26 (2007) 3492-3498.

115 a) H. Seo, H.-J. Park, B. Y. Kim, J. H. Lee, S. U. Son, Y. K. Chung, Organometallics 22 (2003) 618-620; b) H. Seo, B. Y. Kim, J. H. Lee, H.-J. Park, S. U. Son, Y. K. Chung, Organometallics 22 (2003) 4783-4791.

${ }^{116}$ M. Benítez, E. Mas-Marzá, J. A. Mata, E. Peris, Chem. Eur. J. 17 (2011) 10453-10461.

117 a) A. Bartoszewicz, R. Marcos, S. Sahoo, A. K. Inge, X. Zou, B. Martín-Matute, Chem. Eur. J. 18 (2012) 14510 14519; b) A. Bartoszewicz, G. G. Miera, R. Marcos, P.-O. Norrby, B. Martín-Matute, ACS Catal. 5 (2015) $3704-3716$.

${ }^{118}$ H. M. Peng, R. D. Webster, X. Li, Organometallics 27 (2008) 4484-4493.

${ }^{119}$ C.-Y. Wang, C.-F. Fu, Y.-H. Liu, S.-M. Peng, S.-T. Liu, Inorg. Chem. 46 (2007) 5779-5786.

${ }^{120}$ M. V. Jiménez, J. Fernández-Tornos, J. J. Pérez-Torrente, F. J. Modrego, P. García-Orduña, L. A. Oro, Organometallics 34 (2015) 926-940.

${ }^{121}$ J.-F. Sun, F. Chen, B. A. Dougan, H.-J. Xu, Y. Cheng, Y.-Z. Li, X.-T. Chen, Z.-L. Xue, J. Organomet. Chem. 694 (2009) 2096-2105.

${ }^{122}$ H.-C. Huang, M. Ramanathan, Y.-H. Liu, S.-M. Peng, S.-T. Liu, Appl. Organometal. Chem. 31 (2017) e3673.

${ }^{123}$ K. Riener, M. J. Bitzer, A. Pöthig, A. Raba, M. Cokoja, W. A. Herrmann, F. E. Kühn, Inorg. Chem. 53 (2014) 12767-12777.

124 a) Z. G. Specht, S. A. Cortes-Llamas, H. N. Tran, C. J. van Niekerk, K. T. Rancudo, J. A. Golen, C. E. Moore, A. L. Rheingold, T. J. Dwyer, D. B. Grotjahn, Chem. Eur. J. 17 (2011) 6606-6609; b) Z. G. Specht, D. B. Grotjahn, C. E. Moore, A. L. Rheingold, Organometallics 32 (2013) 6400-6409.

${ }^{125}$ D. Gnanamgari, E. L. O. Sauer, N. D. Schley, C. Butler, C. D. Incarvito, R. H. Crabtree, Organometallics 28 (2009) 321-325.

${ }^{126}$ M. V. Jiménez, J. J. Pérez-Torrente, M. I. Batolomé, V. Gierz, F. J. Lahoz, L. A. Oro, Organometallics 27 (2008) 224-234.

${ }^{127}$ E. Jansen, L. S. Jongbloed, D. S. Tromp, M. Lutz, B. de Bruin, C. J. Elsevier, ChemSusChem 6 (2013) 1737-1744.

${ }^{128}$ E. Jansen, M. Lutz, B. de Bruin, C. J. Elsevier, Organometallics 33 (2014) 2853-2861.

${ }^{129}$ S. Díez-González, S. P. Nolan, Coord. Chem. Rev. 251 (2007) 874-883.

${ }^{130}$ A. Liske, K. Verlinden, H. Buhl, K. Schaper, C. Ganter, Organometallics 32 (2013) 5269-5272.

${ }^{131}$ C. A. Tolman, Chem. Rev. 77 (1977) 313-348.

132 a) R. Dorta, E. D. Stevens, C. D. Hoff, S. P. Nolan, J. Am. Chem. Soc. 125 (2003) 10490-10491; b) R. Dorta, E. D. Stevens, N. M. Scott, C. Costabile, L. Cavallo, C. D. Hoff, S. P. Nolan, J. Am. Chem. Soc. 127 (2005) 2485-2495.

${ }^{133}$ S. Leuthäußer, D. Schwarz, H. Plenio, Chem. Eur. J. 13 (2007) 7195-7203.

${ }^{134}$ P. S. Engl, R. Senn, E. Otth, A. Togni, Organometallics 34 (2015) 1384-1395. 
${ }^{135}$ D. J. Nelson, A. Collado, S. Manzini, S. NMeiries, A. M. Z. Slawin, D. B. Cordes, S. P. Nolan, Organometallics 33 (2014) 2048-2058.

136 a) P. Queval, C. Jahier, M. Rouen, I. Artur, J.-C. Legeay, L. Falivene, L. Toupet, C. Crévisy, L. Cavallo, O. Baslé, M. Mauduit, Angew. Chem. Int. Ed. 52 (2013) 14103-14107; b) A. Monney, F. Nastri, M. Albrecht, Dalton Trans. 42 (2013) 5655-5660; c) V. Karthik, I. A. Bhat, G. Anantharaman, Organometallics 32 (2013) 7006-7013; d) M. Jonek, A. Makhloufi, P. Rech, W. Frank, C. Ganter, J. Organomet. Chem. 750 (2014) 140-149; e) R. Savka, M. Bergmann, Y. Kanai, S. Foro, H. Plenio, Chem. Eur. J. 22 (2016) 9667-9675.

${ }^{137}$ J. J. Dunsford, D. S. Tromp, K. J. Cavell, C. J. Elsevier, B. M. Kariuki, Dalton Trans. 42 (2013) 7318-7329.

138 a) J. W. Ogle, S. A. Miller, Chem. Commun. (2009) 5728-5730; b) S. K. Furfari, M. R. Gyton, D. Twycross, M. L. Cole, Chem. Commun. 51 (2015) 74-76.

139 a) S. Gülcemal, A. G. Gökçe, B. Çetinkaya, Dalton Trans. 42 (2013) 7305-7311; b) S. Gülcemal, A. G. Gökçe, B. Çetinkaya, Inorg. Chem. 52 (2013) 10601-10609.

${ }^{140}$ J.-N. Luy, S. A. Hauser, A. B. Chaplin, R. Tonner, Organometallics 34 (2015) 5099-5112.

${ }^{141}$ E. L. Rosen, C. D. Vardano Jr, A. G. Tennyson, D. M. Khramov, J. W. Kamplain, D. H. Sung, P. T. Cresswell, V. M. Lynch, C. W. Bielawski, Organometallics 28 (2009) 6695-6706.

${ }^{142}$ K. Arumugam, C. D. Varnado, S. Sproules, V. M. Lynch, C. W. Bielawski, Chem. Eur. J. 19 (2013) 10866-10875.

${ }^{143}$ S. Ibánez, M. Poyatos, L.N. Dawe, D. Gusev, E. Peris, Organometallics 35 (2016) 2747-2758.

${ }^{144}$ K. Arumugam, J. Chang, V. M. Lynch, C. W. Bielawski, Organometallics 32 (2013) 4334-4341.

${ }^{145}$ K. Verlinden, C. Ganter, J. Organomet. Chem. 750 (2014) 23-29.

${ }^{146}$ H. Valdés, M. Poyatos, E. Peris, Organometallics 33 (2014) 394-401.

${ }^{147}$ H. Buhl, C. Ganter, Chem. Commun. 49 (2013) 5417-5419.

${ }^{148}$ H. Valdés, M. Poyatos, E. Peris, Inorg. Chem. 54 (2015) 3654-3659.

${ }^{149}$ D. Tapu, C. Owens, D. VanDerveer, K. Gwaltney, Organometallics 28 (2009) 270-276.

${ }^{150}$ A. G. Tennyson, E. L. Rosen, M. S. Collins, V. M. Lynch, C. W. Bielawski, Inorg. Chem. 48 (2009) 6924-6933.

${ }^{151}$ D. Tapu, Z. McCarty, L. Hutchinson, C. Ghattas, M. Chowdhurry, D. VanDerveer, J. Organomet. Chem. 749 (2014) 134-141.

${ }^{152}$ S. Ibánez, M. Poyatos, E. Peris, Chem. Commun. 53 (2017) 3733-3736.

153 a) A. B. Powell, C. W. Bielawski, A. H. Cowley, J. Am. Chem. Soc. 131 (2009) 18232-18233; b) A. B. Powell, C. W. Bielawski, A. H. Cowley, J. Am. Chem. Soc. 132 (2010) 10184-10194.

${ }^{154}$ B. M. Neilson, V. M. Lynch, C. W. Bielawski, Angew. Chem. Int. Ed. 50 (2011) 10322-10326.

${ }^{155}$ B. M. Neilson, C. W. Bielawski, J. Am. Chem. Soc. 134 (2012) 12693-12699.

${ }^{156}$ P. Kos, H. Plenio, Chem. Eur. J. 21 (2015) 1088-1095.

157 O. Halter, I. Fernández, H. Plenio, Chem. Eur. J. 23 (2017) 711-719.

${ }^{158}$ P. Kos, H. Plenio, Angew. Chem. Int. Ed. 54 (2015) 13293-13296.

${ }^{159}$ D. Chen, K. Li, X. Guan, G. Cheng, C. Yang, C.-M. Che, Organometallics 36 (2017) 1331-1344.

${ }^{160}$ R. Crabtree, Acc. Chem. Res. 12 (1979) 331-337.

${ }^{161}$ L. D. Vazquez-Serrano, B. T. Owens, J. M. Buriak, Inorg. Chim. Acta 359 (2006) 2786-2797.

${ }^{162}$ L. S. Bennie, C. J. Fraser, S. Irvine, W. J. Kerr, S. Andersson, G. N. Nilsson, Chem. Commun. 47 (2011) $11653-$ 11655 .

${ }^{163}$ W. J. Kerr, R. J. Mudd, J. A. Brown, Chem. Eur. J. 22 (2016) 4738-4742.

${ }^{164}$ C. Metallinos, X. Du, Organometallics 28 (2009) 1233-1242. 
${ }^{165}$ A. Binobaid, M. Iglesias, D. J. Beetstra, B. Kariuki, A. Dervisi, I. A. Fallis, K. J. Cavell, Dalton Trans. (2009) 70997112 .

${ }^{166}$ I. Romanenko, D. Gajan, R. Sayah, D. Crozet, E. Jeanneau, C. Lucas, L. Leroux, L. Veyre, A. Lesage, L. Emsley, E. Lacôte, C. Thieuleux, Angew. Chem. Int. Ed. 54 (2015) 12937-12941.

${ }^{167}$ Y. Liu, Z. Sun, C. Huang, T. Tu, Chem. Asian J. 12 (2017) 355-360.

${ }^{168}$ H. Horváth, Á. Kathó, A. Udvardy, G. Papp, D. Szikszai, F. Joó, Organometallics 33 (2014) 6330-6340.

${ }^{169}$ H. Syska, W. A. Herrmann, F. E. Kühn, J. Organomet. Chem. 703 (2012) 56-62.

${ }^{170}$ M. G. Manas, L. S. Sharninghausen, E. Lin, R. H. Crabtree, J. Organomet. Chem. 792 (2015) 184-189.

171 a) H. Türkmen, T. Pepe, F. E. Hahn, B. Çetinkaya, Eur. J. Inorg. Chem. (2008) 5418-5423; b) H. Türkmen, T. Pepe, F. E. Hahn, B. Çetinkaya, Organometallics 27 (2008) 571-575.

${ }^{172}$ S. C. Zinner, C. F. Rentzsch, E. Herdtweck, W. A. Herrmann, F. E. Kühn, Dalton Trans. (2009) 7055-7062.

${ }^{173}$ D. Gülcemal, A. G. Gökçe, S. Gülcemal, B. Çetinkaya RSC Adv. 4 (2014) 26222-26230.

${ }^{174}$ A. Binobaid, M. Iglesias, D. Beetstra, A. Dervisi, I. Fallis, K. J. Cavell, Eur. J. Inorg. Chem. (2010) 5426-5431.

${ }^{175}$ S. Ruiz-Botella, E. Peris, Chem. Eur. J. 21 (2015) 15263-15271.

${ }^{176}$ F. Carson, E. Martínez-Castro, R. Marcos, G. G. Miera, K. Jansson, X. Zou, B. Martín-Matute, Chem. Commun. 51 (2015) 10864-10867.

${ }^{177}$ X.-H. Zhu, L.-H. Cai, C.-X. Wang, Y.-N. Wang, X.-Q. Guo, X.-F. Hou, J. Mol. Catal. A: Chem. 393 (2014) 134-141

${ }^{178}$ A. Azua, J. A. Mata, E. Peris, F. Lamaty, J. Martinez, E. Colacino, Organometallics 31 (2012) 3911-3919.

${ }^{179}$ S. Sabater, M. Baya, J. A. Mata, Organometallics 33 (2014) 6830-6839.

${ }^{180}$ U. Hintermair, J. Campos, T. P. Brewster, L. M. Pratt, N. D. Schley, R. H. Crabtree, ACS Catal. 4 (2014) 99-108.

${ }^{181}$ S. Sanz, M. Benitez, E. Peris, Organometallics 29 (2010) 275-277.

${ }^{182}$ G. M. Pawar, M. R. Buchmeiser, Adv. Synth. Catal. 352 (2010) 917-928.

${ }^{183}$ G. Modugno, A. Monney, M. Bonchio, M. Albrecht, M. Carraro, Eur. J. Inorg. Chem. (2014) 2356-2360.

${ }^{184}$ M. Blanco, P. Álvarez, C. Blanco, M. V. Jiménez, J. Fernández-Torros, J. J. Pérez-Torrente, L. A. Oro, R. Menéndez, ACS Catal. 3 (2013) 1307-1317.

${ }^{185}$ M. Blanco, P. Álvarez, C. Blanco, M. V. Jiménez, J. J. Pérez-Torrente, L. A. Oro, J. Blasco, V. Cuartero, R. Menéndez, Catal. Sci. Technol. 6 (2016) 5504.

${ }^{186}$ E. Rangel-Rangel, E. Verde-Sesto, A. M. Rasero-Almansa, M. Iglesias, F. Sánchez, Cat. Sci. Technol. 6 (2016) 6037-6045.

${ }^{187}$ M. Blanco, P. Álvarez, C. Blanco, M. V. Jiménez, J. Fernández-Tornos, J. J. Pérez-Torrente, L. A. Oro, R. Menéndez, Carbon 83 (2015) 21-31.

${ }^{188}$ M. Blanco, P. Álvarez, C. Blanco, M. V. Jiménez, J. Fernández-Torros, J. J. Pérez-Torrente, J. Blasco, G. Subías, V. Cuartero, L. A. Oro, R. Menéndez, Carbon 96 (2016) 66-74.

${ }^{189}$ D. Wang, D. Astruc, Chem. Rev. 115 (2015) 6621-6686.

${ }^{190}$ For a overview: J. Atzrodt, V. Derdau, T. Fey, J. Zimmermann, Angew. Chem. Int. Ed. 41 (2007) 7744-7765.

${ }^{191}$ S. Ibánez, M. Poyatos, E. Peris, Dalton Trans 45 (2016) 14154-14159.

${ }^{192}$ G. C. Fortman, H. Jacobsen, L. Cavallo, S. P. Nolan, Chem. Commun. 47 (2011) 9723-9725.

${ }^{193}$ D. J. Nelson, J. D. Egbert, S. P. Nolan, Dalton Trans. 42 (2013) 4105-4109.

194 a) J. A. Brown, S. Irvine, A. R. Kennedy, W. J. Kerr, S. Andersson, G. N. Nilsson, Chem. Commun. (2008) $1115-$ 1117; b) J. Devlin, W. J. Kerr, D. M. Lindsay, T. J. D. McCabe, M. Reid, T. Tuttle, Molecules 20 (2015) 11676-11698.

195 J. A. Brown, A. R. Cochrane, S. Irvine, W. J. Kerr, B. Mondal, J. A. Parkinson, L. C. Paterson, M. Reid, T. Tuttle, S. Andersson, G. N. Nilsson, Adv. Synth. Catal. 356 (2014) 3551-3562. 
${ }^{196}$ A. R. Cochrane, C. Idziak, W. J. Kerr, B. Mondal, L. C. Paterson, T. Tuttle, S. Andersson, G. N. Nilsson, Org. Biomol. Chem. 12 (2014) 3598-3603.

197 a) A. R. Kennedy, W. J. Kerr, R. Moir, M. Reid, Org. Biomol. Chem. 12 (2014) 7927-7931; b) W. J. Kerr, R. J. Mudd, P. K. Owens, M. Reid, J. A. Brown, S. Campos, J. Label Compd Radiopharm. 59 (2016) 601-603.

198 a) G. N. Nilsson, W. J. Kerr, J. Label Compd Radiopharm. 53 (2010) 662-667; b) A. Marek, M. H. F. Pedersen, S. B. Vogensen, R. P. Clausen, B. Frølund, T. Elbert, J. Label Compd Radiopharm. 59 (2016) 476-483.

199 Å. Lindelöf, C. Ericsson, R. Simonsson, G. Nilsson, G. Grönberg, C. S. Elmore, J. Label Compd Radiopharm. 59 (2016) 340-345.

${ }^{200}$ R. Simonsson, G. Stenhagen, C. Ericsson, C. S. Elmore, J. Label Compd Radiopharm. 56 (2013) 334-337.

${ }^{201}$ J. Atzrodt, V. Derdau, W. J. Kerr, M. Reid, P. Rojahn, R. Weck, Tetrahedron 71 (2015) 1924-1929.

${ }^{202}$ W. J. Kerr, R. J. Mudd, L. C. Paterson, J. A. Brown, Chem. Eur. J. 20 (2014) 14604-14607.

${ }^{203}$ W. J. Kerr, D. M. Lindsay, M. Reid, J. Atzrodt, V. Derdau, P. Rojahn, R. Weck, Chem. Commun. 52 (2016) 66696672.

${ }^{204}$ P. W. C. Cross, J. M. Herbert, W. J. Kerr, A. H. McNeill, L. C. Paterson, Synlett 27 (2016) 111-115.

${ }^{205}$ A. R. Cochrane, S. Irvine, W. J. Kerr, M. Reid, S. Andersson, G. N. Nilsson, J. Label Compd Radiopharm. 56 (2013) 451-454.

${ }^{206}$ W. J. Kerr, M. Reid, T. Tuttle, ACS Catal. 5 (2015) 402-410.

${ }^{207}$ A Burhop; R. Weck, J. Atzrodt, V. Derdau, Eur. J. Org. Chem. (2017) 1418-1424.

${ }^{208}$ W.J. Kerr, M. Reid, T. Tuttle, Angew. Chem. Int. Ed. 56 (2017) 7808-7812.

${ }^{209}$ Iridium Complexes in Organic Synthesis (Eds.: L. A. Oro, C. Claver), (2009), Wiley-VCH, Weinheim.

${ }^{210}$ F. Hanasaka, K. Fujita, R. Yamaguchi, Organometallics 25 (2006) 4643-4647.

${ }^{211}$ S. Gülcemal, D. Gülcelmal, G. F. S. Whitehead, J. Xiao, Chem Eur. J. 22 (2016) 10513-10522.

${ }^{212}$ M. G. Manas, J. Campos, L. S. Sharninghausen, E. Lin, R. H. Crabtree, Green Chem. 17 (2015) 594-600.

${ }^{213}$ Z. Sun, Y. Liu, J. Chen, C. Huang, T. Tu, ACS Catal. 5 (2015) 6573-6578.

${ }^{214}$ Y.-M. Wang, F. Lorenzini, M. Rebros, G. C. Saunders, A. C. Marr, Green Chem. 18 (2016) 1751-1761.

215 J. Campos, L. S. Sharninghausen, M. G. Manas, R. H. Crabtree, Inorg. Chem. 54 (2015) 5079-5084.

${ }^{216}$ H. Horváth, G. Papp, R. Szabolcsi, Á. Kathó, F. Joó, ChemSusChem 8 (2015) 3036-3038.

${ }^{217}$ M. V. Jiménez, J. Fernández-Tornos, F. J. Modrego, J. J. Pérez-Torrente, L. A. Oro, Chem. Eur. J. 21 (2015) $17877-$ 17889.

${ }^{218}$ A. Rossin, M. Peruzzini, Chem. Rev. 116 (2016) 8848-8872.

${ }^{219}$ G. C. Fortman, A. M. Z. Slawin, S. P. Nolan, Organometallics 30 (2011) 5487-5492.

${ }^{220}$ D. J. Nelson, B. J. Truscott, J. D. Egbert, S. P. Nolan, Organometallics 32 (2013) 3769-3772.

${ }^{221}$ E. Mas-Marzá, M. Poyatos, M. Sanaú, E. Peris, Inorg. Chem. 43 (2004) 2213-2219.

${ }^{222}$ E. Mas-Marzá, M. Sanaú, E. Peris, Inorg. Chem. 44 (2005) 9961-9967.

${ }^{223}$ C. Vicent, M. Viciano, E. Mas-Marzá, M. Sanaú, E. Peris, Organometallics 25 (2006) 3713-3720.

${ }^{224}$ T. Chen, X.-G. Liu, M. Shi, Tetrahedron 63 (2007) 4874-4880.

${ }^{225}$ A. R. Chianese, A. Mo, D. Datta, Organometallics 28 (2009) 465-472.

${ }^{226}$ D. Tapu, O.J. Buckner, C.M. Boudreaux, B. Norvell, M. Vasiliu, D.A. Dixon, C.D. McMillen, J. Organomet. Chem. 823 (2016) 40-49.

${ }^{227}$ C. F. Rentzsch, E. Tosh, W. A. Herrmann, F. E. Kühn, Green Chem. 11 (2009) 1610-1617.

${ }^{228}$ M. Peters, R. Breinbauer, Tetrahedron Lett. 51 (2010) 6622-6625.

${ }^{229}$ M. Tobisu, T. Igarashi, N. Chatani, Beilstein J. Org. Chem. 12 (2016) 654-661. 
230 a) T. Iwai, T. Fujihara, J. Terao, Y. Tsuji, J. Am. Chem. Soc. 131 (2009) 6668-6669; b) T. Iwai, T. Fujihara, J. Terao, Y. Tsuji, J. Am. Chem. Soc. 134 (2012) 1268-1274.

${ }^{231}$ C. D. Forsyth, W. J. Kerr, L. C. Paterson, Synlett 24 (2013) 587-590.

232 a) M. H. S. A. Hamid, P. A. Slatford, J. M. J. Williams, Adv. Synth. Catal. 349 (2007) 1555-1575; b) G. E. Dobereiner, R. H. Crabtree, Chem. Rev. 110 (2010) 681-703; c) G. Guillena, D. J. Ramón, M. Yus, Chem. Rev. 110 (2010) 1611-1641.

${ }^{233}$ A. Prades, R. Corberán, M. Poyatos, E. Peris, Chem. Eur. J. 14 (2008) 11474-11479.

${ }^{234}$ A. Zanardi, J.A. Mata, E. Peris, Chem. Eur. J. 16 (2010) 10502-10506.

235 a) S. Liu, M. Rebros, G. Stephens, A. C. Marr, Chem. Commun. (2009) 2308-2310; b) S. D. Lacroix, A. Pennycook, S. Liu, T. T. Eisenhart, A. C. Marr, Catal. Sci. Technol. 2 (2012) 288-290.

${ }^{236}$ a) J. Hannedouche, E. Schulz, Chem. Eur. J. 19 (2013) 4972-4985; b) L. Huang, M. Arndt, K. Gooßen, H. Heydt, L. J. Gooßen, Chem. Rev. 115 (2015) 2596-2697; c) E. Bernoud, C. Lepori, M. Mellah, E. Schulz, J. Hannedouche, Catal. Sci. Technol. 5 (2015) 2017-2037; d) A. L. Reznichenko, K. C. Hultzsch, Org. React. 88 (2015) 1-554.

${ }^{237}$ S. Kusumoto, T. Tatsuki, K. Nozaki, Angew. Chem. Int. Ed. 54 (2015) 8458-8461.

${ }^{238}$ D. J. Nelson, J. A. Fernández-Salas, B. J. Truscott, S. P. Nolan, Org. Biomol. Chem. 12 (2014) 6672-6676

239 a) L. S. Ott, M. L. Cline, M. Deetlefs, K. R. Seddon, R. G. Finke, J. Am. Chem. Soc. 127 (2005) 5758-5759; b) L. S. Ott, S. Campbell, K. R. Seddon, R. G. Finke, Inorg. Chem. 46 (2007) 10335-10344.

240 a) D. G. H. Hetterscheid, J. N. H. Reek, Chem. Commun. 47 (2011) 2712-2714; b) O. Diaz-Morales, T. J. P. Hersbach, D. G. H. Hetterscheid, J. N. H. Reek, M. T. M. Koper, J. Am. Chem. Soc. 136 (2014) 10432-10439; c) D. G. H. Hetterscheid, J. N. H. Reek, Eur. J. Inorg. Chem. (2014) 742-749; d) H.-C. Chen, D. G. H. Hetterscheid, R. M. Williams, J. I. van der Vlugt, J. N. H. Reek, A. M. Brouwer, Energy Environ. Sc. 8 (2015) 975-982; e) J. M. Koelewijn, M. Lutz, R. J. Detz, J. N. H. Reek, ChemPlusChem, 81 (2016) 1098-1106/

${ }^{241}$ Z. Codolà, J. M. S. Cardoso, B. Royo, M. Costas, J. Llorret-Fillol, Chem. Eur. J. 19 (2013) 7203-7213.

242 a) A. C. Marr, C. L. Pollock, G. C. Saunders, Organometallics 26 (2007) 3283-3285; b) C. L. Pollock, K. J. Fox, S. D. Lacroix, J. McDonagh, P. C. Marr, A. M. Nethercott, A. Pennycook, S. Qian, L. Robinson, G. C. Saunders, A. C. Marr, Dalton Trans. 41 (2012) 13423-13428.

243 a) S. B. Duckett, R. E. Mewis, Acc. Chem. Res. 45 (2012) 1247-1257; b) P. Nikolaou, B. M. Goodson, E. Y. Chekmenev, Chem. Eur. J. 21 (2015) 3156-3166 and references therein.

${ }^{244}$ R. W. Adams, J. A. Aguilar, K. D. Atkinson, M. J. Cowley, P. I. P. Elliott, S. B. Duckett, G. G. R. Green, I. G. Khazal, J. López-Serrano, D. C. Williamson, Science 323 (2009) 1708-1711.

${ }^{245}$ For selected examples on SABRE, see: a) L. S. Lloyd, R. W. Adams, M. Bernstein, S. Coombes, S. B. Duckett, G. G. R. Green, R. J. Lewis, R. E. Mewis, C. J. Sleigh, J. Am. Chem. Soc. 134 (2012) 12904-12907; b) J.-B. Hövener, N. Schwaderlapp, T. Lickert, S. B. Duckett, R. E. Mewis, L. A. R. Highton, S. M. Kenny, G. G. R. Green, D. Leibfritz, J. G. Korvink, J. Hennig, D. von Elverfeldt, Nature Comm. 4 (2013) 2946; c) D. A. Barskiy, K. V. Kovtunov, I. V. Koptyug, P. He, K. A. Groome, Q. A. Best, F. Shi, B. M. Goodson, R. V. Shchepin, A. M. Coffey, K. W. Waddel, E. Y. Chekmenev, J. Am. Chem. Soc. 136 (2014) 3322-3325; d) K. M. Appleby, R. E. Mewis, A. M. Olaru, G. G. R. Green, I. J. S. Fairlamb, S. B. Duckett, Chem. Sci. 6 (2015) 3981-3993; e) A. M. Olaru, M. J. Burns, G. G. R. Green, S. B. Duckett, Chem. Sci. 8 (2017) 2257-2266; f) W. Iali, A.M. Olaru, G.G.R. Green, S.B. Duckett, Chem. Eur. J. 23 (2017) 10491-10495; g) S.S. Roy, P. Norcott, P.J. Rayner, G.G.R. Green, S.B. Duckett, Chem. Eur. J. 23 (2017) 1049610500; h) K. Shen, A.W.J. Logan, J.F.P. Colell, J. Bae, G.X. Ortiz, T. Theis, W.S. Warren, S.J. Malcolmson, Q. Wang, Angew. Chem. Int. Ed. 56 (2017) doi:10.1002/anie.201704970. 
${ }^{246}$ For selected examples see: a) B. J. A. van Weerdenburg, S. Glöggler, N. Eshuis, A. H. J. T. Engwerda, J. M. M. Smits, R. de Gelder, S. Appelt, S. S. Wymenga, M. Tessari, M. C. Feiters, B. Blümich, F. P. J. T. Rutjes, Chem. Commun. 49 (2013) 7388-7390; b) L. S. Lloyd, A. Asghar, M. J. Burns, A. Charlton, S. Coombes, M. J. Cowley, G. J. Dear, S. B. Duckett, G. R. Genov, L. A. R. Highton, A. J. J. Hooper, M. Khan, I. G. Khazal, R. J. Lewis, R. E. Mewis, A. D. Roberts, A. J. Ruddlesden, Catal. Sci. Technol. 4 (2014) 3544-3554; c) B. J. A. van Weerdenburg, N. Eshuis, M. Tessari, F. P. J. T. Rutjes, M. C. Feiters, Dalton Trans. 44 (2015) 15387-15390; d) A. M. Olaru, S. S. Roy, L. S. Lloyd, S. Coombes, G. G. R. Green, S. B. Duckett, Chem. Commun. 52 (2016) 7842-7845; e) A. J. Ruddlesden, S. B. Duckett, Chem. Commun. 52 (2016) 8467-8470.

${ }^{247}$ F. Shi, A. M. Coffey, K. W. Waddell, E. Y. Chekmenev, B. M. Goodson, Angew. Chem. Int. Ed. 53 (2014) $7495-$ 7498.

248 a) H. Zeng, J. Xu, J. Gillen, M. T. McMahon, D. Artemov, J.-M. Tyburn, J. A. B. Lohman, R. E. Mewis, K. D. Atkinson, G. G. R. Green, S. B. Duckett, P. C. M. van Zijl, J. Magn. Reson. 237 (2013) 73-78; b) J.-H. Hövener, N. Schwaerlapp, R. Borowiak, T. Lickert, S. B. Duckett, R. E. Mewis, R. W. Adams, M. J. Burns, L. A. R. Highton, G. G. R. Green, A. Olaru, J. Hennig, D. von Elverfeldt, Anal. Chem. 86 (2014) 1767-1774; c) M. Fekete, C. Gibard, G. J. Dear, G. G. R. Green, A. J. J. Hooper, A. D. Roberts, F. Cisnetti, S. B. Duckett, Dalton Trans. 44 (2015) 7870-7880; d) R. E. Mewis, M. Fekete, G. G. R. Green, A. C. Whitwood, S. B. Duckett, Chem. Commun. 51 (2015) 9857-9859; e) R. V. Shchepin, D. A. Barskiy, A. M. Coffey, I. V. M. Esteve, E. Y. Chekmenev, Angew. Chem. Int. Ed. 55 (2016) $6071-$ 6074; f) D. A. Barskiy, R. V. Shchepin, A. M. Coffey, T. Theis, W. S. Warren, B. M. Goodson, E. Y. Chekmenev, J. Am. Chem. Soc. 138 (2016) 8080-8083; g) P. Rovedo, S. Knecht, T. Bäumlisberger, A. L. Cremer, S. B. Duckett, R. E. Mewis, G. G. R. Green, M. Burns, P. J. Rayner, D. Leibfritz, J. G. Korvink, J. Hennig, G. Pütz, D. von Elverfeldt, J.-B. Hövener, J. Phys. Chem. B 120 (2016) 5670-5677.

${ }^{249}$ W. A. Herrmann, L. J. Goossen, C. Köcher, G. R. J. Artus, Angew. Chem. Int. Ed. 35 (1996) 2805-2807.

250 a) M. T. Powell, D.-R. Hou, X. Cui, K. Burgess, J. Am. Chem. Soc. 123 (2001) 8878-8879; b) M. C. Perry, X. Cui, M. T. Powell, D.-R. Hou, J. H. Reibenspies, K. Burgess, J. Am. Chem. Soc. 125 (2003) 113-123. For a recent perspective on NHCs in asymmetric hydrogenations: c) D. Zhao, L. Candish, D. Paul, F. Glorius, ACS Catal. 6 (2016) 5978-5988.

251 a) W. A. Herrmann, D. Baskakov, E. Herdtweck, S. D. Hoffmann, T. Bunlaksananusorn, F. Rampf, L. Rodefeld, Organometallics 25 (2006) 2449-2456; b) D. Baskakov, W. A. Herrmann, E. Herdtweck, S. D. Hoffmann, Organometallics 26 (2007) 626-632.

${ }^{252}$ J. John, C. Wilson-Konderka, C. Metallinos, Adv. Synth. Catal. 357 (2015) 2071-2081.

${ }^{253}$ H. Chiyojima, S. Sakaguchi, Tetrahedron Lett. 52 (2011) 6788-6791

${ }^{254}$ K. Yoshida, T. Kamimura, H. Kuwabara, A. Yanagisawa, Chem. Commun. 51 (2015) 15442-15445.

255 a) S. Kawabata, H. Tokura, H. Chiyojima, M. Okamoto, S. Sakaguchi, Adv. Synth. Catal. 354 (2012) 807-812; b) K. Shinohara, S. Kawabata, H. Nakamura, Y. Manabe, S. Sakaguchi, Eur. J. Org. Chem. (2014) 5532-5539; c) Y. Manabe, K. Shinohara, H. Nakamura, H. Teramoto, S. Sakaguchi, J. Mol. Catal. A 421 (2016) 138-145.

${ }^{256}$ K.-Y. Ye, Q. Cheng, C.-X. Zhuo, L.-X. Dai, S.-L. You, Angew. Chem. Int. Ed. 55 (2016) 8113-8116.

${ }^{257}$ For the asymmetric addition of acetonitrile to $\alpha$-iminoesters using a similar 1,2,4-triazolium-based NHC ligand/Ir(I) system, see: S. Lin, N. Kumagai, M. Shibasaki, Org. Biomol. Chem. 14 (2016) 9725-9730.

${ }^{258}$ For selected references see: a) C. A. Kiener, C. Shu, C. D. Incarvito, J. F. Hartwig, J. Am. Chem. Soc. 125 (2003) 14272 -14273; b) A. Leitner, S.Shekhar, M. J. Pouy, J. F. Hartwig, J. Am. Chem. Soc. 127 (2005) 15506-15514.

${ }^{259}$ W. Liu, R. Gust, Coord. Chem. Rev. 329 (2016) 191-213.

${ }^{260}$ P. V. Simpson, C. Schmidt, I. Ott, H. Bruhn, U. Schatzschneider, Eur. J. Inorg. Chem. (2013) 5547-5554. 
${ }^{261}$ Y. Gothe, T. Marzo, L. Messori, N. Metzler-Nolte, Chem. Commun. 51 (2015) 3151-3153.

${ }^{262}$ Y. Gothe, T. Marzo, L. Messori, N. Metzler-Nolte, Chem. Eur. J. 22 (2016) 12487-12494.

${ }^{263}$ E. Maftei, C.V. Maftei, P.G. jones, M. Freytag, M.H. Franz, G. Kelter, H.-H. Fiebig, M. Tamm, I. Neda, Helv. Chim. Acta 99 (2016) 469-481.

${ }^{264}$ For selected reviews, see: a) T. Hayashi, Acc. Chem. Res. 33 (2000) 354-362; b) W. Fu, W. Tang, ACS Catal. 6 (2016) 4814-4858. 